\title{
WestVirginiaUniversity
}

THE RESEARCH REPOSITORY @ WVU

Graduate Theses, Dissertations, and Problem Reports

2006

\section{Evaluation of carbon materials for use in a direct carbon fuel cell}

Gregory A. Hackett

West Virginia University

Follow this and additional works at: https://researchrepository.wvu.edu/etd

\section{Recommended Citation}

Hackett, Gregory A., "Evaluation of carbon materials for use in a direct carbon fuel cell" (2006). Graduate Theses, Dissertations, and Problem Reports. 1731.

https://researchrepository.wvu.edu/etd/1731

This Thesis is protected by copyright and/or related rights. It has been brought to you by the The Research Repository @ WVU with permission from the rights-holder(s). You are free to use this Thesis in any way that is permitted by the copyright and related rights legislation that applies to your use. For other uses you must obtain permission from the rights-holder(s) directly, unless additional rights are indicated by a Creative Commons license in the record and/ or on the work itself. This Thesis has been accepted for inclusion in WVU Graduate Theses, Dissertations, and Problem Reports collection by an authorized administrator of The Research Repository @ WVU. For more information, please contact researchrepository@mail.wvu.edu. 


\title{
Evaluation of Carbon Materials for Use in a Direct Carbon Fuel Cell
}

\section{Gregory A. Hackett}

\author{
Thesis \\ Submitted to the College of Engineering \\ and Mineral Resources at \\ West Virginia University \\ in partial fulfillment of the requirements \\ for the degree of \\ Master of Science \\ in \\ Chemical Engineering
}

John W. Zondlo, Ph.D., Chair

Charter D. Stinespring, Ph.D.

Liviu Magean, M.S.

Department of Chemical Engineering

Morgantown, West Virginia

2006

Keywords:

Direct Carbon Fuel Cell, DCFC, Carbon, Graphite, Coal, Coal Rods

(C) 2006 Gregory A. Hackett 


\begin{abstract}
$\underline{\text { Abstract }}$
Evaluation of Carbon Materials for Use in a Direct Carbon Fuel Cell

Gregory A. Hackett
\end{abstract}

The Direct Carbon Fuel Cell (DCFC) is an efficient, environmentally friendly way to supply the United States with electrical power using its abundant coal reserves. The cell employs a process by which carbon is directly converted to electricity, without the need for combustion or gasification. The thermodynamic efficiency of a DCFC is $80 \%$. The purpose of this research is to renovate fuel cell test stands provided by the US DOE, and to investigate the operation of the DCFC with a variety of solid carbons from several sources. The highly organized carbon form, graphite, is used as the benchmark of the research because of its availability and stability. Another form, which is produced at West Virginia University (WVU), uses different mixtures of Solvent Extracted Carbon Ore (SECO) and petroleum coke. The SECO is derived from coal and both it and the petroleum coke are low in ash, sulfur, and volatiles. Compared to graphite, the SECO is a less-ordered form of carbon. In addition, GrafTech, Inc. supplied a well-fabricated baked carbon rod for testing. The open cell voltage of the SECO rod reaches a maximum of $1.043 \mathrm{~V}$ while the baked and graphite rods only reach $0.972 \mathrm{~V}$ and $0.788 \mathrm{~V}$ respectively. Typical power densities are in the range of 0.02 to $0.08 \mathrm{~W} / \mathrm{cm}^{2}$, while current densities were between 30 and $230 \mathrm{~mA} / \mathrm{cm}^{2}$. This suggests that coal can be used as a fuel source in DCFCs and will provide higher voltage than graphite. 


\section{Acknowledgments}

Many thanks are owed for the dedication and time spent by Dr. John Zondlo to help make this project successful. The committee members Dr. Charter Stinespring and Liviu Magean are thanked for their interest in this project and its findings. Thanks to $\mathrm{Mr}$. Elliott Kennel, the program coordinator for the Carbon Products group at West Virginia University. Thanks also go to Dr. Dady Dadyburjor for his support and interest in this project. Thanks to the source of funding for this project, the Berry Graduate Research Fellowship.

Thanks also go out to the undergraduate students who had a hand in this project. Thanks to Dr. Robert Svenson for his help in the cell design. Thanks to Avram Siegel and Wade Alexander who helped out with the data collection. Thanks also go out to Abha Saddawi and Avram Siegel for producing some of the carbon rods that were investigated in this research. Thanks also to Doug Miller at GrafTech for supplying baked rods for our use. Thanks are also in order for Ned Patton at SARA for providing materials and design information for the cell. I would also like to thank Randall Gemmen at NETL for his help in coordinating the transfer of the fuel cell test stands.

Certainly not to be forgotten are Linda Rogers and Bonita Helmick for their help in everything to keep me up and running during my graduate studies.

Many thanks to Mr. Jim Hall who was kind enough to repeatedly clean the cell after every experiment no matter how tedious it might have been. Without his help, this project would never have proceeded as quickly as it did.

Finally, thanks go to Jesus Christ, my Lord and Savior. Without Him guiding my every step, nothing would be possible for me. 


\section{$\underline{\text { Table of Contents }}$}

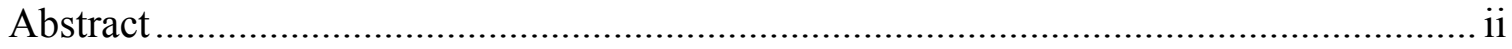

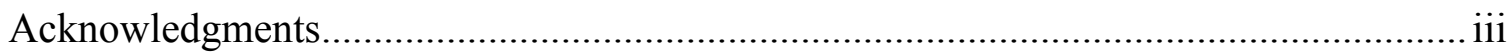

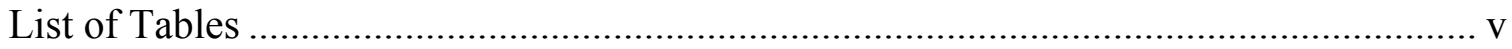

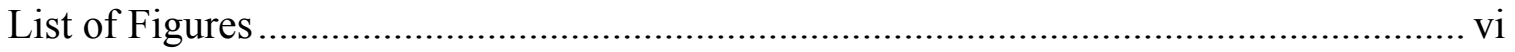

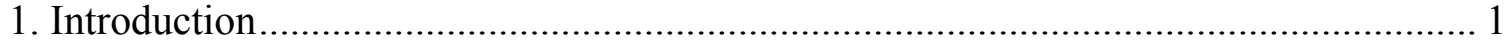

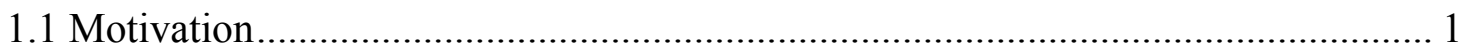

1.2 Research Objectives....................................................................................... 2

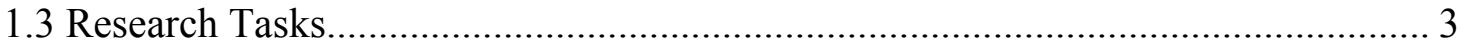

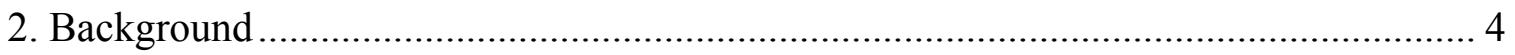

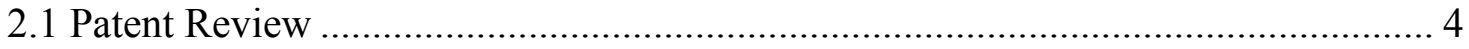

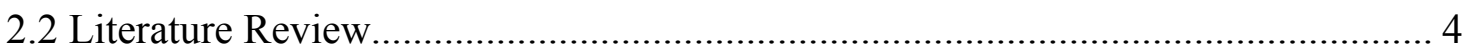

2.3 Other Forms of Direct Carbon Fuel Cells ............................................................ 7

2.4 Electrochemical Process ............................................................................... 8

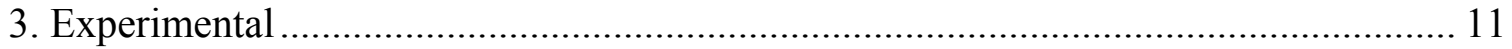

3.1 Direct Carbon Fuel Cell Design...................................................................... 11

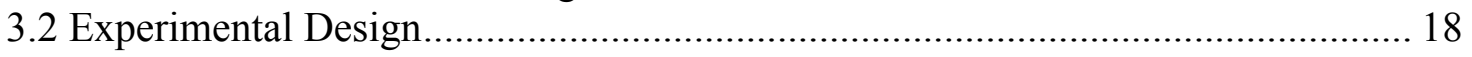

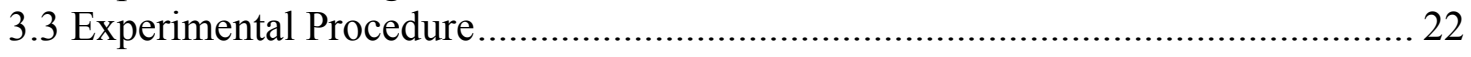

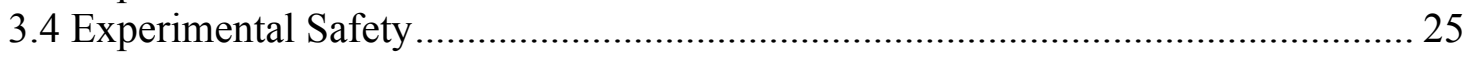

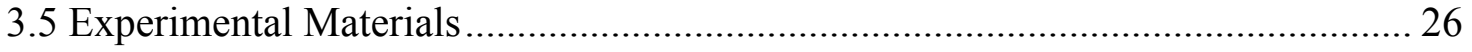

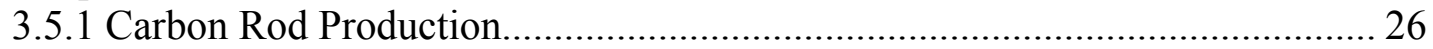

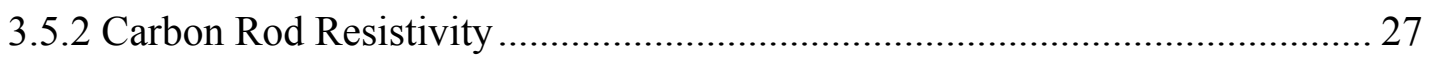

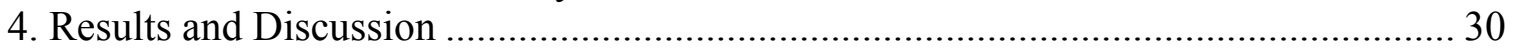

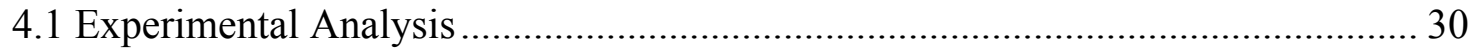

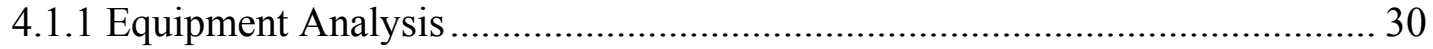

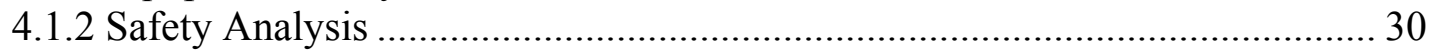

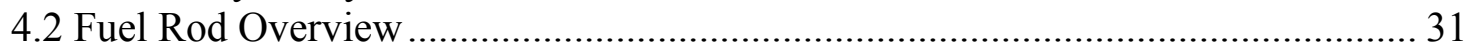

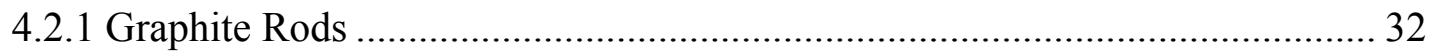

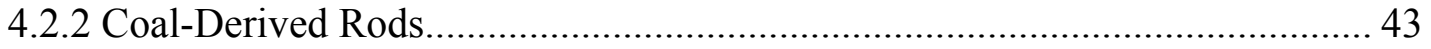

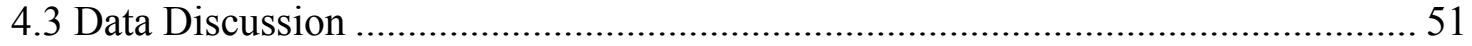

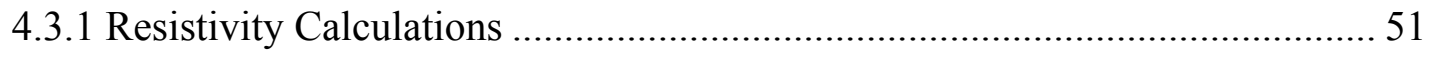

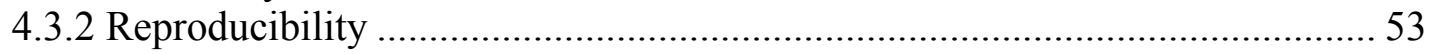

4.3.3 Duplication of Data Provided by SARA .................................................. 56

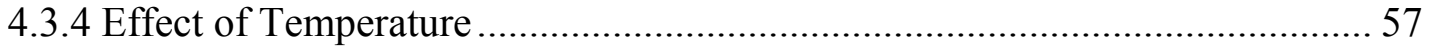

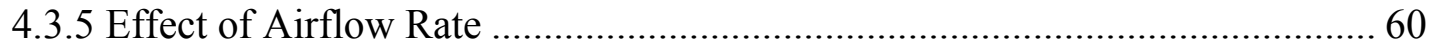

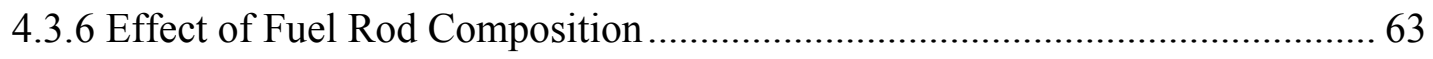

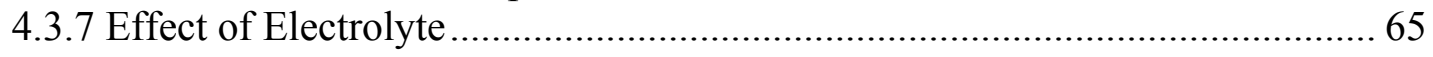

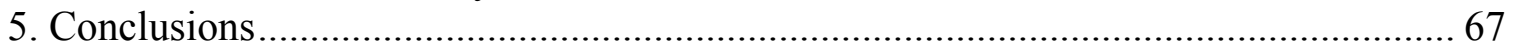

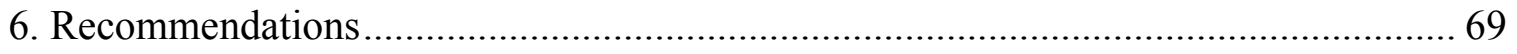

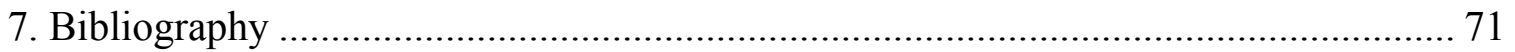

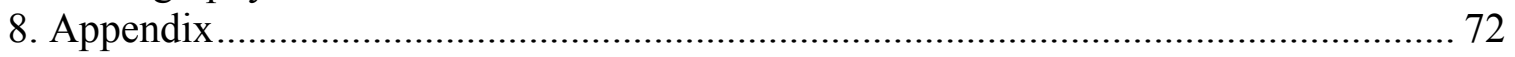




\section{$\underline{\text { List of Tables }}$}

Table 2.1 - Comparison of Efficiencies of Different Fuels ......................................... 10

Table 4.1- Summary of Results from Experimental Design.......................................... 32

Table 4.2 - Summary of Results for Runs Using Graphite Fuel Rods............................ 33

Table 4.3 - Summary of Results for Runs Using Coal-Derived Fuel Rods ..................... 43

Table 4.4 - Calculated Resistivity for Tested Rods ........................................................ 52

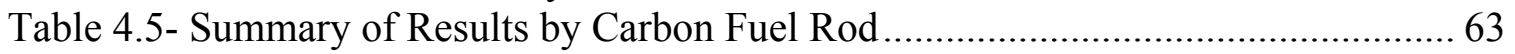




\section{List of Figures}

Figure 2.1 - Line Art Depicting Dr. Jacques' Direct Carbon Fuel Cell [2] ....................... 5

Figure 2.2 - Performance of Various Carbons in a Direct Carbon Fuel Cell [5] ............... 6

Figure 2.3 - Picture and Schematic Diagram of CellTech's Design ............................... 8

Figure 3.1 - Schematic Diagram of Direct Carbon Fuel Cell ...................................... 11

Figure 3.2 - Photograph of Constructed Fuel Cell .......................................................... 12

Figure 3.3 - Schematic Diagram of DCFC Test Stand Showing Location of Component

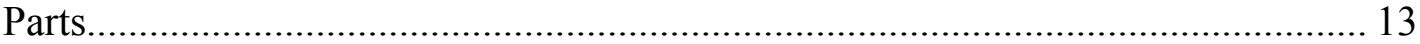

Figure 3.4- Photograph of Fuel Cell Test Stand Donated by the U.S. DOE. .................. 13

Figure 3.5- Photograph of Spider Used for Gently Bubbling Air Along the Cathode ..... 14

Figure 3.6 - Fuel Cell Test Stand Temperature Controllers............................................ 16

Figure 3.7 - Azonix ScannerPlus Data Logger ............................................................. 16

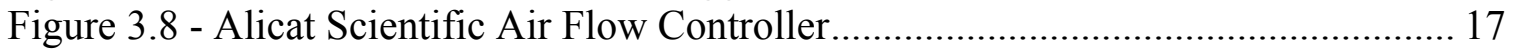

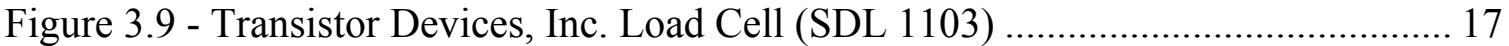

Figure 3.10 - Generic Fuel Cell $i$-V Curves with Specific Regions Highlighted ............ 20

Figure 3.11 - Carbon Rod Resistivity Testing Apparatus ............................................. 29

Figure 3.12 - Schematic Diagram of Four Point Method for Testing Resistivity............ 29

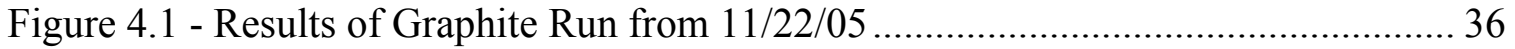

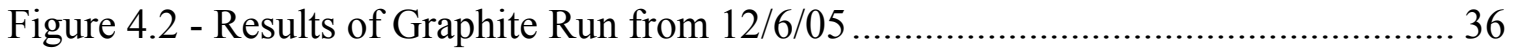

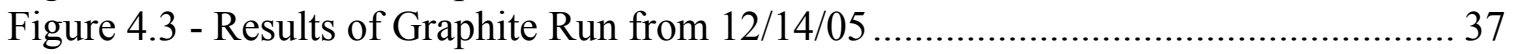

Figure 4.4 - Results of Graphite Run from 1/12/06 ...................................................... 37

Figure 4.5 - Results of Graphite Run from 1/25/06 ..................................................... 38

Figure 4.6 - Long Term Results for Graphite Run from 1/25/06................................. 38

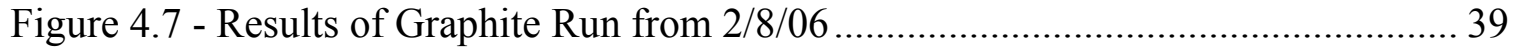

Figure 4.8 - Long Term Results of Graphite Run from 2/8/06 ....................................... 39

Figure 4.9 - Results of Graphite Run from 2/22/06 .................................................. 40

Figure 4.10 - Results of Graphite Run from 3/8/06 .................................................... 40

Figure 4.11 - Long Term Results for Graphite Run from 3/8/06................................. 41

Figure 4.12 - Results of GrafTech Graphite Rod Run ................................................. 41

Figure 4.13 - Long Term Run for GrafTech Graphite Rod from 3/28/06 ....................... 42

Figure 4.14 - SEM Image of Carbon Fuel Rod with $\mathrm{C} / \mathrm{NaOH} / \mathrm{Fe}$ Buildup $(\times 6000)$........ 44

Figure 4.15 - SEM Image of Carbon Fuel Rod with $\mathrm{C} / \mathrm{NaOH} / \mathrm{Fe}$ Builduip $(\times 1500) \ldots \ldots .45$

Figure 4.16 - Results of 100\% PetCoke Rod from 2/28/06 ........................................ 46

Figure 4.17 - Results of 100\% PetCoke Rod from 3/2/06 .............................................. 47

Figure 4.18 - Long Term Results for 100\% PetCoke Rod Run from 3/2/06 ................... 47

Figure 4.19 - Results of 100\% SECO Rod from 3/22/06 ........................................... 48

Figure 4.20 - Long Term Results for 100\% SECO Rod Run from 3/22/06 .................... 48

Figure 4.21 - Results for 50\% SECO/ 50\% PetCoke Rod from 3/23/06 ........................ 49

Figure 4.22 - Long Term Results for 50/50 SECO-PetCoke Rod Run from 3/23/06...... 49

Figure 4.23 - Results for GrafTech Baked Rod from 4/11/06 ........................................ 50

Figure 4.24 - Long Term Results for GrafTech Coal-Derived Rod Run from 4/11/06 ... 50

Figure 4.25 - Resistivity of Coal-Derived Rods as a Function of SECO Content........... 53

Figure 4.26 - Reproducibility of Data Generated During the Same Run......................... 55

Figure 4.27 - Reproducibility of Data Generated During Duplicate Runs ...................... 55 
Figure 4.28 - Results of SARA's Findings Comparing Coal-Derived Fuel to Graphite... 56

Figure 4.29 - Effect of Temperature on Voltage Output and Power Density from 3/15/06

Figure 4.30 - Effect of Temperature on Voltage Output and Power Density from 3/20/06

Figure 4.31 - Trends of Open Cell Voltage and Area Specific Resistance versus Fuel Cell

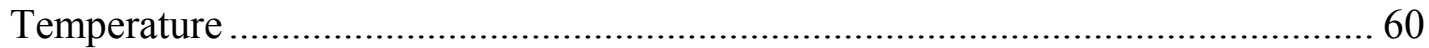

Figure 4.32 - Effect of Airflow Rate on Voltage Output and Power Density at $675^{\circ} \mathrm{C} \ldots 61$

Figure 4.33 - Effect of Airflow Rate on Voltage Output and Power Density at $600^{\circ} \mathrm{C} \ldots 62$

Figure 4.34 - Trends of Open Cell Voltage and Area Specific Resistance when Airflow

Rate is Varied (taken from data of Figure 4.32)

Figure 4.35 - Trends of Open Cell Voltage and Area Specific Resistance versus

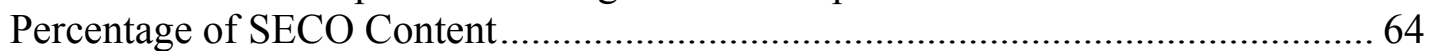

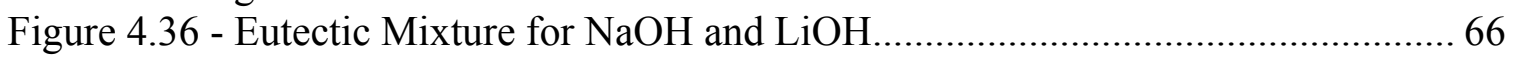

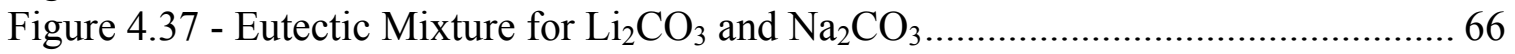




\section{Chapter 1}

\section{Introduction}

\subsection{Motivation}

Coal is the most abundant fossil fuel in the United States. The dependence upon coal as a fuel source continues to be widespread, as other natural resources remain in short supply. In 2004, West Virginia mines produced over 153 million tons of coal. [1] Therefore, it is logical to investigate a new process in which coal is used as a carbon source for direct conversion to electricity.

The direct carbon fuel cell (DCFC) has the potential to convert the chemical energy of carbon directly into electricity without the need for gasification or moving machinery. Moreover, these fuel cells are twice as fuel-efficient as coal-fired power plants, resulting in reduced carbon dioxide emissions per unit of electricity generated. These advantages, and the favorable thermodynamics of direct oxidation, result in thermodynamic efficiencies between 80 and $90 \%$. The process produces almost pure carbon dioxide, which can be easily collected for downstream disposal using methods such as carbon sequestration. Carbon is not burned in air; therefore, the exhaust is free of nitrogen oxides $\left(\mathrm{NO}_{\mathrm{X}}\right)$, eliminating many pollution issues caused by coal combustion.

Because of the absence of a need for smoke stacks, direct carbon fuel cells can easily be located in urban areas. Thus, DCFCs are more environmentally friendly than coal-fired power plants. 


\subsection{Research Objectives}

The problem of converting chemical energy from solid fuels directly into electrical energy, without passing through the intermediate stages of thermal to mechanical and from mechanical to electrical energy, has been a popular topic for years. Carbon is a great resource on which to test this direct conversion procedure. Coal is an ideal carbon source for this purpose because of its abundance, and the lack of pollution when it is used in the DCFC.

The purpose behind this research is to compare the performance of different types of carbon materials for operation in a direct carbon fuel cell. The United States Department of Energy (DOE) was kind enough to supply West Virginia University with two surplus fuel cell test stands. The test stand is shown later in Figure 3.4. These are very sophisticated pieces of equipment but lacked detailed documentation. Therefore, the first objective of this research is to understand how the DOE test stands operate. Without basic knowledge of how the equipment works, the experimentation phase cannot be reached.

Second, because the DOE test stands are designed for investigation of solid-oxide fuel cells, modifications must be made to adapt them for use with the direct carbon fuel cell. Some of the equipment was replaced and updated. For example, the load cell (discussed later) was replaced and an electronic airflow controller was installed.

Third, to make the process more user-friendly, the data acquisition phase of the experimentation was computerized. Using the provided data logger, readings taken from the fuel cell were interfaced to the computer through LabView 6.0 software for real-time data acquisition. 
Fourth, a design for the fuel cell and the other ancillary equipment was determined. The construction material of the fuel cell was based on electrical conductivity, corrosion resistance, and availability. From the chosen design, the fuel cell was constructed at West Virginia University (WVU) with help from Mr. Jim Hall, in the chemical engineering shop.

Once constructed, it was necessary to test the equipment to make sure that everything is operating as expected. The airflow was measured independently to create a calibration for the airflow rotometer. The system was vigorously tested for leaks. The voltages were carefully measured at different points in the system to assess various voltage drops. The safety features of the design were thoroughly examined.

Finally, graphite and different compositions of coal-derived fuel rods were evaluated and their performance recorded. The performance of these fuel rods was tested under varying conditions such as airflow rate, fuel cell operating temperature, and different types of molten electrolyte.

\subsection{Research Tasks}

In order to complete the work for this research efficiently, the overall objectives are broken down into individual tasks to be completed. The tasks are as follows: 1. a completion of a literature review to become familiar with other similar research, 2. an investigation of the electrochemical and physical processes behind the proposed process, 3. the equipment design, and completion of an experimental investigation for the process, and 4. an analysis of the generated data. 


\section{Chapter 2}

\section{Background}

\subsection{Patent Review}

Dr. William W. Jacques was the first to obtain a patent for "Method of Converting Potential Energy of Carbon into Electrical Energy" on March 3, 1896. [2] In this patent, he explains his design for a direct carbon fuel cell, which immerses a carbon material into a bath of molten caustic soda (sodium hydroxide). Also, a "blast of air is forced into the molten sodium hydrate in such a manner that the sodium hydrate becomes saturated with oxygen." He ran the apparatus between 400 and $500^{\circ} \mathrm{C}$. The fuel cell at WVU is designed along these lines using the basic apparatus described by Dr. Jacques.

Philip V. Pesavento also has a patent based on a direct carbon fuel cell. The assignee of the patent is Scientific Application \& Research Associates, Inc. (SARA). The patent was approved March 13, 2001. [3] In this design they claim to use an "anode basket" in which to place pulverized coal. They also use several molten electrolytes such as the hydroxides of aluminum, calcium, cesium, lithium, potassium, sodium, rubidium, strontium, and mixtures thereof. Along the same lines as Jacques, a "bubbler" is used to supply the oxygen to the cathode side of the cell. The addition of the anode basket relieves the requirement that the coal be machined into rods, a more efficient method of operation.

\subsection{Literature Review}

Sir William Grove first discovered the direct carbon fuel cell in 1839. Since then, researchers have attempted to perfect the invention. The first direct carbon fuel cell, as 
shown in Figure 2.1, was built in 1896 by American engineer Dr. William W. Jacques, and was very simple and inexpensive. The cell used a steel pot filled with molten sodium hydroxide, through which air was bubbled. A carbon rod was placed into the molten sodium hydroxide electrolyte. The steel pot acted as the air cathode and the carbon rod acted as both the fuel and the anode.

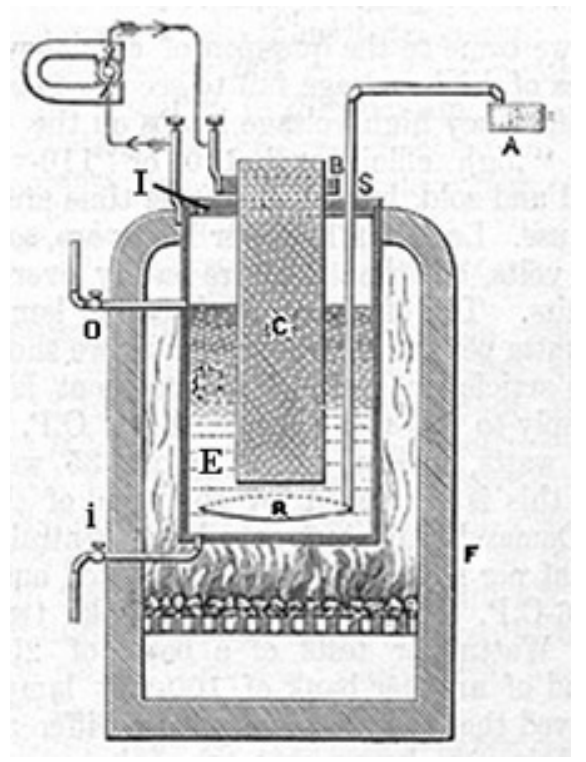

Figure 2.1 - Line Art Depicting Dr. Jacques’ Direct Carbon Fuel Cell [2]

Experiments conducted by Jacques included several different cells, electrolytes, and cathode materials. He then placed his most successful trials in a series of about 100 cells and generated over one kilowatt of electricity. The series produced a current density of $100 \mathrm{~mA} / \mathrm{cm}^{2}$ at $1 \mathrm{VDC}$. It was also the first DCFC to be operated long term [4]. In his patent [2], Jacques claimed an efficiency of $82 \%$; however, reviewers concluded that he had neglected thermal energy requirements for heating the electrolyte and the power needed to run his air pump. Their much-debated conclusion showed an overall efficiency of only $8 \%$. Even so, the cell stack did indeed produce over a kilowatt of electricity. 
Since then, researchers have struggled to reproduce Jacques' data. In his patent, he claimed to use pure iron from Norway for his pot. However, the reason Jacques' cell worked so well may be because the Norway iron contained a small percentage of titanium. As is presently known, iron-titanium oxides that form on the surface in the presence of molten metal hydroxides are degenerate semiconductors. These coatings hinder further corrosion and conduct electricity. There is also some speculation that the titanium catalyzes the cathodic reaction. The other researchers most likely failed because they used "better" steel from Germany, which did not contain titanium.

In the early 1970's during the oil crisis, the Stanford Research Institute (SRI) was funded to complete a carbon fuel cell. The research leader, Dr. Robert Weaver, was successful in proving that the electrochemical oxidation of carbon is feasible. The research group later tested several different types of carbons [5]. As shown in Figure 2.2, the group was able to demonstrate that a coal-derived anode was much more electrochemically active (i.e. gave a larger potential, as shown as a more negative voltage in the figure) than a graphite anode.

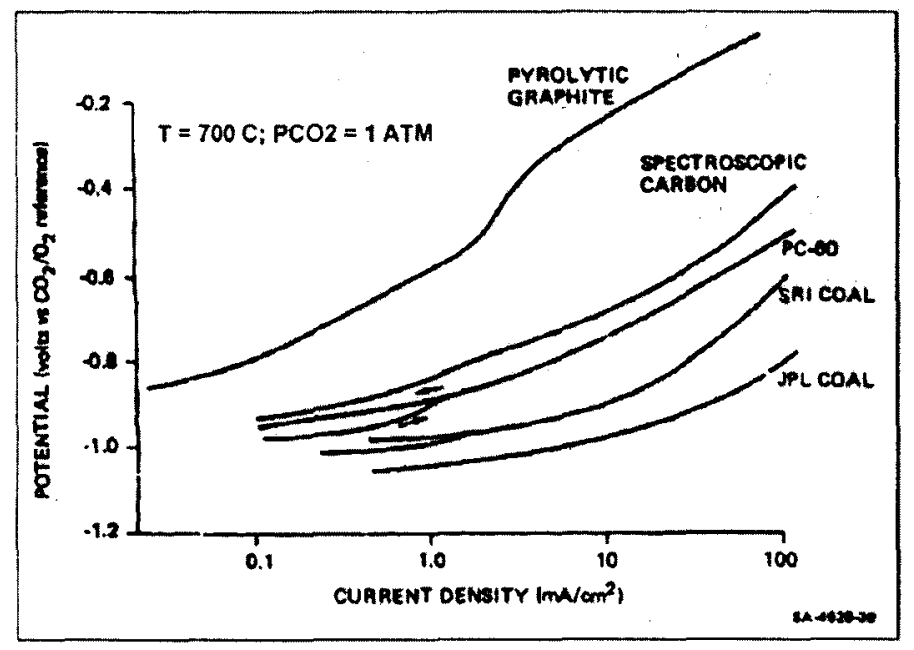

Figure 2.2 - Performance of Various Carbons in a Direct Carbon Fuel Cell [6] 


\subsection{Other Forms of Direct Carbon Fuel Cells}

Other groups have tried fuel cells that do not use the same design or electrolyte as the Jacques' cell. Scientific Applications and Research Associates (SARA) has designed a cell that separates the electrolyte around the anode from the electrolyte around the cathode. The transport of hydroxide ions is allowed across an electrically insulating but ionically conducting separator. Also, a metallic basket type current collector is used along with particulate carbon fuel. This is accomplished using a porous ceramic or sintered porous metal basket that is isolated from the cathode. The basket also acts as the anode in this case. Thus different reactions can occur at each the anode and cathode without the electrolyte mixing.

The Lawrence Livermore National Laboratory has developed the direct conversion of carbon fuels in a cell with a molten carbonate electrolyte, the molten carbonate fuel cell, or MCFC. This method may be beneficial because of the ability of the reactions to consume carbonate at the anode and produce it at the cathode in the same mole ratio without any hindering side reactions.

CellTech Power has also been involved in fuel cell research. They have developed what they call "a unique device with the properties of a primary battery, a secondary battery, and a fuel cell [7]." They have developed this device to be run on multiple fuels, including solid carbon. CellTech claims that their device runs $60 \%$ more efficiently than solid-oxide fuel cells when using a carbon fuel. Figure 2.3 is a picture and schematic diagram of CellTech's design. 

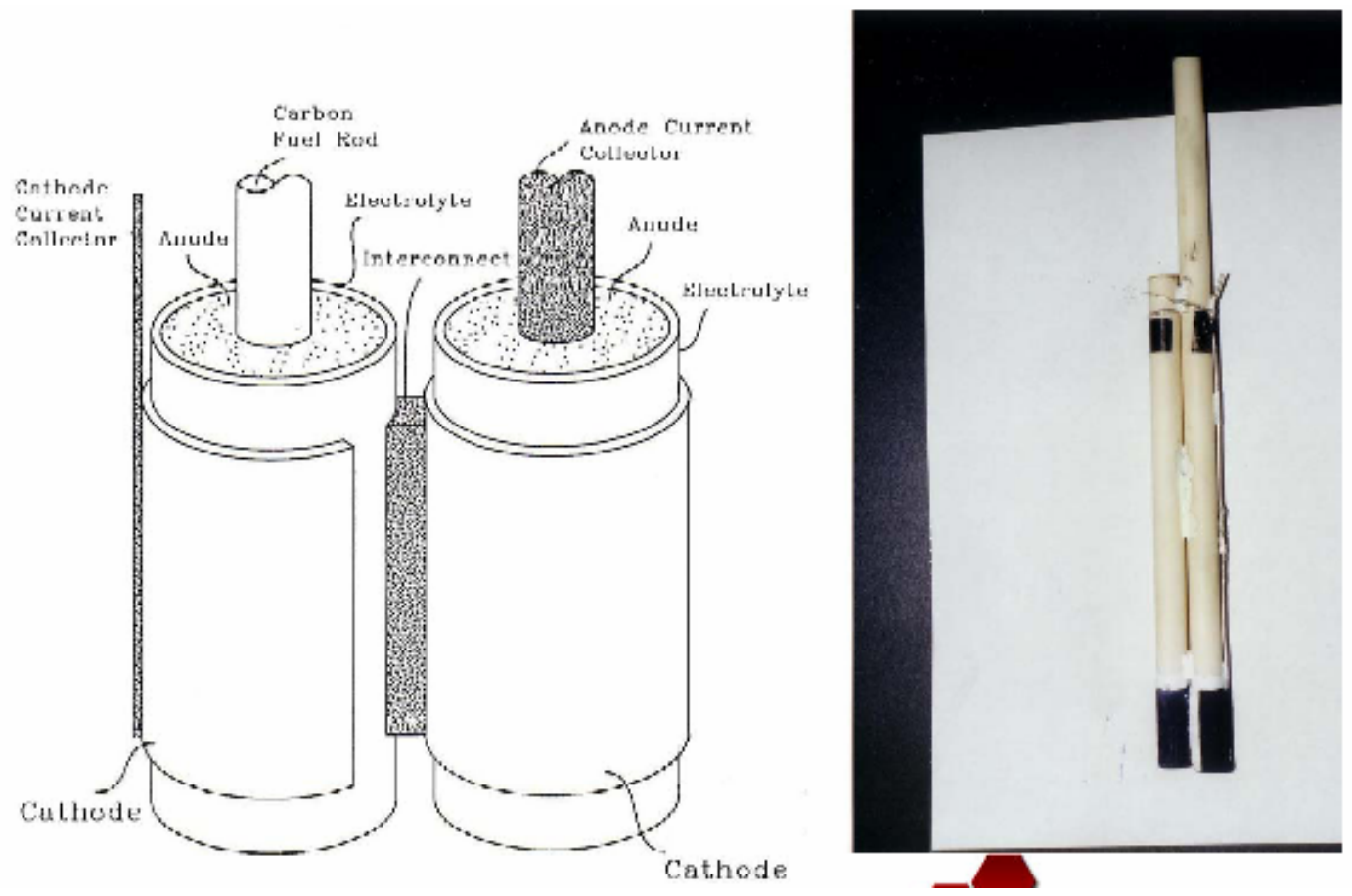

Figure 2.3 - Picture and Schematic Diagram of CellTech's Design

\subsection{Electrochemical Process}

The element carbon has an affinity for combining electrically with a large number of other chemical elements under a variety of conditions. In the DCFC, the exothermic reaction of carbon and oxygen is used to provide the necessary electrons from the system. Using a hydroxide electrolyte, the chemical reactions that occur with a carbon-based fuel in the DCFC are as follows:

$$
\begin{aligned}
\mathrm{C}+\mathrm{O}_{2} & \rightarrow \mathrm{CO}_{2} \\
\mathrm{C}+4 \mathrm{OH}^{-} & \rightarrow \mathrm{CO}_{2}+2 \mathrm{H}_{2} \mathrm{O}+4 e^{-} \\
4 e^{-}+\mathrm{O}_{2}+2 \mathrm{H}_{2} \mathrm{O} & \rightarrow 4 \mathrm{OH}^{-} \\
\mathrm{CO}_{2}+2 \mathrm{OH}^{-} & \rightarrow \mathrm{CO}_{3}{ }^{2-}+\mathrm{H}_{2} \mathrm{O}
\end{aligned}
$$

Equation 2.1 is the overall reaction, and is the direct oxidation of carbon. Equation 2.2 is the reaction between the carbon fuel and the molten hydroxide electrolyte that occurs at the anode, showing that four electrons are produced per mole of carbon. Equation 2.3 
represents the cathode reaction between the oxygen, water, and electrons that replenishes the hydroxide electrolyte. Moreover, the addition of water vapor increases the ionic conductivity in the electrolyte by adding polar molecules. Equation 2.4 is an undesired side reaction that consumes the electrolyte producing the carbonate ion. The carbonate ion will eventually poison the electrolyte as it increases in concentration relative to the hydroxide, causing the cell to fail. The occurrence of this reaction is minimized by the addition of excess water vapor, which will hydrolyze the carbonate atom, reforming the previously consumed hydroxide.

The maximum electrical energy that can be obtained from Equation 2.1 can be calculated from the free energy change involved in the reaction. For example, graphitic carbon reacts with gaseous oxygen at standard temperature and pressure (1atm, $\left.25^{\circ} \mathrm{C}\right)$ resulting in the voltage given by the following relation:

$$
\begin{gathered}
\frac{\Delta G^{\circ} \times 4.18}{N F}=E^{\circ} \\
E_{\text {cell }}=E^{\circ}-\frac{R T}{N F} \cdot \ln \frac{\left[\mathrm{CO}_{2}\right]}{\left[\mathrm{O}_{2}\right]}
\end{gathered}
$$

where $\Delta G^{\circ}$ is the standard free energy change of Reaction $2.1,-94,260 \mathrm{cal} / \mathrm{mol}[8] ; 4.18$ is the constant relating calories and watt-seconds; $N$ is the number of unit charges (moles of electrons) involved, four in this case; $F$ is the Faraday constant, 96,494 coulombs per unit charge (moles of electrons), and $E^{\circ}$ is the standard voltage of a carbon cell, $1.01 \mathrm{~V}$. However, a more practical available voltage, $\mathrm{E}_{\text {cell }}$, as calculated by J.F. Cooper, is about $0.8 \mathrm{~V}$, yielding a total efficiency of 0.80 [9]. Table 2.1 is a comparison of carbon, hydrogen, and methane, which are fuels used in various types of fuel cells. $E^{\circ}$ is the theoretical limit for oxidizing each of the listed reactants. The utilization energy is 
defined as the fraction of fuel consumed in practical operation. $\varepsilon_{v}$ is the fraction of the voltage available at the practical rate. When these values are multiplied, an actual efficiency results, showing carbon to be the most efficient of the three.

It should be noted that changing the temperature of the cell will not affect the voltage much because the value of $\Delta G$ (replaces $\Delta G^{\circ}$ in Equation 2.5 for non-standard conditions) is only different from $\Delta G^{\circ}$ by 16 calories at $1000^{\circ} \mathrm{C}$ and only about 10 calories at $600^{\circ} \mathrm{C}[8][10]$, which is the standard operating temperature for the cell in this project.

Table 2.1 - Comparison of Efficiencies of Different Fuels

\begin{tabular}{|c|c|c|c|c|}
\hline Fuel & $\begin{array}{c}\text { Theoretical Limit }= \\
\Delta \mathbf{G}^{\circ}(\mathbf{T}) / \Delta \mathbf{H}^{\circ}{ }_{\text {std }}\end{array}$ & $\begin{array}{c}\text { Utilization } \\
\text { Energy, } \boldsymbol{\mu}\end{array}$ & $\begin{array}{c}\mathbf{V}(\mathbf{i}), \mathbf{V}(\mathbf{i}=\mathbf{0})= \\
\boldsymbol{\varepsilon}_{\mathbf{v}}\end{array}$ & $\begin{array}{c}\text { Actual Efficiency }= \\
{\left[\Delta \mathbf{G}^{\circ}(\mathbf{T}) / \Delta \mathbf{H}^{\circ}{ }_{\text {std }}(\boldsymbol{\mu})\left(\boldsymbol{\varepsilon}_{\mathbf{v}}\right)\right.}\end{array}$ \\
\hline $\mathrm{C}$ & 1.003 & 1.00 & 0.80 & 0.80 \\
\hline $\mathrm{CH}_{4}$ & 0.895 & 0.80 & 0.80 & 0.57 \\
\hline $\mathrm{H}_{2}$ & 0.700 & 0.80 & 0.80 & 0.45 \\
\hline
\end{tabular}

Usually, the reactants are oxidized at the anode and reduced at the cathode, with platinum wire being used as an electrode. However, carbon does not ionize, and oxygen ionizes extremely slowly. These reactants can, however, react with ions in a molten electrolyte, in this case hydroxide (ionized) as shown in Equations 2.2 and 2.3. Often, platinum, iron, nickel, silver, copper, or some oxide are used as the cathode with the carbon used as the anode. In this research an iron-titanium alloy (98\%-2\%) was selected as the cathode material. This metal is ideal because of the small content of titanium that forms a complex with the ferrous oxides, preventing corrosion. 


\section{Chapter 3}

\section{Experimental}

\subsection{Direct Carbon Fuel Cell Design}

A detailed schematic diagram of the designed fuel cell is given in Figure 3.1.

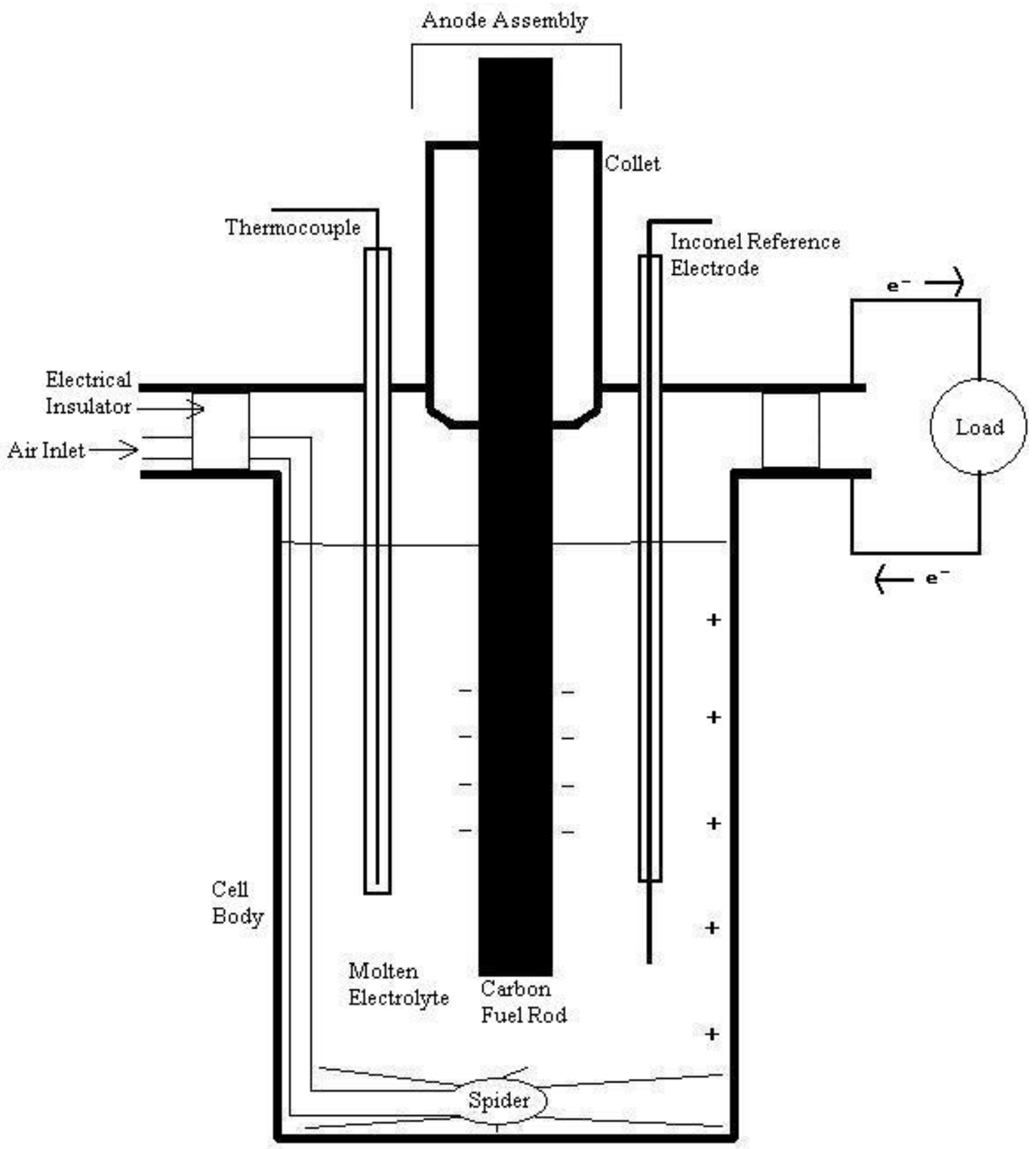

Figure 3.1 - Schematic Diagram of Direct Carbon Fuel Cell 
An actual photograph of the constructed cell is shown below in Figure 3.2.

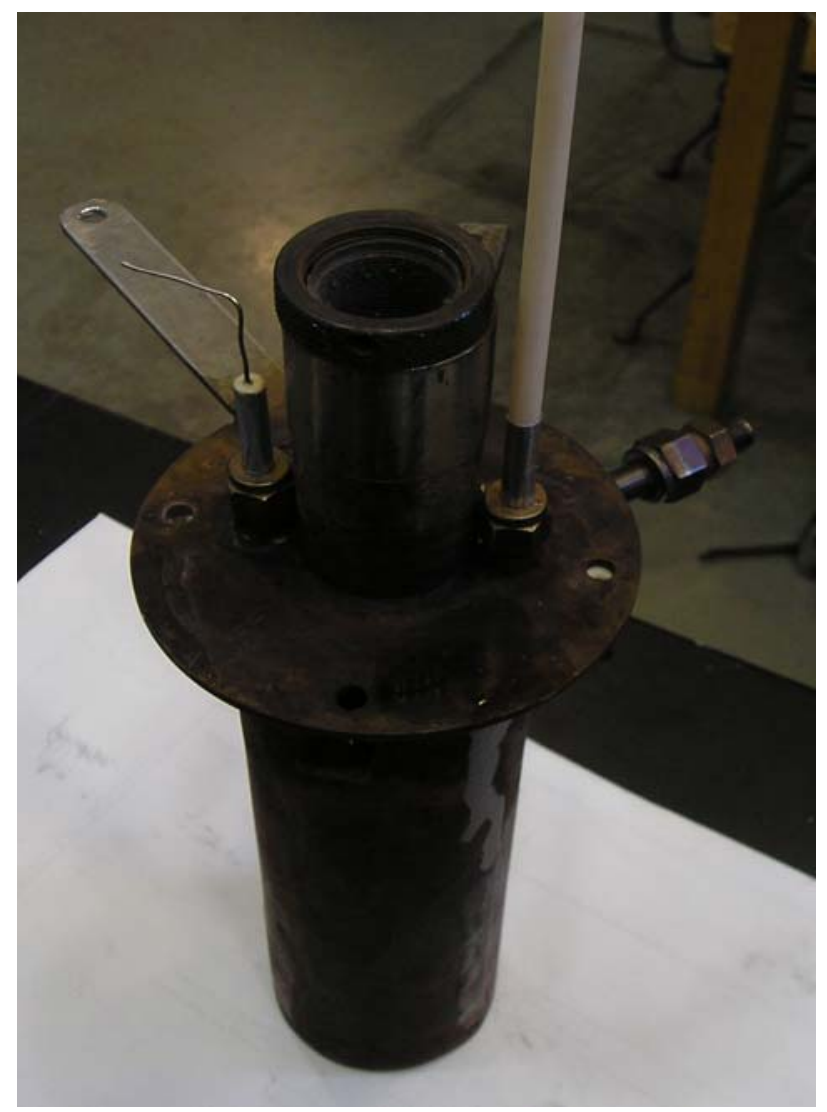

Figure 3.2 - Photograph of Constructed Direct Carbon Fuel Cell

As previously mentioned, the DCFC design, in the most basic sense, consists of a cathode and an anode. More specifically, carbon rods are used as the anode while an irontitanium alloy $(98 \%-2 \%)$ is used as the cathode. In this case, a molten electrolyte of sodium hydroxide $(\mathrm{NaOH})$ supplies the hydroxide ions necessary for the anode halfreaction (Equation 2.2). The electrolyte is surrounded by the cathode, which is shaped into a can.

A schematic diagram of the fuel cell test stand is shown in Figure 3.3 along with an actual photograph of the test stand in Figure 3.4. 


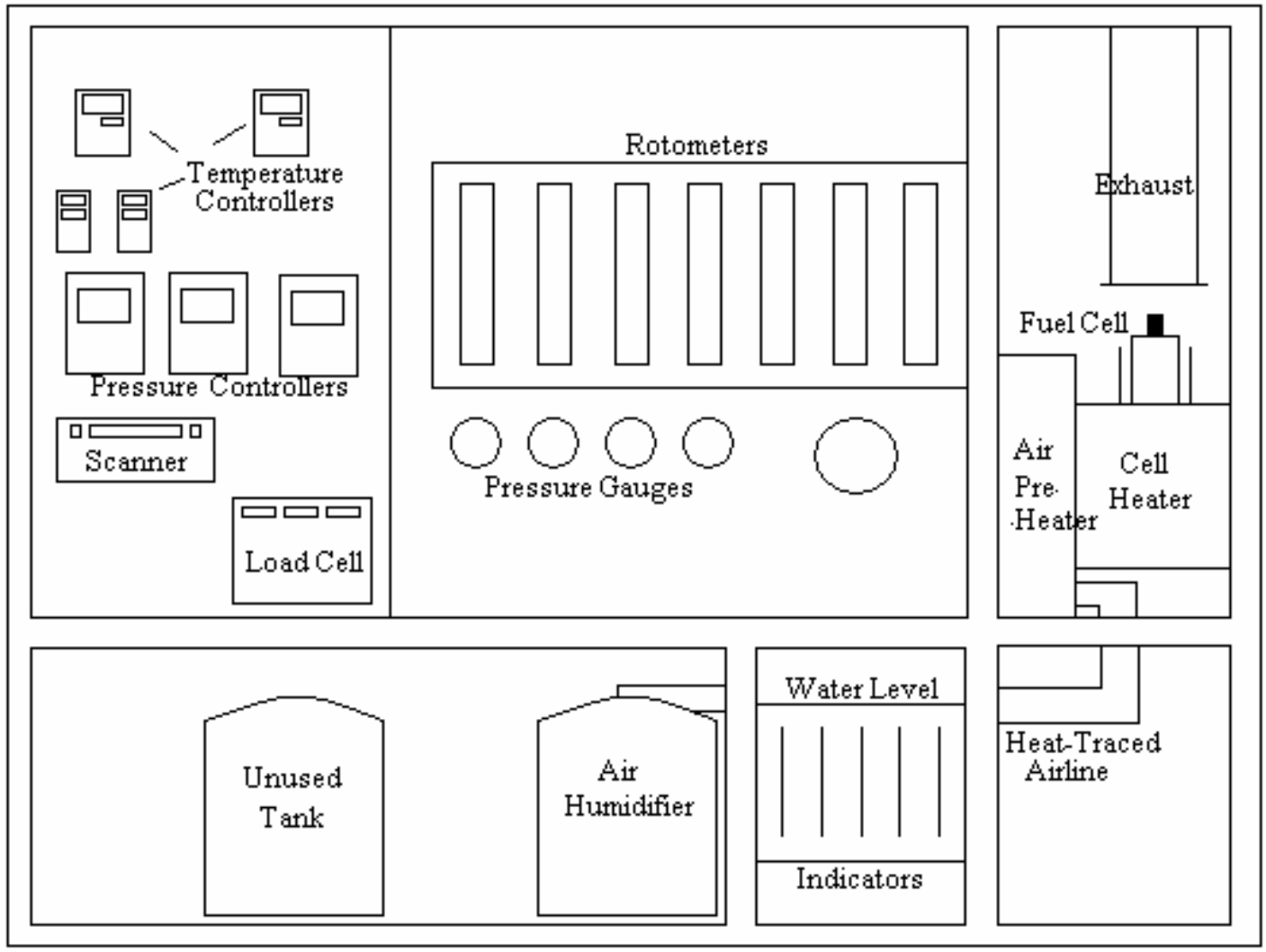

Figure 3.3 - Schematic Diagram of DCFC Test Stand Showing Location of Component Parts

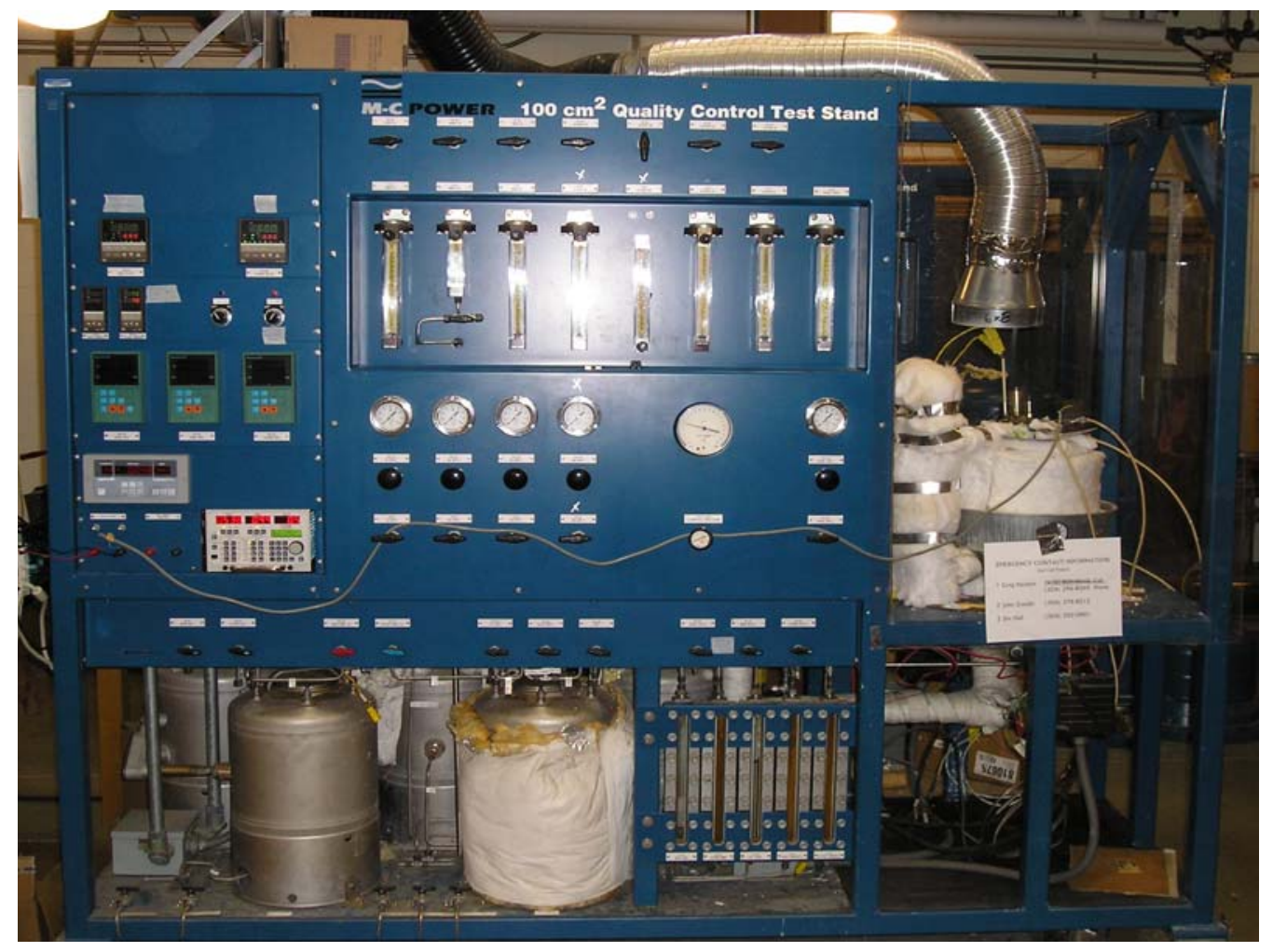

Figure 3.4- Photograph of Fuel Cell Test Stand Donated by the U.S. DOE. 
The oxygen supply, humidified air at $70^{\circ} \mathrm{C}$, is pre-heated to the fuel cell operating temperature, and then is distributed to the cathode by means of a "spider-type" sparger. The spider (Figure 3.5) takes the air inlet and directs it toward the inner surface area of the can, supplying small bubbles of needed oxygen and water to the cathode half-reaction (Equation 2.3). An inconel wire (.041-inch OD) is used as a reference

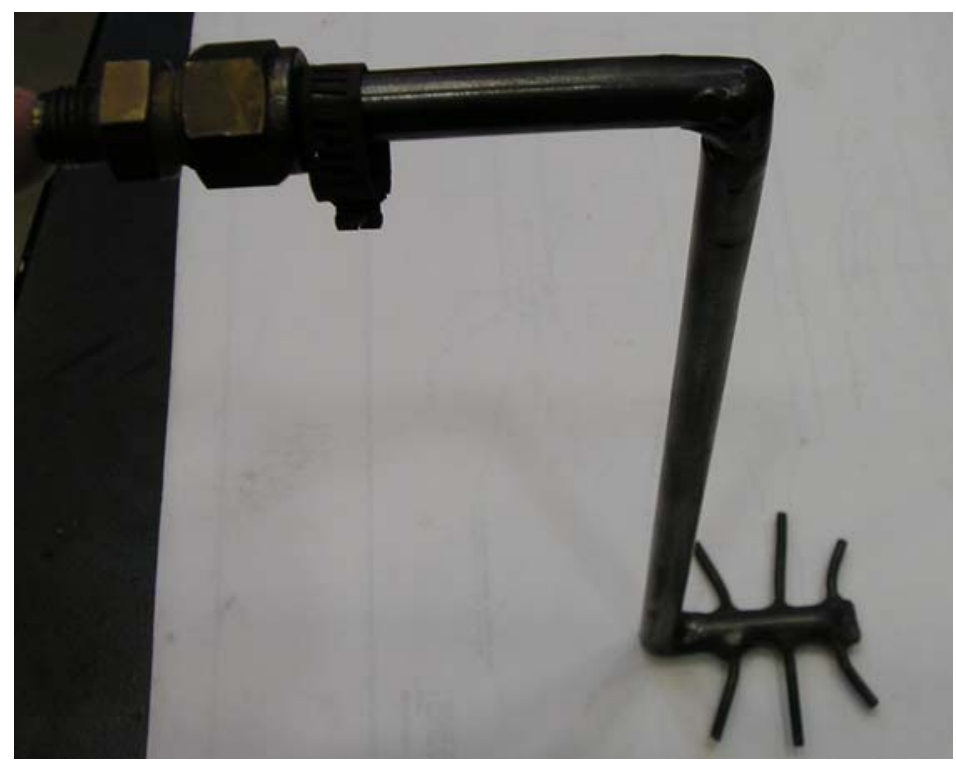

Figure 3.5- Photograph of Spider Used for Gently Bubbling Air Along the Cathode

electrode for separate anode and cathode voltage measurements. A type-K thermocouple is placed in a ceramic thermal well (Omega Engineering, Inc. models KQIN-11611-12 and ORX-11614-6, respectively) to measure the electrolyte temperature for control purposes.

The fuel cell is heated to the desired operating temperature by means of two $1.25 \mathrm{~kW}$ ceramic fiber heaters, supplied by Watlow, Inc. These are labeled "Cell Heaters" in Figure 3.3. The fuel cell and the preheated air tubing, "Air Pre-Heater" are well insulated to help prevent thermal losses. 
As previously mentioned, the fuel cell test stands have been supplied by the United States Department of Energy for research use at West Virginia University. They required vigorous examination before they were put into use. The items discussed in this section are shown in the schematic diagram given as Figure 3.3. The stands contain temperature controllers, which are used to keep the cell and preheated air at a constant temperature (RKC Instruments models REX-P9 and REX-F4, respectively shown in Figure 3.6). Also included are an electronic flow controller for the air (located behind test stand), a humidifier for the air, and a scanning data logger produced by the Azonix Corporation (model ScannerPlus) (Figure 3.7). The electronic flow controller, manufactured by Alicat Scientific, Inc. (Figure 3.8) was added to control the airflow to the system at the precise value desired. The flow controller is model MC-02SLPM-D of the 16 Series, and regulates flows between 0 and 2 SLPM. The air is supplied from a cylinder of breathing quality air through a pressure regulator. A load cell, model number SDL 1103, supplied by Transistor Devices, Inc. (Figure 3.9) simulates a load on the fuel cell by drawing a user-specified current from the cell. All of this equipment adds up to a very comprehensive test stand on which to complete research on a DCFC. 


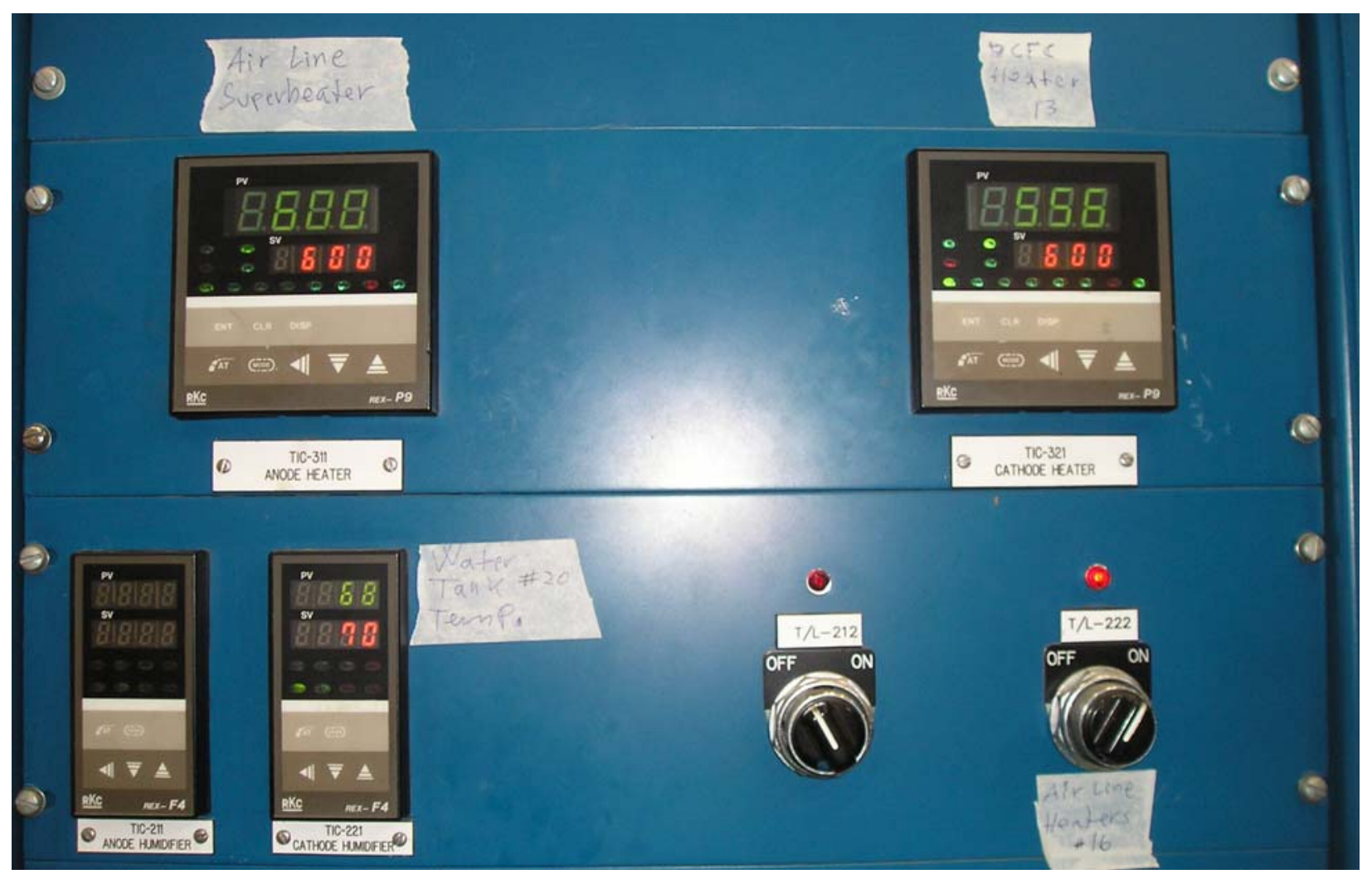

Figure 3.6 - Fuel Cell Test Stand Temperature Controllers

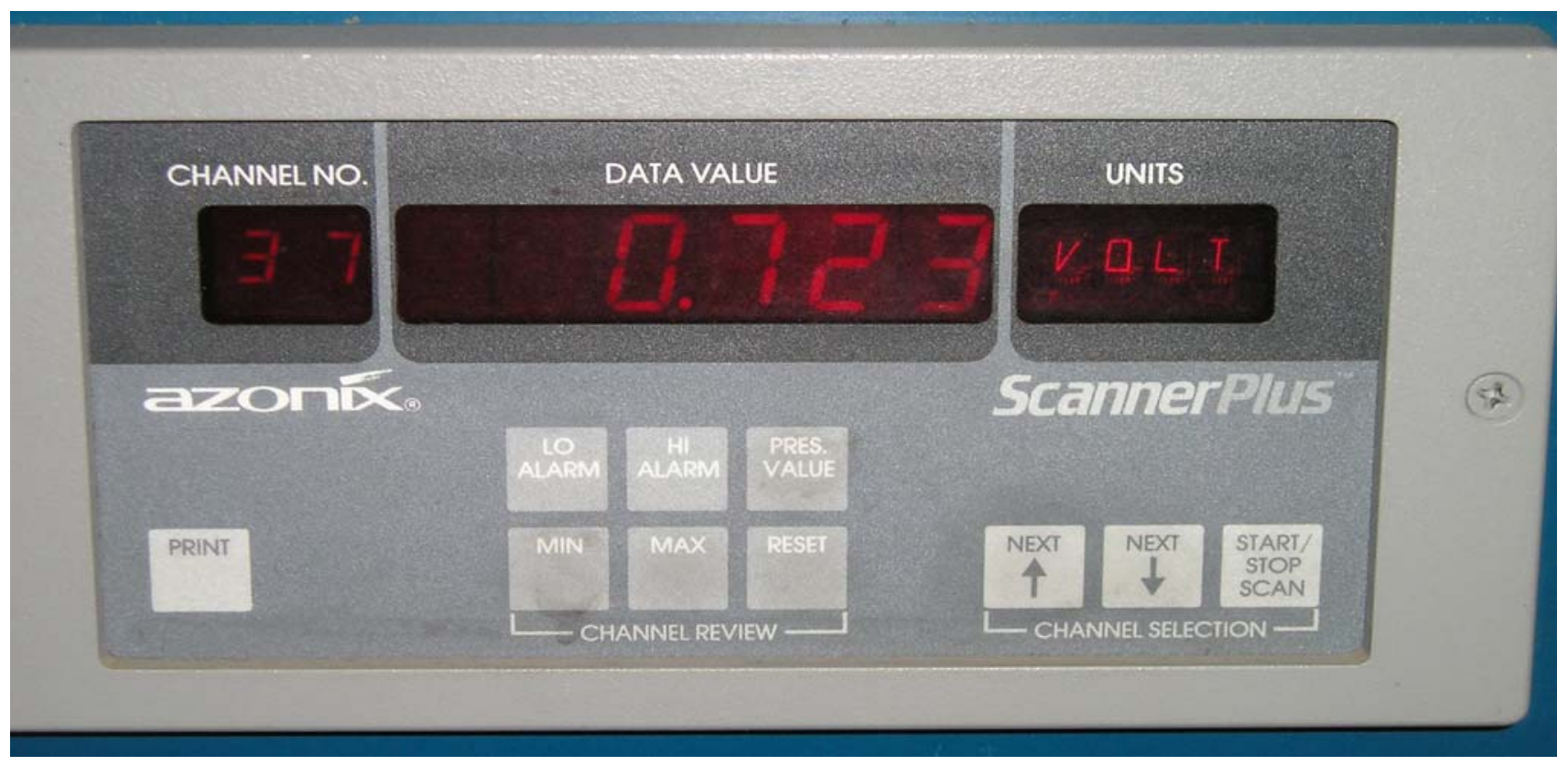

Figure 3.7 - Azonix ScannerPlus Data Logger 


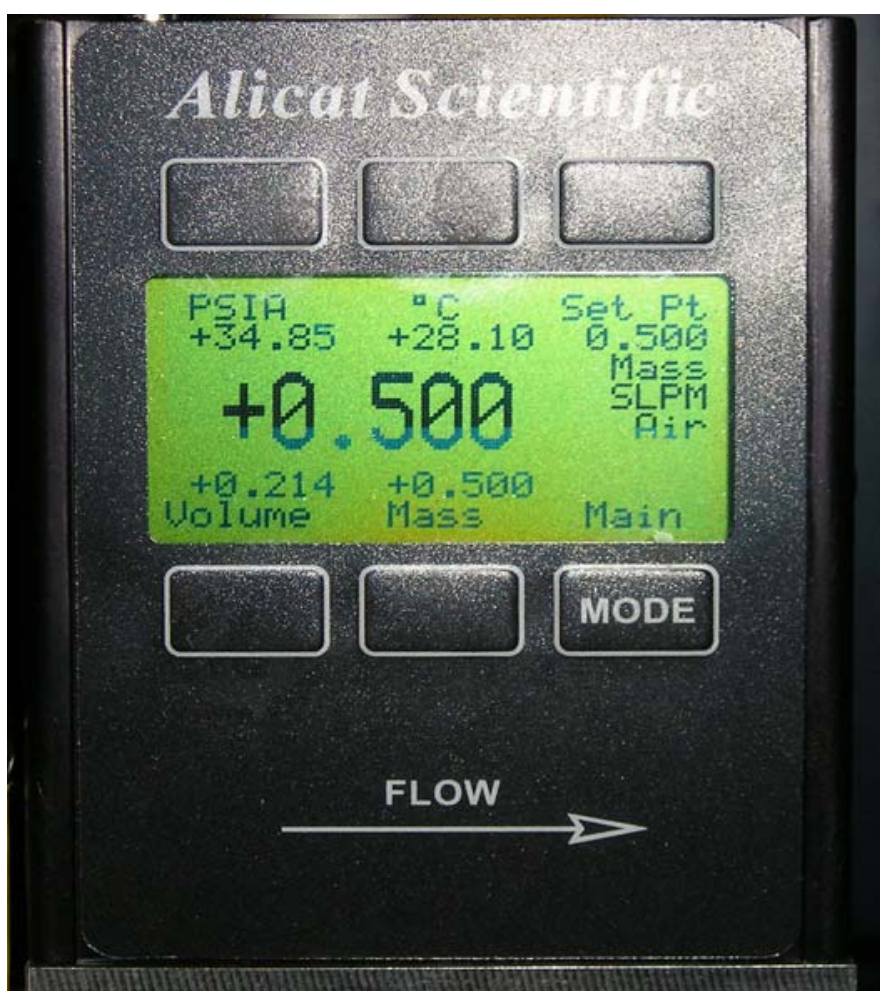

Figure 3.8 - Alicat Scientific Air Flow Controller

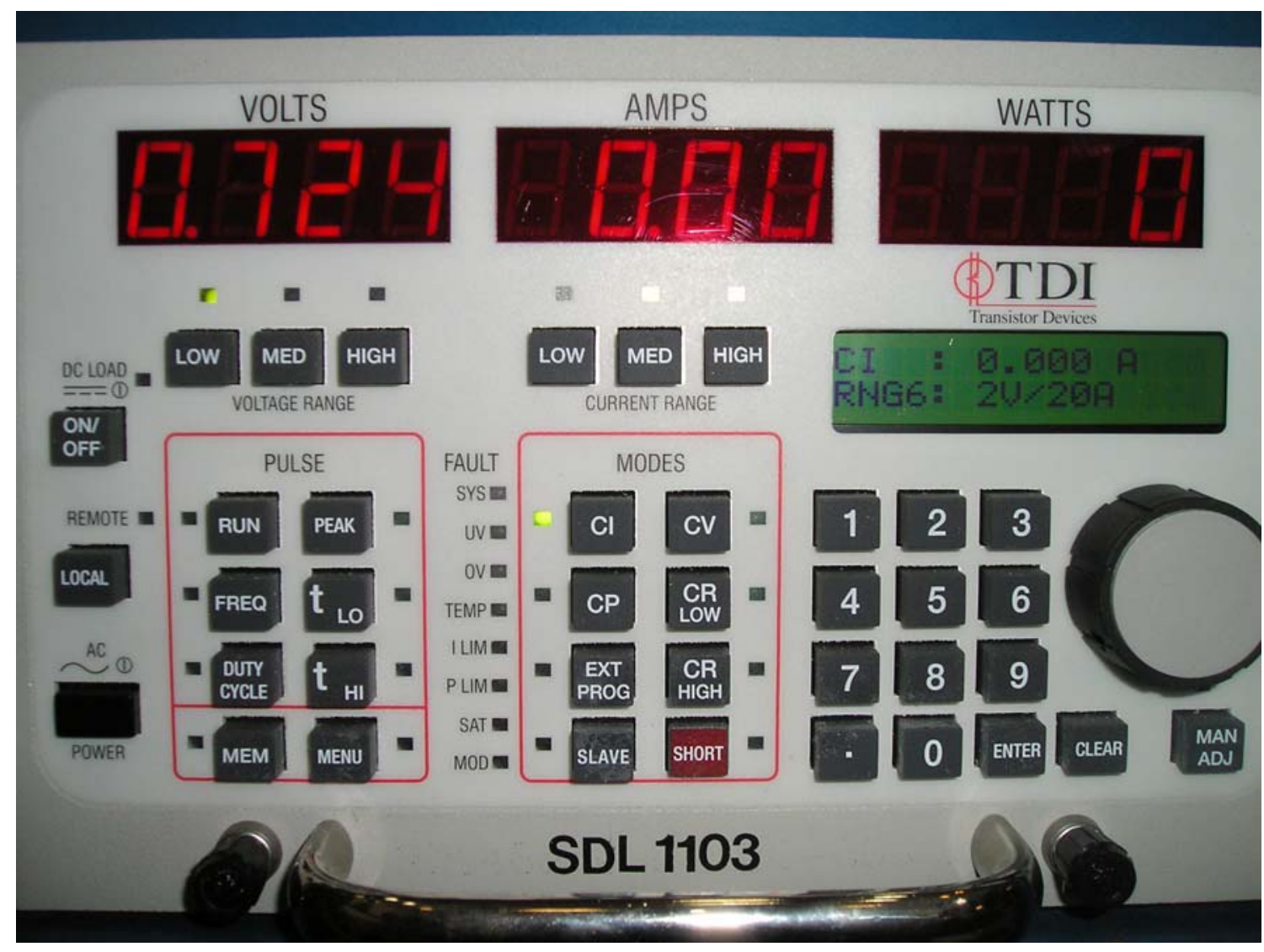

Figure 3.9 - Transistor Devices, Inc. Load Cell (SDL 1103) 


\subsection{Experimental Design}

The main objective of this research is to investigate the effects of different types of carbon-based fuel rods on fuel cell performance. In addition, the operating conditions were changed while using the same type of carbon rod. This allowed an assessment of both the effect of the rod type as well as the operating conditions. Most of the experiments were conducted with graphite rods. These rods were tested multiple times to investigate process variables such as air flow rate, fuel cell temperature, electrolyte changes and additives, and fuel cell modifications. The graphite rods were used more extensively than the others because more were available for use and were manufactured previously.

The experimental design is summarized below:

1. Graphite rod, $\mathrm{T}=600^{\circ} \mathrm{C}$, Air Flow $=0.25 \mathrm{SLPM}, \mathrm{NaOH}$ electrolyte

2. Graphite rod, $\mathrm{T}=600^{\circ} \mathrm{C}$, Air Flow $=0.50 \mathrm{SLPM}, \mathrm{NaOH}$ electrolyte

3. Graphite rod, $\mathrm{T}=600^{\circ} \mathrm{C}$, Air Flow $=0.75 \mathrm{SLPM}, \mathrm{NaOH}$ electrolyte

4. Graphite rod, $\mathrm{T}=600^{\circ} \mathrm{C}$, Air Flow $=0.90 \mathrm{SLPM}, \mathrm{NaOH}$ electrolyte

5. Graphite rod, $\mathrm{T}=625^{\circ} \mathrm{C}$, Air Flow $=0.50 \mathrm{SLPM}, \mathrm{NaOH}$ electrolyte

6. Graphite rod, $\mathrm{T}=650^{\circ} \mathrm{C}$, Air Flow $=0.50$ SLPM, NaOH electrolyte

7. Graphite rod, $\mathrm{T}=675^{\circ} \mathrm{C}$, Air Flow $=0.25 \mathrm{SLPM}, \mathrm{NaOH}$ electrolyte

8. Graphite rod, $\mathrm{T}=675^{\circ} \mathrm{C}$, Air Flow $=0.50 \mathrm{SLPM}, \mathrm{NaOH}$ electrolyte

9. Graphite rod, $\mathrm{T}=675^{\circ} \mathrm{C}$, Air Flow $=0.75 \mathrm{SLPM}, \mathrm{NaOH}$ electrolyte

10. Graphite rod, $\mathrm{T}=700^{\circ} \mathrm{C}$, Air Flow $=0.50$ SLPM, NaOH electrolyte

11. Graphite rod, $\mathrm{T}=600^{\circ} \mathrm{C}$, Air Flow $=0.50 \mathrm{SLPM}, \mathrm{Li}_{2} \mathrm{CO}_{3}+\mathrm{Na}_{2} \mathrm{CO}_{3}$ electrolyte

12. Graphite rod, $\mathrm{T}=600^{\circ} \mathrm{C}$, Air Flow $=0.50 \mathrm{SLPM}, \mathrm{NaOH}+\mathrm{LiOH}$ electrolyte

13. Petcoke Rod $\# 11, \mathrm{~T}=600^{\circ} \mathrm{C}$, Air Flow $=0.50 \mathrm{SLPM}, \mathrm{NaOH}$ electrolyte

14. Petcoke Rod $\# 10, \mathrm{~T}=600^{\circ} \mathrm{C}$, Air Flow $=0.50 \mathrm{SLPM}, \mathrm{NaOH}$ electrolyte

15. $25 \%$ SECO, $75 \%$ PetCoke Rod, $\mathrm{T}=600^{\circ} \mathrm{C}$, Air Flow $=0.50$ SLPM, NaOH el. 
16. $50 \%$ SECO, $50 \%$ PetCoke Rod, $\mathrm{T}=600^{\circ} \mathrm{C}$, Air Flow $=0.50 \mathrm{SLPM}, \mathrm{NaOH}$ el.

17. $75 \%$ SECO, $25 \%$ PetCoke Rod, $\mathrm{T}=600^{\circ} \mathrm{C}$, Air Flow $=0.50$ SLPM, $\mathrm{NaOH}$ el.

18. $100 \%$ SECO, $\mathrm{T}=600^{\circ} \mathrm{C}$, Air Flow $=0.50$ SLPM, NaOH electrolyte

19. GrafTech graphite rod, $\mathrm{T}=600^{\circ} \mathrm{C}$, Air Flow $=0.50 \mathrm{SLPM}, \mathrm{NaOH}$ electrolyte

20. GrafTech baked rod, $\mathrm{T}=600^{\circ} \mathrm{C}$, Air Flow $=0.50 \mathrm{SLPM}, \mathrm{NaOH}$ electrolyte

The carbon rods are different both in their composition and in the way that they

were manufactured. The investigation will include a good sampling of rods that vary in one or both of these characteristics. The manufacture and analysis of each type of rod can be found in Section 3.5, Experimental Materials.

Some of the experiments were completed during the same experimental run. As long as the carbon rod and the electrolyte remain the same, the airflow rate and fuel cell temperature are variable during the experiment. This helps in keeping the supply cost down as well as the time necessary to complete the experimental phase of the research. Most tests were done with the sodium hydroxide electrolyte, but a few trials were made with mixed carbonate and hydroxide electrolytes (Runs \#11 and \#12).

Data analysis consists of plotting the generated cell voltage $(\mathrm{V})$ versus the current density $\left(\mathrm{mA} / \mathrm{cm}^{2}\right)$ that is drawn from the cell using the load cell, the so-called $i-\mathrm{V}$ curves. Current density is the current drawn over the surface area of the rod exposed to the electrolyte. This is used to normalize the data for rods of different diameter and surface area. Similarly, the power density is plotted versus the current density to assess the maximum power generated. Fuel cells are designed to operate at or below the power density maximum. At current densities below the power density maximum, voltage efficiency improves but power density falls. At current densities above the maximum, both voltage efficiency and power density fall. The slope of the cell voltage versus the 
current density curve in the central region of the data supplies a value for the ohmic resistance of the fuel cell, the so-called area specific resistance (ASR). The ASR is an area-normalized resistance. It accounts for the fact that fuel cell resistance scales with area, thus allowing different size fuel cells to be compared.

A typical $i-\mathrm{V}$ curve is shown in Figure 3.10. A few points to notice about the curve are as follows: [12]

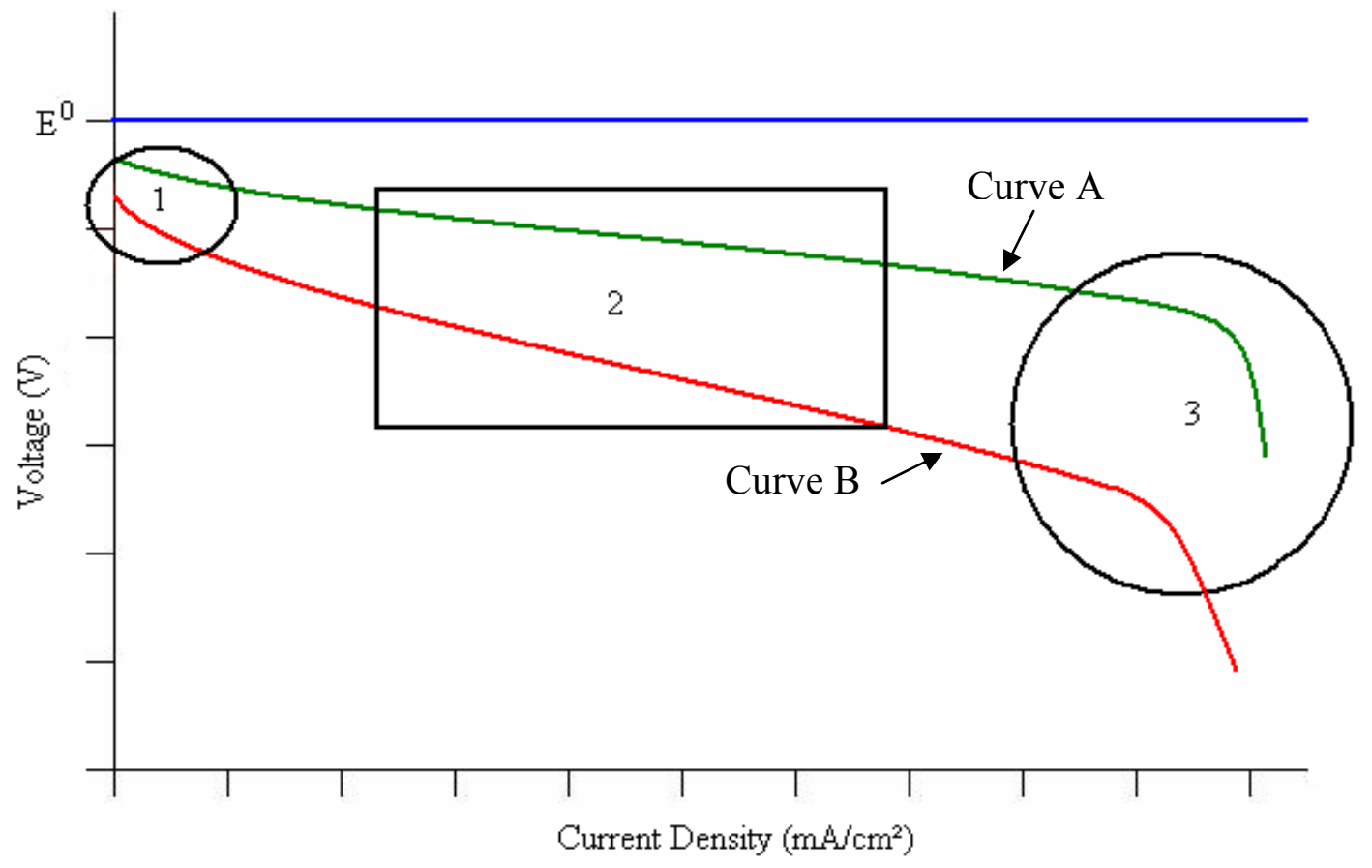

Figure 3.10 - Generic Fuel Cell i-V Curves with Specific Regions Highlighted

- The open circuit voltage (OCV) is the cell voltage at zero current.

- The initial decrease is due to the activation resistance.

- The voltage then falls less rapidly, and more linearly, and is due to ohmic resistance.

- There is usually a higher current density at which the voltage falls more rapidly, and is due to mass transport resistance. 
In the first region, where the initial decrease is slightly steeper, the electrochemical reactions are slow at the electrode surface. When current densities are small, then the voltage losses are dominated by the slowness of the electrochemical reactions. This is called activation resistance. This is voltage lost in driving the chemical reaction that transfers the electrons to or from the electrode. In Figure 3.10, Curve A has faster electrochemical reactions than Curve B as shown in Figure 3.10.

In the second, more linear region, the ohmic resistance of the fuel cell is controlling. This region also has activation losses but it is dominated by the fact that the fuel cell has some resistance. This resistance is mostly found in the electrolyte and electrodes of the fuel cell. When the ohmic resistance is high, ionic and electronic conduction is hindered, which lowers the cell voltage. Electrons will travel more slowly through the fuel cell and more heat will be generated. The rest of these losses can be found in the electrode material and the interconnections of the cell. Curve A has a lower ohmic resistance than Curve B.

In the third, much steeper region, the reactants cannot get to the reaction site quickly enough, the so-called mass transport or diffusion resistance. If the reactants cannot get to the reaction site fast enough, then the rate of the electrochemical reactions is once again limited, due to the low concentration of reactant at the electrode surface. At very high current densities, more reactant has to be supplied so that more electrons can be generated. The difference in the curves is explained by the relative ease of the transport of reactants.

Equation 3.1 summarizes how the cell voltage is obtained after losses.

$$
V=E^{0}-\eta_{A C T}-\eta_{\text {OHMIC }}-\eta_{D I F F}
$$


Here, $V$ is the cell voltage, $E^{0}$ is the thermodynamic cell voltage, $\eta_{A C T}$ is the activation voltage losses, $\eta_{\text {ОНMIC }}$ is the ohmic voltage losses, and $\eta_{D I F F}$ is the concentration voltage losses.

\subsection{Experimental Procedure}

The actual experiments were conducted in the following manner at West Virginia University. The method described in this section is the basic operating procedure for a typical experiment and is not absolute. Different experiments may have required more attention to certain aspects of the procedure than others.

Because of the high heat capacity of water, the first order of business is to begin to heat the water tank used for humidification of the feed air, from room temperature to $70^{\circ} \mathrm{C}$. This tank provides the water vapor to the airline required by the reaction at the cathode. The line from the humidifier to the pre-heater is heat-traced at $70^{\circ} \mathrm{C}$ to prevent the water from condensing.

While the tank is heating, the carbon rod apparatus is prepared. Careful attention must be paid so that the rod is not broken during this process. The metal surfaces on this apparatus are buffed with emery paper to ensure good electrical contact with a fresh metal surface. The cell is similarly cleaned (usually the day before) and the inside is buffed with a wire brush to remove any corroded or rusted portions of the interior. The spider is cleaned to remove any residual electrolyte that may have gotten caught in the

openings during the previous run. The carbon rod is tightened into the apparatus using a collet fitted to the top plate of the fuel cell. The size of the collet depends on the outer diameter of the rod (usually $3 / 4 "$ "). Because electrical contact is very important in this experiment, the collet is firmly tightened using a vice and lever arm tool. 
The fuel cell body is then mounted in the test stand and the airline is connected. The area around the cell and heaters is well insulated to minimize the heat loss from the cell. The airflow is then set to a predetermined rate by means of the electronic flow controller. Once it is confirmed that air is flowing, the solid electrolyte is added to the cell. The temperature controllers for both the air pre-heater and the cell heaters are set to the desired operating temperature and powered on.

When the solid electrolyte has melted (usually about 30 minutes), the carbon rod, previously mounted in the collet, is slowly immersed into the liquid electrolyte and then removed in order to record the submerged length of the rod. This is done because the height of the electrolyte varies from experiment to experiment. This value is then used to calculate the nominal surface area of the carbon rod, the side and bottom areas of a cylinder, which is exposed to the electrolyte, which, in turn, is used to normalize the current. Once the length is obtained, the rod is replaced into the cell. The rod is submerged at an extremely slow rate to alleviate some of the thermal shock from the temperature difference of the room temperature rod and the molten electrolyte.

Once the apparatus is assembled, the proper wires are connected to the anode, cathode, and reference electrode respectively with the other ends being connected to the load cell and the data collection devices. Before any experimental data are collected, it is confirmed that the proper temperatures have been reached and are steady, the cell voltage is in equilibrium and the equipment is functioning properly.

After everything has been checked for proper operation, the experimental data can be collected. The experimental parameters are set and the system is allowed time to reach equilibrium once more. Because most of the tests involve the evaluation of voltage 
versus current density curves, the current drawn is increased in a step-wise manner from zero amps (open cell) to some maximum value determined by the experiment. Each datum point is recorded after 30 seconds of equilibrium time since it was found that the cell voltage and current stabilize very quickly, usually within a few seconds of being changed. The incremental change of the current drawn is usually $0.1-0.2 \mathrm{~A}$ every 30 seconds and is adjusted on the load cell manually. Once the maximum value is reached (determined by a $0.200 \mathrm{~V}$ reading at the cathode), the current is ramped down at about 0.5 $-1.0 \mathrm{~A}$ every 30 seconds. The reason a value of $0.200 \mathrm{~V}$ at the cathode signifies the maximum obtainable current is due to the fact that the cell voltage rapidly decreases at that point even with just a small increase in current. This is due to the transport limitations described earlier.

After again reaching open cell, the system is allowed time to recover (15-20 minutes) and another experiment can then be performed as long as the system is still functioning properly. If an experiment is to be run long term, the desired current is set and the cell is checked hourly to ensure proper operation so that it can be left unattended overnight.

After all the experiments have been completed on a particular carbon rod, the shutdown and cleanup procedure begins. The heaters are turned off and the air is allowed to flow to prevent the electrolyte from backing up into the air supply line. Once the fuel cell has cooled to a temperature near the melting point of the electrolyte (approximately $300^{\circ} \mathrm{C}$ for sodium hydroxide), the carbon rod apparatus is removed and the molten electrolyte is dumped into a tray so that it can solidify and be properly disposed of. Great 
care must be taken in this procedure, as the cell is still extremely hot $\left(300^{\circ} \mathrm{C}\right)$. Proper clothing, hand protection, eye protection, and face shielding must be worn.

After everything has been taken apart, the cell is once again cleaned and all the parts are prepared for the next experiment. With this procedure, it is possible to run an experiment every $1-2$ days.

\subsection{Experimental Safety}

The described experiment poses several serious safety concerns that can be readily alleviated through proper procedures and precautions. Material safety and data sheets for all the chemicals in this study are included in the appendix.

First, proper eyewear and protective gloves should be worn at all times when dealing with corrosive chemicals such as sodium hydroxide. When handling the hot fuel cell, it is extremely important to wear high temperature heat resistant gloves. Severe burns occur when skin is exposed to temperatures around $600^{\circ} \mathrm{C}$.

Second, when dealing with molten chemicals, there is always a risk of spatter or spilling. Acrylic panels have been placed around the fuel cell testing area shown in Figure 3.4, located on the right side of the diagram. These are removable when it is necessary to adjust the fuel cell. While in operation, these shields are always to be in place. Molten sodium hydroxide, other than being at $600+{ }^{\circ} \mathrm{C}$, is highly corrosive and will cause damage upon exposure to skin or nearby equipment.

Third, an emergency electrical shut-off switch is installed. Some of these experiments require long-term runs. Therefore, if something malfunctions in the middle

of the night, the emergency shut-off is clearly labeled so that anyone can shut down the system immediately. 
Fourth, exhaust fumes may contain sodium hydroxide vapors or other potential hazards. A fan-powered duct has been routed from just above the fuel cell to the nearest fume hood to insure that none of these fumes escapes into the surrounding air in the laboratory.

Fifth, to prevent the heaters from overshooting the set point by an extreme amount, the temperature controllers include an over temperature protection system that will immediately shut off the heaters in the event that the preset high-limit temperature is reached. Also, to prevent the water from condensing in the airlines, heat tapes and insulation have been wrapped around the line carrying the humidified air from the humidification tank to the air pre-heater to keep it at the proper temperature.

Finally, when dealing with electricity, one must be sure not to short out the system or touch any exposed wires that have a current running through them. Although measures are taken to insulate any wires from exposure, there is always the possibility of an exposed connection. Therefore, users must heed caution and always be able to see where their hands are being placed. Safety is very important in any experimental process and was not taken lightly in these experiments.

\subsection{Experimental Materials}

\subsubsection{Carbon Rod Production}

The graphite rods tested in these experiments were remaining from a previous project and were found in a large quantity at WVU. The place or method of manufacture is not known. The only thing known about these is the resistivity (discussed later) and that the rods are well made. 
The coal-derived rods were made at WVU using a combination of Solvent Extracted Carbon Ore (SECO), petroleum coke (PetCoke), and a coal tar binder pitch that binds the SECO and PetCoke together. SECO is a low-ash extract material that is produced at WVU by solvent extraction of raw coal using N-methylpyrrolidone as the solvent. Petroleum coke is an anisotropic carbon produced in a delayed coker at the refinery. It has a low electrical resistivity, making it ideal for use as an anode material. Some of the rods were created as pure PetCoke (no SECO in mixture) at a composition of $\left(80 \%\right.$ PetCoke $/ 20 \%$ binder pitch). These rods were pressed in a heated mold at $200^{\circ} \mathrm{C}$ and then calcined to $1000^{\circ} \mathrm{C}$. They were used in Runs \#13 and \#14. Other rods were made by the same procedure and included different compositions of SECO and PetCoke, using a $15 \%$ coal tar binder pitch to hold the mixture together. It should be noted that the rods produced in this manner had visible cracks in the surface and had some variation in their quality. The production of these rods was the subject of a previous M.S. thesis at WVU. [13]

The GrafTech rods were either baked or graphitized and were produced by GrafTech, Inc., which specializes in the production of synthetic graphite. West Virginia University has a good working relationship with GrafTech and these rods were provided free of charge by Mr. Doug Miller. The rods produced by GrafTech did not have any visible cracks and were well made. The baked rods were made from premium petroleum coke and binder pitch. They were baked at $1000^{\circ} \mathrm{C}$ but not graphitized.

\subsubsection{Carbon Rod Resistivity}

In the fuel cell design used for this work, the carbon rod is both the fuel and the anode. Therefore, it must be able to carry electricity fairly well in order for the system to 
work. The resistivity of the rods is the physical parameter that indicates how well they are able to carry electricity in comparison to each other. The resistivity of a representative rod of each type was measured and recorded using a standard four-point apparatus available at WVU. This apparatus contains a power supply, a current meter, a variable resistor, a voltmeter, and a carbon rod holder consisting of two copper plates on both ends to make electrical contact with the rod. With this information, the resistivity of the rod can be calculated. A picture of the resistivity apparatus is shown below in Figure 3.11 .

A Keithley Model 2000 multi-meter (in current mode) in series with the carbon fuel rod measures the current. The voltage drop across the rod is measured with a second digital multi-meter (same model, in voltage mode) that is connected to the rod by two pointed contact pins over a precisely measured distance. The variable resistor allows for control of the current in the circuit. A schematic diagram of this method is shown in Figure 3.12. The resistivity can then be calculated using the following relation:

$$
\rho=\left(\frac{V}{I}\right)\left(\frac{A_{C S}}{L}\right)\left(10^{3}\right)
$$

The resistivity, $\rho(\mu \Omega \cdot \mathrm{m})$ is found by taking the voltage, $V(\mathrm{~V})$ to current, $I(\mathrm{~A})$ ratio and multiplying by the ratio of the rod's cross-sectional area, $A_{C S}\left(\mathrm{~mm}^{2}\right)$ to the length between contact points, $L(\mathrm{~mm})$. Finally, multiplying by $10^{3}$ converts to the desired units of $(\mu \Omega \cdot m)$ for resistivity. 


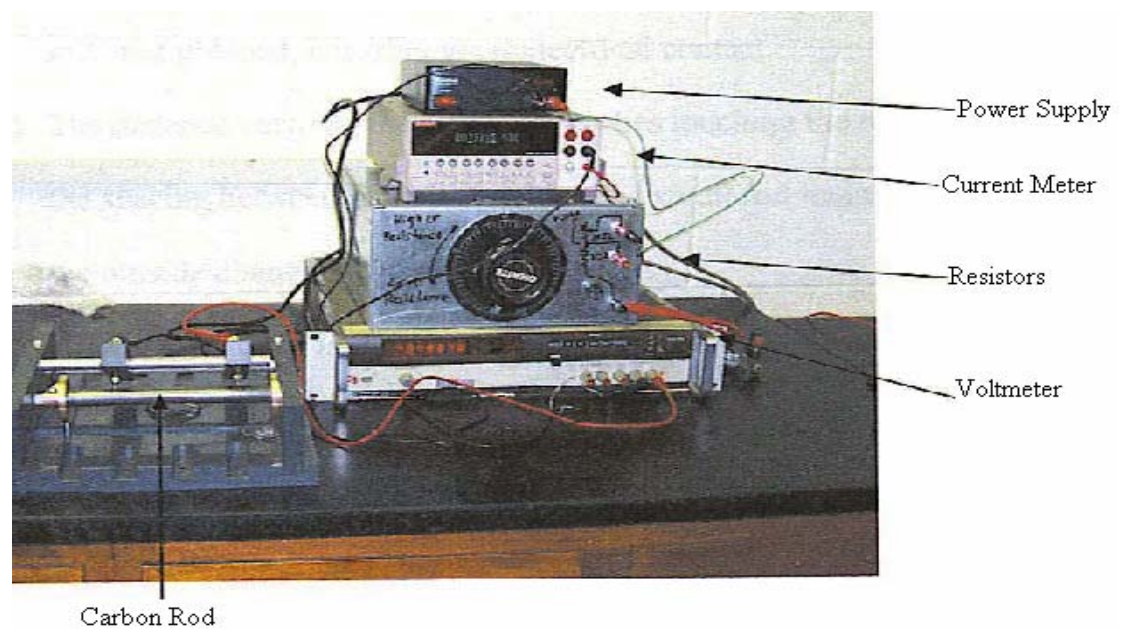

Figure 3.11 - Carbon Rod Resistivity Testing Apparatus

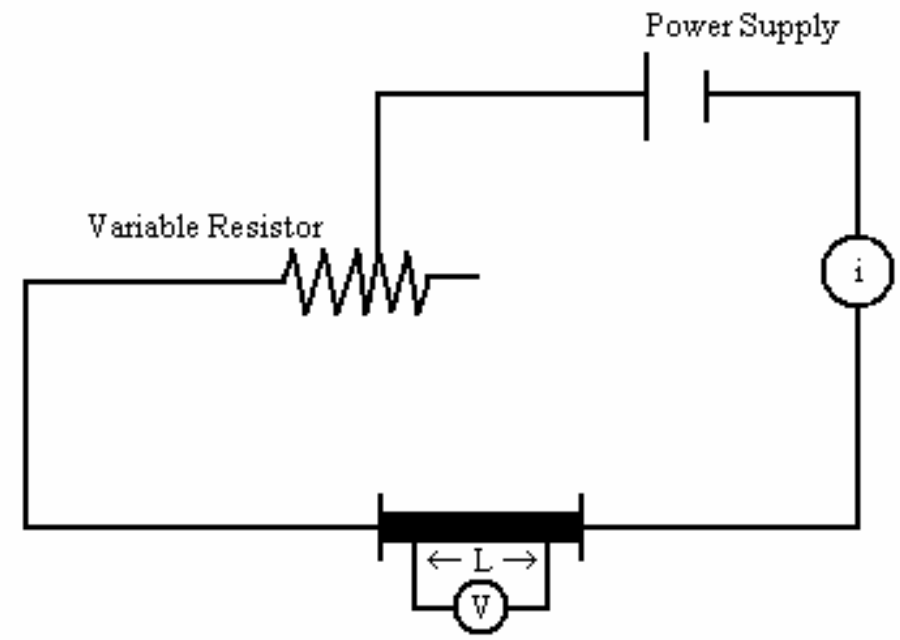

Figure 3.12 - Schematic Diagram of Four Point Method for Testing Resistivity 


\section{Chapter 4}

\section{$\underline{\text { Results and Discussion }}$}

\subsection{Experimental Analysis}

\subsubsection{Equipment Analysis}

In this section, the results of the experimental procedure and some unanticipated events are discussed.

The test stand has been successfully modified from a solid-oxide fuel cell to a direct carbon fuel cell. The equipment that was replaced (as discussed previously) all functioned properly. After experimenting with the test stand for an extended period of time, it became easier to manipulate the system to meet the needs of the project. The computer system allowed data points to be collected electronically, saving a lot of time compared to hand written data.

The data were accurate because several conditions of the cell could be monitored simultaneously, giving a clearer sense of what was occurring within the cell at a specific moment, as opposed to reading meters and recording values individually. In this sense, human error was alleviated for the data collection.

\subsection{2 $\underline{\text { Safety Analysis }}$}

During a few runs, the molten electrolyte erupted out of the cell. The cause of this is not well understood, but there are a few hypotheses, as discussed below.

One hypothesis for this occurrence could be an air pressure buildup. At the time of the first occurrence, the air was fed from the "house air" line at WVU that is connected to all of the laboratories in the building. The remedy for this was to install a breathing 
quality air cylinder and pressure regulator directly to the system to alleviate any pressure buildups. This would also take care of any purity issues, as it was suspected that excess moisture was in the house airline. However, this solution did not solve the problem.

A second hypothesis is that while the load cell was set to a current of zero, a static charge built up between the anode and the cathode. This would likely happen because with the load cell turned off, the flow of electrons is stopped. The chemical reactions were ongoing and electrons were still being produced and consumed at the anode and cathode respectively. After the charges increased to a certain point, it is believed that a spark may have formed causing the major disruption within the cell, which led to molten electrolyte being expelled up to 15 feet away from the experiment. This prompted the installation of acrylic sheets around the cell for shielding.

As a remedy to this problem, the load cell was never actually turned off, but set at the lowest possible current setting. By keeping the electrons flowing, the static charge should not build up. After using this method, only one further eruption occurred and it was small in comparison.

\subsection{Fuel Rod Overview}

A summary of all results from the experimental setup discussed previously is given below as Table 4.1 . 
Table 4.1- Summary of Results from Experimental Design

\begin{tabular}{|c|c|c|c|c|c|c|}
\hline Run & $\begin{array}{c}\text { Open Cell } \\
\text { Voltage (V) }\end{array}$ & $\begin{array}{c}\text { Maximum } \\
\text { Current Density } \\
\left(\mathrm{mA} / \mathrm{cm}^{2}\right)\end{array}$ & $\begin{array}{c}\text { Maximum } \\
\text { Power Density } \\
\left(\mathrm{W} / \mathrm{cm}^{2}\right)\end{array}$ & $\begin{array}{c}\text { Area Specific } \\
\text { Resistance } \\
\left(\Omega \times \mathrm{cm}^{2}\right) \\
\end{array}$ & $\begin{array}{c}\text { Active Surface } \\
\text { Area }\left(\mathrm{cm}^{2}\right)\end{array}$ & Resistance $(\Omega)$ \\
\hline 1 & 0.751 & 230 & 0.066 & 2.91 & 50.5 & 0.058 \\
\hline 2 & 0.767 & 207 & 0.068 & 2.75 & 49.5 & 0.056 \\
\hline 3 & 0.779 & 175 & 0.065 & 2.74 & 50.5 & 0.054 \\
\hline 4 & 0.788 & 105 & 0.048 & 2.50 & 54.5 & 0.046 \\
\hline 5 & 0.757 & 133 & 0.057 & 2.00 & 51.9 & 0.039 \\
\hline 6 & 0.760 & 170 & 0.073 & 1.60 & 51.9 & 0.031 \\
\hline 7 & 0.773 & 183 & 0.062 & 2.60 & 51.9 & 0.050 \\
\hline 8 & 0.735 & 185 & 0.048 & 3.00 & 51.9 & 0.058 \\
\hline 9 & 0.770 & 197 & 0.084 & 1.60 & 51.9 & 0.031 \\
\hline 10 & 0.729 & 214 & 0.062 & 2.20 & 51.9 & 0.042 \\
\hline 11 & \multicolumn{6}{|c|}{ NO DATA COLLECTED } \\
\hline 12 & \multicolumn{6}{|c|}{ NO DATA COLLECTED } \\
\hline 13 & 0.963 & 53 & 0.033 & 4.30 & 60.6 & 0.071 \\
\hline 14 & 0.981 & 48 & 0.032 & 4.20 & 43.7 & 0.096 \\
\hline 15 & \multicolumn{6}{|c|}{ ROD BROKE OFF AT ELECTROLYTE SURFACE } \\
\hline 16 & 0.963 & 31 & 0.020 & 8.10 & 71.7 & 0.113 \\
\hline 17 & \multicolumn{6}{|c|}{ ROD DID NOT SURVIVE EXPERIMENT PREPARATION } \\
\hline 18 & 1.044 & 35 & 0.024 & 7.55 & 66.5 & 0.114 \\
\hline 19 & 0.705 & 107 & 0.041 & 2.20 & 41.3 & 0.053 \\
\hline 20 & 0.972 & 38 & 0.026 & 4.20 & 65.2 & 0.064 \\
\hline
\end{tabular}

\subsubsection{Graphite Rods}

The graphite rods operated very well in the DCFC. The method in which they were manufactured allowed for reliable experiments to be conducted. Also, because of their stability, it was possible to run multiple types of experiments, changing the process variables without the rod degrading. The graphite rods left the electrolyte fairly clear after finishing an experiment, which shows that not much particulate carbon was dissolving into the electrolyte. Any carbon that was missing from the surface of the rod was therefore, reacting with the hydroxide to form electrical power. 
The maximum open-circuit voltage (OCV) from a graphite rod was a value of $0.788 \mathrm{~V}$. This value for the graphite rods was not as high as obtained from the coalderived rods, as previously noted in the literature. A summary of the runs involving graphite fuel rods is given below in Table 4.2 .

Table 4.2 - Summary of Results for Runs Using Graphite Fuel Rods

\begin{tabular}{|c|c|c|c|c|c|c|}
\hline Run & $\begin{array}{c}\text { Open Cell } \\
\text { Voltage (V) }\end{array}$ & $\begin{array}{c}\text { Maximum } \\
\text { Current Density } \\
\left(\mathrm{mA} / \mathrm{cm}^{2}\right)\end{array}$ & $\begin{array}{l}\text { Maximum } \\
\text { Power Density } \\
\left(\mathrm{W} / \mathrm{cm}^{2}\right)\end{array}$ & $\begin{array}{c}\text { Area Specific } \\
\text { Resistance } \\
\left(\Omega \times \mathrm{cm}^{2}\right)\end{array}$ & $\begin{array}{c}\text { Active Surface } \\
\text { Area }\left(\mathrm{cm}^{2}\right)\end{array}$ & Resistance $(\Omega)$ \\
\hline 1 & 0.751 & 230 & 0.066 & 2.91 & 50.5 & 0.058 \\
\hline 2 & 0.767 & 207 & 0.068 & 2.75 & 49.5 & 0.056 \\
\hline 3 & 0.779 & 175 & 0.065 & 2.74 & 50.5 & 0.054 \\
\hline 4 & 0.788 & 105 & 0.048 & 2.50 & 54.5 & 0.046 \\
\hline 5 & 0.757 & 133 & 0.057 & 2.00 & 51.9 & 0.039 \\
\hline 6 & 0.760 & 170 & 0.073 & 1.60 & 51.9 & 0.031 \\
\hline 7 & 0.773 & 183 & 0.062 & 2.60 & 51.9 & 0.050 \\
\hline 8 & 0.735 & 185 & 0.048 & 3.00 & 51.9 & 0.058 \\
\hline 9 & 0.770 & 197 & 0.084 & 1.60 & 51.9 & 0.031 \\
\hline 10 & 0.729 & 214 & 0.062 & 2.20 & 51.9 & 0.042 \\
\hline 11 & \multicolumn{6}{|c|}{ NO DATA COLLECTED } \\
\hline 12 & \multicolumn{6}{|c|}{ NO DATA COLLECTED } \\
\hline 19 & 0.705 & 107 & 0.041 & 2.20 & 41.3 & 0.053 \\
\hline
\end{tabular}

Conditions for Runs \#1, \#2, and \#3 were repeated throughout the experimentation process. Therefore, several values were obtained that are not recorded in Table 4.2. The area specific resistance (ASR), active surface area, and resistance are reported as average values of these repetitions. The active surface area is the amount of the fuel rod that is in contact with the electrolyte, where the anode reaction occurs, and is used to normalize the ASR data because the various runs had different active surface areas.

The results of the graphite runs are given below as Figure 4.1, Figure 4.2, Figure 4.3, Figure 4.4, Figure 4.5, Figure 4.7, Figure 4.9, and Figure 4.10. It is interesting to note that all of the graphite runs have the same shape for their $i-\mathrm{V}$ curve. This is the shape that was discussed previously. The curves all drop quickly at the smaller currents 
due to the activation resistance. They continue to decrease in a linear fashion due to the ohmic resistance of the cell. Finally, the voltage decreases drastically at high currents due to the concentration or transport limitation being reached. The fuel cell power density increases with increasing current density, reaches a maximum, and then falls at still higher current densities.

These results, which all showed the same trend, were sometimes very different in magnitude. The run shown as Figure 4.1 was the first attempt and was terminated prior to reaching the maximum power density. This explains why the basic trend was not obtained. The run displayed in Figure 4.2, produced the most current, and therefore, produced a high power density. Each of these runs showed slightly different results and this may be due to some coating of the rods (which is discussed later), poisoned electrolyte (due to cell corrosion), etc. What is important to note is that the trends are similar and produce nearly the same voltages and power.

Long-term runs for some graphite experiments were conducted to investigate the long-term effects of the DCFC. These results are given in Figure 4.6, Figure 4.8, Figure 4.11, and Figure 4.13. In Figure 4.6, a constant current of 2.0A was set and the cell is allowed to run for an extended period of time ( $\sim 17$ hours). This graphite rod held up well and only degraded slightly after 17 hours. It should be noted that for the long-term testing, the active surface area of the rod was assumed to remain constant over the entire course of the test. In reality, this is not the case as the rod diameter decreases as more carbon reacts. Since there is no easy way to follow the change in area, it was taken as constant. 
In Figure 4.8, a constant current of 2.0A was also set. However, in this case, the cell voltage degrades much quicker. There was a coating on the surface of this rod that most likely hindered the reaction at the rod's surface. Therefore, the reaction could not take place at this current. After shutting off the load (current), the cell recovered to $0.700 \mathrm{~V}$. Once the current was turned back on, cell voltage decreased drastically. This reinforces the idea that the coating of the anode that was causing the problem.

In Figure 4.11, a constant current of 1.5A was set. After a small initial decrease, the cell recovered and produced a constant voltage over the remaining 15 hours. This run proved to be the most stable of the long-term runs as the voltage decrease over time was minimal.

In Figure 4.13, a constant current of 1.0A was set. The cell seems to struggle throughout the long term run, holding steady for the first 12 hours and slowly decreasing cell voltage over the next 9 hours. During this long-term run, a large pressure buildup was noticed and the airflow rate was stuck at 0.075 SLPM, which was way below the set point of 0.50 SLPM. 


\section{Cell Voltage and Power Density versus Current Density}

Graphite Rod, $\mathrm{T}=600^{\circ} \mathrm{C}, 11 / 22 / 05$

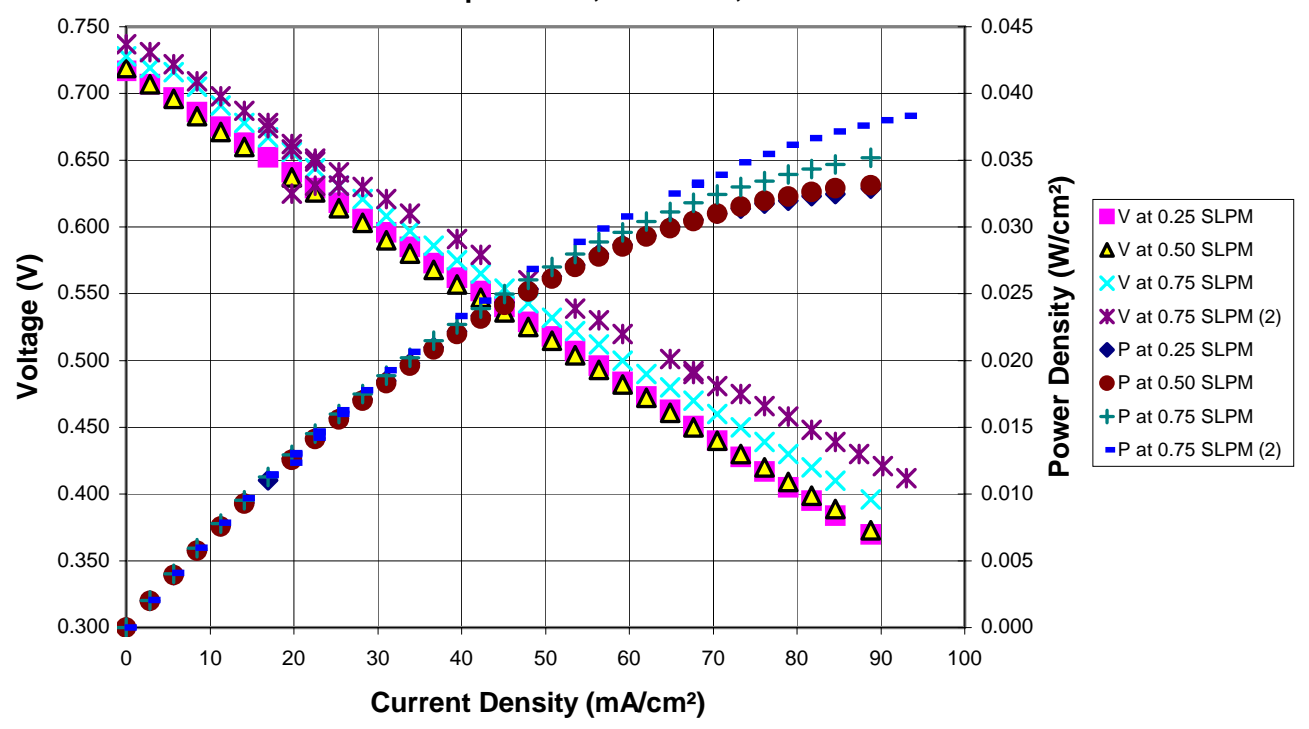

Figure 4.1 - Results of Initial Graphite Experiment Subject to the Conditions of Runs \#1, \#2, and \#3

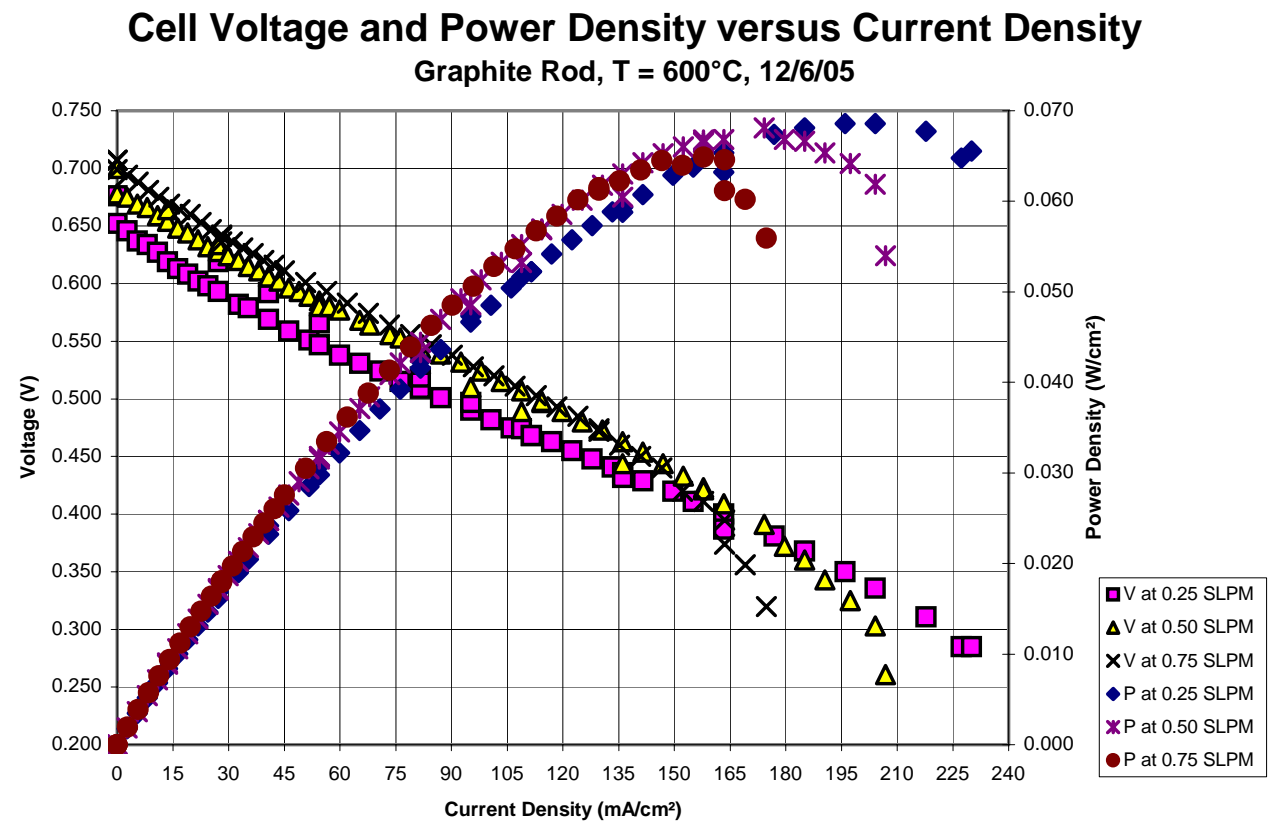

Figure 4.2 - Results of Graphite Experiment Subject to the Conditions of Runs \#1, \#2, and \#3 


\section{Cell Voltage and Power Density versus Current Density Graphite Rod, $\mathrm{T}=600^{\circ} \mathrm{C}, 12 / 14 / 05$}

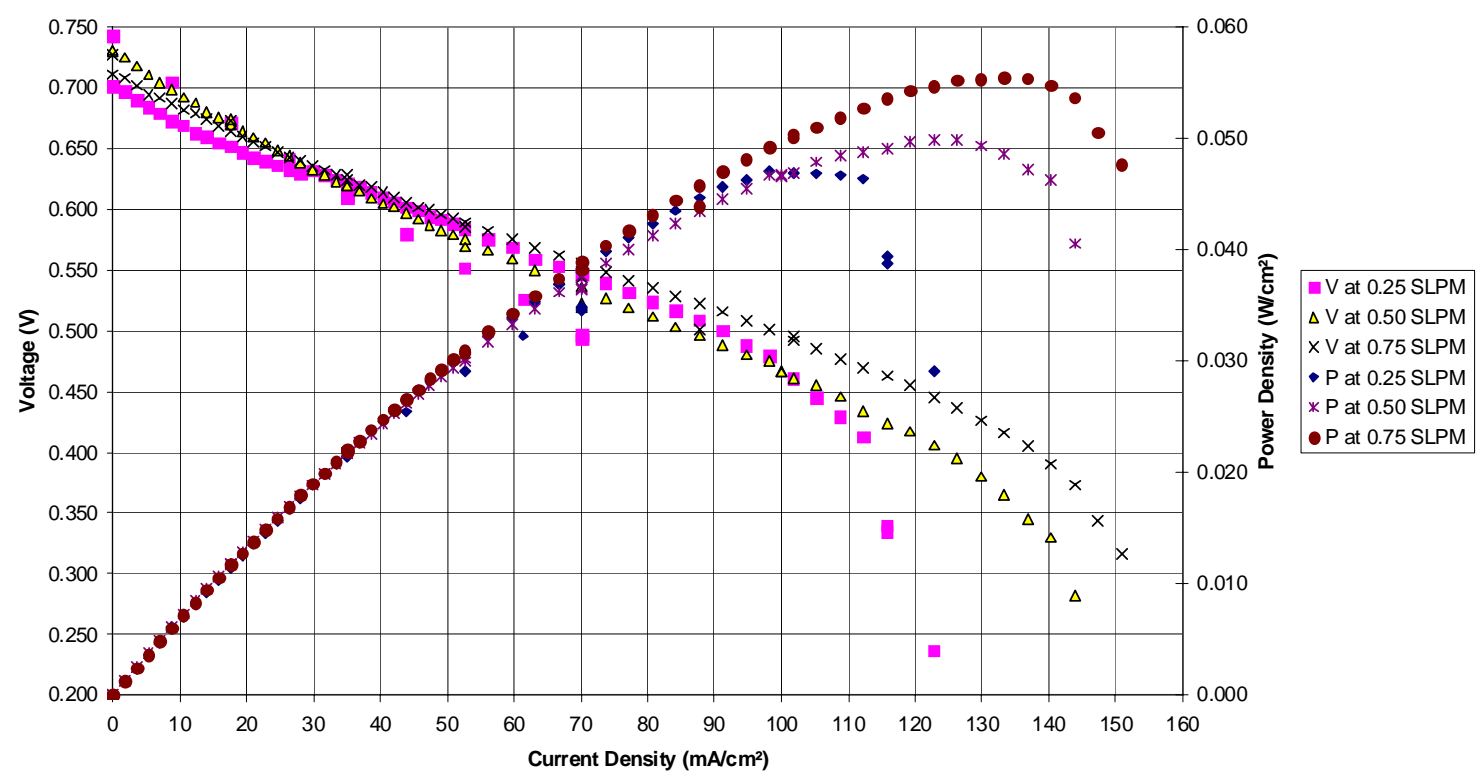

Figure 4.3 - Results of Graphite Experiment Subject to the Conditions of Runs \#1, \#2, and \#3

\section{Cell Voltage and Power Density versus Current Density Graphite Rod, $\mathrm{T}=600^{\circ} \mathrm{C}, 1 / 12 / 06$}

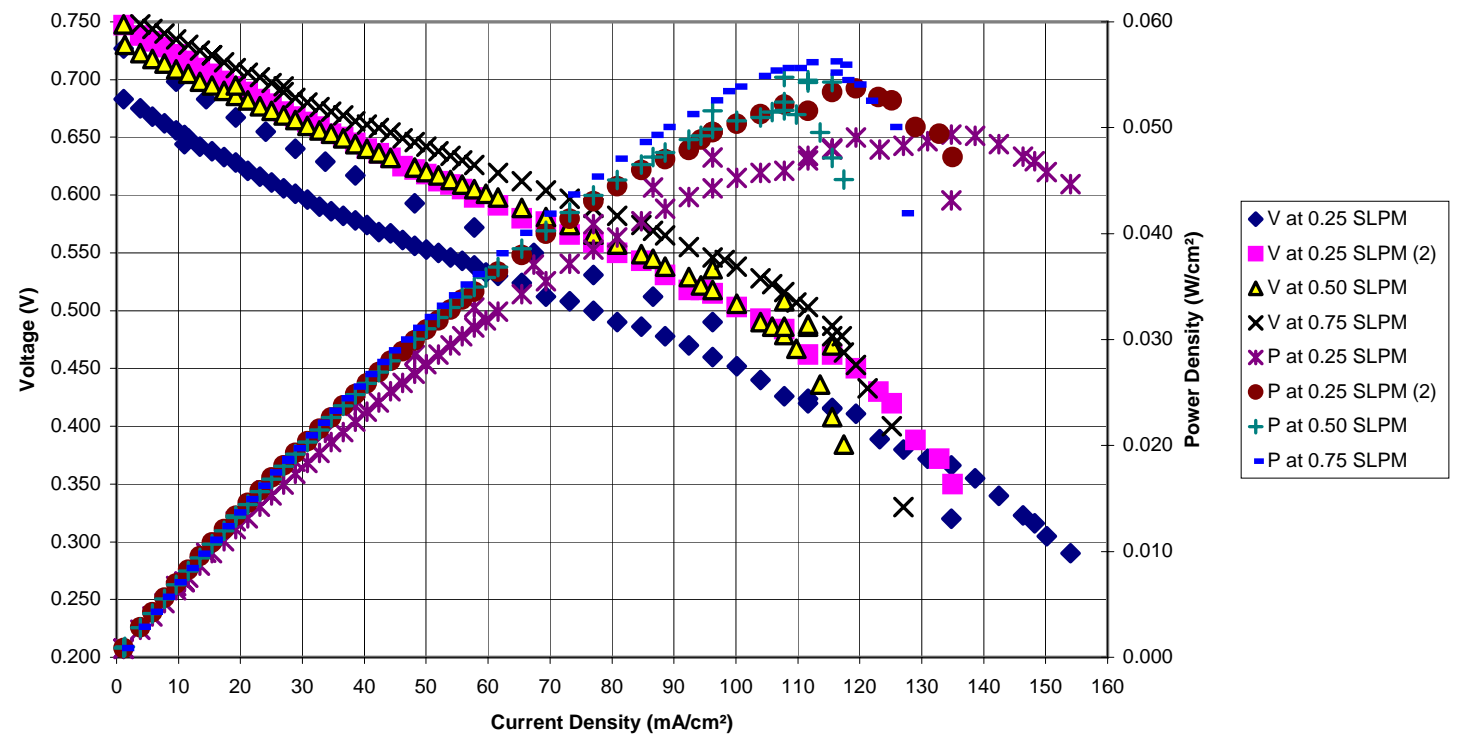

Figure 4.4 - Results of Graphite Experiment Subject to the Conditions of Runs \#1, \#2, and \#3 


\section{Cell Voltage and Power Density versus Current Density}

Graphite Rod, $\mathrm{T}=600^{\circ} \mathrm{C}, 1 / 25 / 06$

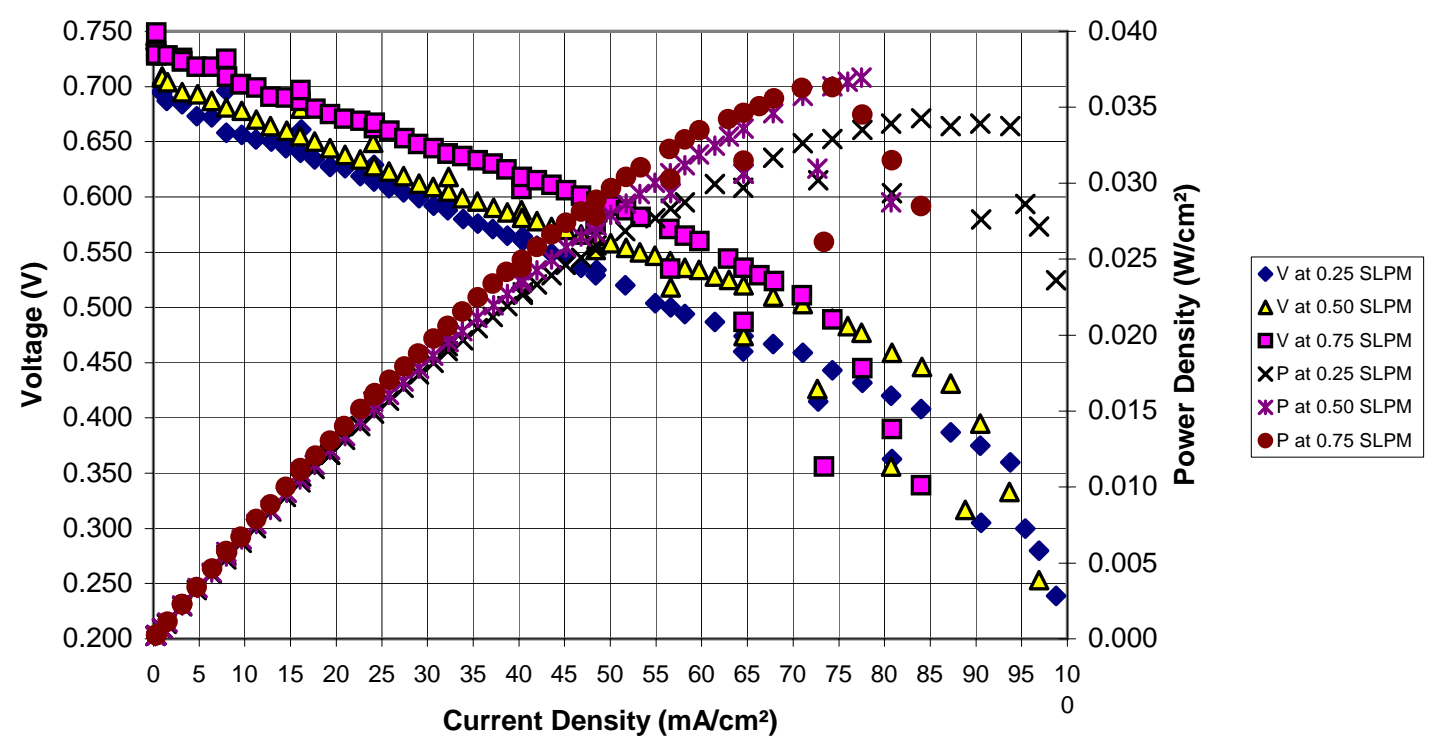

Figure 4.5 - Results of Graphite Experiment Subject to the Conditions of Runs \#1, \#2, and \#3

Cell Voltage over Time

Graphite Rod, Airflow $=0.25$ SLPM, $T=600^{\circ} \mathrm{C}, 1 / 25 / 06$

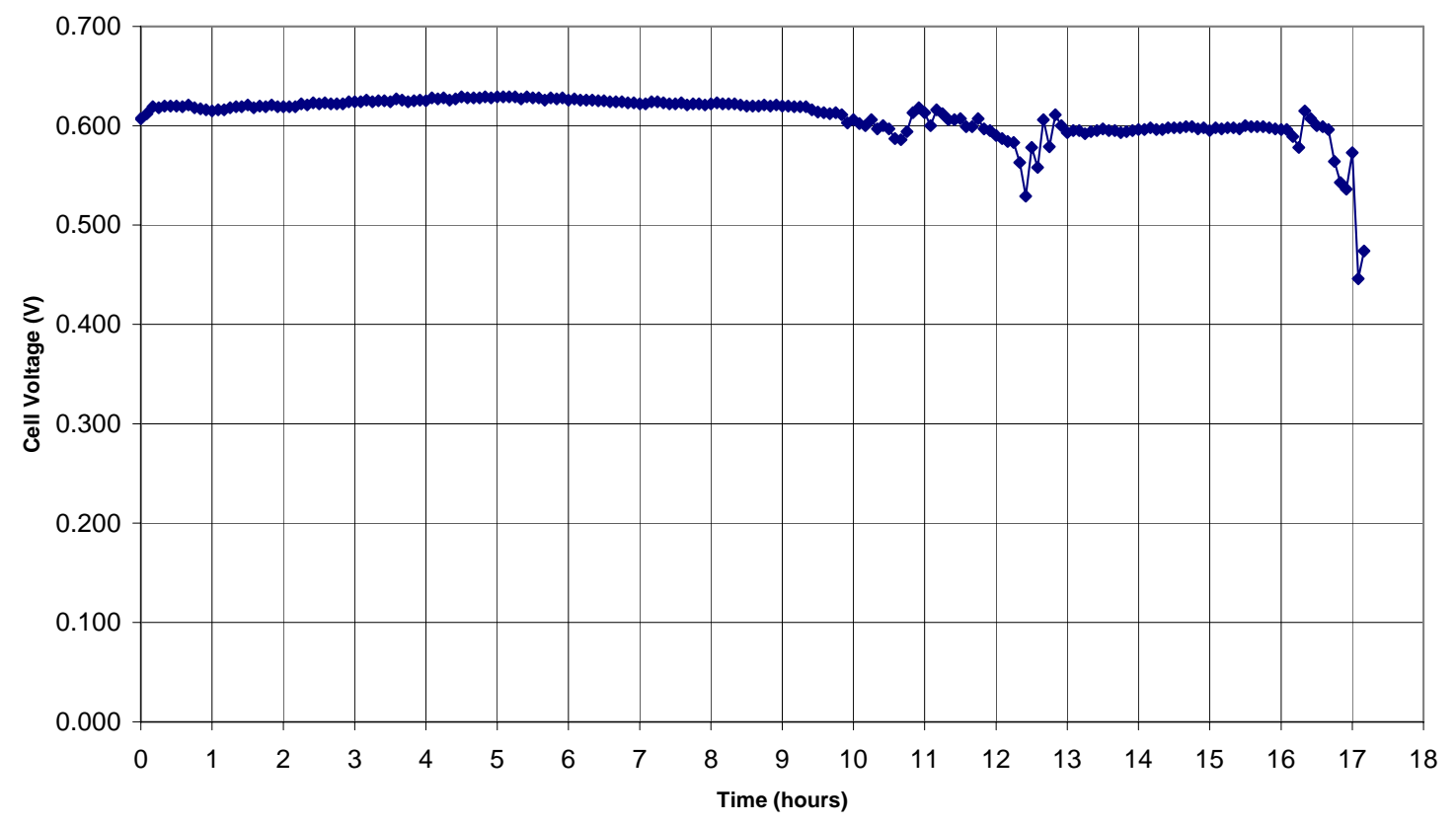

Figure 4.6 - Long-Term Results for Graphite Experiment Subject to Condition of Run \#1 


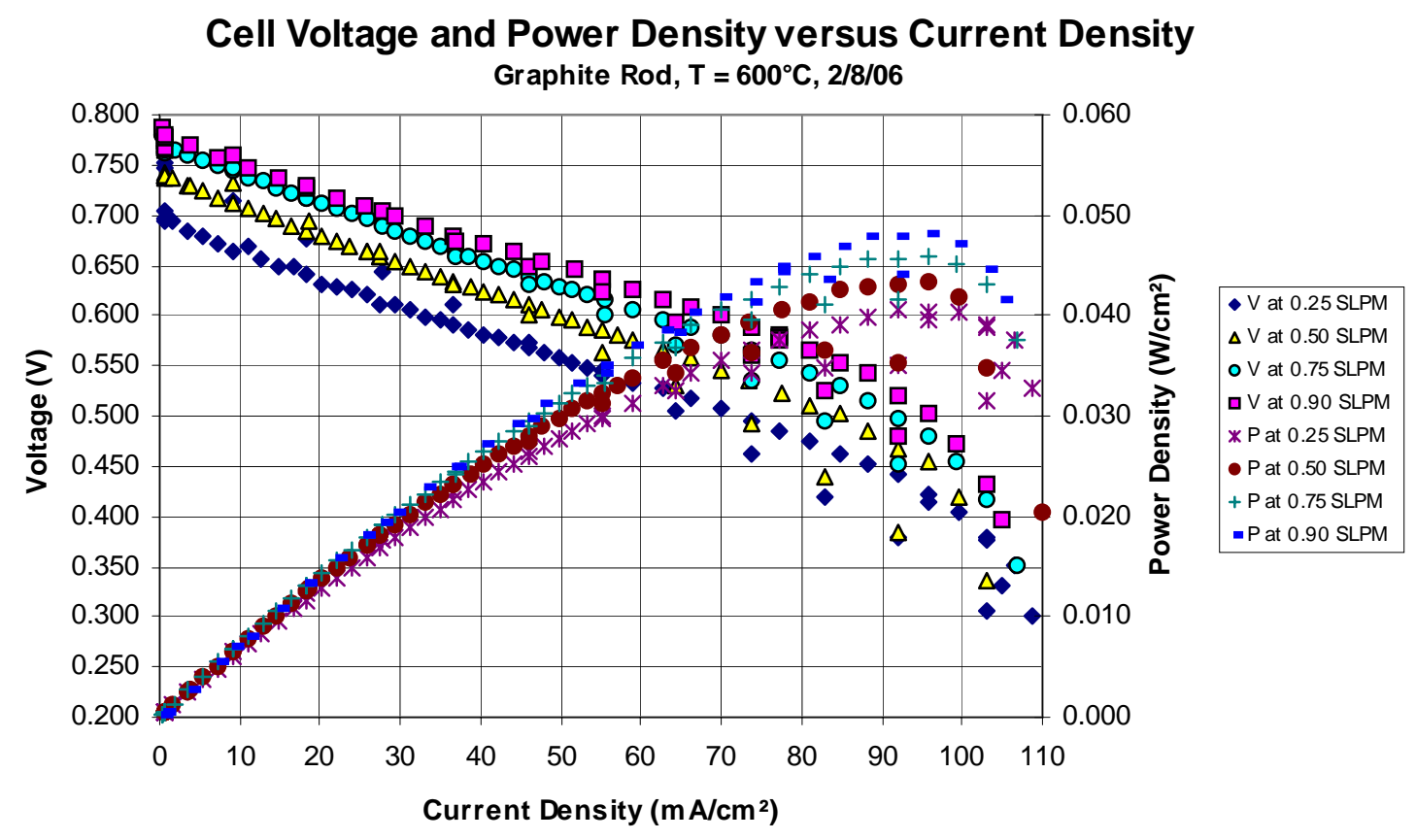

Figure 4.7 - Results of Graphite Experiment Subject to the Conditions of Runs \#1, \#2, \#3, and \#4

\section{Cell Voltage and Current Density over Time Graphite Rod, Flow $=0.50$ SLPM, $\mathrm{T}=600^{\circ} \mathrm{C}, 2 / 08 / 06-2 / 09 / 06$}

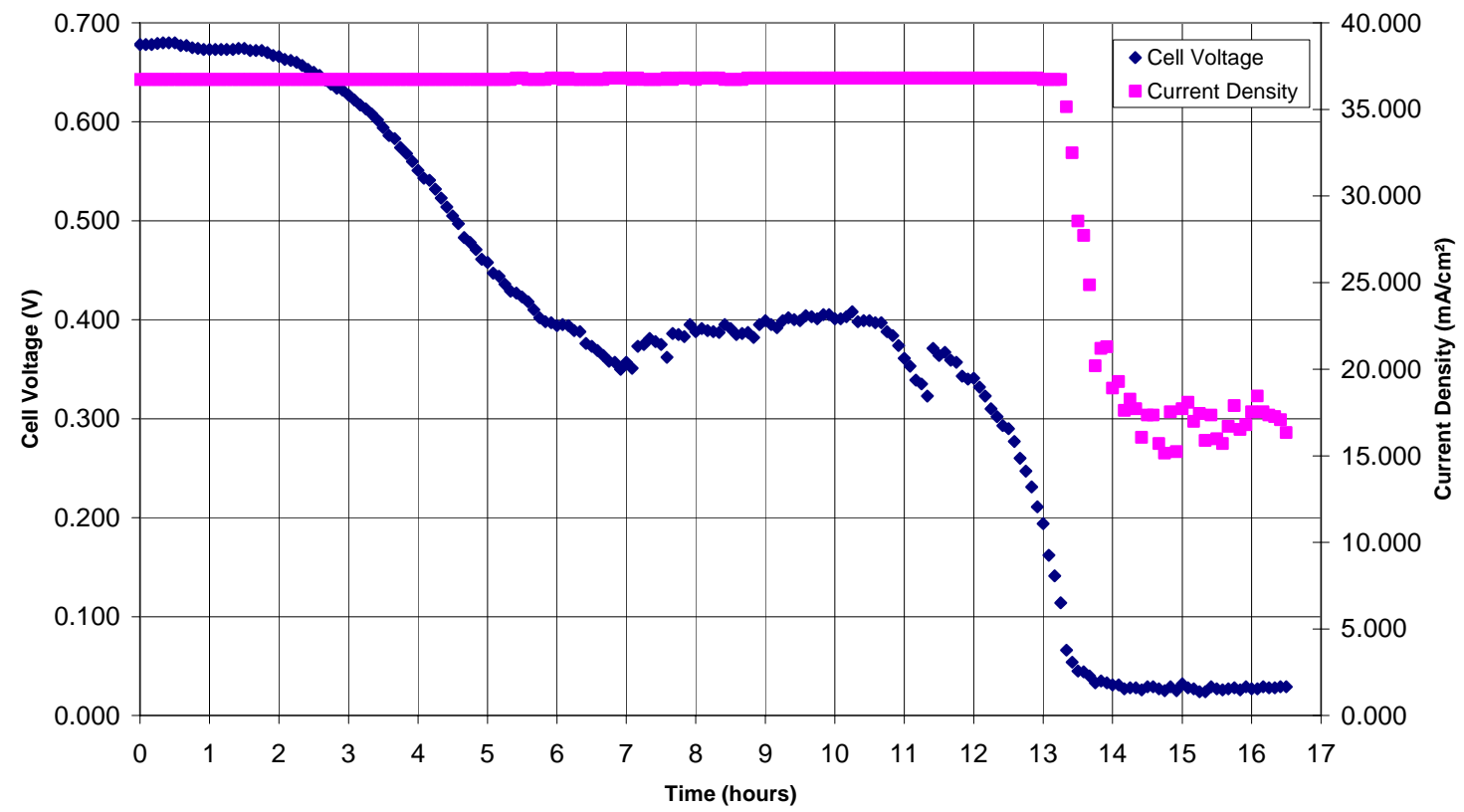

Figure 4.8 - Long-Term Results of Graphite Experiment Subject to the Conditions of Run \#2 


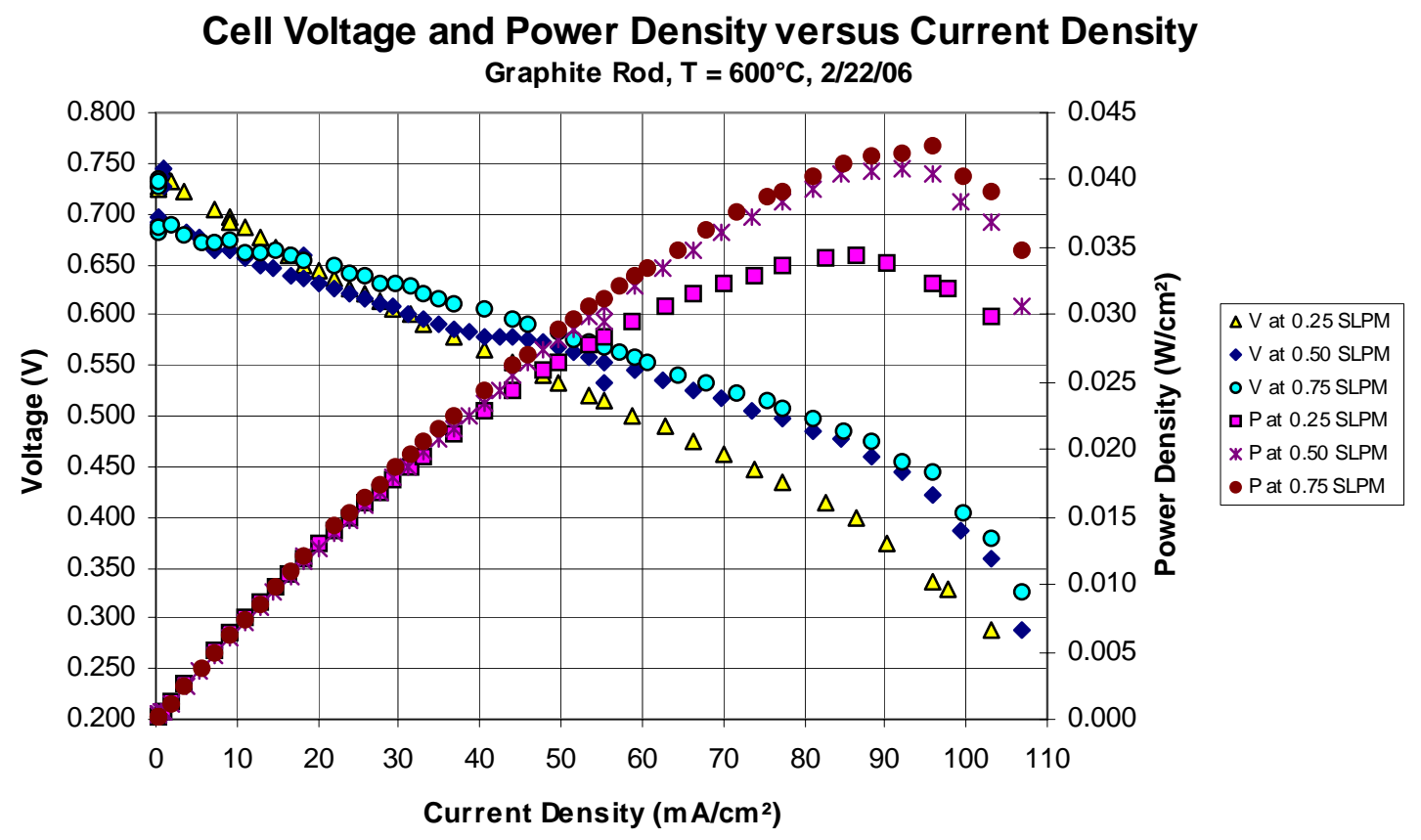

Figure 4.9 - Results of Graphite Experiment Subject to the Conditions of Runs \#1, \#2, and

\#3

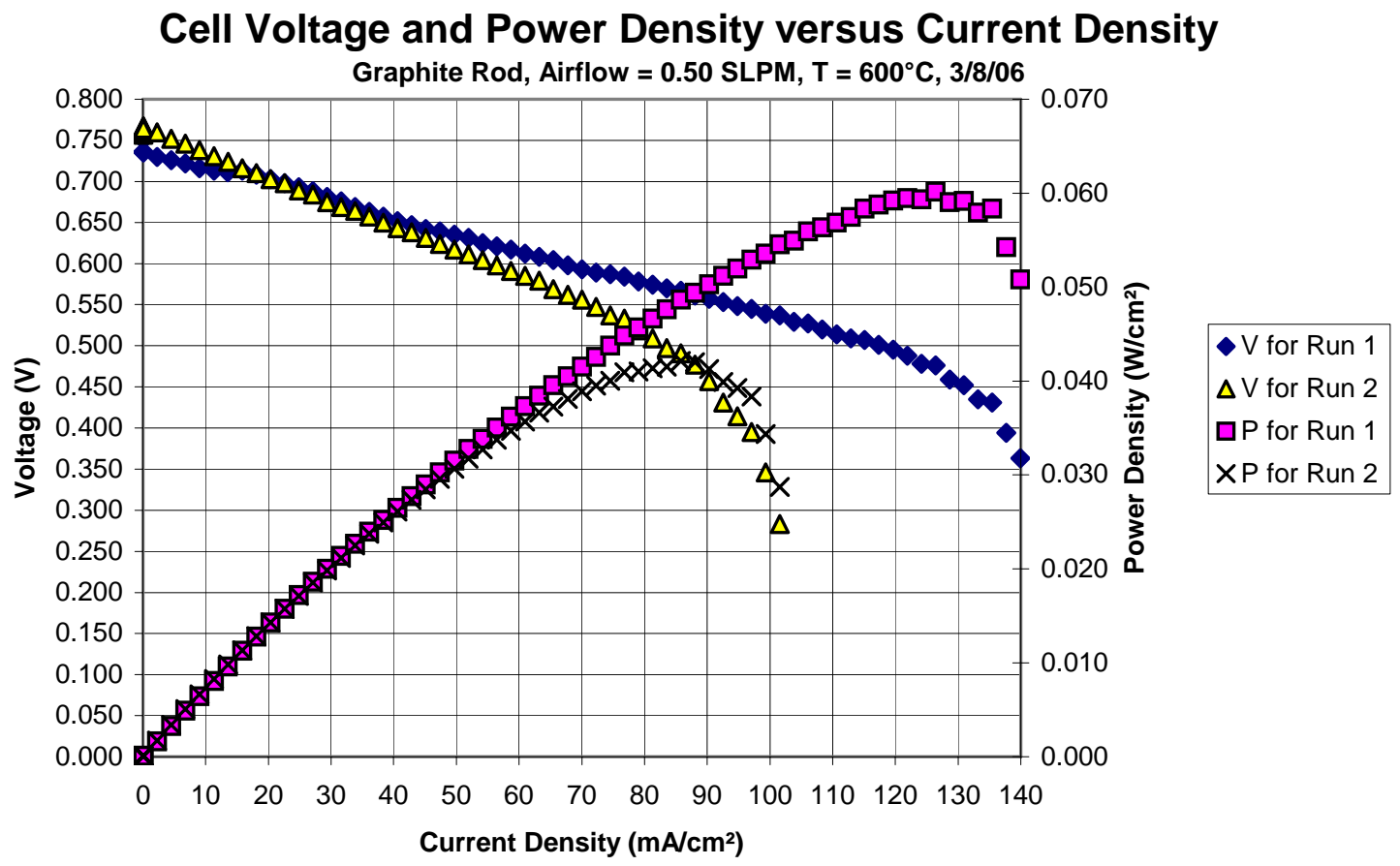

Figure 4.10 - Results of Graphite Experiment Subject to the Conditions of Run \#2 


\section{Cell Voltage and Current Density over Time Graphite Rod, Flow $=0.50$ SLPM, $\mathrm{T}=600^{\circ} \mathrm{C}, 3 / 8 / 06-3 / 9 / 06$}

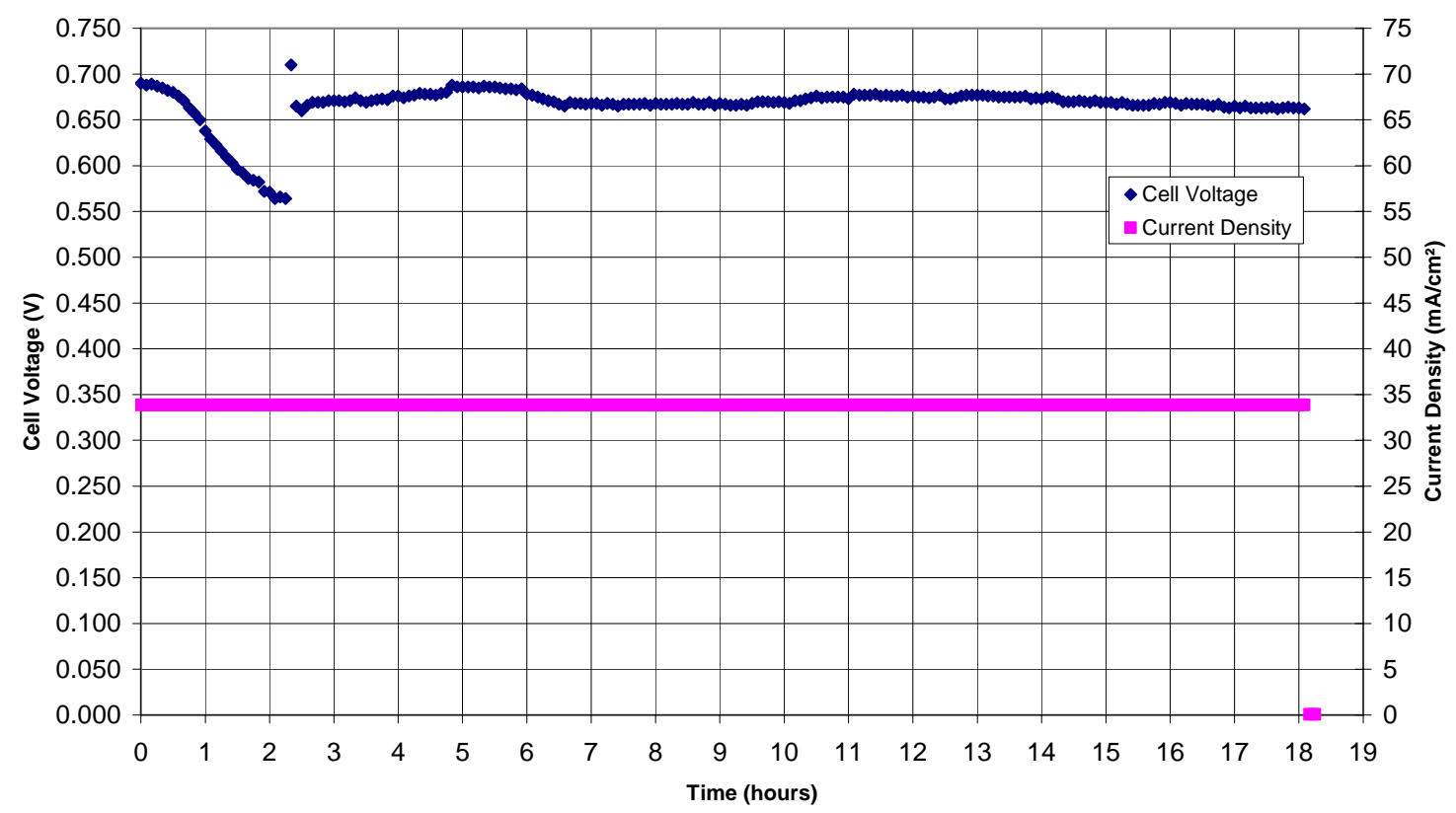

Figure 4.11 - Long-Term Results for Graphite Experiment Subject to the Conditions of Run \#2

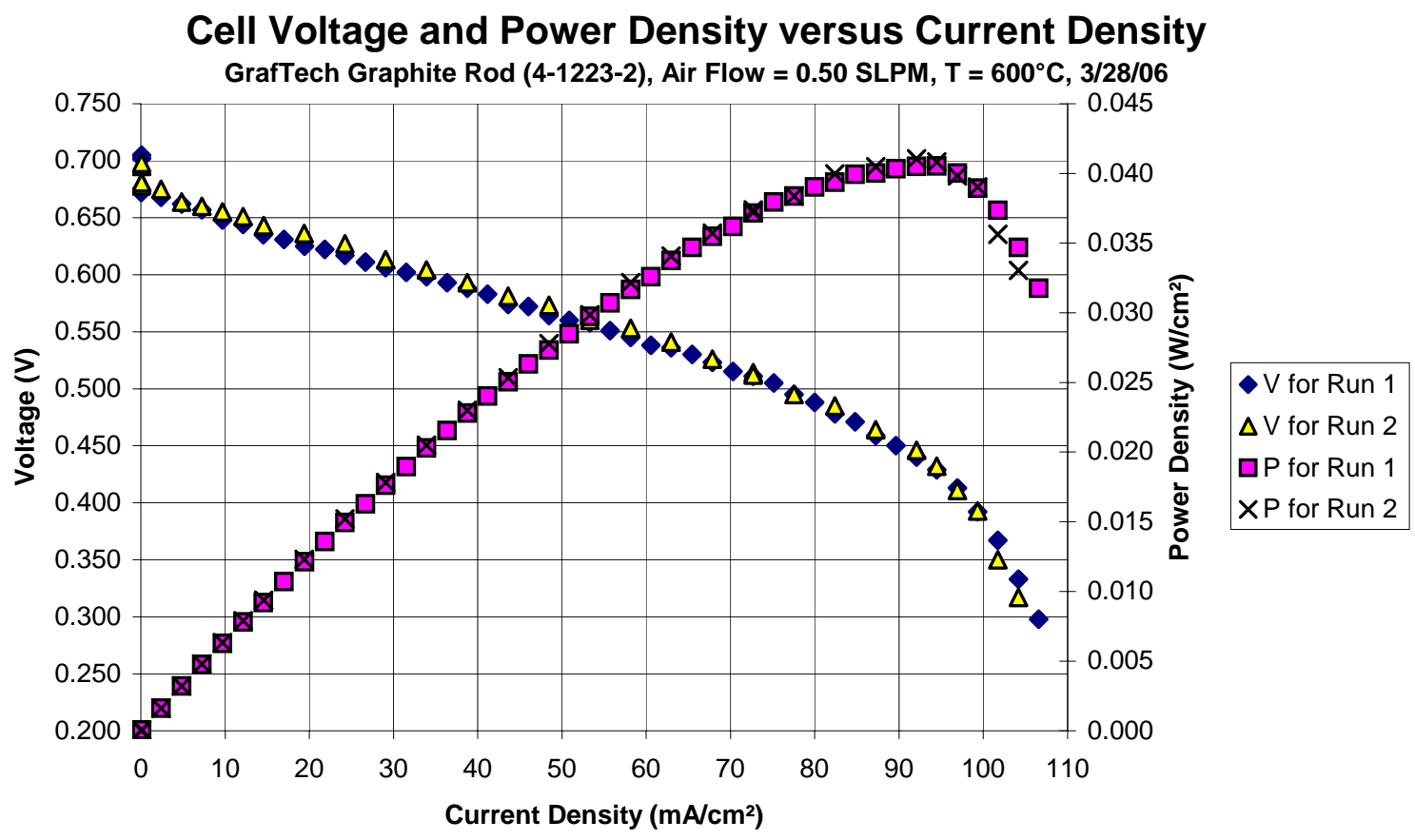

Figure 4.12 - Results of GrafTech Graphite Rod from Run \#19 
Voltage over Time

GrafTech Graphite Rod (4-1223-2), Air Flow $=0.50$ SLPM, $\mathrm{T}=600^{\circ} \mathrm{C}, 3 / 28 / 06-3 / 29 / 06$

Long Term Run

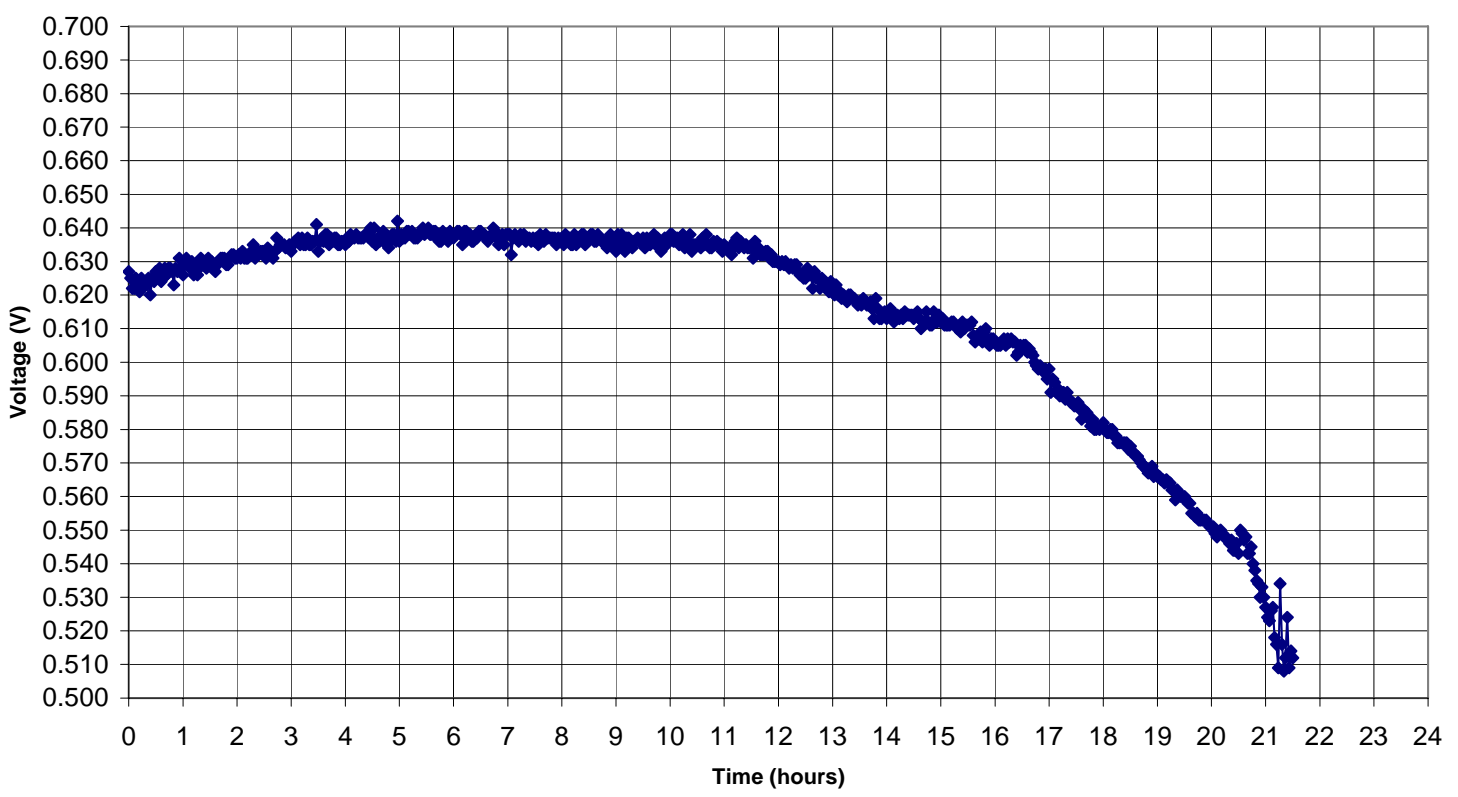

Figure 4.13 - Long-Term Results for GrafTech Graphite Rod from Run \#19

Runs \#11 and \#12 involved an electrolyte other than sodium hydroxide. The runs did not provide any meaningful data other than the knowledge that the use of other electrolytes was unsuccessful. For both of these runs, the cell did not produce any voltage. This is discussed further in Section 4.3.7, Effect of Electrolyte.

The GrafTech graphite rod (Run \#19) results show that the rod performance is about the same as the other graphite rods. The results of this run are given in Figure 4.12. The cell voltage degraded over time, as shown in Figure 4.13, the long term results for this experiment that were discussed above. It is unknown why the performance with this rod deteriorated so quickly. The GrafTech rods were expected to be of very high quality. Because only one of these rods were tested, it is hard to say whether or not this rod was superior. However, the point of running this rod as a separate experiment was because 
GrafTech is a well-known manufacturer of graphite electrodes. Therefore, because GrafTech's rod operated about the same as the other graphite rods, there is even more confidence in the results obtained from the other graphite rods.

\subsubsection{Coal-Derived Rods}

The results from the coal-derived rods are show in Table 4.3. As can be seen, the coal-derived rods produced a higher open-circuit voltage as compared to the graphite rods. This is because the molecular alignment in the coal-derived rods is not as organized as in the graphite rods and the carbon is more accessible for reaction. Therefore, there are more active reaction sites on the coal-derived rods and hence these rods show a higher electrochemical activity.

Table 4.3 - Summary of Results for Runs Using Coal-Derived Fuel Rods

\begin{tabular}{|c|c|c|c|c|c|c|}
\hline Run & $\begin{array}{c}\text { Open Cell } \\
\text { Voltage (V) }\end{array}$ & $\begin{array}{c}\text { Maximum } \\
\text { Current Density } \\
\left(\mathbf{m A} / \mathbf{c m}^{2}\right)\end{array}$ & $\begin{array}{c}\text { Maximum } \\
\text { Power Density } \\
\left(\mathbf{W} / \mathbf{c m}^{2}\right)\end{array}$ & $\begin{array}{c}\text { Area Specific } \\
\text { Resistance } \\
\left(\Omega \times \mathbf{c m}^{2}\right)\end{array}$ & $\begin{array}{c}\text { Active Surface } \\
\text { Area }\left(\mathbf{c m}^{2}\right)\end{array}$ & Resistance $(\Omega)$ \\
\hline 13 & 0.963 & 53 & 0.033 & 4.30 & 60.6 & 0.071 \\
\hline 14 & 0.981 & 48 & 0.032 & 4.20 & 43.7 & 0.096 \\
\hline 15 & \multicolumn{7}{|c|}{ ROD BROKE OFF AT ELECTROLYTE SURFACE } \\
\hline 16 & 0.963 & 31 & O.020 & 8.10 & 71.7 & 0.113 \\
\hline 17 & ROD DID NOT SURVIVE EXPERIMENT PREPARATION \\
\hline 18 & 1.044 & 35 & 0.024 & 7.55 & 66.5 & 0.114 \\
\hline 20 & 0.972 & 38 & 0.026 & 4.20 & 65.2 & 0.064 \\
\hline
\end{tabular}

The method in which the rods were produced led to a problem. The rods seemed to physically degrade in the cell. Therefore, these rods did not last as long as the graphite rods while in the electrolyte. After an experiment had been run, the electrolyte turned black. There also seemed to be a carbon buildup around the surface of the molten electrolyte clinging to the surface of the cell body. This buildup also occurred at the 
point on the rod that was at the top surface of the electrolyte. A portion of this buildup has been analyzed and it seems to be the electrolyte and some iron corroded from the cell body. Two scanning electron micrographs of these deposits are included below as Figure 4.14 and Figure 4.15.

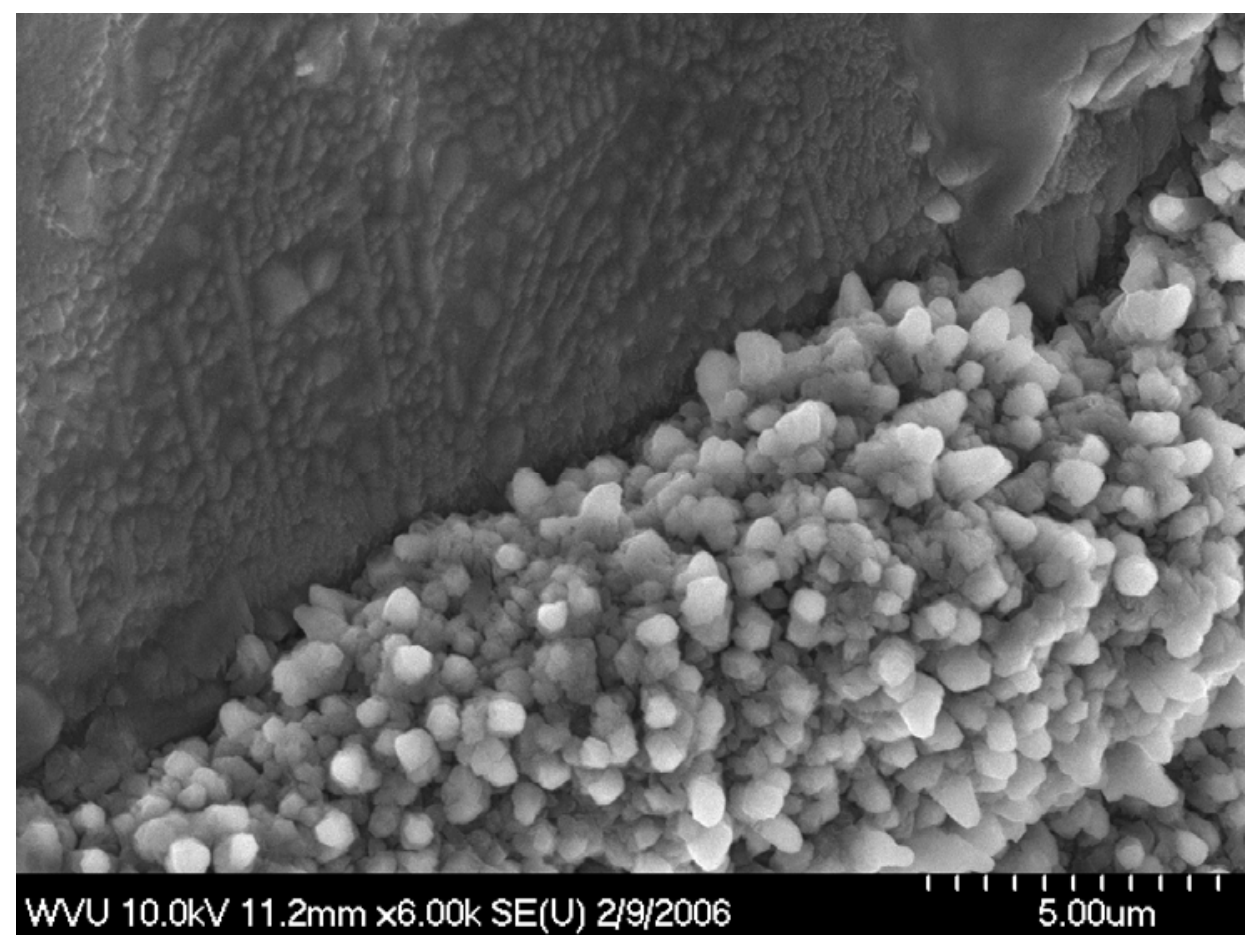

Figure 4.14 - SEM Image of Carbon Fuel Rod with C/NaOH/Fe Buildup (×6000) 


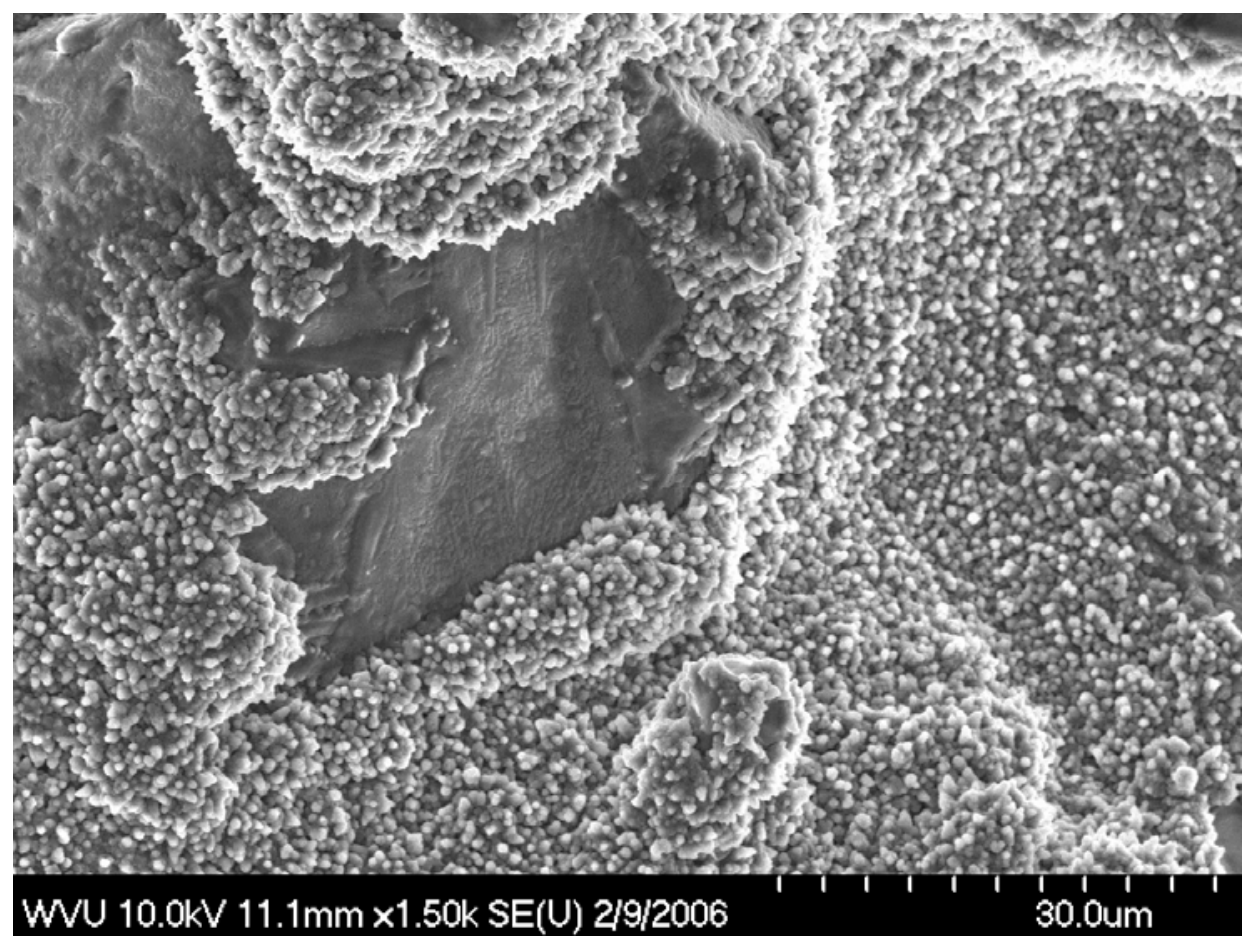

Figure 4.15 - SEM Image of Carbon Fuel Rod with C/NaOH/Fe Builduip (×1500)

In Run \#15, the rod did not last long enough for any data to be collected. The rod broke off at the electrolyte surface and sank into the cell, causing the active surface area to be zero. In Run \#17, no run was actually conducted. This rod did not survive the assembly process and broke before it could be inserted into the fuel cell.

The following figures are the results of the runs involving the non-graphitized coal-derived fuel rods. The results from the 100\% PetCoke rods (Runs \#13 and \#14) are given in Figure 4.16 and Figure 4.17, respectively. The results show the same trend as the experiments with the graphite rods, except for the cell voltages, which are appreciably higher, as seen in Table 4.3. Results for the 100\% SECO rod (Run \#18) are given as Figure 4.19. The results for the 50\% SECO/50\% PetCoke rod (Run \#16) are given as Figure 4.21. The reason for there being only one run here is because the rod degraded very quickly and the other results are unreliable. 
Long term run results for the non-graphite rods are given below in Figure 4.18, Figure 4.20, Figure 4.22, and Figure 4.24. In Figure 4.18, the current was set at $0 \mathrm{~A}$ and allowed to run long term. In this case, the cell voltage decreased steadily over time. After 200 minutes, the cell voltage had reached zero. When the cell was taken apart, the rod was broken into several pieces, making the active surface area very small; therefore, smaller amounts of voltage could be drawn as the rod degraded. In Figure 4.20, the $100 \%$ SECO rod was run at a constant current of $0.5 \mathrm{~A}$. The rod produced a steady cell voltage for about an hour, and then the cell voltage quickly decreased. Once again, the rod had degraded and broke into pieces in the cell. In Figure 4.22, the 50\% SECO/50\% PetCoke rod showed about the same results as the 100\% SECO rod. Again, the rod had degraded in the cell.

\section{Cell Voltage and Power Density versus Current Density}

Coal Derived Rod \#11, $100 \%$ PetCoke, $T=600^{\circ} \mathrm{C}, 2 / 28 / 06$

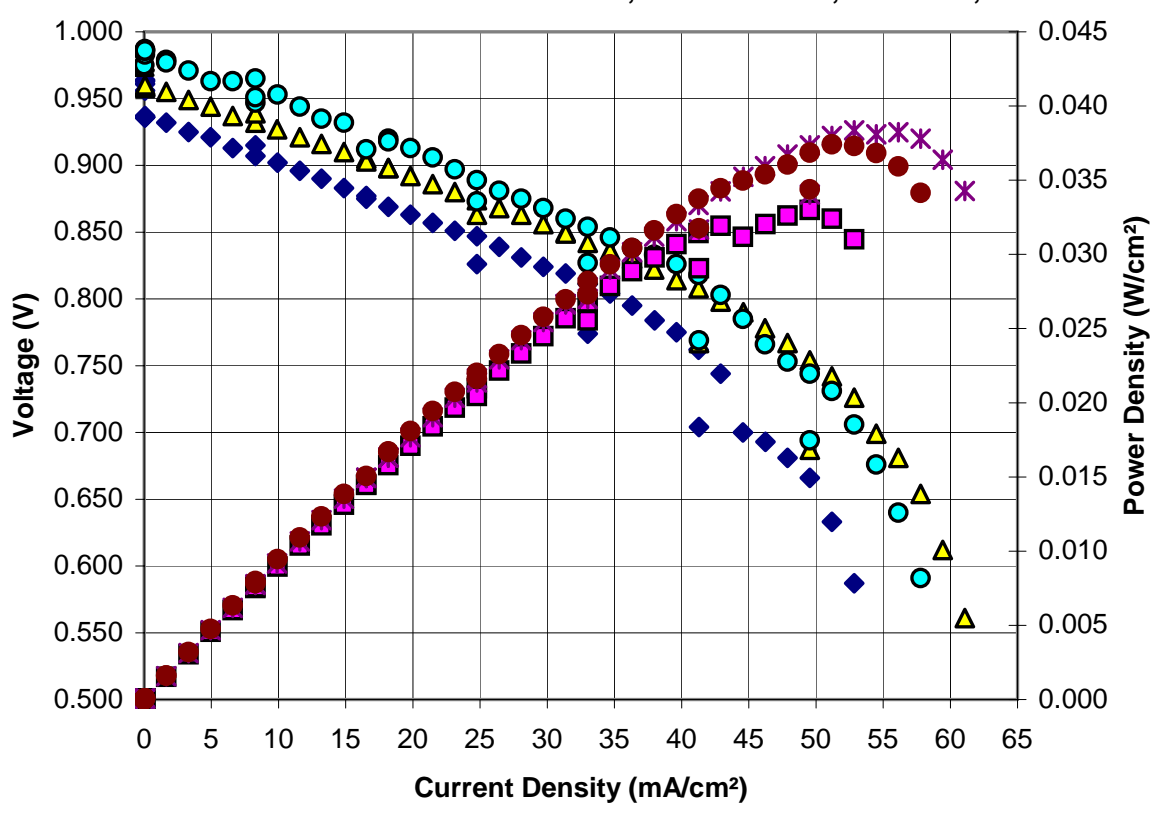

Figure 4.16 - Results of $100 \%$ PetCoke Rod from Run \#13 


\section{Cell Voltage and Power Density versus Current Density}

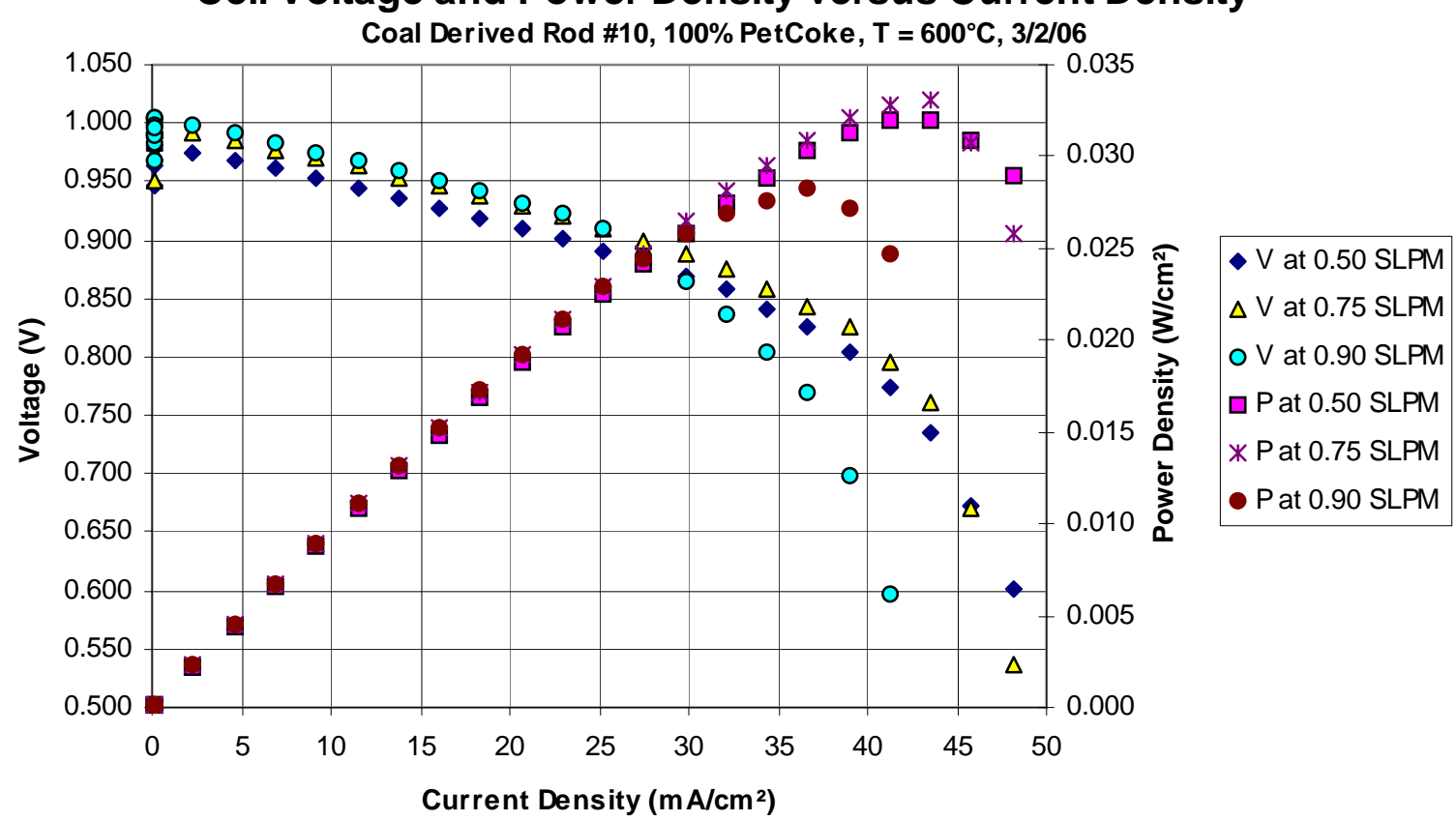

Figure 4.17 - Results of $100 \%$ PetCoke Rod from Run \#14

\section{Cell Voltage and Current Density over Time}

Coal-Derived Rod $\# 10,100 \%$ PetCoke Rod, Flow $=0.75$ SLPM, $\mathrm{T}=600^{\circ} \mathrm{C}, 3 / 2 / 06$

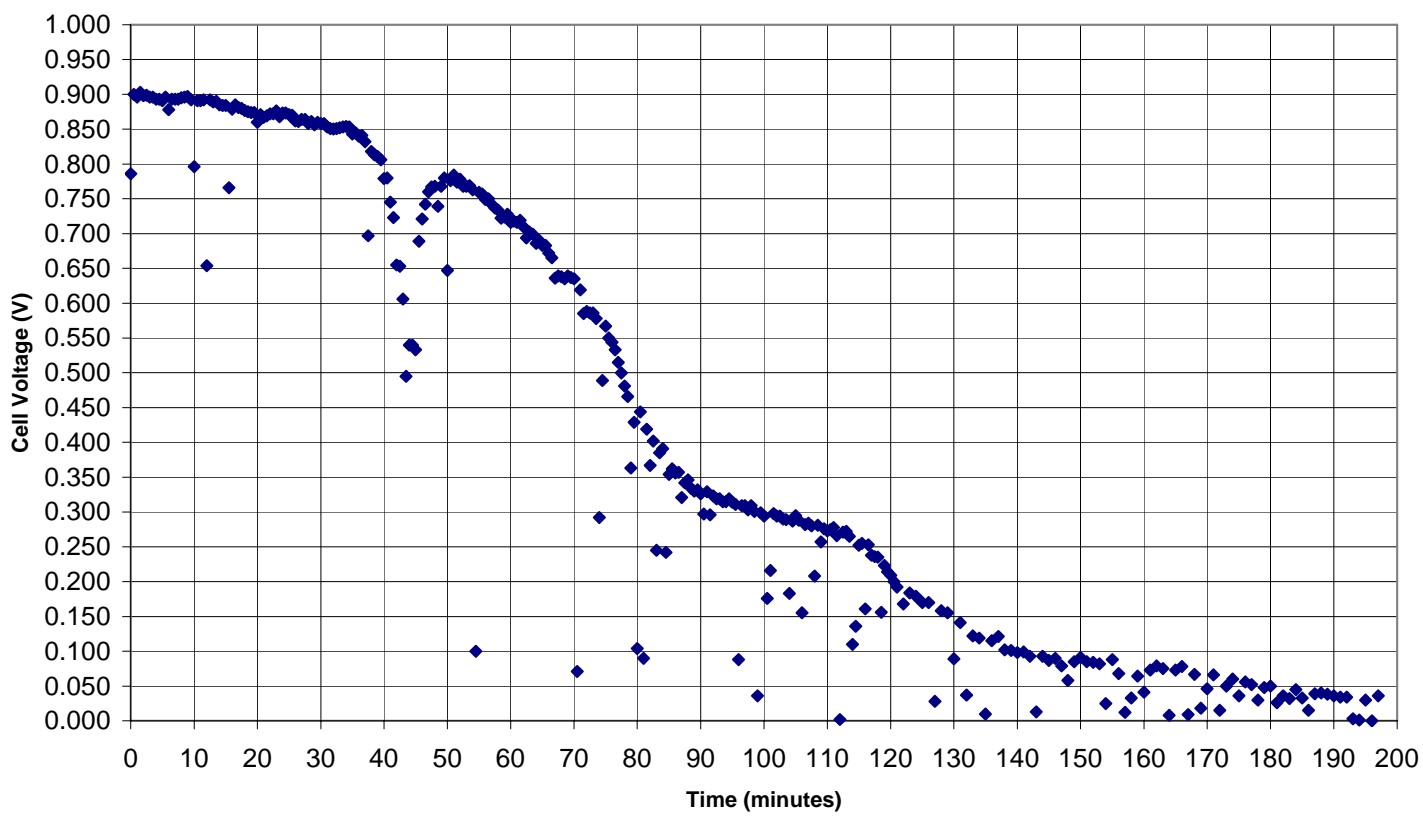

Figure 4.18 - Long Term Results for 100\% PetCoke Rod Run from Run \#14 


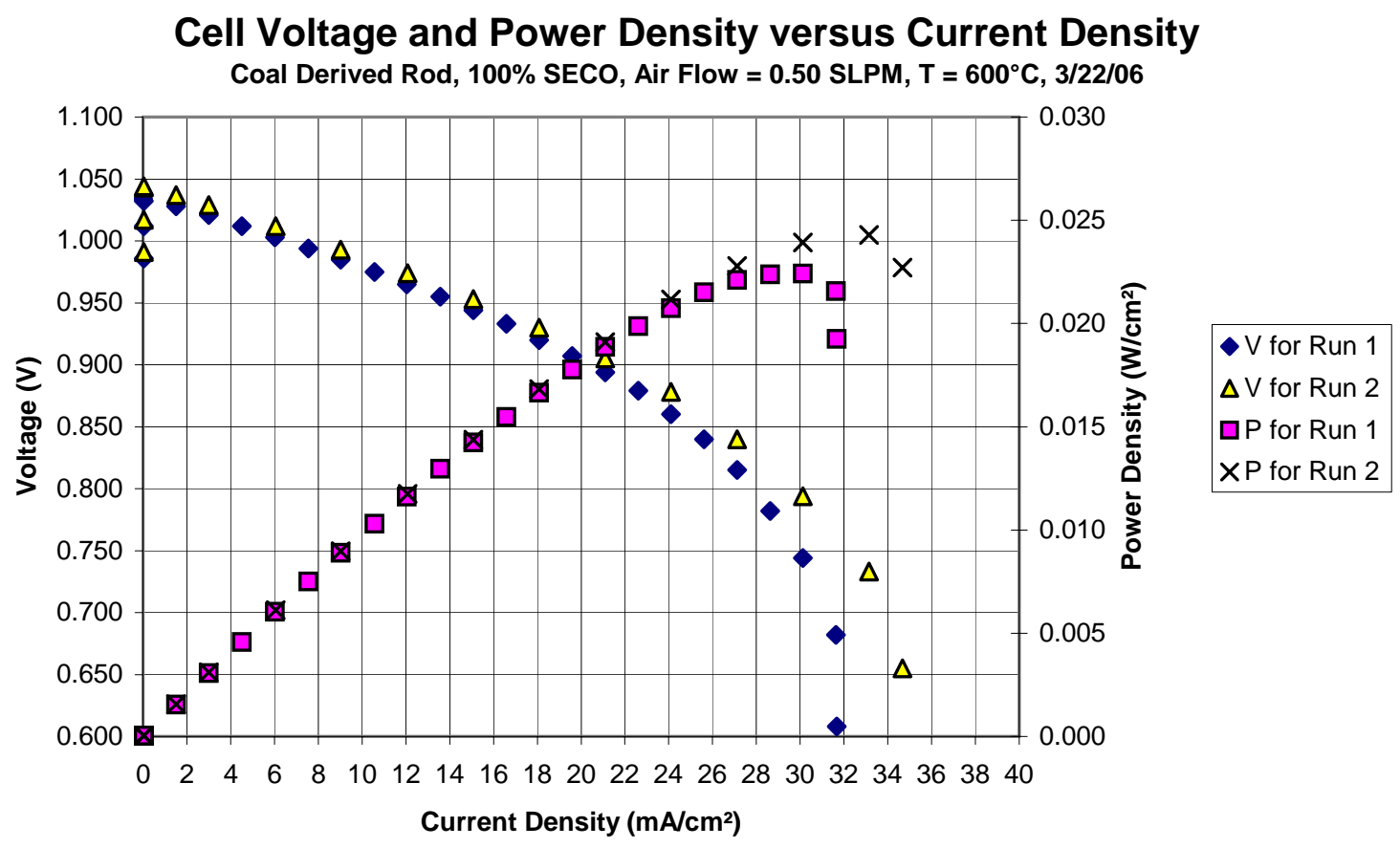

Figure 4.19 - Results of $100 \%$ SECO Rod from Run \#18

\section{Voltage over Time}

Coal Derived Rod (85-15 SECO-Pitch), Air Flow $=0.50$ SLPM, $\mathrm{T}=600^{\circ} \mathrm{C}, 3 / 22 / 06$ Long Term Run

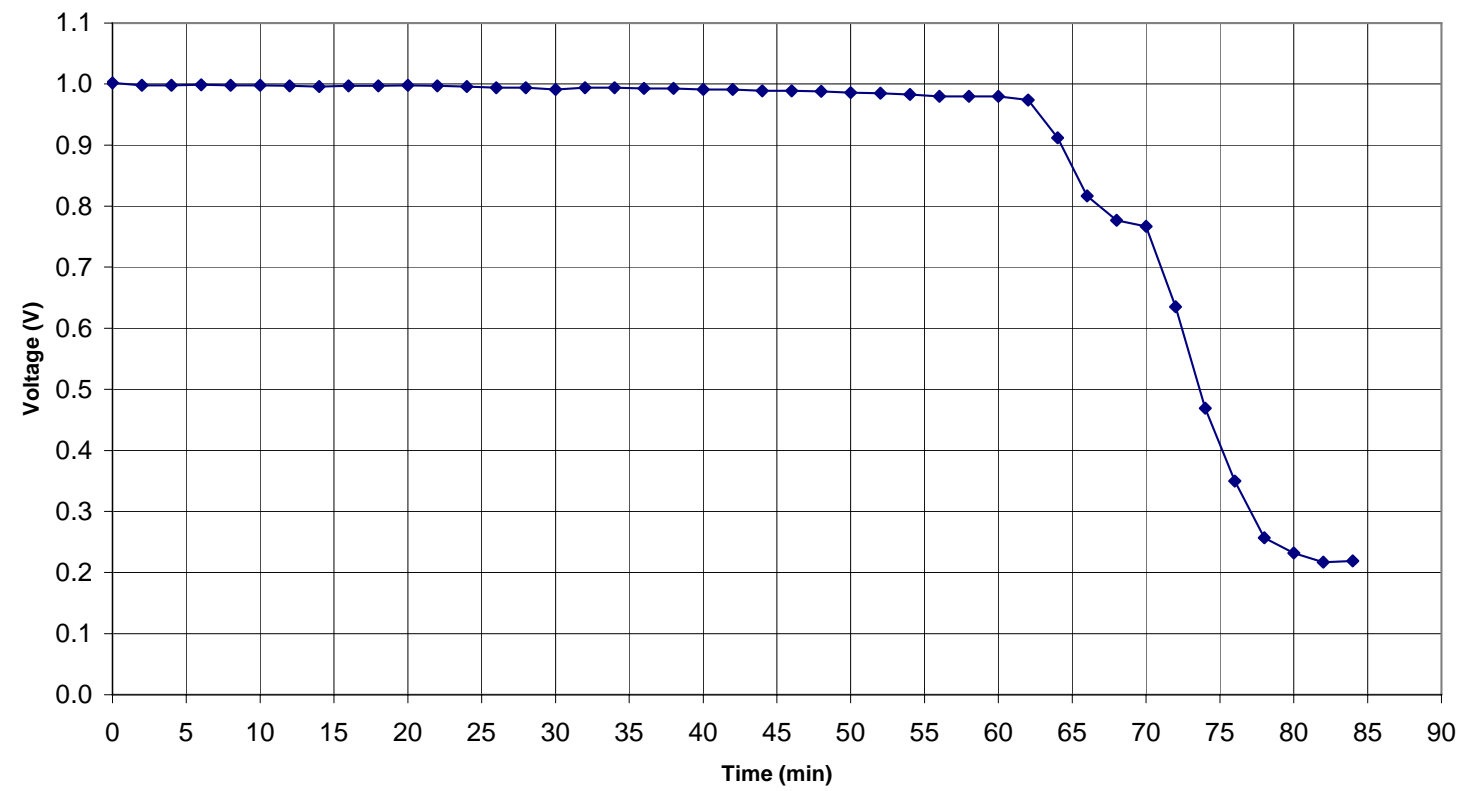

Figure 4.20 - Long Term Results for 100\% SECO Rod Run from Run \#18 


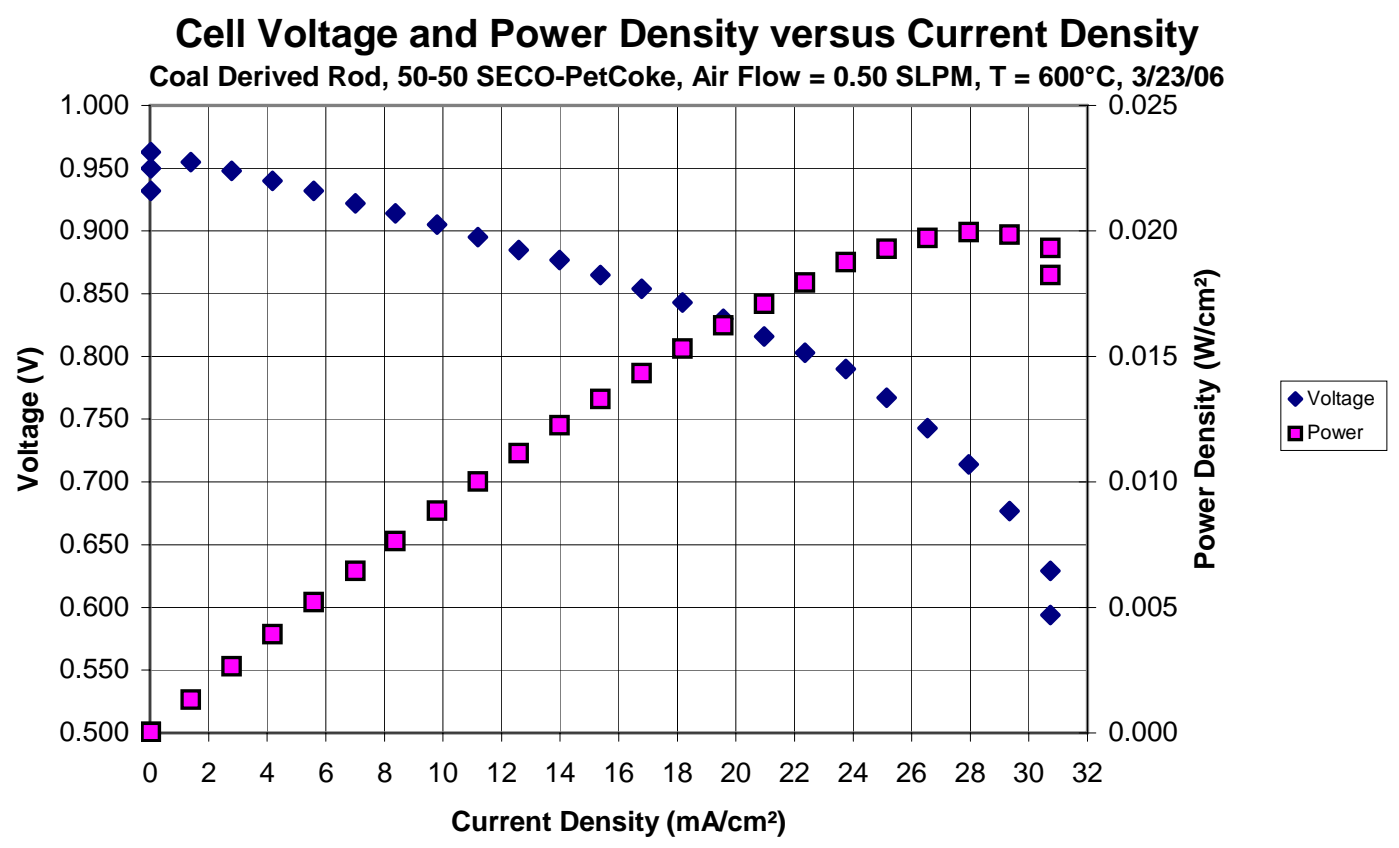

Figure 4.21 - Results for 50\% SECO/ 50\% PetCoke Rod from Run \#16

Voltage over Time

Coal Derived Rod (50-50 SECO-PetCoke), Air Flow $=0.50$ SLPM, $\mathrm{T}=600^{\circ} \mathrm{C}, 3 / 23 / 06$

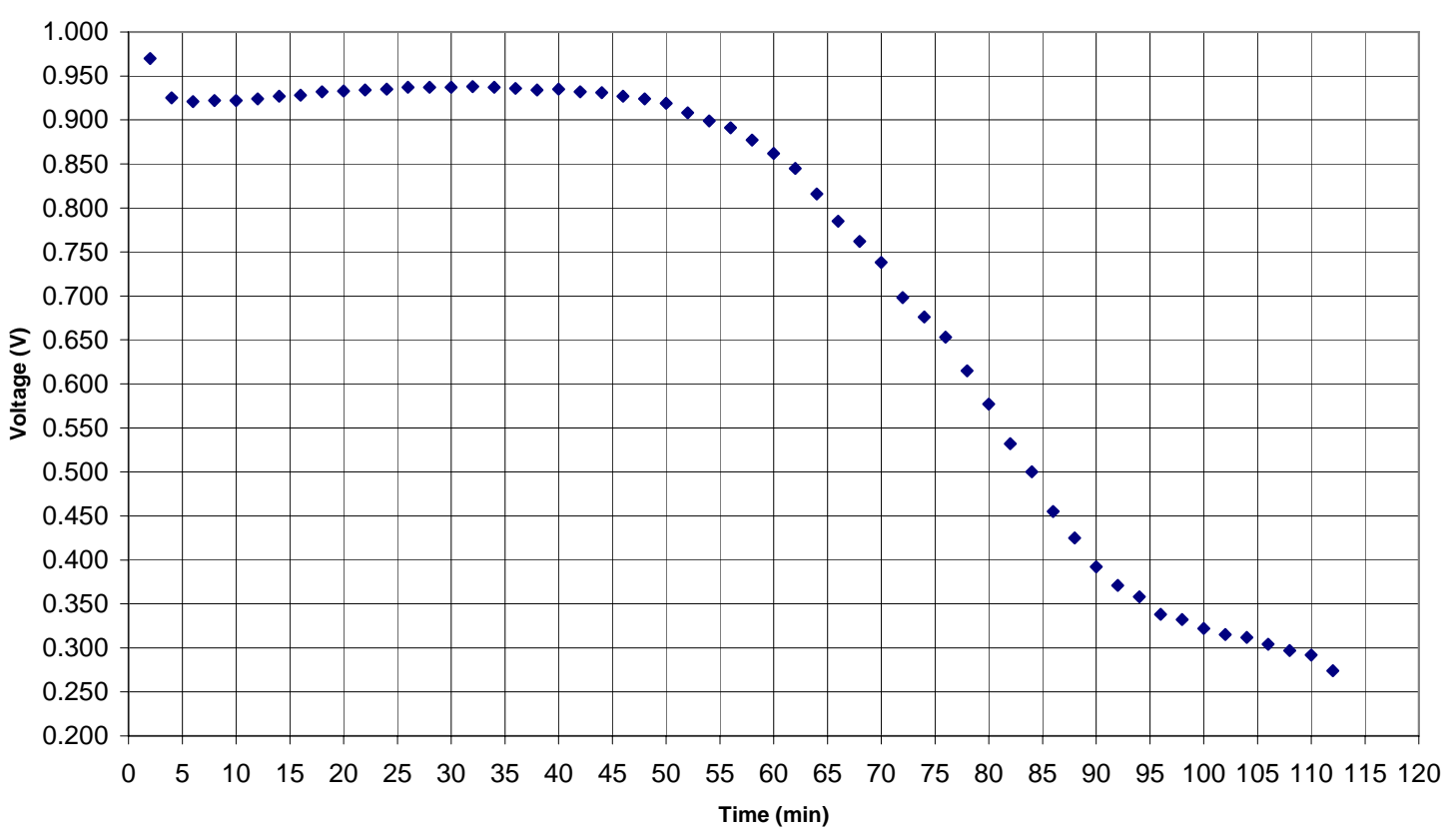

Figure 4.22 - Long Term Results for 50/50 SECO-PetCoke Rod Run from Run \#16 


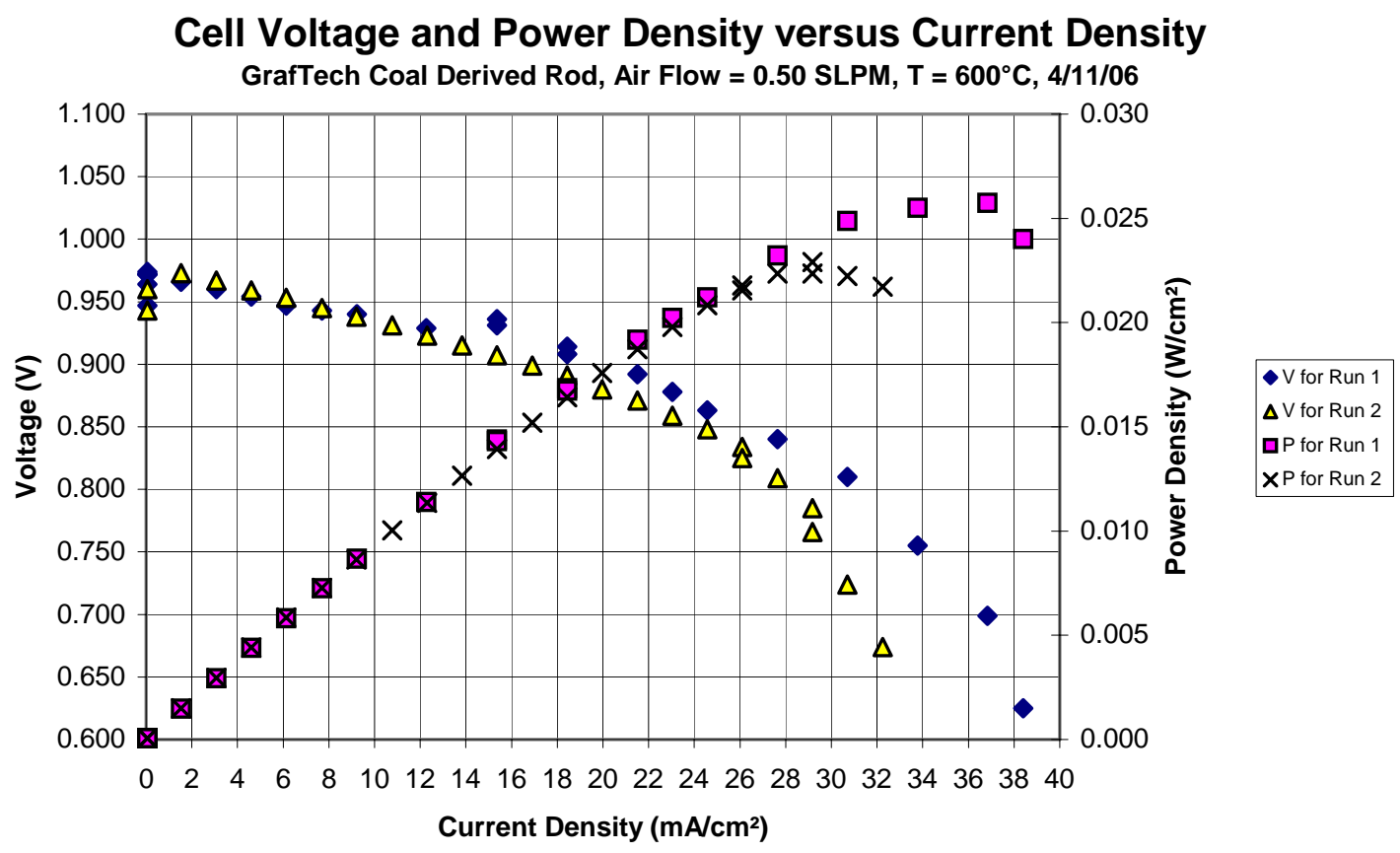

Figure 4.23 - Results for GrafTech Baked Rod from Run \#20

\section{Voltage over Time}

GrafTech Coal Derived Rod, Air Flow $=0.50$ SLPM, $T=600^{\circ} \mathrm{C}, 4 / 11 / 06-4 / 12 / 06$

Long Term Run

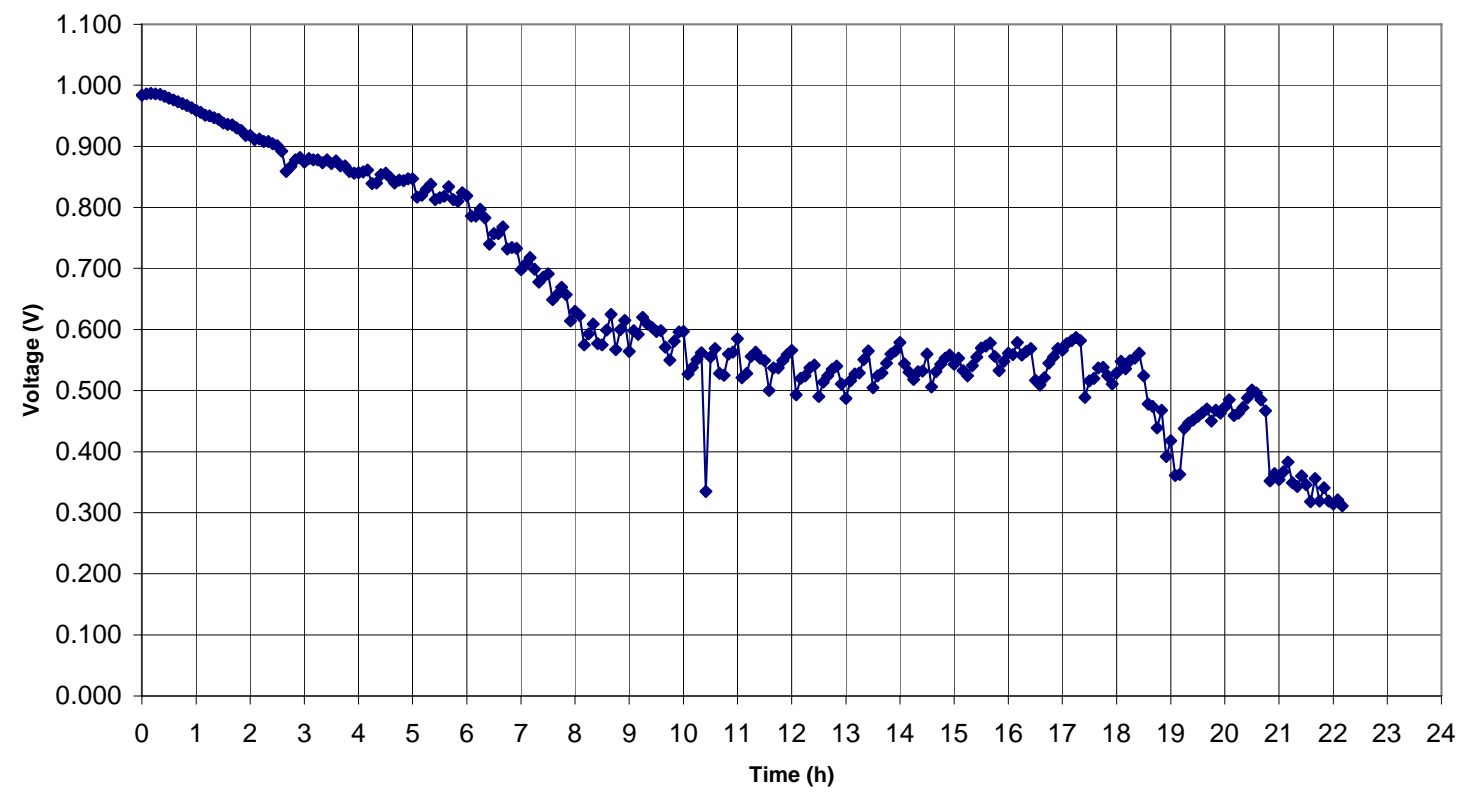

Figure 4.24 - Long Term Results for GrafTech Non-Graphitized Rod Run from Run \#20 
In Figure 4.23, the results of the GrafTech baked rod are presented. In order to investigate the degradation of the coal-derived rods, a rod made from premium petroleum coke and binder pitch was supplied by GrafTech. In Figure 4.24, the rod provided by GrafTech also shows degradation over time. However, this degradation was much slower than the WVU rods as the run was conducted for 22 hours. Instead of breaking off into large chunks, this rod slowly disintegrated into the electrolyte, making it black with carbon particles. This shows that the manufacture method was a problem for the WVU rods but is not a problem if the rods are carefully made. Once again, the rods produced at GrafTech are manufactured commercially, so their technique is proven and wellestablished.

The speculation as to why the coal-derived rods fell apart is due to the binder pitch that holds the rods together. It is theorized that this binder pitch is preferentially reacting in the baked rods. Therefore, it is unable to hold the rods together after it has reacted. Binder pitch is used in both the WVU and GrafTech baked rods and the same behavior was noted for all these rods. Binder pitch is also a part of the graphite rods but is converted to graphite during the graphitization and hence is no longer as reactive as it is in the baked rods.

\subsection{Data Discussion}

\subsubsection{Resistivity Calculations}

The resistivity of the rods was calculated using the method described in Section 3.5.2, Carbon Rod Resistivity. (See the summarized calculations in Table 4.4). It can be seen that the coal-derived rods have a higher resistivity than the graphite rods. The variability of the resistivity for the SECO/PetCoke rods can be due to the composition of 
the rods but more probably due to the technique used in their manufacture. The pressing of the rods in the laboratory was shown to be problematic and resulted in rods of inconsistent quality. Nonetheless, the resistivity of these rods is still quite low and they performed well, albeit for a shorter time, in the DCFC.

Table 4.4 - Calculated Resistivity for Tested Rods

\begin{tabular}{|l|c|}
\hline \multicolumn{1}{|c|}{ Rod } & Resistivity $(\mu \Omega$-m) \\
\hline Graphite & 6.201 \\
\hline GrafTech Graphite & 8.670 \\
\hline & \\
\hline $0 \%$ SECO / 100\% PetCoke & 52.720 \\
\hline $25 \%$ SECO / 75\% PetCoke & 137.250 \\
\hline $50 \%$ SECO / 50\% PetCoke & 139.920 \\
\hline $75 \%$ SECO / 25\% PetCoke & 78.600 \\
\hline $100 \%$ SECO / 0\% PetCoke & 81.900 \\
\hline GrafTech Baked Rod & 60.101 \\
\hline
\end{tabular}

The graphite rods show a low resistivity and the calculated values are comparable to the average literature value of $7.837 \mu \Omega-\mathrm{m}[14]$. The resistivity of the blended rods resulted in a bell-shaped profile. The expectation was for the resistivity to increase exponentially with increasing SECO content since the SECO is coal-derived and should have a higher resistance than the PetCoke. Instead, the 50\% blend resulted in the highest resistivity, and therefore had the highest ASR as shown in Table 4.3. The ASR for the graphite rods was about half of the ASR for coal, reflecting the higher resistivity of the coal rods. The results from Table 4.4 are plotted below in Figure 4.25, illustrating the bell-shaped curve generated with data of increasing SECO content. This behavior is most likely due to difficulties associated with the manufacture of the rods rather than the inherent resistance of the cokes. However, the very low resistance of the pure SECO rod 
is an unexpected result and indicates that coke made from SECO has a resistance comparable to that of PetCoke.

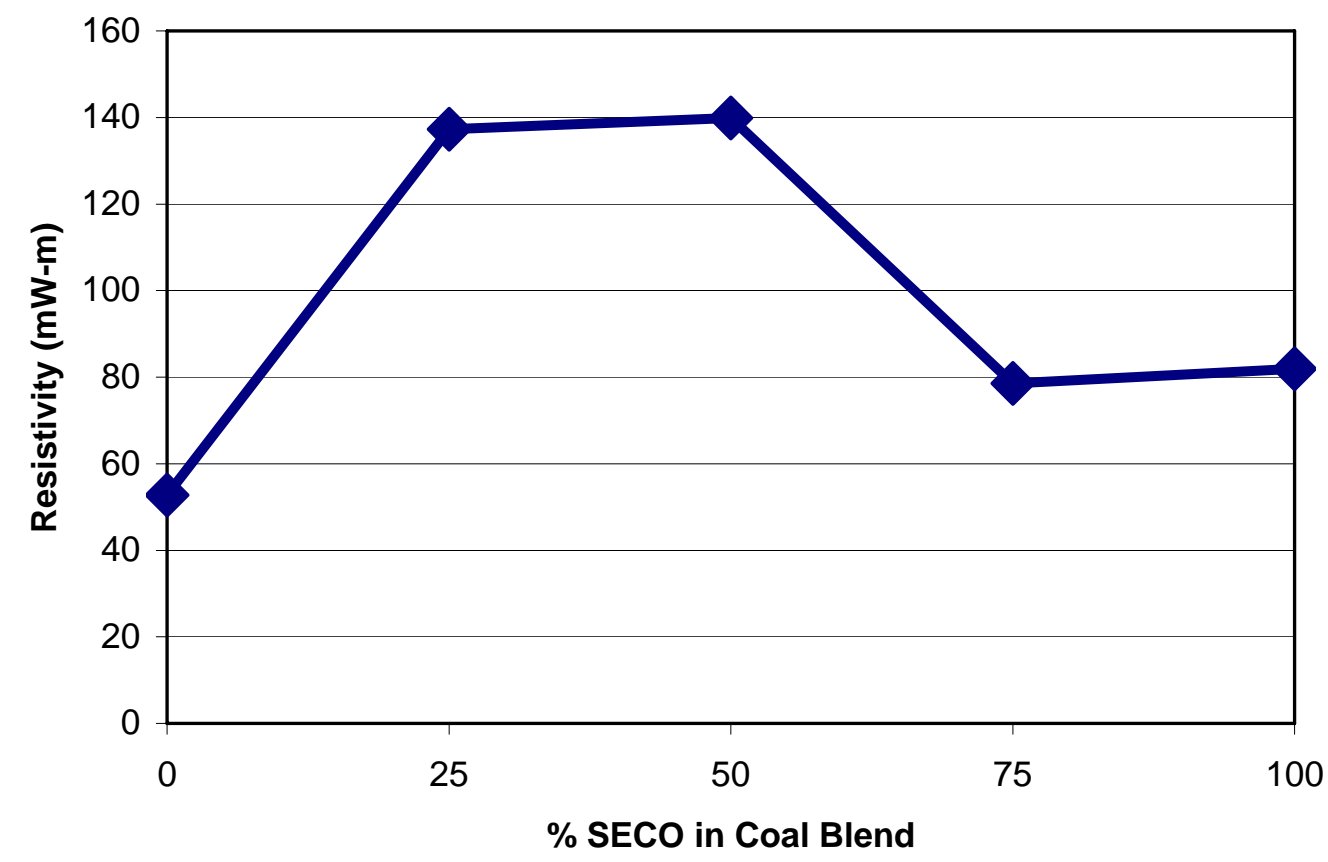

Figure 4.25 - Resistivity of Coal-Derived Rods as a Function of SECO Content

\subsubsection{Reproducibility}

Several of the experiments were conducted more than once to ensure that the data were reproducible, as demonstrated in the previous sections. It is essential in any research to prove that the data are reliable. The data obtained during the same experimental run was, in fact, reproducible as shown in Figure 4.26. In this experiment, four separate runs were conducted at the same conditions, with a stepwise increase in current. Between runs, the cell was allowed approximately 30 minutes of recovery so that the starting conditions would be the same as the first run. This recovery time was required because once the system was set to open-circuit, the voltage did not immediately return to the open-circuit value obtained in the previous run suggesting some major 
physical or electrical relaxation in the cell. The response to small perturbations is instantaneous, but the response to larger perturbations is not as fast. The results show that the data are readily reproduced when the experimental runs are completed in the same day.

It can also be shown that using runs conducted at different times, the same basic trend in the data can be obtained for the graphite rods. In some cases, more current was drawn, as shown by the higher values of the current density, illustrated in Figure 4.27. In this series of experiments, constant cell conditions were maintained on runs conducted on different days. In the ohmic resistance region, the difference between the voltages generated for these three days is $11 \%$ at $50 \mathrm{~mA} / \mathrm{cm}^{2}$. In the unstable mass transport region, the difference was larger at $25 \%$ at $90 \mathrm{~mA} / \mathrm{cm}^{2}$. The results at the higher current densities show a larger percent difference. It is likely due to slight differences in the graphite rods (the rods were unused at the beginning of each run). Also, because the cell was taken apart after each run, the assembly and connections may have been slightly different. However, the data generated by this research are reproducible, and therefore, reliable. 
Cell Voltage versus Current Density

Graphite Rod, Airflow $=0.50$ SLPM, $\mathrm{T}=600^{\circ} \mathrm{C}, 2 / 15 / 06$

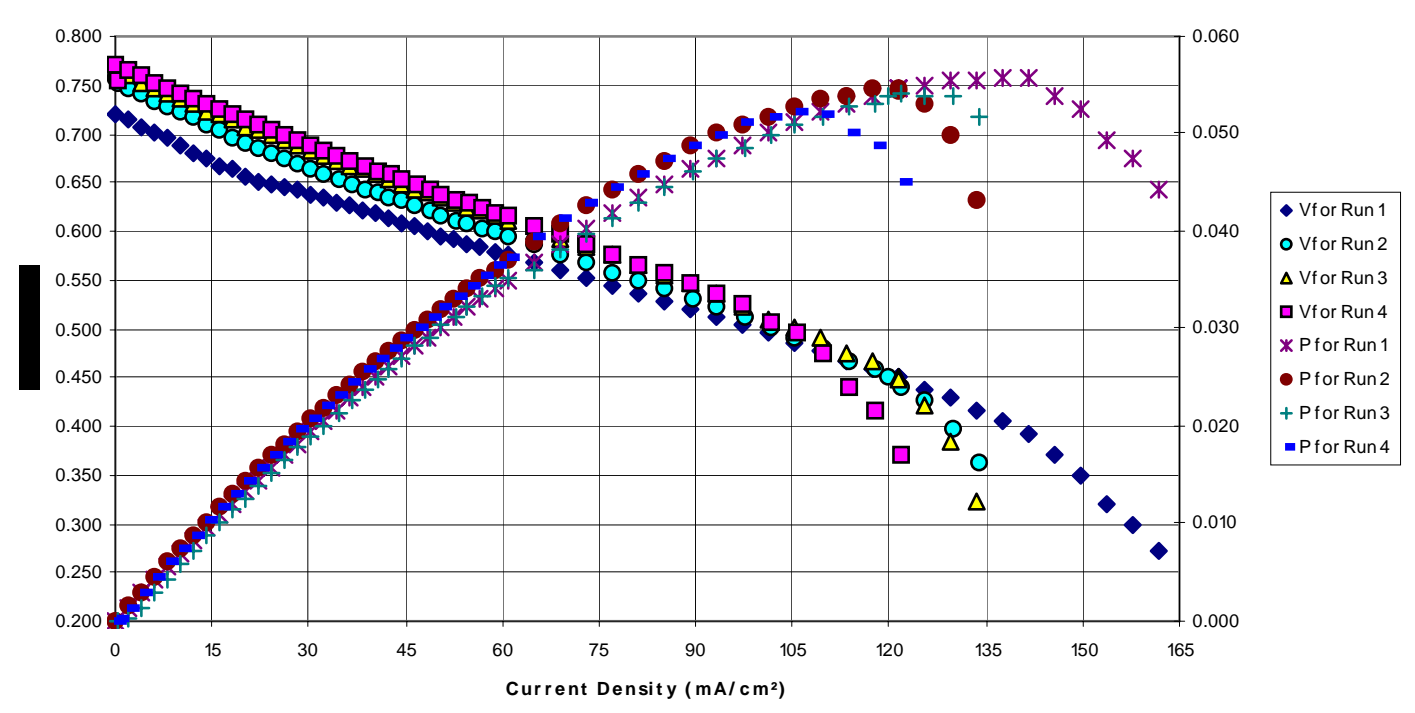

Figure 4.26 - Reproducibility of Data Generated During the Same Run

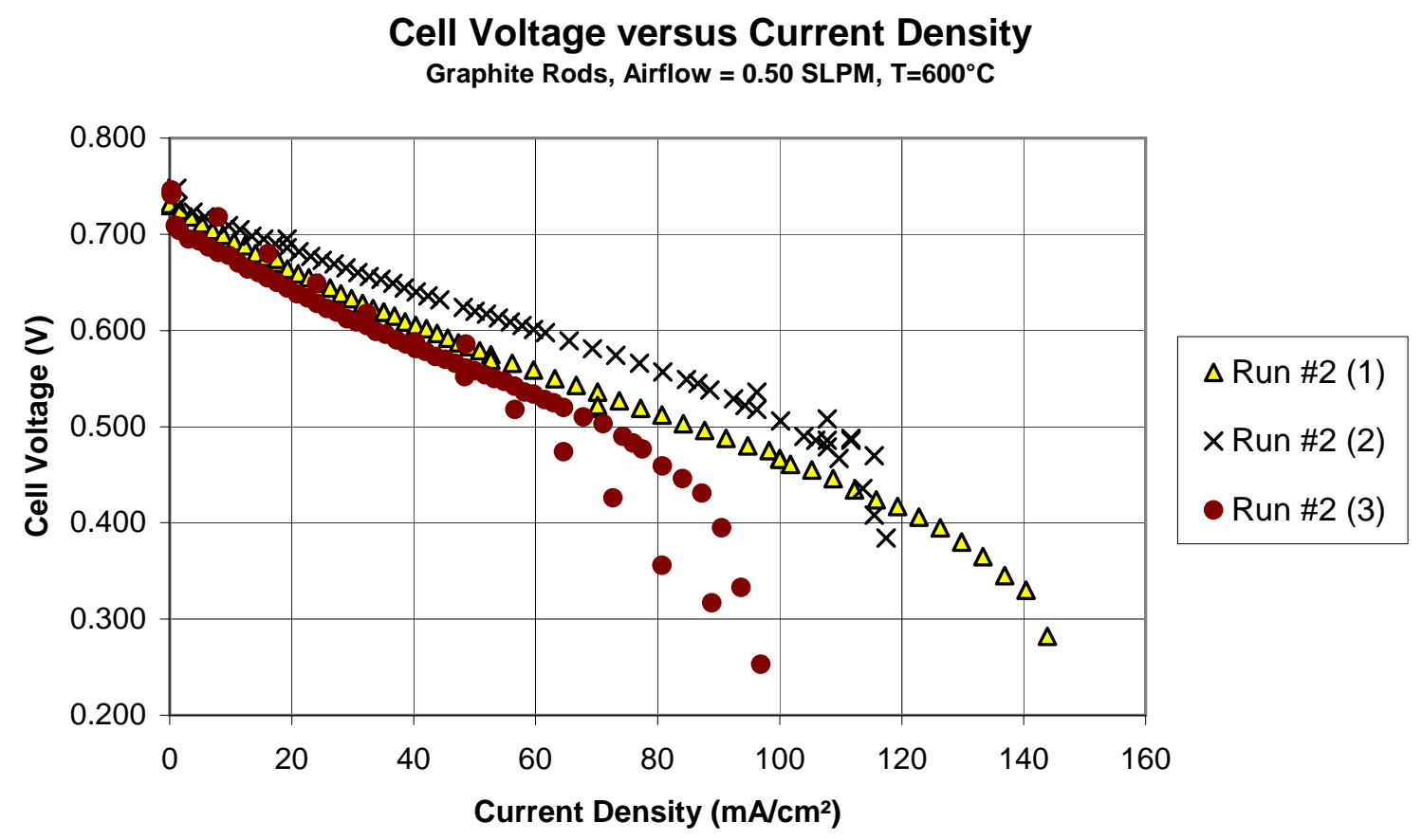

Figure 4.27 - Reproducibility of Data Generated During Duplicate Runs 


\subsubsection{Duplication of Data Provided by SARA}

Research conducted at SARA found that the coal-derived rods produce more voltage than graphite rods, as is the finding in this work. SARA used the following figure to show their findings.

The experiment shown in Figure 4.28 was conducted for the first 100 hours with a coal-derived fuel rod. The remaining 70 hours was conducted with a graphite fuel rod. It can be seen that at the interface between the two, there is an abrupt drop-off in cell voltage mainly due to the change in the anode potential. Therefore, SARA's findings agree with those herein and show that coal-derived rods produced more voltage than the graphite rods.

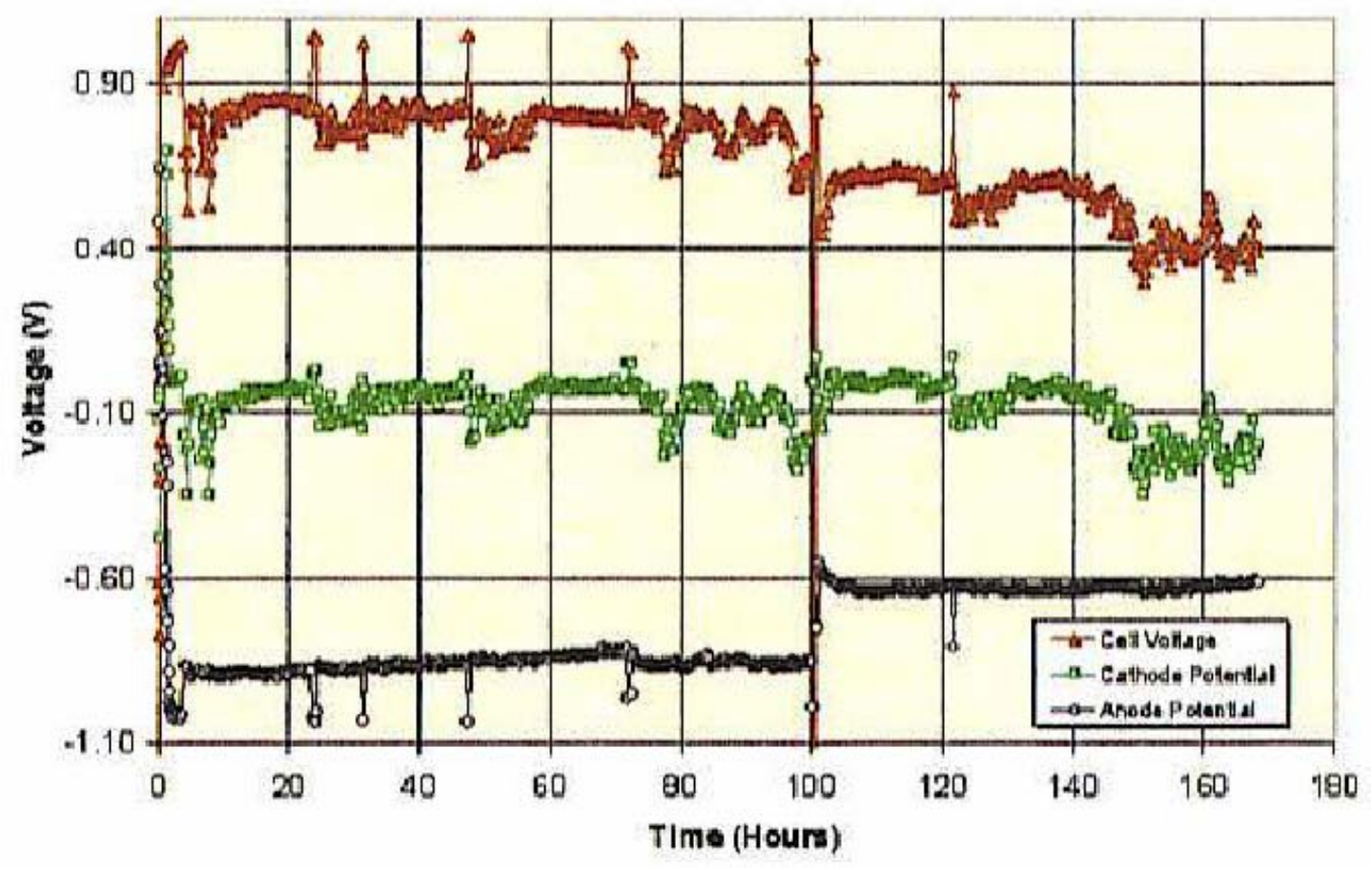

Figure 4.28 - Results of SARA's Findings Comparing Coal-Derived Fuel to Graphite 


\subsubsection{Effect of Temperature}

During one of the tests with the graphite rods, the cell temperature was varied stepwise from $600^{\circ} \mathrm{C}$ to $700^{\circ} \mathrm{C}$ and the $i$-V scans were made. The results indicate that the increase in temperature clearly causes an increase in performance in the cell, as shown in Figure 4.29 and Figure 4.30. However, there is a maximum temperature at which the temperature effect ceases to increase performance. It appears that the reaction is optimized at around $675^{\circ} \mathrm{C}$, according to these data. Data at $700^{\circ} \mathrm{C}$ show that the cell voltage is less, even though more current is drawn than at the lower temperatures.

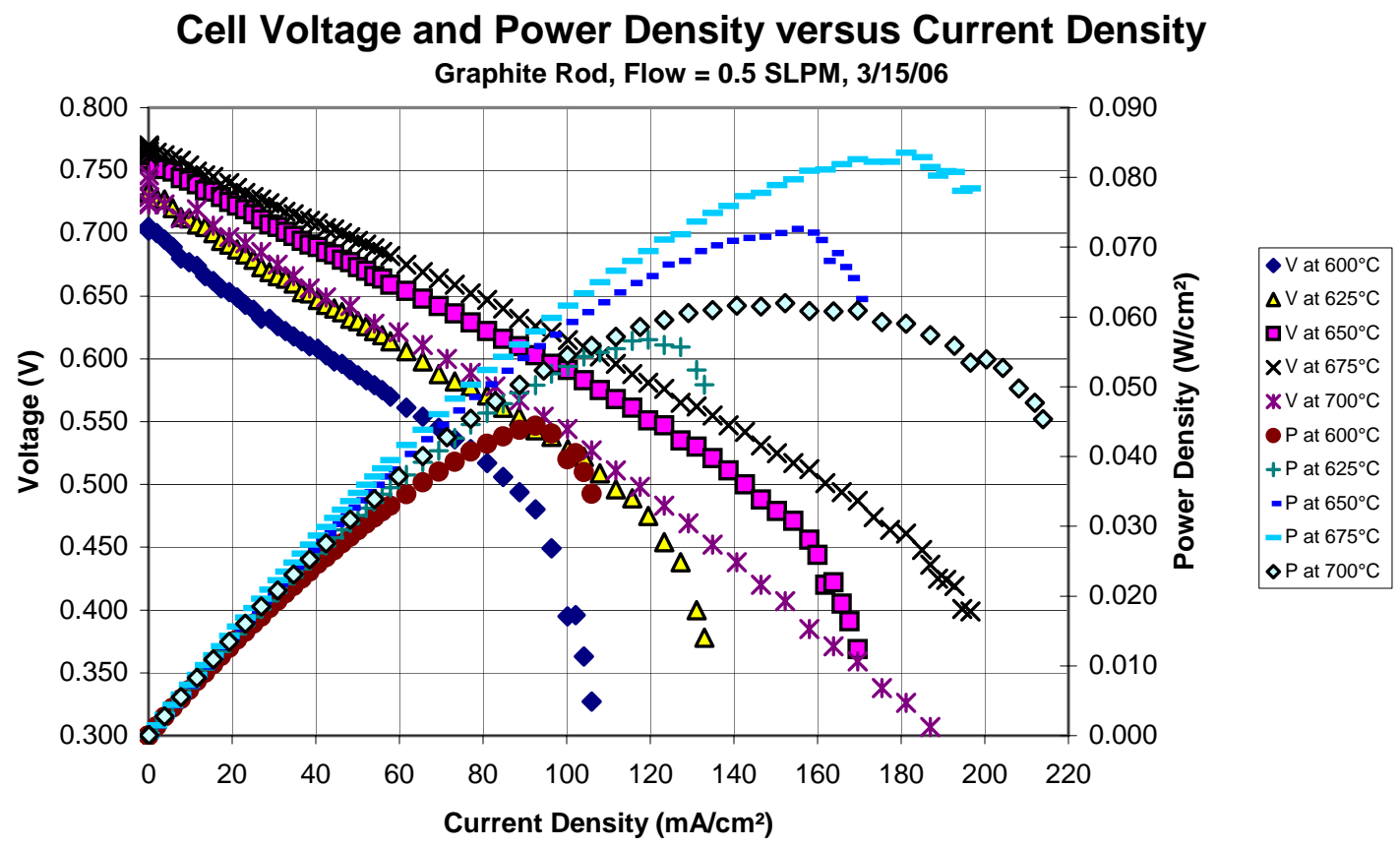

Figure 4.29 - Effect of Temperature on Voltage Output and Power Density from Runs \#4, \#5, \#6, \#8, and \#10 (Trial 1) 


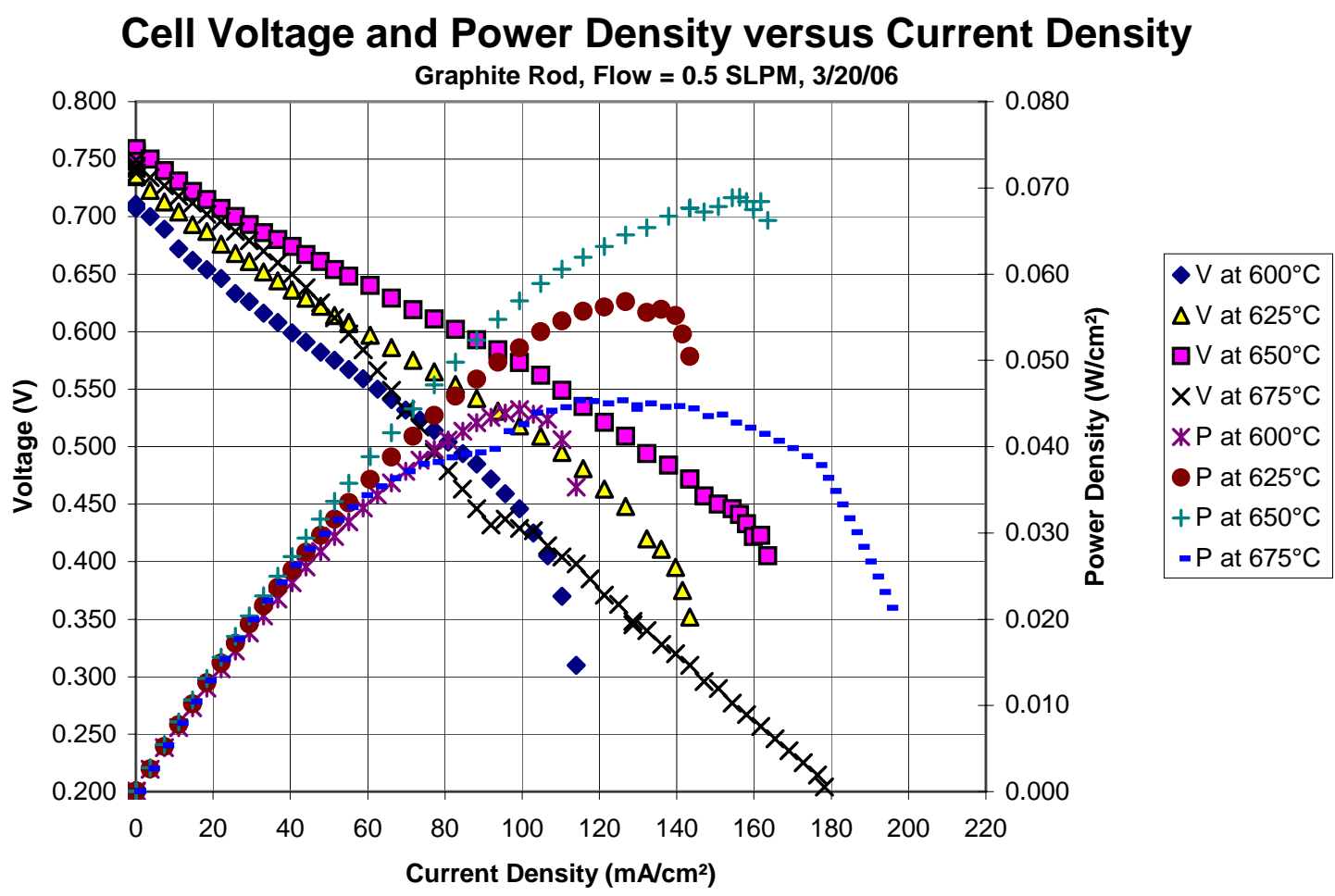

Figure 4.30 - Effect of Temperature on Voltage Output and Power Density from Runs \#4, \#5, \#6, and \#8 (Trial 2)

The same can be seen for the power output in this case, as illustrated in Figure 4.29 and Figure 4.30 . The maximum power is obtained at $675^{\circ} \mathrm{C}$ after a trend of increasing performance. The power output at $700^{\circ} \mathrm{C}$ is lower, and therefore it appears that the optimum temperature for power output is also around $675^{\circ} \mathrm{C}$, even though more current is drawn at $700^{\circ} \mathrm{C}$.

Although the values of $E^{\circ}$ obtained for different temperatures in Equation 4.1 are similar (see Section 2.4), the values for $E_{\text {cell }}$ obtained experimentally clearly show that temperature has more of an effect than originally anticipated. From the above equation, it seems logical that raising the temperature increases the voltage of the cell, which is seen in the increase in cell voltage from $600^{\circ} \mathrm{C}$ to $675^{\circ} \mathrm{C}$. This is due to the natural log of the 
ratio of the partial pressures of $\mathrm{CO}_{2}$ and $\mathrm{O}_{2}$ being negative (because the partial pressure of $\mathrm{CO}_{2}$ in the inlet gas is small compared to $\mathrm{O}_{2}$, assuming a well-mixed environment. At the higher temperature, there may be more $\mathrm{CO}_{2}$ produced in the cell, which would cause the voltage output to decrease at even higher temperatures.

$$
E_{\text {cell }}=E^{\circ}-\frac{R T}{N F} \cdot \ln \frac{\left[\mathrm{CO}_{2}\right]}{\left[\mathrm{O}_{2}\right]}
$$

It should be noted that this equation holds for $\mathrm{C}$ reacting with gaseous $\mathrm{O}_{2}$ to make gaseous $\mathrm{CO}_{2}$, a situation that is not present in these experiments. However, this equation is frequently cited in the literature and may be relevant when using the concentrations of gaseous $\mathrm{O}_{2}$ and $\mathrm{CO}_{2}$ in the electrolyte.

A trend of how the OCV changed with respect to the temperature is given in Figure 4.31. The ASR shows the opposite trend of the OCV. When the ASR is at a minimum, the OCV reaches a maximum. This makes sense because when there is less ohmic resistance, the ionic and electronic conduction is higher, leading to increased cell voltage. The ASR varied in this experiment from $1.6 \Omega-\mathrm{cm}^{2}$ to $2.2 \Omega-\mathrm{cm}^{2}$, since this test was conducted using graphite rods. 


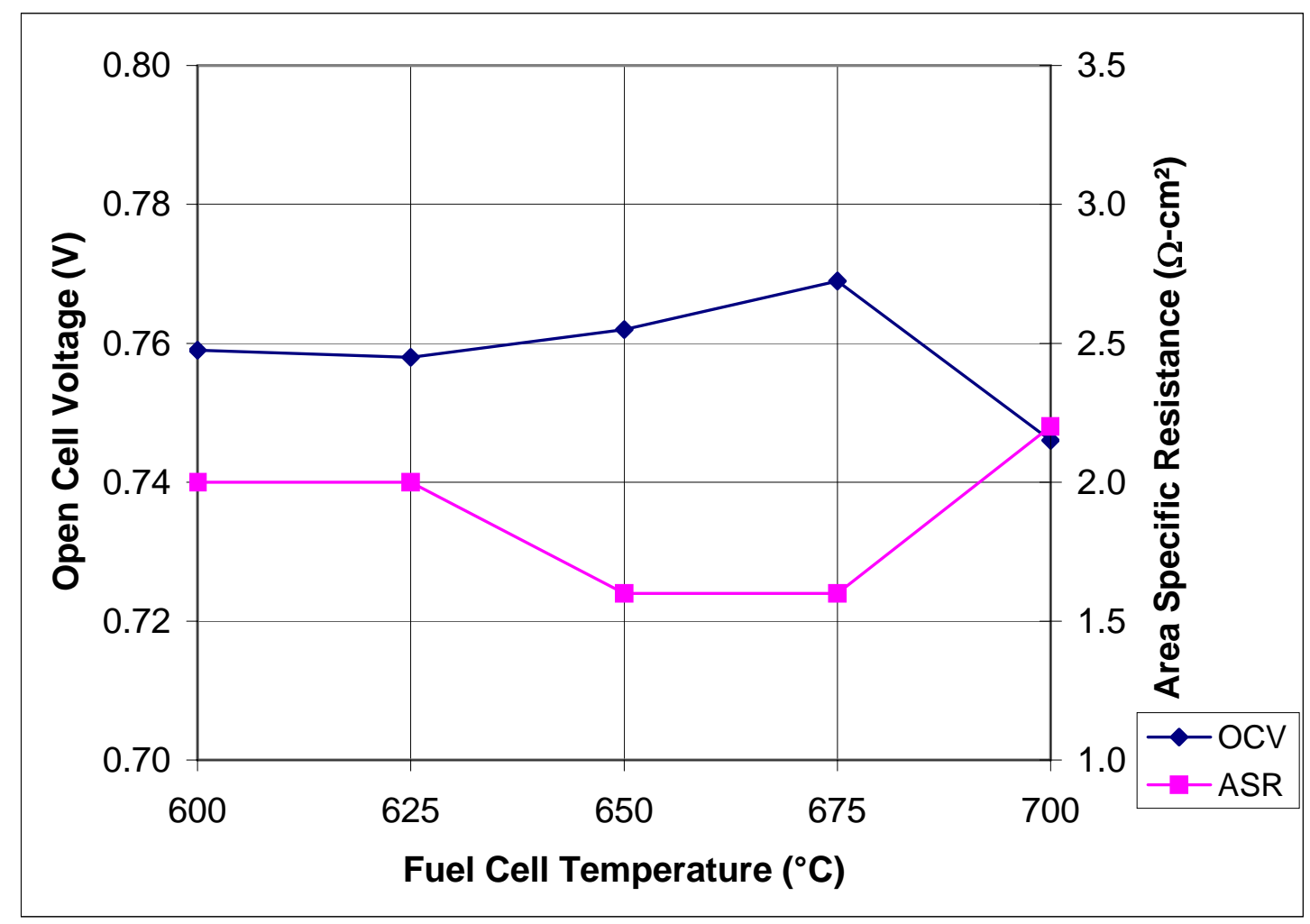

Figure 4.31 - Trends of Open Cell Voltage and Area Specific Resistance versus Fuel Cell Temperature Using a Graphite Rod

\subsubsection{Effect of Airflow Rate}

The effect of the airflow rate into the cell influences the performance of the cell as shown below in Figure 4.32 and Figure 4.33. There is a clear peak at 0.50 SLPM where the maximum performance is obtained at $675^{\circ} \mathrm{C}$, while the optimum performance at $600^{\circ} \mathrm{C}$ appears to be at higher airflow rates.

At a flow rate below the optimum airflow value (0.25 SLPM), the optimum amount of air is not being supplied for the reaction. Referring to Equation 4.1, supplying more oxygen into the system would cause the natural log of the ratio to be more negative, causing the cell voltage to increase. 
At a flow rate above the optimum airflow value (0.75 SLPM), the air is either flowing too quickly for the reaction to occur optimally, or it may be that the bubbles emanating from the spider are too large. This causes the surface area for the cathode reaction to be smaller because the air is occupying a large amount of the cathode surface, resulting in less contact between the reactants.

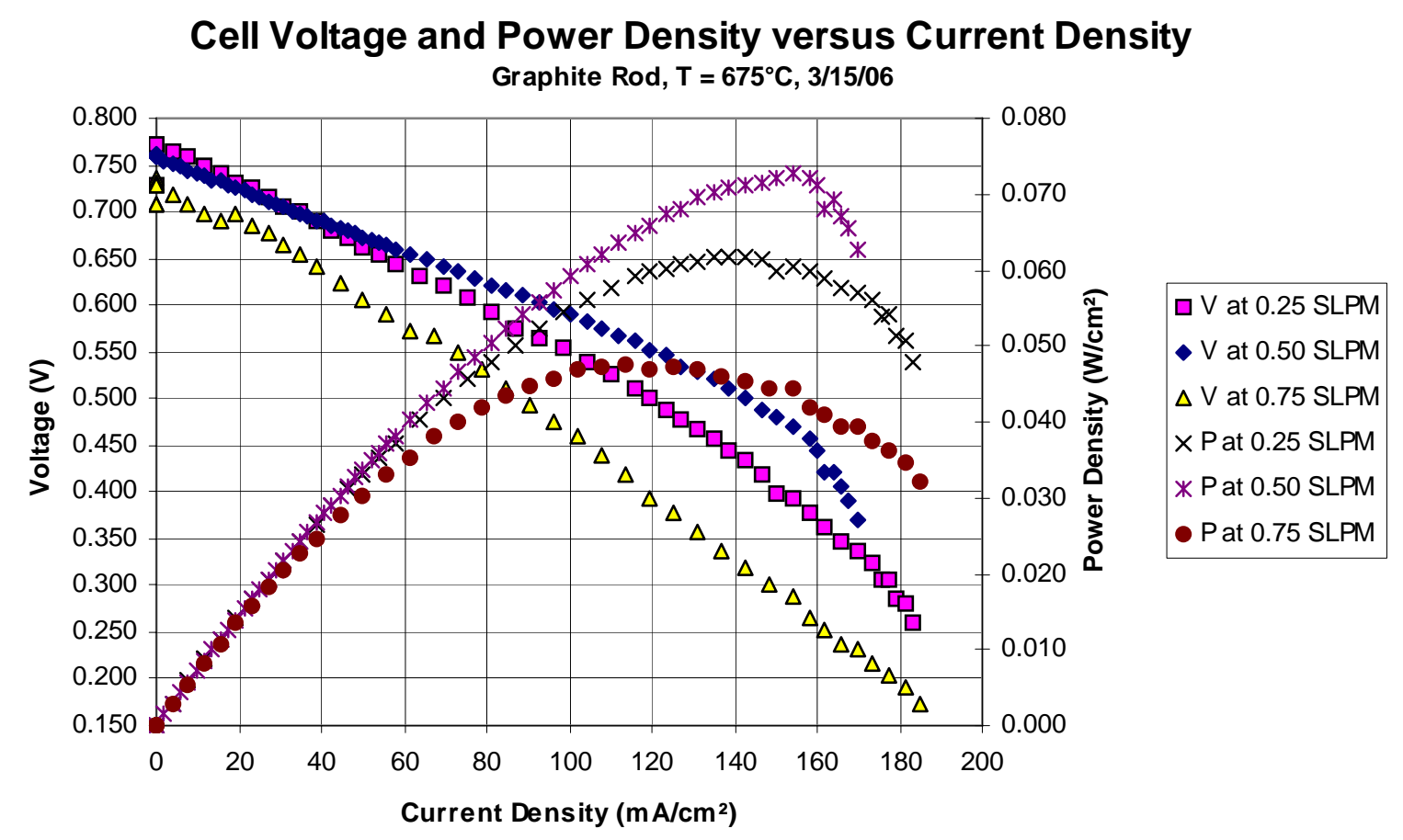

Figure 4.32 - Effect of Airflow Rate on Voltage Output and Power Density at $675^{\circ} \mathrm{C}$ 


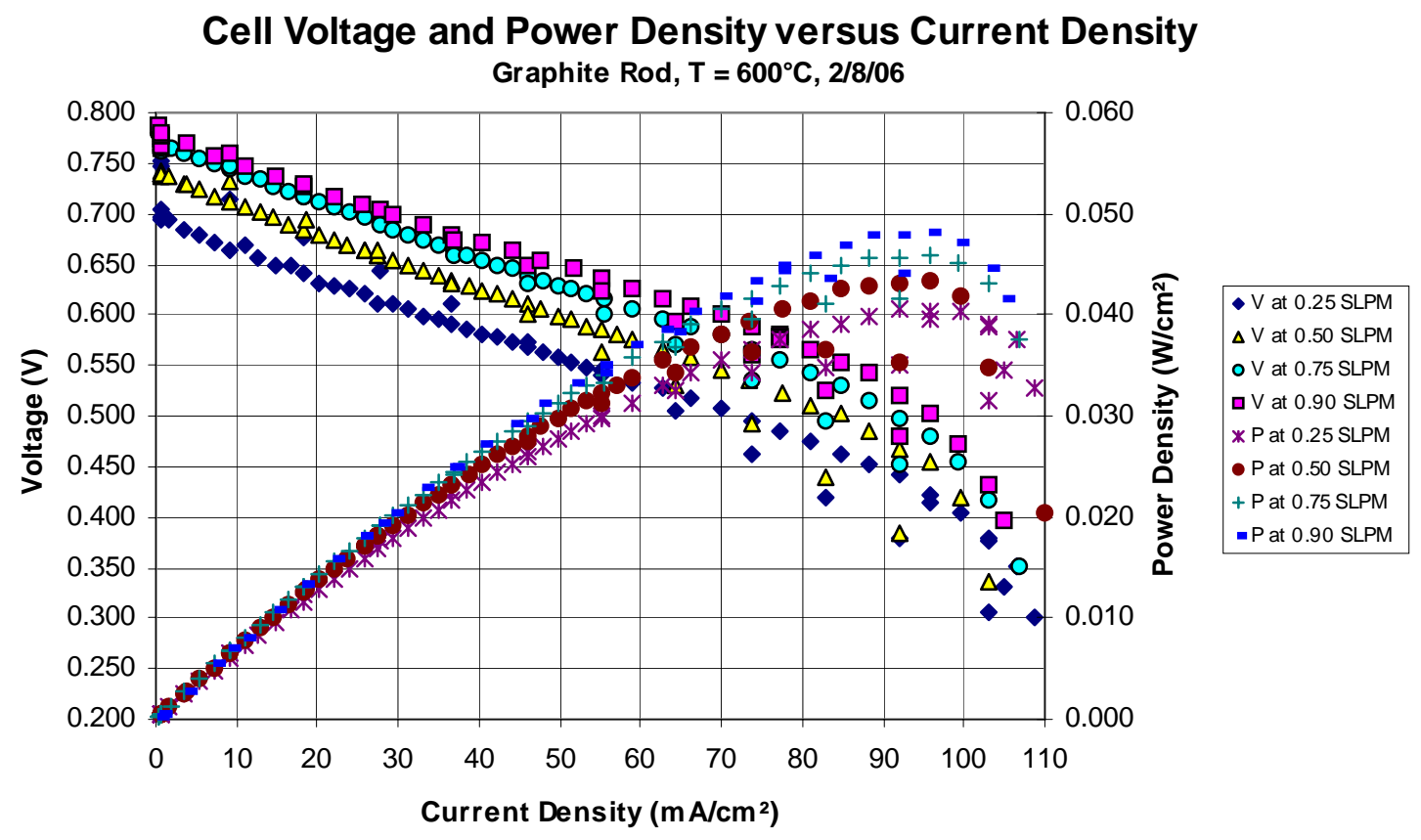

Figure 4.33 - Effect of Airflow Rate on Voltage Output and Power Density at $600^{\circ} \mathrm{C}$

Oxygen is required at the cathode, as seen in Equation 4.2, and is supplied in this process through the air feed. This equation shows that the airflow directly effects the cathode half-cell reaction. This is where the electrons are reintroduced into the system, react with the humidified air and replenish the hydroxide ions that are consumed at the anode.

$$
4 e^{-}+\mathrm{O}_{2}+2 \mathrm{H}_{2} \mathrm{O} \rightarrow 4 \mathrm{OH}^{-}
$$

The trends of OCV and ASR with the airflow rate are given in Figure 4.34 for the graphite rod. It can be seen here that the open cell voltage decreases steadily as airflow rate is increased. However, as shown in Figure 4.32, the voltage decreases faster at 0.25 SLPM than it does at 0.50 SLPM, catching up at about $35 \mathrm{~mA} / \mathrm{cm}^{2}$. The ASR shows the same trend as it did for the temperature study, with the minimum correlating to a 
maximum in cell voltage (not $\mathrm{OCV}$, in this case). The minimum resistance is at an airflow rate of 0.50 SLPM. Further data are provided in the presentation of the graphite rod results above.

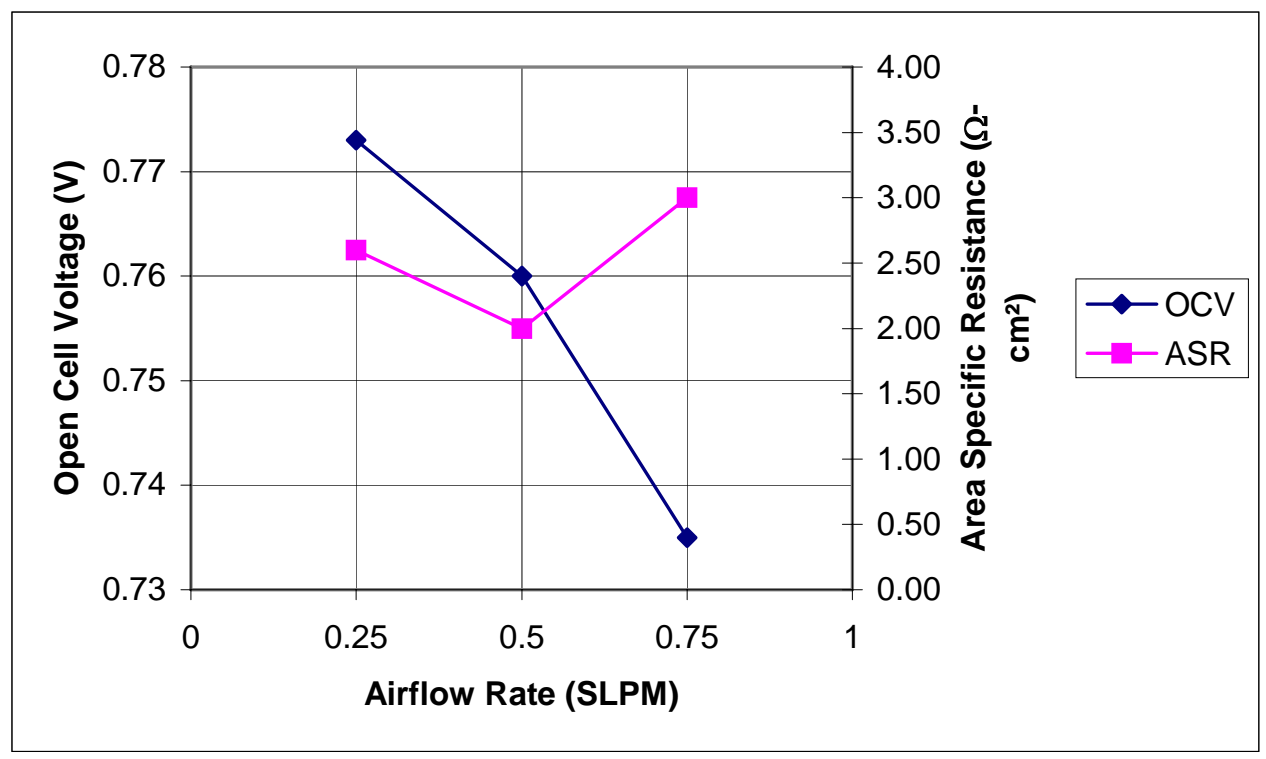

Figure 4.34 - Trends of Open Cell Voltage and Area Specific Resistance Using a Graphite Rod when Airflow Rate is Varied (taken from data of Figure 4.32)

\subsubsection{Effect of Fuel Rod Composition}

Table 4.5 is a summary of the main results obtained from the different fuels.

Table 4.5- Summary of Results by Carbon Fuel Rod

\begin{tabular}{|l|c|c|c|c|c|}
\hline \multicolumn{1}{|c|}{ Rod (Run \#) } & $\begin{array}{c}\text { Maximum } \\
\text { OCV (V) }\end{array}$ & $\begin{array}{c}\text { Maximum } \\
\text { Current Density } \\
\left(\mathbf{m A} / \mathbf{c m}^{2}\right)\end{array}$ & $\begin{array}{c}\text { Maximum } \\
\text { Power Density } \\
\left(\mathbf{W} / \mathbf{c m}^{2}\right)\end{array}$ & $\begin{array}{c}\text { Area Specific } \\
\text { Resistance } \\
\left(\Omega \times \mathbf{c m}^{2}\right)\end{array}$ & $\begin{array}{c}\text { Resistance } \\
(\Omega)\end{array}$ \\
\hline Graphite (4) & 0.788 & 230 & 0.084 & 2.59 & 0.054 \\
\hline $\begin{array}{l}\text { WVU Coal- } \\
\text { Derived (18) }\end{array}$ & 1.043 & 61 & 0.038 & 5.90 & 0.108 \\
\hline $\begin{array}{l}\text { GrafTech Baked } \\
(20)\end{array}$ & 0.972 & 38 & 0.026 & 4.20 & 0.065 \\
\hline
\end{tabular}

The best voltage output was obtained using the WVU coal-derived rods, specifically, the rod used in Run \#18 (Section 3.2), composed of pure SECO. The 
GrafTech baked rod also reached nearly 1.0V. Recall that the standard potential for the oxidation of carbon is $1.01 \mathrm{~V}$. The SECO rod recorded a voltage slightly over the standard potential, probably due to reactions of some impurities or the binder pitch used in the rod.

The trends in the OCV and ASR for the SECO blend rods are given below in Figure 4.35. It can be seen that the OCV is the highest at about $100 \%$ SECO content. The OCV is the lowest where the ASR is at its maximum, as expected. Once again, the ohmic resistance hinders ionic and electronic conduction in the electrolyte and electrodes, and therefore lowers cell voltage.

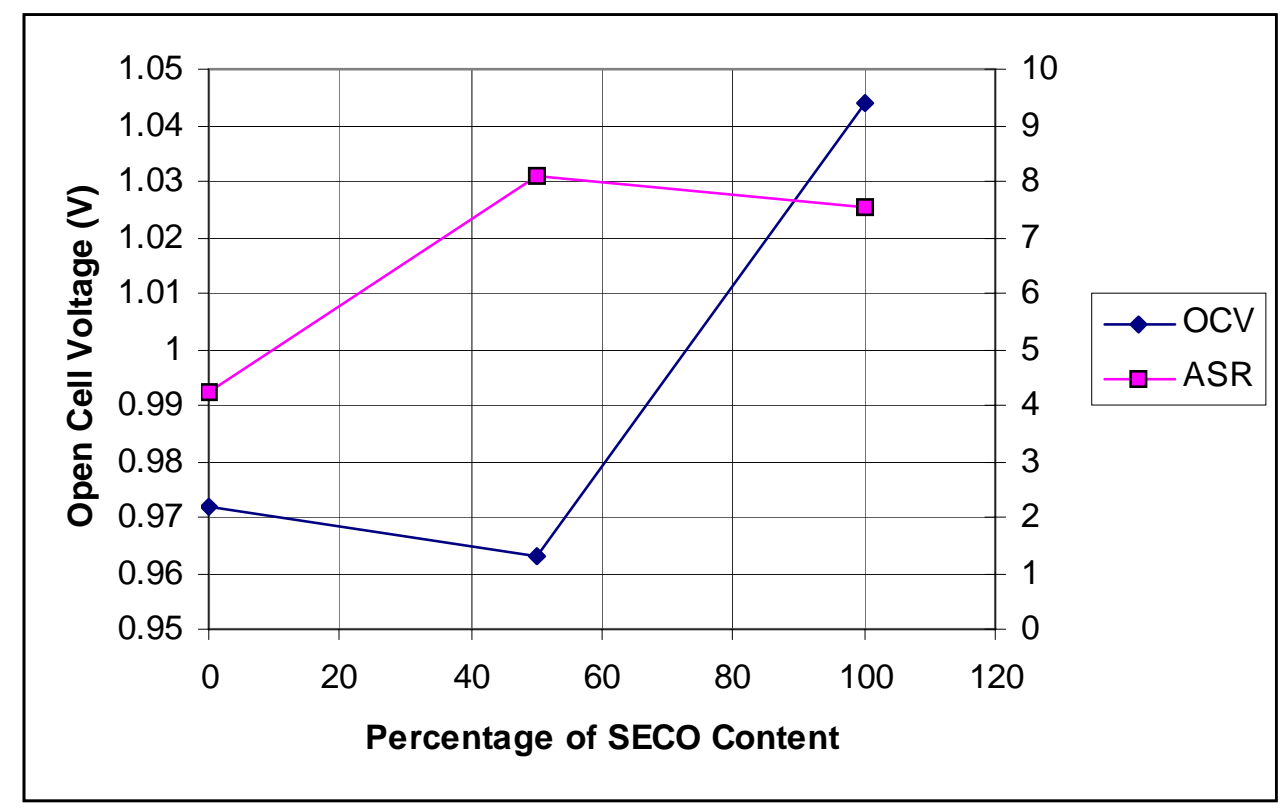

Figure 4.35 - Trends of Open Cell Voltage and Area Specific Resistance versus Percentage of SECO Content

The most current was drawn from the graphite rods, due to the ordered molecular structure of graphite and the stability of the rod over time. The graphite rods clearly allow more current to be drawn per unit of surface area because of their low ohmic resistance (recall ASR is a measurement of ohmic resistance). Therefore, more power is 
produced from graphite rods in this case because power is the product of current times voltage. Power is the most important parameter in evaluating a fuel cell. The resistance of the coal-derived rods is almost twice as much as that of graphite. Hence ohmic heating in the coal-derived rods, dissipates more power, so less current can be drawn. This explains why higher current could be drawn from graphite despite the lower OCV.

\subsubsection{Effect of Electrolyte}

An attempt was made to try electrolytes other than the sodium hydroxide that was used in most of the experiments. However, these tests did not produce any positive results. Using lithium hydroxide $(\mathrm{LiOH})$ did not allow the cell to produce a steady voltage. A mole ratio of 1.64:1 NaOH to $\mathrm{LiOH}$, the eutectic mixture suggested in literature, was used for Run \#12. The phase diagram for this mixture is given in Figure 4.36. The use of the eutectic mixture in this case was to reproduce some alternate experimental conditions examined at SARA.

The use of carbonate electrolytes did not produce any cell voltage whatsoever. The eutectic of a 1:1 mole ratio of $\mathrm{Li}_{2} \mathrm{CO}_{3}$ and $\mathrm{Na}_{2} \mathrm{CO}_{3}$ was used to lower the melting point of the mixture to $510^{\circ} \mathrm{C}$, slightly below the operating temperature of $600^{\circ} \mathrm{C}$. The diagram for this mixture is given in Figure 4.37. The eutectic melted at the proper temperature; however, the experiment did not produce any results. The reason may be due to the fact that carbonate reactions do not involve the use of water molecules. As the setup was made to include humidified air to the cell, this may have caused the problems that were experienced. Using dry air directly may have solved the problem, but it would require that the test stand be taken apart to bypass the water tank. Further experiments using alternate electrolytes were not conducted and were beyond the scope of this work. 


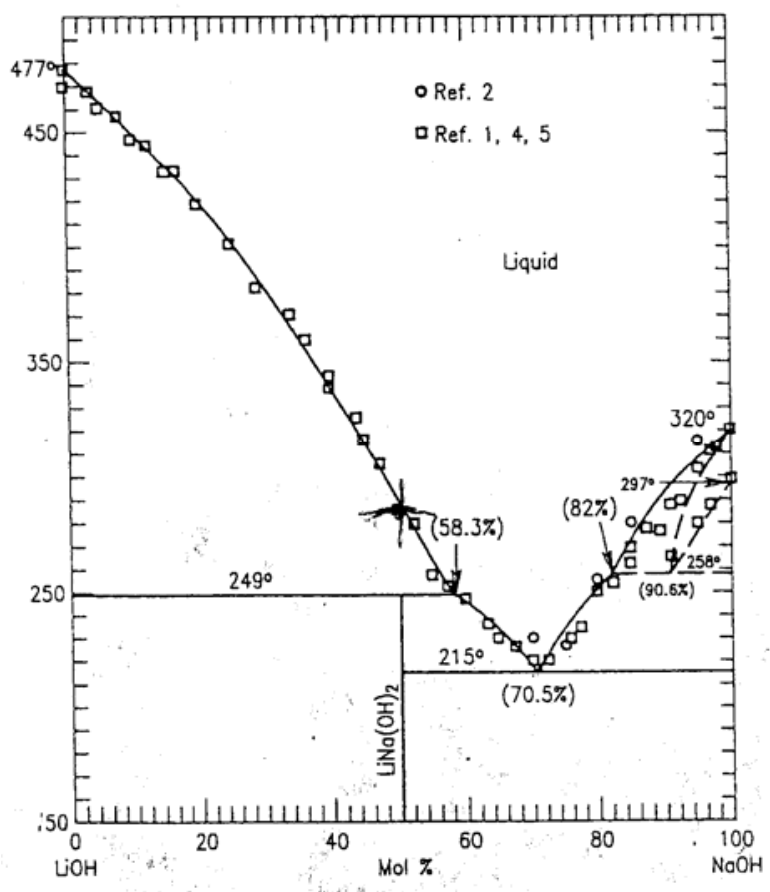

Figure 4.36 - Phase Diagram Showing Eutectic Mixture for NaOH and LiOH

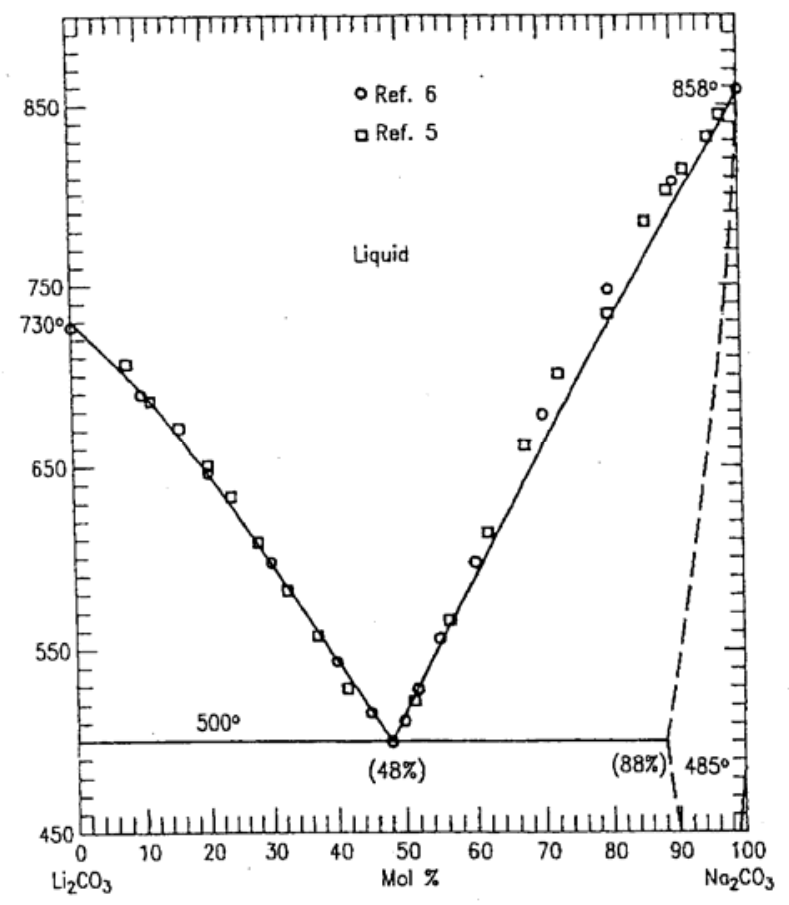

Figure 4.37 - Phase Diagram Showing Eutectic Mixture for $\mathrm{Li}_{2} \mathrm{CO}_{3}$ and $\mathrm{Na}_{2} \mathrm{CO}_{3}$ 


\section{Chapter 5}

\section{Conclusions}

Using carbon rods as a fuel source, the direct carbon fuel cell produced electricity as predicted. The following conclusions can be drawn from the work:

- The test stands provided by the U.S. Department of Energy were carefully studied. The modifications necessary to transition the stand from SOFC to DCFC were successfully completed.

- Graphite rods were used to evaluate the system. They provided reliable and reproducible data and ensured proper operation of the system.

- Rods derived from coal were successfully tested in the system

- The effects of temperature, airflow, electrolyte, long-term exposure, and different rods were investigated and showed that cell performance peaks at about $675^{\circ} \mathrm{C}$ and 0.50 SLPM with $\mathrm{NaOH}$ as the electrolyte. Graphite rods had better long-term results as they contained no binder pitch.

- The fuel cell performance was evaluated via $i-\mathrm{V}$ curves, which can be used to investigate different types of resistances such as activation, ohmic, and transport resistances. Graphite rods produced open cell voltages of up to $0.788 \mathrm{~V}$ and current densities up to $230 \mathrm{~mA} / \mathrm{cm}^{2}$ while coal-derived rods produced open cell voltages of $1.044 \mathrm{~V}$ and only $50 \mathrm{~mA} / \mathrm{cm}^{2}$ in current density.

- The fuel cell performance was evaluated by comparing plots of power densities, which can be used to evaluate the current needed for peak power output. Graphite rods produced $0.084 \mathrm{~W} / \mathrm{cm}^{2}$ while coal-derived rods were 
only able to produce $0.041 \mathrm{~W} / \mathrm{cm}^{2}$ because of their higher ASR ( 4-8

$\Omega \times \mathrm{cm}^{2}$ as opposed to $\sim 2 \Omega \times \mathrm{cm}^{2}$ ).

- Binder pitch is attacked preferentially in the reaction. Therefore, the baked coal-derived rods crumbled over time in the electrolyte.

- GrafTech baked rods were tested to investigate whether the method of manufacture influenced the behavior of the coal-derived rods. These rods were not able to stand long-term runs due to the binder pitch preferentially reacting. 


\section{Chapter 6}

\section{Recommendations}

This technology is extremely promising. Further work should be conducted to find a way around using rods. The process of making the rods is time consuming, expensive, and energy inefficient. A method of inserting raw coal into the cell would save both time and money in the future. This would also solve the problem of the rods disintegrating in the cell. If this did not happen, it would be more likely that more power would be produced from the coal-derived rods than the graphite rods.

The test stands could be modified to handle a molten carbonate fuel cell design. The electrolyte may allow better cell performance and should be considered an important factor in a DCFC.

The cell could be modified to allow the electrolyte to be reused. With the carbon anode directly immersed into the electrolyte, particulate matter contaminates the electrolyte slowly rendering it ineffective. In future applications, it may be feasible to remove and replace electrolyte while the cell is in use. This would save valuable time and energy. Perhaps a method of electrolyte filtration would be effective.

In order for the cell to be more efficient, some of the following could be investigated.

- To reduce activation losses

o The use of a catalyst in the electrolyte.

0 Increase the surface area of the anode and cathode by making it rougher

0 Use enriched air with higher oxygen concentration to increase reactant concentration

o Investigate pressure effects

- To reduce ohmic losses 
o Use a highly conductive metal for the cathode and a highly conductive electrolyte

o Reducing the space between the cathode and anode

- To reduce mass transport losses

o Introduce a "spider" that makes smaller bubbles, perhaps more legs

o Have the bubbles pass through a fine wire mesh to prevent large bubbles

o Run as low airflow rates as possible 


\section{Chapter 7}

\section{Bibliography}

1. West Virginia Department of Commerce, Office of Miners' Health Safety and Training, http://www.wvminesafety.org/.

2. Jacques, William W., "Method of Converting the Potential Energy of Carbon into Electricity," Patent Number 555,511, March 3, 1896, Newton, MA.

3. Pesavento, Philip V., "Carbon-air Fuel Cell," Patent Number 6,200,697, March 13, 2001, Lomita, CA

4. Blomen, Leo J. M. J. and Mugerwa, Michael N., Fuel Cell Systems, Plenum Press, New York, 1993, pp. 22-23.

5. R. D. Weaver, S.C. Leach, A. E. Bayce, and L. Nanis, Direct Electrochemical Generation of Electricity from Coal, February 15, 1979, SRI, Menlo Park, CA.

6. R. D. Weaver and L. Nanis. Electrochemical Oxidation of Carbon in Molten Carbonate Coal/Air Fuel Cell, Proc. $3^{\text {rd }}$ Int. Symp. On Molten Salts, Electrochem. Soc., 81-9, p. 316, 1981.

7. Proceedings of the Direct Carbon Fuel Cell Presentation, CellTech Power, July 30, 2003, http://www.netl.doe.gov/publications/proceedings/03/dcfcw/Tao.pdf

8. Lewis, G.N., and Randall, M., Thermodynamics, McGraw-Hill, New York, 1923, p. 576.

9. Cherepy, N.J., Krueger, R., Fiet, K.J., Jankowski, A.F., Cooper, J.F., Direct Conversion of Carbon Fuels in a Molten Carbonate Fuel Cell, Journal of the Electrochemical Society, February 25, 2004.

10. Lowry, H.H., Chemistry of Coal Utilization, Volume II, John Wiley and Sons, New York, 1945, pp. 1568-1573.

11. O’Hayre, R., Cha, S., Colella, W., and Prinz, F., Fuel Cell Fundamentals, John Wiley and Sons, New York, 2006, p. 225.

12. Dicks, A., Larminie, J., Fuel Cell Systems Explained, Second Edition, John Wiley and Sons, New York, 2003, Chapter 3.

13. Saddawi, Abha, Carbon Fuels for the Direct Carbon Fuel Cell, Master's Thesis, West Virginia University, 2005.

14. NDT Resource Center, http://www.ndt-ed.org/ 


\section{Chapter 8}

Appendix A - Graphite Rods Raw Data

\begin{tabular}{|c|c|c|c|c|c|c|c|c|c|c|c|}
\hline & & $\mathrm{DI1}$ & $\mathrm{od}$ & Flo & ate & ed, & 600 & 11 & 2005 & & \\
\hline & $M=40$ & & & $M=50$ & & & $1=65$ & & & $=65(2)$ & \\
\hline I/SA & $\mathrm{V}_{\mathrm{CELL}}$ & $\mathrm{P} / \mathrm{SA}$ & I/SA & $\mathrm{V}_{\mathrm{CELL}}$ & P/SA & I/SA & $\mathrm{V}_{\mathrm{CELL}}$ & P/SA & I/SA & $V_{\text {CELL }}$ & $\mathrm{P} / \mathrm{SA}$ \\
\hline 0.000 & 0.717 & 0.000 & 0.000 & 0.719 & 0.000 & 0.000 & 0.728 & 0.000 & 0.000 & 0.737 & 0.000 \\
\hline 2.819 & 0.707 & 0.002 & 2.819 & 0.707 & 0.002 & 2.819 & 0.719 & 0.002 & 2.819 & 0.731 & 0.002 \\
\hline 5.639 & 0.697 & 0.004 & 5.639 & 0.696 & 0.004 & 5.639 & 0.716 & 0.004 & 5.639 & 0.722 & 0.004 \\
\hline 8.458 & 0.686 & 0.006 & 8.458 & 0.683 & 0.006 & 8.458 & 0.705 & 0.006 & 8.458 & 0.709 & 0.006 \\
\hline 11.277 & 0.675 & 0.008 & 11.277 & 0.671 & 0.008 & 11.277 & 0.691 & 0.008 & 11.277 & 0.698 & 0.008 \\
\hline 14.096 & 0.663 & 0.009 & 14.096 & 0.660 & 0.009 & 14.096 & 0.678 & 0.010 & 14.096 & 0.687 & 0.010 \\
\hline 16.916 & 0.652 & 0.011 & 19.735 & 0.637 & 0.013 & 16.916 & 0.667 & 0.011 & 16.916 & 0.678 & 0.011 \\
\hline 19.735 & 0.641 & 0.013 & 22.554 & 0.626 & 0.014 & 19.735 & 0.656 & 0.013 & 16.916 & 0.674 & 0.011 \\
\hline 22.554 & 0.629 & 0.014 & 25.374 & 0.614 & 0.016 & 22.554 & 0.644 & 0.015 & 19.735 & 0.625 & 0.012 \\
\hline 25.374 & 0.618 & 0.016 & 28.193 & 0.603 & 0.017 & 25.374 & 0.631 & 0.016 & 19.735 & 0.658 & 0.013 \\
\hline 28.193 & 0.606 & 0.017 & 31.012 & 0.590 & 0.018 & 28.193 & 0.621 & 0.018 & 19.735 & 0.662 & 0.013 \\
\hline 31.012 & 0.596 & 0.018 & 33.831 & 0.580 & 0.020 & 31.012 & 0.608 & 0.019 & 22.554 & 0.631 & 0.014 \\
\hline 33.831 & 0.585 & 0.020 & 36.651 & 0.568 & 0.021 & 33.831 & 0.597 & 0.020 & 22.554 & 0.649 & 0.015 \\
\hline 36.651 & 0.573 & 0.021 & 39.470 & 0.557 & 0.022 & 36.651 & 0.586 & 0.021 & 22.554 & 0.651 & 0.015 \\
\hline 39.470 & 0.562 & 0.022 & 42.289 & 0.547 & 0.023 & 39.470 & 0.575 & 0.023 & 25.374 & 0.631 & 0.016 \\
\hline 42.289 & 0.552 & 0.023 & 45.109 & 0.536 & 0.024 & 42.289 & 0.565 & 0.024 & 25.374 & 0.641 & 0.016 \\
\hline 45.109 & 0.540 & 0.024 & 47.928 & 0.525 & 0.025 & 45.109 & 0.554 & 0.025 & 28.193 & 0.630 & 0.018 \\
\hline 47.928 & 0.529 & 0.025 & 50.747 & 0.515 & 0.026 & 47.928 & 0.543 & 0.026 & 31.012 & 0.621 & 0.019 \\
\hline 50.747 & 0.518 & 0.026 & 53.566 & 0.504 & 0.027 & 50.747 & 0.532 & 0.027 & 33.831 & 0.610 & 0.021 \\
\hline 53.566 & 0.507 & 0.027 & 56.386 & 0.493 & 0.028 & 53.566 & 0.522 & 0.028 & 39.470 & 0.591 & 0.023 \\
\hline 56.386 & 0.496 & 0.028 & 59.205 & 0.482 & 0.029 & 56.386 & 0.512 & 0.029 & 42.289 & 0.579 & 0.024 \\
\hline 59.205 & 0.484 & 0.029 & 62.024 & 0.472 & 0.029 & 59.205 & 0.500 & 0.030 & 47.928 & 0.560 & 0.027 \\
\hline 62.024 & 0.473 & 0.029 & 64.844 & 0.461 & 0.030 & 62.024 & 0.490 & 0.030 & 53.566 & 0.539 & 0.029 \\
\hline 64.844 & 0.463 & 0.030 & 67.663 & 0.450 & 0.030 & 64.844 & 0.480 & 0.031 & 56.386 & 0.530 & 0.030 \\
\hline 67.663 & 0.451 & 0.031 & 70.482 & 0.440 & 0.031 & 67.663 & 0.470 & 0.032 & 59.205 & 0.520 & 0.031 \\
\hline 70.482 & 0.440 & 0.031 & 73.301 & 0.430 & 0.032 & 70.482 & 0.460 & 0.032 & 64.844 & 0.501 & 0.032 \\
\hline 73.301 & 0.428 & 0.031 & 76.121 & 0.420 & 0.032 & 73.301 & 0.450 & 0.033 & 67.663 & 0.490 & 0.033 \\
\hline 76.121 & 0.417 & 0.032 & 78.940 & 0.409 & 0.032 & 76.121 & 0.439 & 0.033 & 67.663 & 0.492 & 0.033 \\
\hline 78.940 & 0.405 & 0.032 & 81.759 & 0.399 & 0.033 & 78.940 & 0.430 & 0.034 & 70.482 & 0.481 & 0.034 \\
\hline 81.759 & 0.395 & 0.032 & 84.579 & 0.389 & 0.033 & 81.759 & 0.420 & 0.034 & 73.301 & 0.475 & 0.035 \\
\hline 84.579 & 0.384 & 0.032 & 88.807 & 0.373 & 0.033 & 84.579 & 0.410 & 0.035 & 76.121 & 0.466 & 0.035 \\
\hline 88.807 & 0.370 & 0.033 & & & & 88.807 & 0.396 & 0.035 & 78.940 & 0.458 & 0.036 \\
\hline & & & & & & & & & 81.759 & 0.448 & 0.037 \\
\hline & & & & & & & & & 84.579 & 0.439 & 0.037 \\
\hline & & & & & & & & & 87.398 & 0.430 & 0.038 \\
\hline & & & & & & & & & 90.217 & 0.421 & 0.038 \\
\hline & & & & & & & & & 93.036 & 0.412 & 0.038 \\
\hline & & & & & & & & & 164.646 & 0.193 & 0.032 \\
\hline
\end{tabular}




\begin{tabular}{|c|c|c|c|c|c|c|c|c|c|c|c|}
\hline & & & & & & & - & , & $0 / 20$ & & \\
\hline & $M=20$ & & & $M=40$ & & & $\mathrm{RM}=50$ & & & $M=65$ & \\
\hline I/SA & VCELL & P/SA & I/SA & VCELL & P/SA & I/SA & VCELL & P/SA & I/SA & VCELL & P/SA \\
\hline 0.000 & 0 & 0.000 & 0.000 & 52 & 0.000 & 0.000 & 78 & 0.000 & 0.000 & 99 & .000 \\
\hline 0.000 & & . & 0.000 & 76 & 00 & 000 & & .000 & 0.000 & & 000 \\
\hline 0.000 & 686 & 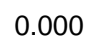 & 2.722 & 46 & 2 & 722 & 75 & 02 & 0.000 & 07 & 000 \\
\hline 2.722 & & & 5.444 & & & 144 & & 4 & 9 & & 02 \\
\hline 4.083 & 55 & 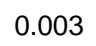 & 8.165 & 34 & & 8.165 & 66 & 05 & 5.639 & 88 & 004 \\
\hline 5.444 & 48 & 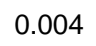 & 0.887 & 27 & 7 & 387 & 59 & 7 & 8.458 & 81 & 006 \\
\hline 5.444 & 77 & 0.004 & 609 & 19 & 88 & 09 & 54 & 99 & 1.277 & 75 & 008 \\
\hline 8.165 & 37 & 0.005 & 331 & 13 & 0 & 09 & 64 & .009 & .096 & 69 & 009 \\
\hline 10.887 & 29 & 0.0 & 53 & 0.608 & 2 & 6.331 & 648 & .011 & 6.916 & 664 & 011 \\
\hline 609 & 0.620 & 0.008 & 21.775 & 0.602 & 0.013 & 9.053 & 644 & 0.012 & 19.735 & 60 & 013 \\
\hline 609 & 0.648 & 0.009 & 4.496 & 0.598 & 0.015 & 1.775 & 638 & .014 & 2.554 & 53 & 015 \\
\hline 0.331 & 0.613 & 0.010 & 27.218 & 0.593 & 0.016 & 24.496 & 632 & 0.015 & 25.374 & 647 & .016 \\
\hline 9.053 & 0.606 & 0.01 & 27.2 & 0.619 & 0.0 & & 0.628 & 0.0 & & & 018 \\
\hline 21.775 & 0.599 & 0.013 & 32.662 & 0.582 & 0.019 & 27.218 & 0.634 & 0.017 & 28.193 & 641 & .018 \\
\hline 24.496 & 0.591 & 0.014 & 35.384 & 0.579 & 0.020 & 29.940 & 0.624 & 0.019 & 28.193 & 636 & 0.018 \\
\hline 7.218 & 0.584 & 0.016 & 40.827 & 0.569 & 0.023 & 32.662 & 620 & 0.020 & 31.012 & 636 & .020 \\
\hline 27.218 & 0.605 & 0.016 & 40.827 & 92 & 0.024 & 35.384 & 615 & 0.022 & 33.831 & 631 & 0.021 \\
\hline 29.940 & 0.577 & 0.017 & 46.271 & 0.559 & 0.026 & 38.106 & 0.611 & 0.023 & 36.651 & 626 & 0.023 \\
\hline 32.662 & 0.570 & 0.019 & 51.715 & 0.551 & 0.028 & 40.827 & 0.606 & 0.025 & 39.470 & .620 & 0.024 \\
\hline 35.384 & 0.562 & 0.020 & 54.437 & 0.547 & 0.030 & 40.827 & 606 & 0.025 & 42.289 & 616 & 0.026 \\
\hline 35.384 & 563 & 0.020 & 54.437 & 0.566 & 0.031 & 43.549 & 02 & 0.026 & 45.109 & 611 & 0.028 \\
\hline 38.106 & 0.557 & 0.021 & 59.880 & 0.538 & 0.032 & 46.271 & 96 & 0.028 & 50.747 & 601 & .030 \\
\hline 40.827 & 0.550 & 0.022 & 65.324 & 0.531 & 0.035 & 48.993 & 93 & 0.029 & 56.386 & 593 & .033 \\
\hline 40.827 & 0.568 & 0.023 & 70.768 & 0.524 & 0.037 & 51.715 & 0.589 & 0.030 & 62.024 & 583 & 0.036 \\
\hline 43.549 & 0.546 & 0.024 & 76.211 & 0.515 & 0.039 & 54.437 & 585 & 0.032 & 67.663 & 574 & .039 \\
\hline 0.271 & 539 & 0.025 & 81.655 & 0.509 & 0.042 & 54.437 & 80 & 0.032 & 73.301 & 64 & .041 \\
\hline 48.993 & 0.534 & 0.026 & 81.655 & 0.519 & 0.042 & 57.158 & 580 & 0.033 & 78.940 & 556 & .044 \\
\hline 51.715 & 0.528 & 0.027 & 87.099 & 0.501 & 0.044 & 59.880 & 577 & 0.035 & 84.579 & 547 & .046 \\
\hline 54.437 & 0.523 & 0.028 & 95.264 & 0.490 & 0.047 & 65.324 & 0.568 & 0.037 & 90.217 & .538 & 0.049 \\
\hline 54.437 & 0.536 & 0.029 & 95.264 & 0.497 & 0.047 & 68.046 & 564 & 0.038 & 95.856 & 528 & .051 \\
\hline 57.158 & 0.516 & 0.029 & 0.708 & .482 & 0.049 & 73.489 & 556 & 0.041 & 01.494 & 520 & .053 \\
\hline 59.880 & 0.51 & & & 5 & & & & 42 & & & 55 \\
\hline 62.602 & 0.507 & 0.0 & 108.873 & 0.474 & 0.052 & 55 & 0.544 & 0.044 & 112.771 & 03 & 0.057 \\
\hline 65.324 & 0.502 & 0.033 & 111.5 & 0.468 & 0.052 & 81.655 & 0.530 & 0.043 & 118.410 & 493 & 0.058 \\
\hline 68.046 & 498 & 0.034 & 1.5 & .468 & 0.052 & 87.099 & 539 & 0.047 & 124.048 & 485 & .060 \\
\hline 68.046 & 0.506 & 0.034 & 17.039 & 0.463 & 0.054 & 92.542 & 0.532 & 0.049 & 129.687 & .474 & 0.061 \\
\hline 70.76 & 0.492 & 0.035 & 122.482 & 0.455 & 0.056 & 95.264 & 0.510 & 0.049 & 129.687 & 0.472 & 0.061 \\
\hline 73.489 & 0.488 & 0.036 & 127.926 & 0.448 & 0.057 & 97.986 & 0.524 & 0.051 & 135.326 & .460 & 0.062 \\
\hline 76.211 & 0.481 & 0.037 & 133.370 & 0.441 & 0.059 & 103.430 & 0.515 & 0.053 & 140.964 & 450 & 0.063 \\
\hline 78.933 & .476 & 0.038 & 36.091 & .436 & 0.059 & 08.873 & .507 & 0.055 & 46.603 & .440 & 065 \\
\hline 81.655 & 0.471 & 0.038 & 136.091 & 0.432 & 0.059 & 108.873 & 0.489 & 0.053 & 152.241 & .420 & 0.064 \\
\hline 81.655 & 0.478 & 0.039 & 141.535 & 0.429 & 0.061 & 114.317 & 0.497 & 0.057 & 157.880 & 0.411 & 0.065 \\
\hline 84.377 & 0.466 & 0.039 & 149.701 & 0.420 & 0.063 & 114.317 & 0.498 & 0.057 & 163.518 & 0.395 & 0.065 \\
\hline 87.099 & 0.462 & 0.040 & 155.144 & 0.411 & 0.064 & 119.760 & 0.489 & 0.059 & 163.518 & 0.374 & 0.061 \\
\hline 89.820 & 0.456 & 0.041 & 163.310 & 0.400 & 0.065 & 125.204 & 0.480 & 0.060 & 169.157 & 0.356 & 0.060 \\
\hline 92.542 & 0.450 & 0.042 & 163.310 & 0.387 & 0.063 & 130.648 & 0.473 & 0.062 & 174.796 & 0.320 & 0.056 \\
\hline 95.264 & 0.443 & 0.042 & 176.919 & 0.381 & 0.067 & 136.091 & 0.463 & 0.063 & & & \\
\hline
\end{tabular}




\begin{tabular}{|c|c|c|c|c|c|c|c|c|}
\hline 95.264 & 0.450 & 0.043 & 185.084 & 0.368 & 0.068 & 136.091 & 0.444 & 0.060 \\
\hline 97.986 & 0.438 & 0.043 & 195.972 & 0.350 & 0.069 & 141.535 & 0.454 & 0.064 \\
\hline 100.708 & 0.431 & 0.043 & 204.137 & 0.336 & 0.069 & 146.979 & 0.444 & 0.065 \\
\hline 103.430 & 0.427 & 0.044 & 217.746 & 0.311 & 0.068 & 152.422 & 0.433 & 0.066 \\
\hline 106.151 & 0.420 & 0.045 & 227.273 & 0.285 & 0.065 & 157.866 & 0.423 & 0.067 \\
\hline 108.873 & 0.414 & 0.045 & 229.995 & 0.285 & 0.066 & 157.866 & 0.421 & 0.066 \\
\hline 108.873 & 0.424 & 0.046 & & & & 163.310 & 0.409 & 0.067 \\
\hline 111.595 & 0.409 & 0.046 & & & & 174.197 & 0.391 & 0.068 \\
\hline 114.317 & 0.403 & 0.046 & & & & 179.641 & 0.372 & 0.067 \\
\hline 117.039 & 0.392 & 0.046 & & & & 185.084 & 0.360 & 0.067 \\
\hline 119.760 & 0.388 & 0.046 & & & & 190.528 & 0.343 & 0.065 \\
\hline 122.482 & 0.380 & 0.047 & & & & 197.333 & 0.325 & 0.064 \\
\hline 122.482 & 0.398 & 0.049 & & & & 204.137 & 0.303 & 0.062 \\
\hline 127.926 & 0.368 & 0.047 & & & & 206.859 & 0.261 & 0.054 \\
\hline 130.648 & 0.359 & 0.047 & & & & & & \\
\hline 133.370 & 0.351 & 0.047 & & & & & & \\
\hline 136.091 & 0.342 & 0.047 & & & & & & \\
\hline 136.091 & 0.371 & 0.050 & & & & & & \\
\hline 138.813 & 0.336 & 0.047 & & & & & & \\
\hline 141.535 & 0.326 & 0.046 & & & & & & \\
\hline 144.257 & 0.316 & 0.046 & & & & & & \\
\hline 146.979 & 0.310 & 0.046 & & & & & & \\
\hline 149.701 & 0.299 & 0.045 & & & & & & \\
\hline 152.422 & 0.289 & 0.044 & & & & & & \\
\hline 155.144 & 0.282 & 0.044 & & & & & & \\
\hline 157.866 & 0.273 & 0.043 & & & & & & \\
\hline 160.588 & 0.258 & 0.041 & & & & & & \\
\hline 163.310 & 0.249 & 0.041 & & & & & & \\
\hline 166.032 & 0.238 & 0.040 & & & & & & \\
\hline 174.197 & 0.216 & 0.038 & & & & & & \\
\hline
\end{tabular}

Graphite Rod, Air Flow Rate Varied, $\mathrm{T}=600^{\circ} \mathrm{C}, 12 / 14 / 2005$

\begin{tabular}{|c|c|c|c|c|c|c|c|c|c|c|c|}
\hline \multicolumn{3}{|c|}{$\mathrm{RM}=20, \mathrm{~T}=600$} & \multicolumn{3}{|c|}{$\mathrm{RM}=40, \mathrm{~T}=600$} & \multicolumn{3}{|c|}{$\mathrm{RM}=50, \mathrm{~T}=600$} & \multicolumn{3}{|c|}{$\mathrm{RM}=65, \mathrm{~T}=600$} \\
\hline I/SA & VCELL & $\mathrm{P} / \mathrm{SA}$ & I/SA & VCELL & P/SA & I/SA & VCELL & P/SA & $\mathrm{I} / \mathrm{SA}$ & VCELL & P/SA \\
\hline 0.000 & 0.653 & 0.000 & 0.000 & 0.701 & 0.000 & 0.000 & 0.730 & 0.000 & 0.000 & 0.711 & 0.000 \\
\hline 0.000 & 0.653 & 0.000 & 0.000 & 0.743 & 0.000 & 0.000 & 0.731 & 0.000 & 0.000 & 0.727 & 0.000 \\
\hline 0.000 & 0.715 & 0.000 & 1.754 & 0.697 & 0.001 & 1.754 & 0.725 & 0.001 & 1.754 & 0.708 & 0.001 \\
\hline 1.754 & 0.645 & 0.001 & 3.509 & 0.690 & 0.002 & 3.509 & 0.718 & 0.003 & 3.509 & 0.702 & 0.002 \\
\hline 3.509 & 0.638 & 0.002 & 5.263 & 0.684 & 0.004 & 5.263 & 0.711 & 0.004 & 5.263 & 0.694 & 0.004 \\
\hline 5.263 & 0.632 & 0.003 & 7.018 & 0.679 & 0.005 & 7.018 & 0.704 & 0.005 & 7.018 & 0.692 & 0.005 \\
\hline 7.018 & 0.633 & 0.004 & 8.772 & 0.673 & 0.006 & 8.772 & 0.699 & 0.006 & 8.772 & 0.687 & 0.006 \\
\hline 7.018 & 0.623 & 0.004 & 8.772 & 0.705 & 0.006 & 10.526 & 0.692 & 0.007 & 10.526 & 0.682 & 0.007 \\
\hline 8.772 & 0.623 & 0.005 & 10.526 & 0.669 & 0.007 & 12.281 & 0.688 & 0.008 & 12.281 & 0.679 & 0.008 \\
\hline 8.772 & 0.619 & 0.005 & 12.281 & 0.663 & 0.008 & 14.035 & 0.680 & 0.010 & 14.035 & 0.674 & 0.009 \\
\hline 10.526 & 0.613 & 0.006 & 14.035 & 0.660 & 0.009 & 15.789 & 0.676 & 0.011 & 15.789 & 0.669 & 0.011 \\
\hline 12.281 & 0.606 & 0.007 & 15.789 & 0.655 & 0.010 & 17.544 & 0.670 & 0.012 & 17.544 & 0.664 & 0.012 \\
\hline 14.035 & 0.599 & 0.008 & 17.544 & 0.652 & 0.011 & 17.544 & 0.674 & 0.012 & 17.544 & 0.673 & 0.012 \\
\hline 15.789 & 0.606 & 0.010 & 17.544 & 0.671 & 0.012 & 19.298 & 0.664 & 0.013 & 19.298 & 0.660 & 0.013 \\
\hline
\end{tabular}




\begin{tabular}{|c|c|c|c|c|c|c|c|c|c|c|c|}
\hline 17.544 & 0.594 & 0.010 & 19.298 & 0.647 & 0.012 & 21.053 & 0.659 & 0.014 & 21.053 & 0.655 & 0.014 \\
\hline 17.544 & 0.611 & 0.011 & 21.053 & 0.643 & 0.014 & 22.807 & 0.655 & 0.015 & 22.807 & 0.652 & 0.015 \\
\hline 19.298 & 0.592 & 0.011 & 22.807 & 0.640 & 0.015 & 24.561 & 0.649 & 0.016 & 24.561 & 0.647 & 0.016 \\
\hline 21.053 & 0.576 & 0.012 & 24.561 & 0.636 & 0.016 & 26.316 & 0.644 & 0.017 & 26.316 & 0.643 & 0.017 \\
\hline 22.807 & 0.570 & 0.013 & 26.316 & 0.633 & 0.017 & 28.070 & 0.638 & 0.018 & 28.070 & 0.640 & 0.018 \\
\hline 24.561 & 0.563 & 0.014 & 26.316 & 0.641 & 0.017 & 29.825 & 0.633 & 0.019 & 29.825 & 0.636 & 0.019 \\
\hline 26.316 & 0.564 & 0.015 & 28.070 & 0.629 & 0.018 & 31.579 & 0.628 & 0.020 & 31.579 & 0.632 & 0.020 \\
\hline 28.070 & 0.554 & 0.016 & 29.825 & 0.632 & 0.019 & 33.333 & 0.623 & 0.021 & 33.333 & 0.628 & 0.021 \\
\hline 29.825 & 0.549 & 0.016 & 31.579 & 0.628 & 0.020 & 35.088 & 0.619 & 0.022 & 35.088 & 0.624 & 0.022 \\
\hline 29.825 & 0.549 & 0.016 & 33.333 & 0.625 & 0.021 & 35.088 & 0.619 & 0.022 & 35.088 & 0.628 & 0.022 \\
\hline 31.579 & 0.546 & 0.017 & 35.088 & 0.621 & 0.022 & 36.842 & 0.615 & 0.023 & 36.842 & 0.620 & 0.023 \\
\hline 33.333 & 0.544 & 0.018 & 35.088 & 0.610 & 0.021 & 38.596 & 0.609 & 0.024 & 38.596 & 0.618 & 0.024 \\
\hline 35.088 & 0.535 & 0.019 & 35.088 & 0.611 & 0.021 & 40.351 & 0.605 & 0.024 & 40.351 & 0.614 & 0.025 \\
\hline 35.088 & 0.541 & 0.019 & 36.842 & 0.618 & 0.023 & 42.105 & 0.602 & 0.025 & 42.105 & 0.610 & 0.026 \\
\hline 36.842 & 0.529 & 0.019 & 38.596 & 0.614 & 0.024 & 43.860 & 0.597 & 0.026 & 43.860 & 0.606 & 0.027 \\
\hline 38.596 & 0.524 & 0.020 & 40.351 & 0.610 & 0.025 & 45.614 & 0.592 & 0.027 & 45.614 & 0.602 & 0.027 \\
\hline 40.351 & 0.522 & 0.021 & 42.105 & 0.606 & 0.026 & 47.368 & 0.587 & 0.028 & 47.368 & 0.600 & 0.028 \\
\hline 42.105 & 0.515 & 0.022 & 43.860 & 0.602 & 0.026 & 49.123 & 0.583 & 0.029 & 49.123 & 0.596 & 0.029 \\
\hline 43.860 & 0.512 & 0.022 & 43.860 & 0.580 & 0.025 & 50.877 & 0.579 & 0.029 & 50.877 & 0.593 & 0.030 \\
\hline 43.860 & 0.505 & 0.022 & 45.614 & 0.599 & 0.027 & 52.632 & 0.575 & 0.030 & 52.632 & 0.589 & 0.031 \\
\hline 45.614 & 0.509 & 0.023 & 47.368 & 0.594 & 0.028 & 52.632 & 0.569 & 0.030 & 52.632 & 0.585 & 0.031 \\
\hline 47.368 & 0.507 & 0.024 & 49.123 & 0.592 & 0.029 & 56.140 & 0.566 & 0.032 & 56.140 & 0.582 & 0.033 \\
\hline 49.123 & 0.501 & 0.025 & 50.877 & 0.588 & 0.030 & 59.649 & 0.559 & 0.033 & 59.649 & 0.575 & 0.034 \\
\hline 50.877 & 0.497 & 0.025 & 52.632 & 0.584 & 0.031 & 63.158 & 0.550 & 0.035 & 63.158 & 0.568 & 0.036 \\
\hline 52.632 & 0.492 & 0.026 & 52.632 & 0.552 & 0.029 & 66.667 & 0.543 & 0.036 & 66.667 & 0.562 & 0.037 \\
\hline 52.632 & 0.473 & 0.025 & 56.140 & 0.575 & 0.032 & 70.175 & 0.536 & 0.038 & 70.175 & 0.555 & 0.039 \\
\hline 54.386 & 0.490 & 0.027 & 59.649 & 0.569 & 0.034 & 70.175 & 0.519 & 0.036 & 70.175 & 0.544 & 0.038 \\
\hline 56.140 & 0.482 & 0.027 & 61.404 & 0.526 & 0.032 & 70.175 & 0.522 & 0.037 & 73.684 & 0.548 & 0.040 \\
\hline 57.895 & 0.477 & 0.028 & 63.158 & 0.559 & 0.035 & 73.684 & 0.527 & 0.039 & 77.193 & 0.541 & 0.042 \\
\hline 59.649 & 0.478 & 0.029 & 66.667 & 0.553 & 0.037 & 77.193 & 0.519 & 0.040 & 80.702 & 0.535 & 0.043 \\
\hline 61.404 & 0.474 & 0.029 & 70.175 & 0.547 & 0.038 & 80.702 & 0.512 & 0.041 & 84.211 & 0.528 & 0.044 \\
\hline 63.158 & 0.464 & 0.029 & 70.175 & 0.493 & 0.035 & 84.211 & 0.503 & 0.042 & 87.719 & 0.522 & 0.046 \\
\hline 64.912 & 0.456 & 0.030 & 70.175 & 0.497 & 0.035 & 87.719 & 0.496 & 0.044 & 87.719 & 0.501 & 0.044 \\
\hline 66.667 & 0.455 & 0.030 & 73.684 & 0.540 & 0.040 & 91.228 & 0.488 & 0.045 & 91.228 & 0.516 & 0.047 \\
\hline 68.421 & 0.455 & 0.031 & 77.193 & 0.532 & 0.041 & 94.737 & 0.480 & 0.045 & 94.737 & 0.508 & 0.048 \\
\hline 70.175 & 0.452 & 0.032 & 80.702 & 0.524 & 0.042 & 98.246 & 0.475 & 0.047 & 98.246 & 0.501 & 0.049 \\
\hline 70.175 & 0.404 & 0.028 & 84.211 & 0.517 & 0.044 & 100.000 & 0.467 & 0.047 & 101.754 & 0.495 & 0.050 \\
\hline 71.930 & 0.450 & 0.032 & 87.719 & 0.509 & 0.045 & 100.000 & 0.466 & 0.047 & 101.754 & 0.492 & 0.050 \\
\hline 73.684 & 0.431 & 0.032 & 91.228 & 0.500 & 0.046 & 101.754 & 0.461 & 0.047 & 105.263 & 0.485 & 0.051 \\
\hline 75.439 & 0.441 & 0.033 & 94.737 & 0.488 & 0.046 & 105.263 & 0.455 & 0.048 & 108.772 & 0.477 & 0.052 \\
\hline 75.439 & 0.425 & 0.032 & 98.246 & 0.479 & 0.047 & 108.772 & 0.446 & 0.049 & 112.281 & 0.47 & 0.053 \\
\hline 77.193 & 0.428 & 0.033 & 101.754 & 0.461 & 0.047 & 112.281 & 0.434 & 0.049 & 115.789 & 0.463 & 0.054 \\
\hline 77.193 & 0.439 & 0.034 & 105.263 & 0.445 & 0.047 & 115.789 & 0.424 & 0.049 & 119.298 & 0.455 & 0.054 \\
\hline 78.947 & 0.432 & 0.034 & 108.772 & 0.429 & 0.047 & 119.298 & 0.417 & 0.050 & 122.807 & 0.445 & 0.055 \\
\hline 78.947 & 0.370 & 0.029 & 112.281 & 0.413 & 0.046 & 122.807 & 0.406 & 0.050 & 126.316 & 0.437 & 0.055 \\
\hline 80.702 & 0.428 & 0.035 & 115.789 & 0.335 & 0.039 & 126.316 & 0.395 & 0.050 & 129.825 & 0.426 & 0.055 \\
\hline 82.456 & 0.400 & 0.033 & 115.789 & 0.34 & 0.039 & 129.825 & 0.380 & 0.049 & 133.333 & 0.416 & 0.055 \\
\hline 84.211 & 0.420 & 0.035 & 122.807 & 0.237 & 0.029 & 133.333 & 0.365 & 0.049 & 136.842 & 0.405 & 0.055 \\
\hline 85.965 & 0.377 & 0.032 & & & & 136.842 & 0.345 & 0.047 & 140.351 & 0.39 & 0.055 \\
\hline 87.719 & 0.412 & 0.036 & & & & 140.351 & 0.33 & 0.046 & 143.860 & 0.373 & 0.054 \\
\hline
\end{tabular}




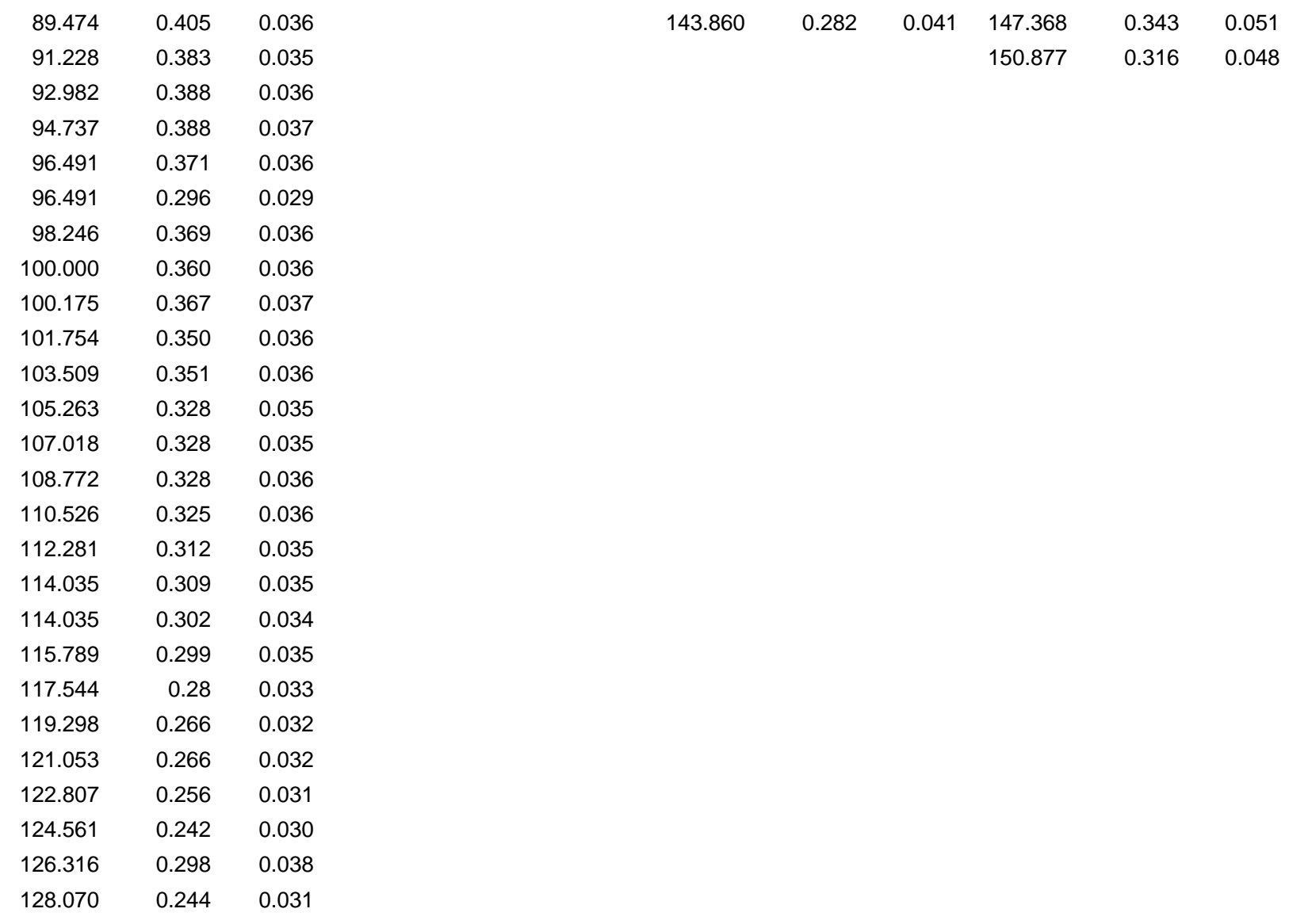

Graphite Rod, Air Flow Rate Varied, $\mathrm{T}=600^{\circ} \mathrm{C}, 1 / 12 / 2006$

\begin{tabular}{|c|c|c|c|c|c|c|c|c|c|c|c|}
\hline \multicolumn{3}{|c|}{$\mathrm{RM}=40(1), \mathrm{T}=600$} & \multicolumn{3}{|c|}{$\mathrm{RM}=40(2), \mathrm{T}=600$} & \multicolumn{3}{|c|}{$\mathrm{RM}=50, \mathrm{~T}=600$} & \multicolumn{3}{|c|}{$\mathrm{RM}=65, \mathrm{~T}=600$} \\
\hline I/SA & VCELL & P/SA & I/SA & VCELL & P/SA & I/SA & VCELL & P/SA & I/SA & VCELL & P/SA \\
\hline 1.155 & 0.683 & 0.001 & 1.155 & 0.747 & 0.001 & 1.155 & 0.748 & 0.001 & 1.155 & 0.756 & 0.001 \\
\hline 1.155 & 0.727 & 0.001 & 3.851 & 0.738 & 0.003 & 1.348 & 0.730 & 0.001 & 3.851 & 0.748 & 0.003 \\
\hline 3.851 & 0.675 & 0.003 & 5.776 & 0.733 & 0.004 & 3.851 & 0.723 & 0.003 & 5.776 & 0.744 & 0.004 \\
\hline 5.776 & 0.668 & 0.004 & 7.701 & 0.728 & 0.006 & 5.776 & 0.718 & 0.004 & 7.701 & 0.740 & 0.006 \\
\hline 7.701 & 0.662 & 0.005 & 9.626 & 0.722 & 0.007 & 7.701 & 0.714 & 0.005 & 9.626 & 0.735 & 0.007 \\
\hline 9.626 & 0.656 & 0.006 & 11.552 & 0.716 & 0.008 & 9.626 & 0.709 & 0.007 & 11.552 & 0.730 & 0.008 \\
\hline 9.626 & 0.698 & 0.007 & 13.477 & 0.710 & 0.010 & 11.552 & 0.705 & 0.008 & 13.477 & 0.725 & 0.010 \\
\hline 10.974 & 0.644 & 0.007 & 15.402 & 0.705 & 0.011 & 13.477 & 0.698 & 0.009 & 15.402 & 0.721 & 0.011 \\
\hline 10.974 & 0.652 & 0.007 & 17.328 & 0.699 & 0.012 & 15.402 & 0.695 & 0.011 & 15.402 & 0.721 & 0.011 \\
\hline 11.552 & 0.649 & 0.007 & 19.253 & 0.694 & 0.013 & 17.328 & 0.690 & 0.012 & 17.328 & 0.715 & 0.012 \\
\hline 13.477 & 0.642 & 0.009 & 21.178 & 0.689 & 0.015 & 19.253 & 0.686 & 0.013 & 19.253 & 0.710 & 0.014 \\
\hline 14.440 & 0.683 & 0.010 & 23.104 & 0.683 & 0.016 & 19.253 & 0.695 & 0.013 & 21.178 & 0.706 & 0.015 \\
\hline 15.402 & 0.638 & 0.010 & 25.029 & 0.679 & 0.017 & 21.178 & 0.682 & 0.014 & 23.104 & 0.702 & 0.016 \\
\hline 17.328 & 0.633 & 0.011 & 26.954 & 0.672 & 0.018 & 23.104 & 0.677 & 0.016 & 25.029 & 0.697 & 0.017 \\
\hline 19.253 & 0.628 & 0.012 & 28.879 & 0.668 & 0.019 & 25.029 & 0.673 & 0.017 & 26.954 & 0.694 & 0.019 \\
\hline 19.253 & 0.667 & 0.013 & 30.805 & 0.663 & 0.020 & 26.954 & 0.669 & 0.018 & 26.954 & 0.689 & 0.019 \\
\hline 21.178 & 0.621 & 0.013 & 32.730 & 0.659 & 0.022 & 28.879 & 0.665 & 0.019 & 28.879 & 0.684 & 0.020 \\
\hline 23.104 & 0.616 & 0.014 & 34.655 & 0.653 & 0.023 & 30.805 & 0.660 & 0.020 & 30.805 & 0.680 & 0.021 \\
\hline 24.066 & 0.655 & 0.016 & 36.581 & 0.650 & 0.024 & 32.730 & 0.656 & 0.021 & 32.730 & 0.676 & 0.022 \\
\hline 25.029 & 0.611 & 0.015 & 38.506 & 0.645 & 0.025 & 34.655 & 0.653 & 0.023 & 34.655 & 0.672 & 0.023 \\
\hline 26.954 & 0.606 & 0.016 & 40.431 & 0.640 & 0.026 & 36.581 & 0.649 & 0.024 & 36.581 & 0.669 & 0.024 \\
\hline
\end{tabular}




\begin{tabular}{|c|c|c|c|c|c|c|c|c|c|c|c|}
\hline 28.879 & 0.601 & 0.017 & 42.357 & 0.636 & 0.027 & 38.506 & 0.644 & 0.025 & 38.506 & 0.664 & 0.026 \\
\hline 28.879 & 0.640 & 0.018 & 44.282 & 0.632 & 0.028 & 40.431 & 0.640 & 0.026 & 40.431 & 0.661 & 0.027 \\
\hline 30.805 & 0.596 & 0.018 & 46.207 & 0.625 & 0.029 & 42.357 & 0.636 & 0.027 & 42.357 & 0.658 & 0.028 \\
\hline 32.730 & 0.590 & 0.019 & 48.132 & 0.622 & 0.030 & 44.282 & 0.632 & 0.028 & 44.282 & 0.654 & 0.029 \\
\hline 33.693 & 0.629 & 0.021 & 50.058 & 0.618 & 0.031 & 48.132 & 0.624 & 0.030 & 46.207 & 0.649 & 0.030 \\
\hline 34.655 & 0.586 & 0.020 & 51.983 & 0.612 & 0.032 & 50.058 & 0.620 & 0.031 & 48.132 & 0.646 & 0.031 \\
\hline 36.581 & 0.582 & 0.021 & 53.908 & 0.609 & 0.033 & 51.983 & 0.617 & 0.032 & 50.058 & 0.642 & 0.032 \\
\hline 38.506 & 0.578 & 0.022 & 55.834 & 0.605 & 0.034 & 53.908 & 0.613 & 0.033 & 51.983 & 0.638 & 0.033 \\
\hline 38.506 & 0.617 & 0.024 & 57.759 & 0.598 & 0.035 & 55.834 & 0.609 & 0.034 & 53.908 & 0.634 & 0.034 \\
\hline 40.431 & 0.574 & 0.023 & 61.610 & 0.591 & 0.036 & 57.759 & 0.605 & 0.035 & 55.834 & 0.630 & 0.035 \\
\hline 42.357 & 0.568 & 0.024 & 65.460 & 0.580 & 0.038 & 59.684 & 0.601 & 0.036 & 57.759 & 0.626 & 0.036 \\
\hline 44.282 & 0.567 & 0.025 & 69.311 & 0.577 & 0.040 & 61.610 & 0.598 & 0.037 & 61.610 & 0.619 & 0.038 \\
\hline 46.207 & 0.561 & 0.026 & 73.161 & 0.566 & 0.041 & 65.460 & 0.589 & 0.039 & 65.460 & 0.612 & 0.040 \\
\hline 48.132 & 0.556 & 0.027 & 77.012 & 0.559 & 0.043 & 69.311 & 0.581 & 0.040 & 69.311 & 0.604 & 0.042 \\
\hline 48.132 & 0.593 & 0.029 & 80.863 & 0.550 & 0.044 & 73.161 & 0.574 & 0.042 & 73.161 & 0.597 & 0.044 \\
\hline 50.058 & 0.553 & 0.028 & 84.713 & 0.543 & 0.046 & 77.012 & 0.566 & 0.044 & 77.012 & 0.589 & 0.045 \\
\hline 51.983 & 0.550 & 0.029 & 88.564 & 0.531 & 0.047 & 80.863 & 0.557 & 0.045 & 80.863 & 0.582 & 0.047 \\
\hline 53.908 & 0.546 & 0.029 & 92.414 & 0.518 & 0.048 & 84.713 & 0.549 & 0.047 & 84.713 & 0.574 & 0.049 \\
\hline 55.834 & 0.543 & 0.030 & 94.340 & 0.518 & 0.049 & 86.638 & 0.545 & 0.047 & 86.638 & 0.569 & 0.049 \\
\hline 57.759 & 0.539 & 0.031 & 96.265 & 0.515 & 0.050 & 88.564 & 0.538 & 0.048 & 88.564 & 0.565 & 0.050 \\
\hline 57.759 & 0.572 & 0.033 & 96.265 & 0.515 & 0.050 & 92.414 & 0.529 & 0.049 & 92.414 & 0.555 & 0.051 \\
\hline 59.684 & 0.533 & 0.032 & 100.116 & 0.503 & 0.050 & 94.340 & 0.522 & 0.049 & 96.265 & 0.546 & 0.053 \\
\hline 61.610 & 0.530 & 0.033 & 103.966 & 0.493 & 0.051 & 96.265 & 0.536 & 0.052 & 98.190 & 0.544 & 0.053 \\
\hline 65.460 & 0.524 & 0.034 & 107.817 & 0.484 & 0.052 & 96.265 & 0.518 & 0.050 & 100.116 & 0.538 & 0.054 \\
\hline 67.385 & 0.550 & 0.037 & 111.667 & 0.462 & 0.052 & 100.116 & 0.506 & 0.051 & 103.966 & 0.528 & 0.055 \\
\hline 69.311 & 0.512 & 0.035 & 115.518 & 0.462 & 0.053 & 103.966 & 0.490 & 0.051 & 105.891 & 0.523 & 0.055 \\
\hline 73.161 & 0.508 & 0.037 & 119.369 & 0.450 & 0.054 & 105.891 & 0.486 & 0.051 & 107.817 & 0.516 & 0.056 \\
\hline 77.012 & 0.500 & 0.039 & 123.027 & 0.430 & 0.053 & 107.817 & 0.508 & 0.055 & 109.742 & 0.507 & 0.056 \\
\hline 77.012 & 0.531 & 0.041 & 125.144 & 0.420 & 0.053 & 107.817 & 0.479 & 0.052 & 111.667 & 0.503 & 0.056 \\
\hline 80.863 & 0.490 & 0.040 & 128.995 & 0.388 & 0.050 & 107.817 & 0.486 & 0.052 & 115.518 & 0.487 & 0.056 \\
\hline 84.713 & 0.486 & 0.041 & 132.846 & 0.372 & 0.049 & 109.742 & 0.467 & 0.051 & 117.058 & 0.478 & 0.056 \\
\hline 86.638 & 0.512 & 0.044 & 134.963 & 0.350 & 0.047 & 111.667 & 0.486 & 0.054 & 115.518 & 0.478 & 0.055 \\
\hline 88.564 & 0.478 & 0.042 & & & & 111.667 & 0.488 & 0.054 & 117.443 & 0.464 & 0.054 \\
\hline 92.414 & 0.470 & 0.043 & & & & 113.593 & 0.436 & 0.050 & 119.369 & 0.453 & 0.054 \\
\hline 96.265 & 0.460 & 0.044 & & & & 115.518 & 0.470 & 0.054 & 121.294 & 0.433 & 0.053 \\
\hline 96.265 & 0.490 & 0.047 & & & & 115.518 & 0.408 & 0.047 & 125.144 & 0.4 & 0.050 \\
\hline 100.116 & 0.452 & 0.045 & & & & 117.443 & 0.384 & 0.045 & 127.070 & 0.33 & 0.042 \\
\hline
\end{tabular}


Graphite Rod, Air Flow Rate Varied, $\mathrm{T}=600^{\circ} \mathrm{C}, 1 / 25 / 2006$

\begin{tabular}{|c|c|c|c|c|c|c|c|c|}
\hline \multicolumn{3}{|c|}{$\mathrm{RM}=40, \mathrm{~T}=600$} & \multicolumn{3}{|c|}{$\mathrm{RM}=50, \mathrm{~T}=600$} & \multicolumn{3}{|c|}{$\mathrm{RM}=65, \mathrm{~T}=600$} \\
\hline I/SA & VCELL & $\mathrm{P} / \mathrm{SA}$ & $\mathrm{I} / \mathrm{SA}$ & VCELL & $\mathrm{P} / \mathrm{SA}$ & $\mathrm{I} / \mathrm{SA}$ & VCELL & P/SA \\
\hline 0.322 & 0.728 & 0.000 & 0.242 & 0.746 & 0.000 & 0.322 & 0.728 & 0.000 \\
\hline 0.967 & 0.696 & 0.001 & 0.242 & 0.742 & 0.000 & 0.322 & 0.732 & 0.000 \\
\hline 0.967 & 0.703 & 0.001 & 0.322 & 0.746 & 0.000 & 0.322 & 0.729 & 0.000 \\
\hline 0.967 & 0.694 & 0.001 & 0.322 & 0.741 & 0.000 & 0.322 & 0.753 & 0.000 \\
\hline 1.450 & 0.687 & 0.001 & 0.967 & 0.709 & 0.001 & 0.322 & 0.749 & 0.000 \\
\hline 3.142 & 0.684 & 0.002 & 0.967 & 0.709 & 0.001 & 1.531 & 0.728 & 0.001 \\
\hline 4.753 & 0.673 & 0.003 & 0.967 & 0.708 & 0.001 & 3.142 & 0.726 & 0.002 \\
\hline 6.364 & 0.672 & 0.004 & 1.531 & 0.704 & 0.001 & 3.142 & 0.723 & 0.002 \\
\hline 7.975 & 0.658 & 0.005 & 3.142 & 0.695 & 0.002 & 3.142 & 0.723 & 0.002 \\
\hline 7.975 & 0.696 & 0.006 & 4.833 & 0.693 & 0.003 & 4.753 & 0.718 & 0.003 \\
\hline 9.667 & 0.656 & 0.006 & 6.364 & 0.687 & 0.004 & 6.444 & 0.718 & 0.005 \\
\hline 11.197 & 0.652 & 0.007 & 7.975 & 0.681 & 0.005 & 7.975 & 0.725 & 0.006 \\
\hline 12.889 & 0.650 & 0.008 & 7.975 & 0.718 & 0.006 & 8.055 & 0.709 & 0.006 \\
\hline 14.500 & 0.644 & 0.009 & 9.667 & 0.678 & 0.007 & 9.586 & 0.702 & 0.007 \\
\hline 16.111 & 0.640 & 0.010 & 11.278 & 0.670 & 0.008 & 9.586 & 0.702 & 0.007 \\
\hline 16.191 & 0.661 & 0.011 & 12.808 & 0.664 & 0.009 & 11.278 & 0.699 & 0.008 \\
\hline 17.641 & 0.634 & 0.011 & 14.580 & 0.660 & 0.010 & 12.808 & 0.691 & 0.009 \\
\hline 19.333 & 0.628 & 0.012 & 16.030 & 0.655 & 0.010 & 14.500 & 0.690 & 0.010 \\
\hline 19.333 & 0.627 & 0.012 & 16.111 & 0.680 & 0.011 & 16.111 & 0.687 & 0.011 \\
\hline 20.944 & 0.626 & 0.013 & 17.641 & 0.650 & 0.011 & 16.111 & 0.697 & 0.011 \\
\hline 22.636 & 0.619 & 0.014 & 19.333 & 0.644 & 0.012 & 17.722 & 0.680 & 0.012 \\
\hline 24.166 & 0.614 & 0.015 & 20.944 & 0.638 & 0.013 & 19.333 & 0.675 & 0.013 \\
\hline 24.166 & 0.629 & 0.015 & 22.636 & 0.634 & 0.014 & 20.864 & 0.671 & 0.014 \\
\hline 25.777 & 0.608 & 0.016 & 24.086 & 0.649 & 0.016 & 22.636 & 0.669 & 0.015 \\
\hline 27.388 & 0.604 & 0.017 & 24.166 & 0.628 & 0.015 & 24.166 & 0.662 & 0.016 \\
\hline 29.080 & 0.599 & 0.017 & 25.777 & 0.623 & 0.016 & 24.247 & 0.667 & 0.016 \\
\hline 30.691 & 0.592 & 0.018 & 27.388 & 0.619 & 0.017 & 25.858 & 0.660 & 0.017 \\
\hline 32.222 & 0.588 & 0.019 & 29.080 & 0.612 & 0.018 & 27.469 & 0.653 & 0.018 \\
\hline 32.222 & 0.598 & 0.019 & 30.611 & 0.609 & 0.019 & 29.000 & 0.648 & 0.019 \\
\hline 33.913 & 0.580 & 0.020 & 32.302 & 0.605 & 0.020 & 30.691 & .644 & 0.020 \\
\hline 35.524 & 0.576 & 0.020 & 32.302 & 0.618 & 0.020 & 32.222 & 0.639 & 0.021 \\
\hline 37.135 & 0.571 & 0.021 & 33.833 & 0.599 & 0.020 & 32.222 & 0.639 & 0.021 \\
\hline 38.747 & 0.565 & 0.022 & 35.444 & 0.596 & 0.021 & 33.833 & 0.637 & 0.022 \\
\hline 40.438 & 0.560 & 0.023 & 37.216 & 0.590 & 0.022 & 35.524 & 0.633 & 0.022 \\
\hline 40.438 & 0.564 & 0.023 & 38.747 & 0.586 & 0.023 & 37.135 & 0.630 & 0.023 \\
\hline 41.969 & 0.556 & 0.023 & 40.277 & 0.588 & 0.024 & 38.666 & 0.625 & 0.024 \\
\hline 43.580 & 0.549 & 0.024 & 40.358 & 0.581 & 0.023 & 40.277 & 0.607 & 0.024 \\
\hline 45.110 & 0.546 & 0.025 & 41.969 & 0.578 & 0.024 & 40.358 & 0.618 & 0.025 \\
\hline 46.802 & 0.536 & 0.025 & 43.580 & 0.573 & 0.025 & 41.969 & 0.615 & 0.026 \\
\hline 48.413 & 0.529 & 0.026 & 45.191 & 0.570 & 0.026 & 43.580 & 0.611 & 0.027 \\
\hline 48.494 & 0.534 & 0.026 & 46.802 & 0.566 & 0.026 & 45.191 & 0.606 & 0.027 \\
\hline 51.635 & 0.520 & 0.027 & 48.413 & 0.552 & 0.027 & 46.802 & 0.601 & 0.028 \\
\hline 54.938 & 0.504 & 0.028 & 48.494 & 0.561 & 0.027 & 48.413 & 0.575 & 0.028 \\
\hline 56.630 & 0.500 & 0.028 & 48.574 & 0.586 & 0.028 & 48.494 & 0.596 & 0.029 \\
\hline 58.160 & 0.494 & 0.029 & 50.024 & 0.558 & 0.028 & 50.105 & 0.592 & 0.030 \\
\hline 61.463 & 0.487 & 0.030 & 51.716 & 0.554 & 0.029 & 51.716 & 0.588 & 0.030 \\
\hline 64.524 & 0.460 & 0.030 & 53.246 & 0.550 & 0.029 & 53.327 & 0.582 & 0.031 \\
\hline 64.604 & 0.474 & 0.031 & 54.857 & 0.547 & 0.030 & 56.469 & 0.571 & 0.032 \\
\hline 67.827 & 0.467 & 0.032 & 56.549 & 0.542 & 0.031 & 56.549 & 0.535 & 0.030 \\
\hline 71.049 & 0.459 & 0.033 & 56.630 & 0.518 & 0.029 & 58.160 & 0.565 & 0.033 \\
\hline 72.740 & 0.415 & 0.030 & 58.160 & 0.536 & 0.031 & 59.771 & 0.560 & 0.033 \\
\hline
\end{tabular}




\begin{tabular}{|c|c|c|c|c|c|c|c|c|}
\hline 74.271 & 0.443 & 0.033 & 59.691 & 0.534 & 0.032 & 62.913 & 0.544 & 0.034 \\
\hline 77.574 & 0.432 & 0.034 & 61.463 & 0.528 & 0.032 & 64.604 & 0.536 & 0.035 \\
\hline 80.715 & 0.420 & 0.034 & 62.993 & 0.525 & 0.033 & 64.604 & 0.487 & 0.031 \\
\hline 80.796 & 0.363 & 0.029 & 64.604 & 0.520 & 0.034 & 66.296 & 0.529 & 0.035 \\
\hline 84.018 & 0.408 & 0.034 & 64.604 & 0.474 & 0.031 & 67.907 & 0.524 & 0.036 \\
\hline 87.240 & 0.387 & 0.034 & 67.827 & 0.510 & 0.035 & 70.968 & 0.511 & 0.036 \\
\hline 90.462 & 0.375 & 0.034 & 71.049 & 0.503 & 0.036 & 73.385 & 0.356 & 0.026 \\
\hline 90.543 & 0.305 & 0.028 & 72.660 & 0.426 & 0.031 & 74.271 & 0.489 & 0.036 \\
\hline 93.765 & 0.360 & 0.034 & 74.271 & 0.490 & 0.036 & 77.574 & 0.445 & 0.035 \\
\hline 95.376 & 0.300 & 0.029 & 75.963 & 0.483 & 0.037 & 80.796 & 0.390 & 0.032 \\
\hline 96.907 & 0.280 & 0.027 & 77.493 & 0.477 & 0.037 & 84.018 & 0.339 & 0.028 \\
\hline \multirow[t]{8}{*}{98.759} & 0.239 & 0.024 & 80.715 & 0.356 & 0.029 & & & \\
\hline & & & 80.796 & 0.459 & 0.037 & & & \\
\hline & & & 84.099 & 0.446 & 0.038 & & & \\
\hline & & & 87.240 & 0.431 & 0.038 & & & \\
\hline & & & 88.851 & 0.317 & 0.028 & & & \\
\hline & & & 90.462 & 0.395 & 0.036 & & & \\
\hline & & & 93.685 & 0.333 & 0.031 & & & \\
\hline & & & 96.907 & 0.253 & 0.025 & & & \\
\hline Time & $\begin{array}{c}\text { Temp } \\
\left({ }^{\circ} \mathrm{C}\right)\end{array}$ & VCELL & VANODE & VCATHODE & $I(A)$ & $\begin{array}{c}\text { I } \\
(\mathrm{mA})\end{array}$ & I/SA & \\
\hline $16: 50: 00$ & 600 & 0.607 & -0.662 & -0.055 & 2.000 & 2000 & 32.222 & \\
\hline $16: 55: 00$ & 600 & 0.612 & -0.661 & -0.049 & 2.000 & 2000 & 32.222 & \\
\hline $17: 00: 00$ & 600 & 0.619 & -0.664 & -0.045 & 2.000 & 2000 & 32.222 & \\
\hline 17:05:00 & 600 & 0.618 & -0.662 & -0.044 & 2.000 & 2000 & 32.222 & \\
\hline 17:10:00 & 599 & 0.620 & -0.662 & -0.042 & 2.000 & 2000 & 32.222 & \\
\hline $17: 15: 00$ & 599 & 0.620 & -0.663 & -0.043 & 2.000 & 2000 & 32.222 & \\
\hline $17: 20: 00$ & 599 & 0.620 & -0.663 & -0.043 & 2.000 & 2000 & 32.222 & \\
\hline $17: 25: 00$ & 600 & 0.619 & -0.663 & -0.044 & 2.000 & 2000 & 32.222 & \\
\hline 17:30:00 & 599 & 0.621 & -0.663 & -0.042 & 2.000 & 2000 & 32.222 & \\
\hline $17: 35: 00$ & 600 & 0.618 & -0.663 & -0.045 & 2.000 & 2000 & 32.222 & \\
\hline $17: 40: 00$ & 599 & 0.617 & -0.659 & -0.042 & 2.000 & 2000 & 32.222 & \\
\hline $17: 45: 00$ & 600 & 0.616 & -0.661 & -0.045 & 2.000 & 2000 & 32.222 & \\
\hline 17:50:00 & 600 & 0.615 & -0.661 & -0.046 & 2.000 & 2000 & 32.222 & \\
\hline 17:55:00 & 599 & 0.616 & -0.661 & -0.045 & 2.000 & 2000 & 32.222 & \\
\hline 18:00:00 & 600 & 0.616 & -0.663 & -0.047 & 2.000 & 2000 & 32.222 & \\
\hline 18:05:00 & 600 & 0.618 & -0.663 & -0.045 & 2.000 & 2000 & 32.222 & \\
\hline 18:10:00 & 599 & 0.619 & -0.663 & -0.044 & 2.000 & 2000 & 32.222 & \\
\hline $18: 15: 00$ & 600 & 0.619 & -0.666 & -0.047 & 2.000 & 2000 & 32.222 & \\
\hline $18: 20: 00$ & 599 & 0.621 & -0.666 & -0.045 & 2.000 & 2000 & 32.222 & \\
\hline $18: 25: 00$ & 599 & 0.618 & -0.665 & -0.047 & 2.000 & 2000 & 32.222 & \\
\hline 18:30:00 & 600 & 0.620 & -0.667 & -0.047 & 2.000 & 2000 & 32.222 & \\
\hline $18: 35: 00$ & 600 & 0.619 & -0.665 & -0.046 & 2.000 & 2000 & 32.222 & \\
\hline 18:40:00 & 599 & 0.621 & -0.666 & -0.045 & 2.000 & 2000 & 32.222 & \\
\hline $18: 45: 00$ & 599 & 0.619 & -0.666 & -0.047 & 2.000 & 2000 & 32.222 & \\
\hline $18: 50: 00$ & 599 & 0.619 & -0.666 & -0.047 & 2.000 & 2000 & 32.222 & \\
\hline $18: 55: 00$ & 599 & 0.619 & -0.665 & -0.046 & 2.000 & 2000 & 32.222 & \\
\hline 19:00:00 & 599 & 0.619 & -0.667 & -0.048 & 2.000 & 2000 & 32.222 & \\
\hline 19:05:00 & 599 & 0.622 & -0.669 & -0.047 & 2.000 & 2000 & 32.222 & \\
\hline $19: 10: 00$ & 599 & 0.621 & -0.668 & -0.047 & 2.000 & 2000 & 32.222 & \\
\hline $19: 15: 00$ & 599 & 0.623 & -0.668 & -0.045 & 2.000 & 2000 & 32.222 & \\
\hline 19:20:00 & 599 & 0.622 & -0.669 & -0.047 & 2.000 & 2000 & 32.222 & \\
\hline $19: 25: 00$ & 599 & 0.623 & -0.669 & -0.046 & 2.000 & 2000 & 32.222 & \\
\hline 19:30:00 & 599 & 0.622 & -0.668 & -0.046 & 2.000 & 2000 & 32.222 & \\
\hline 19:35:00 & 599 & 0.622 & -0.670 & -0.048 & 2.000 & 2000 & 32.222 & \\
\hline $19: 40: 00$ & 599 & 0.622 & -0.671 & -0.049 & 2.000 & 2000 & 32.222 & \\
\hline $19: 45: 00$ & 599 & 0.624 & -0.668 & -0.044 & 2.000 & 2000 & 32.222 & \\
\hline $19: 50: 00$ & 599 & 0.624 & -0.671 & -0.047 & 2.000 & 2000 & 32.222 & \\
\hline $19: 55: 00$ & 599 & 0.624 & -0.671 & -0.047 & 2.000 & 2000 & 32.222 & \\
\hline 20:00:00 & 599 & 0.626 & -0.671 & -0.045 & 2.000 & 2000 & 32.222 & \\
\hline 20:05:00 & 599 & 0.624 & -0.671 & -0.047 & 2.000 & 2000 & 32.222 & \\
\hline
\end{tabular}




\begin{tabular}{|c|c|c|c|c|c|c|c|}
\hline $20: 10: 00$ & 600 & 0.625 & -0.671 & -0.046 & 2.000 & 2000 & 32.222 \\
\hline 20:15:00 & 600 & 0.625 & -0.671 & -0.046 & 2.000 & 2000 & 32.222 \\
\hline 20:20:00 & 600 & 0.624 & -0.672 & -0.048 & 2.005 & 2005 & 32.302 \\
\hline 20:25:00 & 599 & 0.627 & -0.673 & -0.046 & 2.000 & 2000 & 32.222 \\
\hline 20:30:00 & 599 & 0.626 & -0.672 & -0.046 & 2.000 & 2000 & 32.222 \\
\hline $20: 35: 00$ & 599 & 0.624 & -0.673 & -0.049 & 2.005 & 2005 & 32.302 \\
\hline 20:40:00 & 600 & 0.625 & -0.671 & -0.046 & 2.005 & 2005 & 32.302 \\
\hline $20: 45: 00$ & 600 & 0.626 & -0.673 & -0.047 & 2.000 & 2000 & 32.222 \\
\hline 20:50:00 & 600 & 0.625 & -0.673 & -0.048 & 2.005 & 2005 & 32.302 \\
\hline 20:55:00 & 599 & 0.628 & -0.675 & -0.047 & 2.000 & 2000 & 32.222 \\
\hline 21:00:00 & 600 & 0.627 & -0.674 & -0.047 & 2.000 & 2000 & 32.222 \\
\hline $21: 05: 00$ & 600 & 0.628 & -0.674 & -0.046 & 2.000 & 2000 & 32.222 \\
\hline 21:10:00 & 599 & 0.626 & -0.675 & -0.049 & 2.005 & 2005 & 32.302 \\
\hline $21: 15: 00$ & 600 & 0.627 & -0.674 & -0.047 & 2.000 & 2000 & 32.222 \\
\hline $21: 20: 00$ & 600 & 0.629 & -0.674 & -0.045 & 2.005 & 2005 & 32.302 \\
\hline 21:25:00 & 599 & 0.628 & -0.676 & -0.048 & 2.000 & 2000 & 32.222 \\
\hline 21:30:00 & 599 & 0.628 & -0.676 & -0.048 & 2.000 & 2000 & 32.222 \\
\hline $21: 35: 00$ & 600 & 0.628 & -0.676 & -0.048 & 2.005 & 2005 & 32.302 \\
\hline 21:40:00 & 600 & 0.629 & -0.676 & -0.047 & 2.005 & 2005 & 32.302 \\
\hline 21:45:00 & 600 & 0.628 & -0.676 & -0.048 & 2.005 & 2005 & 32.302 \\
\hline 21:50:00 & 600 & 0.629 & -0.676 & -0.047 & 2.005 & 2005 & 32.302 \\
\hline 21:55:00 & 600 & 0.629 & -0.676 & -0.047 & 2.005 & 2005 & 32.302 \\
\hline 22:00:00 & 600 & 0.629 & -0.675 & -0.046 & 2.005 & 2005 & 32.302 \\
\hline 22:05:00 & 599 & 0.629 & -0.676 & -0.047 & 2.005 & 2005 & 32.302 \\
\hline 22:10:00 & 600 & 0.627 & -0.674 & -0.047 & 2.005 & 2005 & 32.302 \\
\hline 22:15:00 & 599 & 0.629 & -0.676 & -0.047 & 2.005 & 2005 & 32.302 \\
\hline 22:20:00 & 599 & 0.628 & -0.675 & -0.047 & 2.005 & 2005 & 32.302 \\
\hline $22: 25: 00$ & 599 & 0.628 & -0.675 & -0.047 & 2.005 & 2005 & 32.302 \\
\hline 22:30:00 & 600 & 0.626 & -0.675 & -0.049 & 2.005 & 2005 & 32.302 \\
\hline $22: 35: 00$ & 599 & 0.628 & -0.676 & -0.048 & 2.005 & 2005 & 32.302 \\
\hline $22: 40: 00$ & 600 & 0.627 & -0.676 & -0.049 & 2.005 & 2005 & 32.302 \\
\hline $22: 45: 00$ & 600 & 0.628 & -0.676 & -0.048 & 2.005 & 2005 & 32.302 \\
\hline 22:50:00 & 600 & 0.626 & -0.675 & -0.049 & 2.005 & 2005 & 32.302 \\
\hline 22:55:00 & 600 & 0.627 & -0.674 & -0.047 & 2.005 & 2005 & 32.302 \\
\hline 23:00:00 & 600 & 0.626 & -0.675 & -0.049 & 2.005 & 2005 & 32.302 \\
\hline 23:05:00 & 600 & 0.626 & -0.674 & -0.048 & 2.005 & 2005 & 32.302 \\
\hline $23: 10: 00$ & 600 & 0.626 & -0.676 & -0.050 & 2.005 & 2005 & 32.302 \\
\hline 23:15:00 & 599 & 0.625 & -0.672 & -0.047 & 2.005 & 2005 & 32.302 \\
\hline $23: 20: 00$ & 600 & 0.625 & -0.674 & -0.049 & 2.005 & 2005 & 32.302 \\
\hline $23: 25: 00$ & 600 & 0.624 & -0.673 & -0.049 & 2.005 & 2005 & 32.302 \\
\hline 23:30:00 & 599 & 0.624 & -0.672 & -0.048 & 2.005 & 2005 & 32.302 \\
\hline 23:35:00 & 600 & 0.624 & -0.672 & -0.048 & 2.005 & 2005 & 32.302 \\
\hline 23:40:00 & 600 & 0.623 & -0.672 & -0.049 & 2.005 & 2005 & 32.302 \\
\hline $23: 45: 00$ & 600 & 0.623 & -0.673 & -0.050 & 2.005 & 2005 & 32.302 \\
\hline 23:50:00 & 600 & 0.622 & -0.673 & -0.051 & 2.005 & 2005 & 32.302 \\
\hline 23:55:00 & 600 & 0.622 & -0.670 & -0.048 & 2.005 & 2005 & 32.302 \\
\hline 00:00:00 & 600 & 0.624 & -0.672 & -0.048 & 2.005 & 2005 & 32.302 \\
\hline 00:05:00 & 599 & 0.624 & -0.674 & -0.050 & 2.005 & 2005 & 32.302 \\
\hline 00:10:00 & 600 & 0.623 & -0.673 & -0.050 & 2.005 & 2005 & 32.302 \\
\hline 00:15:00 & 600 & 0.622 & -0.673 & -0.051 & 2.005 & 2005 & 32.302 \\
\hline 00:20:00 & 600 & 0.622 & -0.673 & -0.051 & 2.005 & 2005 & 32.302 \\
\hline $00: 25: 00$ & 600 & 0.623 & -0.672 & -0.049 & 2.005 & 2005 & 32.302 \\
\hline 00:30:00 & 600 & 0.621 & -0.673 & -0.052 & 2.005 & 2005 & 32.302 \\
\hline 00:35:00 & 599 & 0.622 & -0.671 & -0.049 & 2.005 & 2005 & 32.302 \\
\hline 00:40:00 & 600 & 0.622 & -0.671 & -0.049 & 2.005 & 2005 & 32.302 \\
\hline $00: 45: 00$ & 600 & 0.621 & -0.671 & -0.050 & 2.005 & 2005 & 32.302 \\
\hline 00:50:00 & 600 & 0.622 & -0.672 & -0.050 & 2.005 & 2005 & 32.302 \\
\hline 00:55:00 & 600 & 0.623 & -0.672 & -0.049 & 2.005 & 2005 & 32.302 \\
\hline 01:00:00 & 600 & 0.622 & -0.672 & -0.050 & 2.005 & 2005 & 32.302 \\
\hline 01:05:00 & 600 & 0.622 & -0.671 & -0.049 & 2.005 & 2005 & 32.302 \\
\hline 01:10:00 & 600 & 0.622 & -0.670 & -0.048 & 2.005 & 2005 & 32.302 \\
\hline 01:15:00 & 600 & 0.621 & -0.672 & -0.051 & 2.005 & 2005 & 32.302 \\
\hline 01:20:00 & 600 & 0.620 & -0.670 & -0.050 & 2.005 & 2005 & 32.302 \\
\hline
\end{tabular}




\begin{tabular}{|c|c|c|c|c|c|c|c|}
\hline $01: 25: 00$ & 600 & 0.620 & -0.670 & -0.050 & 2.005 & 2005 & 32.302 \\
\hline 01:30:00 & 600 & 0.620 & -0.671 & -0.051 & 2.005 & 2005 & 32.302 \\
\hline $01: 35: 00$ & 600 & 0.621 & -0.671 & -0.050 & 2.005 & 2005 & 32.302 \\
\hline 01:40:00 & 600 & 0.620 & -0.670 & -0.050 & 2.005 & 2005 & 32.302 \\
\hline 01:45:00 & 600 & 0.621 & -0.671 & -0.050 & 2.005 & 2005 & 32.302 \\
\hline 01:50:00 & 600 & 0.620 & -0.670 & -0.050 & 2.005 & 2005 & 32.302 \\
\hline 01:55:00 & 600 & 0.620 & -0.671 & -0.051 & 2.005 & 2005 & 32.302 \\
\hline 02:00:00 & 600 & 0.619 & -0.670 & -0.051 & 2.005 & 2005 & 32.302 \\
\hline 02:05:00 & 600 & 0.619 & -0.671 & -0.052 & 2.005 & 2005 & 32.302 \\
\hline 02:10:00 & 600 & 0.619 & -0.670 & -0.051 & 2.005 & 2005 & 32.302 \\
\hline 02:15:00 & 600 & 0.616 & -0.668 & -0.052 & 2.005 & 2005 & 32.302 \\
\hline 02:20:00 & 599 & 0.614 & -0.666 & -0.052 & 2.005 & 2005 & 32.302 \\
\hline $02: 25: 00$ & 600 & 0.613 & -0.665 & -0.052 & 2.005 & 2005 & 32.302 \\
\hline 02:30:00 & 600 & 0.612 & -0.665 & -0.053 & 2.005 & 2005 & 32.302 \\
\hline $02: 35: 00$ & 600 & 0.613 & -0.664 & -0.051 & 2.005 & 2005 & 32.302 \\
\hline $02: 40: 00$ & 600 & 0.611 & -0.663 & -0.052 & 2.005 & 2005 & 32.302 \\
\hline $02: 45: 00$ & 600 & 0.603 & -0.660 & -0.057 & 2.005 & 2005 & 32.302 \\
\hline 02:50:00 & 601 & 0.606 & -0.660 & -0.054 & 2.005 & 2005 & 32.302 \\
\hline $02: 55: 00$ & 599 & 0.602 & -0.657 & -0.055 & 2.005 & 2005 & 32.302 \\
\hline 03:00:00 & 600 & 0.600 & -0.657 & -0.057 & 2.005 & 2005 & 32.302 \\
\hline 03:05:00 & 600 & 0.606 & -0.658 & -0.052 & 2.005 & 2005 & 32.302 \\
\hline 03:10:00 & 599 & 0.597 & -0.653 & -0.056 & 2.005 & 2005 & 32.302 \\
\hline 03:15:00 & 600 & 0.600 & -0.652 & -0.052 & 2.005 & 2005 & 32.302 \\
\hline 03:20:00 & 600 & 0.597 & -0.652 & -0.055 & 2.005 & 2005 & 32.302 \\
\hline $03: 25: 00$ & 600 & 0.587 & -0.649 & -0.062 & 2.005 & 2005 & 32.302 \\
\hline 03:30:00 & 600 & 0.586 & -0.647 & -0.061 & 2.005 & 2005 & 32.302 \\
\hline 03:35:00 & 600 & 0.594 & -0.648 & -0.054 & 2.005 & 2005 & 32.302 \\
\hline 03:40:00 & 598 & 0.613 & -0.653 & -0.040 & 2.005 & 2005 & 32.302 \\
\hline $03: 45: 00$ & 601 & 0.618 & -0.666 & -0.048 & 2.005 & 2005 & 32.302 \\
\hline 03:50:00 & 600 & 0.613 & -0.662 & -0.049 & 2.005 & 2005 & 32.302 \\
\hline $03: 55: 00$ & 600 & 0.600 & -0.656 & -0.056 & 2.000 & 2000 & 32.222 \\
\hline 04:00:00 & 600 & 0.616 & -0.663 & -0.047 & 2.005 & 2005 & 32.302 \\
\hline 04:05:00 & 601 & 0.612 & -0.662 & -0.050 & 2.005 & 2005 & 32.302 \\
\hline 04:10:00 & 599 & 0.606 & -0.659 & -0.053 & 2.005 & 2005 & 32.302 \\
\hline $04: 15: 00$ & 600 & 0.606 & -0.656 & -0.050 & 2.005 & 2005 & 32.302 \\
\hline 04:20:00 & 601 & 0.607 & -0.658 & -0.051 & 2.005 & 2005 & 32.302 \\
\hline $04: 25: 00$ & 600 & 0.599 & -0.654 & -0.055 & 2.005 & 2005 & 32.302 \\
\hline 04:30:00 & 600 & 0.599 & -0.653 & -0.054 & 2.005 & 2005 & 32.302 \\
\hline $04: 35: 00$ & 601 & 0.607 & -0.651 & -0.044 & 2.005 & 2005 & 32.302 \\
\hline 04:40:00 & 601 & 0.597 & -0.654 & -0.057 & 2.005 & 2005 & 32.302 \\
\hline $04: 45: 00$ & 600 & 0.595 & -0.651 & -0.056 & 2.000 & 2000 & 32.222 \\
\hline 04:50:00 & 600 & 0.590 & -0.648 & -0.058 & 2.000 & 2000 & 32.222 \\
\hline 04:55:00 & 600 & 0.587 & -0.646 & -0.059 & 2.000 & 2000 & 32.222 \\
\hline 05:00:00 & 600 & 0.584 & -0.645 & -0.061 & 2.000 & 2000 & 32.222 \\
\hline 05:05:00 & 598 & 0.583 & -0.637 & -0.054 & 2.000 & 2000 & 32.222 \\
\hline 05:10:00 & 599 & 0.563 & -0.647 & -0.084 & 2.000 & 2000 & 32.222 \\
\hline $05: 15: 00$ & 601 & 0.529 & -0.635 & -0.106 & 2.000 & 2000 & 32.222 \\
\hline $05: 20: 00$ & 595 & 0.578 & -0.614 & -0.036 & 2.000 & 2000 & 32.222 \\
\hline $05: 25: 00$ & 604 & 0.558 & -0.654 & -0.096 & 2.000 & 2000 & 32.222 \\
\hline $05: 30: 00$ & 599 & 0.606 & -0.660 & -0.054 & 2.000 & 2000 & 32.222 \\
\hline $05: 35: 00$ & 601 & 0.579 & -0.649 & -0.070 & 2.000 & 2000 & 32.222 \\
\hline $05: 40: 00$ & 600 & 0.611 & -0.661 & -0.050 & 2.000 & 2000 & 32.222 \\
\hline $05: 45: 00$ & 601 & 0.600 & -0.651 & -0.051 & 2.000 & 2000 & 32.222 \\
\hline 05:50:00 & 599 & 0.593 & -0.642 & -0.049 & 2.000 & 2000 & 32.222 \\
\hline $05: 55: 00$ & 600 & 0.595 & -0.643 & -0.048 & 2.000 & 2000 & 32.222 \\
\hline 06:00:00 & 600 & 0.595 & -0.643 & -0.048 & 2.000 & 2000 & 32.222 \\
\hline 06:05:00 & 600 & 0.592 & -0.641 & -0.049 & 2.000 & 2000 & 32.222 \\
\hline 06:10:00 & 600 & 0.594 & -0.642 & -0.048 & 2.000 & 2000 & 32.222 \\
\hline $06: 15: 00$ & 600 & 0.595 & -0.642 & -0.047 & 2.000 & 2000 & 32.222 \\
\hline $06: 20: 00$ & 600 & 0.597 & -0.644 & -0.047 & 2.000 & 2000 & 32.222 \\
\hline $06: 25: 00$ & 600 & 0.595 & -0.643 & -0.048 & 2.000 & 2000 & 32.222 \\
\hline 06:30:00 & 600 & 0.595 & -0.644 & -0.049 & 2.000 & 2000 & 32.222 \\
\hline $06: 35: 00$ & 600 & 0.593 & -0.641 & -0.048 & 2.000 & 2000 & 32.222 \\
\hline
\end{tabular}




\begin{tabular}{|c|c|c|c|c|c|c|c|}
\hline $06: 40: 00$ & 600 & 0.594 & -0.643 & -0.049 & 2.000 & 2000 & 32.222 \\
\hline $06: 45: 00$ & 600 & 0.595 & -0.644 & -0.049 & 2.000 & 2000 & 32.222 \\
\hline 06:50:00 & 600 & 0.596 & -0.645 & -0.049 & 2.000 & 2000 & 32.222 \\
\hline 06:55:00 & 600 & 0.596 & -0.646 & -0.050 & 2.000 & 2000 & 32.222 \\
\hline 07:00:00 & 600 & 0.598 & -0.647 & -0.049 & 2.000 & 2000 & 32.222 \\
\hline 07:05:00 & 600 & 0.596 & -0.646 & -0.050 & 2.000 & 2000 & 32.222 \\
\hline 07:10:00 & 600 & 0.596 & -0.647 & -0.051 & 2.000 & 2000 & 32.222 \\
\hline 07:15:00 & 600 & 0.598 & -0.648 & -0.050 & 2.000 & 2000 & 32.222 \\
\hline 07:20:00 & 600 & 0.598 & -0.648 & -0.050 & 2.000 & 2000 & 32.222 \\
\hline $07: 25: 00$ & 600 & 0.598 & -0.648 & -0.050 & 2.000 & 2000 & 32.222 \\
\hline 07:30:00 & 600 & 0.599 & -0.649 & -0.050 & 2.000 & 2000 & 32.222 \\
\hline 07:35:00 & 600 & 0.599 & -0.651 & -0.052 & 2.000 & 2000 & 32.222 \\
\hline $07: 40: 00$ & 600 & 0.597 & -0.650 & -0.053 & 2.000 & 2000 & 32.222 \\
\hline $07: 45: 00$ & 600 & 0.598 & -0.650 & -0.052 & 2.000 & 2000 & 32.222 \\
\hline 07:50:00 & 600 & 0.595 & -0.650 & -0.055 & 2.000 & 2000 & 32.222 \\
\hline 07:55:00 & 600 & 0.598 & -0.650 & -0.052 & 2.000 & 2000 & 32.222 \\
\hline 08:00:00 & 600 & 0.597 & -0.650 & -0.053 & 2.000 & 2000 & 32.222 \\
\hline 08:05:00 & 600 & 0.598 & -0.651 & -0.053 & 2.000 & 2000 & 32.222 \\
\hline 08:10:00 & 600 & 0.598 & -0.651 & -0.053 & 1.995 & 1995 & 32.141 \\
\hline 08:15:00 & 600 & 0.597 & -0.650 & -0.053 & 1.995 & 1995 & 32.141 \\
\hline 08:20:00 & 600 & 0.600 & -0.652 & -0.052 & 1.995 & 1995 & 32.141 \\
\hline 08:25:00 & 600 & 0.599 & -0.651 & -0.052 & 1.995 & 1995 & 32.141 \\
\hline 08:30:00 & 600 & 0.599 & -0.651 & -0.052 & 1.995 & 1995 & 32.141 \\
\hline 08:35:00 & 600 & 0.599 & -0.652 & -0.053 & 2.000 & 2000 & 32.222 \\
\hline 08:40:00 & 600 & 0.598 & -0.651 & -0.053 & 2.000 & 2000 & 32.222 \\
\hline 08:45:00 & 600 & 0.597 & -0.650 & -0.053 & 1.995 & 1995 & 32.141 \\
\hline 08:50:00 & 600 & 0.596 & -0.650 & -0.054 & 2.000 & 2000 & 32.222 \\
\hline 08:55:00 & 600 & 0.596 & -0.649 & -0.053 & 2.000 & 2000 & 32.222 \\
\hline 09:00:00 & 600 & 0.589 & -0.646 & -0.057 & 2.000 & 2000 & 32.222 \\
\hline 09:05:00 & 600 & 0.578 & -0.640 & -0.062 & 1.995 & 1995 & 32.141 \\
\hline 09:10:00 & 597 & 0.615 & -0.656 & -0.041 & 1.995 & 1995 & 32.141 \\
\hline 09:15:00 & 602 & 0.607 & -0.669 & -0.062 & 2.010 & 2010 & 32.383 \\
\hline 09:20:00 & 599 & 0.600 & -0.657 & -0.057 & 2.010 & 2010 & 32.383 \\
\hline $09: 25: 00$ & 600 & 0.599 & -0.652 & -0.053 & 2.005 & 2005 & 32.302 \\
\hline 09:30:00 & 601 & 0.596 & -0.649 & -0.053 & 2.010 & 2010 & 32.383 \\
\hline 09:35:00 & 600 & 0.564 & -0.637 & -0.073 & 2.000 & 2000 & 32.222 \\
\hline 09:40:00 & 600 & 0.543 & -0.627 & -0.084 & 2.000 & 2000 & 32.222 \\
\hline $09: 45: 00$ & 600 & 0.536 & -0.623 & -0.087 & 2.000 & 2000 & 32.222 \\
\hline 09:50:00 & 600 & 0.573 & -0.628 & -0.055 & 2.000 & 2000 & 32.222 \\
\hline 09:55:00 & 605 & 0.446 & -0.602 & -0.156 & 2.000 & 2000 & 32.222 \\
\hline 10:00:00 & 599 & 0.474 & -0.555 & -0.081 & 2.000 & 2000 & 32.222 \\
\hline
\end{tabular}

Graphite Rod, Air Flow Rate Varied, $\mathrm{T}=600^{\circ} \mathrm{C}, 2 / 8 / 2006$

\begin{tabular}{cccccccccccc}
\multicolumn{2}{c}{ Flow $=$} & $=0.40, T=600$ & \multicolumn{3}{c}{ Flow $=0.50, T=600$} & \multicolumn{3}{c}{ Flow $=0.75, T=600$} & \multicolumn{2}{c}{ Flow $=0.90, T=600$} \\
I/SA & VCELL & P/SA & I/SA & VCELL & P/SA & I/SA & VCELL & P/SA & I/SA & VCELL & P/SA \\
0.551 & 0.696 & 0.000 & 0.551 & 0.738 & 0.000 & 0.459 & 0.779 & 0.000 & 0.459 & 0.788 & 0.000 \\
0.551 & 0.694 & 0.000 & 0.551 & 0.739 & 0.000 & 0.459 & 0.779 & 0.000 & 0.551 & 0.766 & 0.000 \\
0.551 & 0.703 & 0.000 & 0.551 & 0.739 & 0.000 & 0.551 & 0.761 & 0.000 & 0.551 & 0.777 & 0.000 \\
0.551 & 0.748 & 0.000 & 0.551 & 0.740 & 0.000 & 0.551 & 0.762 & 0.000 & 0.551 & 0.777 & 0.000 \\
0.551 & 0.751 & 0.000 & 0.551 & 0.742 & 0.000 & 0.551 & 0.765 & 0.000 & 0.551 & 0.779 & 0.000 \\
1.652 & 0.694 & 0.001 & 0.551 & 0.767 & 0.000 & 0.551 & 0.766 & 0.000 & 3.672 & 0.769 & 0.003 \\
3.580 & 0.685 & 0.002 & 0.551 & 0.765 & 0.000 & 0.551 & 0.767 & 0.000 & 7.252 & 0.757 & 0.005 \\
5.508 & 0.678 & 0.004 & 0.643 & 0.740 & 0.000 & 0.551 & 0.767 & 0.000 & 9.179 & 0.759 & 0.007 \\
7.252 & 0.671 & 0.005 & 1.652 & 0.736 & 0.001 & 0.551 & 0.769 & 0.000 & 10.923 & 0.747 & 0.008 \\
8.996 & 0.663 & 0.006 & 3.580 & 0.730 & 0.003 & 1.744 & 0.764 & 0.001 & 14.687 & 0.737 & 0.011 \\
9.088 & 0.714 & 0.006 & 3.672 & 0.729 & 0.003 & 3.580 & 0.760 & 0.003 & 18.267 & 0.726 & 0.013 \\
10.923 & 0.668 & 0.007 & 5.416 & 0.724 & 0.004 & 5.508 & 0.754 & 0.004 & 18.267 & 0.730 & 0.013 \\
12.759 & 0.657 & 0.008 & 7.160 & 0.718 & 0.005 & 7.252 & 0.749 & 0.005 & 22.122 & 0.717 & 0.016
\end{tabular}




\begin{tabular}{|c|c|c|c|c|c|c|c|c|c|c|c|}
\hline 14.687 & 0.650 & 0.010 & 9.088 & 0.733 & 0.007 & 9.179 & 0.744 & 0.007 & 25.610 & 0.708 & 0.018 \\
\hline 16.615 & 0.650 & 0.011 & 9.179 & 0.711 & 0.007 & 9.179 & 0.748 & 0.007 & 25.610 & 0.708 & 0.018 \\
\hline 18.267 & 0.640 & 0.012 & 11.015 & 0.706 & 0.008 & 11.015 & 0.738 & 0.008 & 27.630 & 0.703 & 0.019 \\
\hline 18.359 & 0.677 & 0.012 & 12.851 & 0.702 & 0.009 & 12.851 & 0.734 & 0.009 & 29.282 & 0.699 & .020 \\
\hline 20.195 & 0.632 & 0.013 & 14.595 & 0.696 & 0.010 & 14.595 & 0.728 & 0.011 & 33.138 & 0.689 & 0.023 \\
\hline 22.030 & 0.628 & 0.014 & 16.431 & 0.689 & 0.011 & 16.431 & 0.723 & 0.012 & 36.717 & 0.680 & 0.025 \\
\hline 23.958 & 0.625 & 0.015 & 18.359 & 0.685 & 0.013 & 18.359 & 0.718 & 0.013 & 36.901 & 0.675 & 0.025 \\
\hline 25.702 & 0.620 & 0.016 & 18.451 & 0.695 & 0.013 & 18.359 & 0.717 & 0.013 & 40.481 & 0.671 & 0.027 \\
\hline 27.538 & 0.612 & 0.017 & 20.286 & 0.679 & 0.014 & 20.195 & 0.713 & 0.014 & 44.153 & 0.663 & 0.029 \\
\hline 27.630 & 0.643 & 0.018 & 22.030 & 0.674 & 0.015 & 22.030 & 0.707 & 0.016 & 45.989 & 0.649 & 0.030 \\
\hline 29.466 & 0.610 & 0.018 & 23.775 & 0.669 & 0.016 & 23.866 & 0.702 & 0.017 & 47.733 & 0.654 & 0.031 \\
\hline 31.210 & 0.605 & 0.019 & 25.702 & 0.665 & 0.017 & 25.702 & 0.697 & 0.018 & 51.588 & 0.645 & 0.033 \\
\hline 33.138 & 0.599 & 0.020 & 25.702 & 0.665 & 0.017 & 27.630 & 0.691 & 0.019 & 55.076 & 0.637 & 0.035 \\
\hline 34.882 & 0.595 & 0.021 & 27.538 & 0.660 & 0.018 & 27.722 & 0.688 & 0.019 & 55.076 & 0.636 & 0.035 \\
\hline 36.717 & 0.591 & 0.022 & 27.538 & 0.658 & 0.018 & 29.466 & 0.685 & 0.020 & 55.168 & 0.623 & 0.034 \\
\hline 36.717 & 0.610 & 0.022 & 27.538 & 0.663 & 0.018 & 31.210 & 0.680 & 0.021 & 58.932 & 0.627 & 0.037 \\
\hline 38.553 & 0.586 & 0.023 & 29.282 & 0.653 & 0.019 & 33.046 & 0.675 & 0.022 & 62.695 & 0.617 & 0.039 \\
\hline 40.389 & 0.581 & 0.023 & 31.210 & 0.649 & 0.020 & 34.882 & 0.670 & 0.023 & 64.439 & 0.593 & 0.038 \\
\hline 42.317 & 0.577 & 0.024 & 33.138 & 0.643 & 0.021 & 36.901 & 0.664 & 0.025 & 66.183 & 0.609 & 0.040 \\
\hline 44.153 & 0.572 & 0.025 & 34.882 & 0.639 & 0.022 & 36.901 & 0.659 & 0.024 & 69.855 & 0.600 & 0.042 \\
\hline 45.897 & 0.568 & 0.026 & 36.626 & 0.634 & 0.023 & 38.553 & 0.660 & 0.025 & 73.619 & 0.560 & 0.041 \\
\hline 46.080 & 0.574 & 0.026 & 36.717 & 0.631 & 0.023 & 40.481 & 0.653 & 0.026 & 73.710 & 0.589 & 0.043 \\
\hline 47.824 & 0.562 & 0.027 & 38.645 & 0.629 & 0.024 & 42.317 & 0.649 & 0.027 & 77.290 & 0.580 & 0.045 \\
\hline 49.752 & 0.558 & 0.028 & 40.481 & 0.624 & 0.025 & 44.153 & 0.645 & 0.028 & 77.290 & 0.579 & 0.045 \\
\hline 51.496 & 0.553 & 0.028 & 42.317 & 0.620 & 0.026 & 45.989 & 0.639 & 0.029 & 77.290 & 0.577 & 0.045 \\
\hline 53.424 & 0.549 & 0.029 & 44.061 & 0.615 & 0.027 & 45.989 & 0.631 & 0.029 & 77.290 & 0.575 & 0.044 \\
\hline 55.168 & 0.546 & 0.030 & 45.897 & 0.611 & 0.028 & 47.824 & 0.634 & 0.030 & 80.870 & 0.566 & 0.046 \\
\hline 55.260 & 0.540 & 0.030 & 45.897 & 0.600 & 0.028 & 49.752 & 0.629 & 0.031 & 82.890 & 0.525 & 0.044 \\
\hline 58.840 & 0.533 & 0.031 & 47.733 & 0.605 & 0.029 & 51.496 & 0.625 & 0.032 & 84.726 & 0.554 & 0.047 \\
\hline 62.603 & 0.527 & 0.033 & 49.660 & 0.599 & 0.030 & 53.424 & 0.620 & 0.033 & 88.397 & 0.543 & 0.048 \\
\hline 64.439 & 0.506 & 0.033 & 51.496 & 0.596 & 0.031 & 55.352 & 0.615 & 0.034 & 92.069 & 0.480 & 0.044 \\
\hline 66.183 & 0.518 & 0.034 & 53.332 & 0.589 & 0.031 & 55.352 & 0.601 & 0.033 & 92.161 & 0.521 & 0.048 \\
\hline 70.039 & 0.507 & 0.036 & 55.260 & 0.585 & 0.032 & 58.932 & 0.606 & 0.036 & 95.833 & 0.503 & 0.048 \\
\hline 73.710 & 0.496 & 0.037 & 55.260 & 0.564 & 0.031 & 62.603 & 0.597 & 0.037 & 99.413 & 0.473 & 0.047 \\
\hline 73.894 & 0.463 & 0.034 & 57.004 & 0.581 & 0.033 & 64.439 & 0.570 & 0.037 & 103.084 & 0.432 & 0.04 \\
\hline 77.290 & 0.485 & 0.037 & 58.932 & 0.575 & 0.034 & 66.275 & 0.589 & 0.039 & 104.920 & 0.396 & 0.04 \\
\hline 80.962 & 0.475 & 0.038 & 62.603 & 0.566 & 0.035 & 69.947 & 0.580 & 0.041 & & & \\
\hline 82.890 & 0.419 & 0.035 & 64.439 & 0.531 & 0.034 & 73.619 & 0.566 & 0.042 & & & \\
\hline 84.634 & 0.462 & 0.039 & 66.275 & 0.557 & 0.037 & 73.619 & 0.536 & 0.039 & & & \\
\hline 88.397 & 0.451 & 0.040 & 69.947 & 0.545 & 0.038 & 77.290 & 0.556 & 0.043 & & & \\
\hline 92.069 & 0.441 & 0.041 & 73.527 & 0.535 & 0.039 & 81.054 & 0.544 & 0.044 & & & \\
\hline 92.161 & 0.379 & 0.035 & 73.710 & 0.492 & 0.036 & 82.890 & 0.495 & 0.041 & & & \\
\hline 95.741 & 0.422 & 0.040 & 77.382 & 0.523 & 0.040 & 84.634 & 0.531 & 0.045 & & & \\
\hline 95.833 & 0.414 & 0.040 & 81.054 & 0.511 & 0.041 & 88.305 & 0.516 & 0.046 & & & \\
\hline 99.504 & 0.405 & 0.040 & 82.798 & 0.440 & 0.036 & 91.977 & 0.497 & 0.046 & & & \\
\hline 103.176 & 0.379 & 0.039 & 84.634 & 0.502 & 0.042 & 92.069 & 0.451 & 0.042 & & & \\
\hline 103.176 & 0.376 & 0.039 & 88.397 & 0.485 & 0.043 & 95.741 & 0.479 & 0.046 & & & \\
\hline 103.176 & 0.306 & 0.032 & 91.977 & 0.384 & 0.035 & 99.413 & 0.455 & 0.045 & & & \\
\hline 105.012 & 0.330 & 0.035 & 92.161 & 0.468 & 0.043 & 103.176 & 0.417 & 0.043 & & & \\
\hline 106.664 & 0.351 & 0.037 & 95.741 & 0.454 & 0.043 & 106.756 & 0.352 & 0.038 & & & \\
\hline \multirow[t]{3}{*}{108.592} & 0.301 & 0.033 & 99.504 & 0.420 & 0.042 & & & & & & \\
\hline & & & 103.176 & 0.336 & 0.035 & & & & & & \\
\hline & & & 110.152 & 0.186 & 0.020 & & & & & & \\
\hline
\end{tabular}

Graphite Rod, Long Term Run, Air Flow Rate $=0.50$ SLPM, T $=600^{\circ}$ C, 2/8/2006

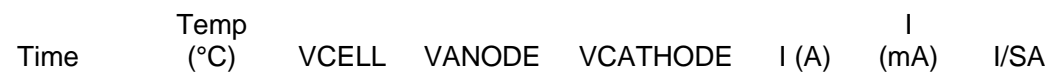




\begin{tabular}{|c|c|c|c|c|c|c|c|}
\hline $15: 55: 00$ & 600 & 0.678 & -0.714 & -0.036 & 2.000 & 2000 & 36.717 \\
\hline $16: 00: 00$ & 600 & 0.678 & -0.714 & -0.036 & 2.000 & 2000 & 36.717 \\
\hline $16: 05: 00$ & 599 & 0.678 & -0.715 & -0.037 & 2.000 & 2000 & 36.717 \\
\hline $16: 10: 00$ & 600 & 0.679 & -0.715 & -0.036 & 2.000 & 2000 & 36.717 \\
\hline $16: 15: 00$ & 600 & 0.680 & -0.716 & -0.036 & 2.000 & 2000 & 36.717 \\
\hline $16: 20: 00$ & 600 & 0.680 & -0.716 & -0.036 & 2.000 & 2000 & 36.717 \\
\hline $16: 25: 00$ & 600 & 0.680 & -0.716 & -0.036 & 2.000 & 2000 & 36.717 \\
\hline $16: 30: 00$ & 600 & 0.677 & -0.715 & -0.038 & 2.000 & 2000 & 36.717 \\
\hline 16:35:00 & 600 & 0.677 & -0.713 & -0.036 & 2.000 & 2000 & 36.717 \\
\hline $16: 40: 00$ & 599 & 0.675 & -0.711 & -0.036 & 2.000 & 2000 & 36.717 \\
\hline $16: 45: 00$ & 600 & 0.674 & -0.710 & -0.036 & 2.000 & 2000 & 36.717 \\
\hline $16: 50: 00$ & 600 & 0.673 & -0.709 & -0.036 & 2.000 & 2000 & 36.717 \\
\hline $16: 55: 00$ & 599 & 0.673 & -0.709 & -0.036 & 2.000 & 2000 & 36.717 \\
\hline 17:00:00 & 599 & 0.673 & -0.708 & -0.035 & 2.000 & 2000 & 36.717 \\
\hline 17:05:00 & 600 & 0.673 & -0.709 & -0.036 & 2.000 & 2000 & 36.717 \\
\hline $17: 10: 00$ & 599 & 0.673 & -0.708 & -0.035 & 2.000 & 2000 & 36.717 \\
\hline $17: 15: 00$ & 599 & 0.673 & -0.708 & -0.035 & 2.000 & 2000 & 36.717 \\
\hline $17: 20: 00$ & 600 & 0.674 & -0.709 & -0.035 & 2.000 & 2000 & 36.717 \\
\hline $17: 25: 00$ & 599 & 0.674 & -0.708 & -0.034 & 2.000 & 2000 & 36.717 \\
\hline $17: 30: 00$ & 599 & 0.672 & -0.707 & -0.035 & 2.000 & 2000 & 36.717 \\
\hline 17:35:00 & 600 & 0.672 & -0.707 & -0.035 & 2.000 & 2000 & 36.717 \\
\hline $17: 40: 00$ & 599 & 0.672 & -0.707 & -0.035 & 2.000 & 2000 & 36.717 \\
\hline $17: 45: 00$ & 599 & 0.670 & -0.704 & -0.034 & 2.000 & 2000 & 36.717 \\
\hline $17: 50: 00$ & 600 & 0.667 & -0.702 & -0.035 & 2.000 & 2000 & 36.717 \\
\hline 17:55:00 & 599 & 0.666 & -0.700 & -0.034 & 2.000 & 2000 & 36.717 \\
\hline 18:00:00 & 600 & 0.663 & -0.698 & -0.035 & 2.000 & 2000 & 36.717 \\
\hline $18: 05: 00$ & 600 & 0.662 & -0.696 & -0.034 & 2.000 & 2000 & 36.717 \\
\hline 18:10:00 & 600 & 0.660 & -0.694 & -0.034 & 2.000 & 2000 & 36.717 \\
\hline $18: 15: 00$ & 599 & 0.657 & -0.691 & -0.034 & 2.000 & 2000 & 36.717 \\
\hline $18: 20: 00$ & 600 & 0.653 & -0.688 & -0.035 & 2.000 & 2000 & 36.717 \\
\hline $18: 25: 00$ & 599 & 0.650 & -0.684 & -0.034 & 2.000 & 2000 & 36.717 \\
\hline $18: 30: 00$ & 599 & 0.647 & -0.679 & -0.032 & 2.000 & 2000 & 36.717 \\
\hline $18: 35: 00$ & 600 & 0.642 & -0.674 & -0.032 & 2.000 & 2000 & 36.717 \\
\hline 18:40:00 & 599 & 0.638 & -0.669 & -0.031 & 2.000 & 2000 & 36.717 \\
\hline $18: 45: 00$ & 599 & 0.634 & -0.665 & -0.031 & 2.000 & 2000 & 36.717 \\
\hline $18: 50: 00$ & 600 & 0.632 & -0.662 & -0.030 & 2.000 & 2000 & 36.717 \\
\hline $18: 55: 00$ & 599 & 0.627 & -0.657 & -0.030 & 2.000 & 2000 & 36.717 \\
\hline 19:00:00 & 599 & 0.622 & -0.652 & -0.030 & 2.000 & 2000 & 36.717 \\
\hline $19: 05: 00$ & 600 & 0.617 & -0.648 & -0.031 & 2.000 & 2000 & 36.717 \\
\hline 19:10:00 & 600 & 0.613 & -0.643 & -0.030 & 2.000 & 2000 & 36.717 \\
\hline 19:15:00 & 599 & 0.608 & -0.637 & -0.029 & 2.000 & 2000 & 36.717 \\
\hline $19: 20: 00$ & 600 & 0.602 & -0.631 & -0.029 & 2.000 & 2000 & 36.717 \\
\hline $19: 25: 00$ & 600 & 0.594 & -0.622 & -0.028 & 2.000 & 2000 & 36.717 \\
\hline 19:30:00 & 599 & 0.586 & -0.614 & -0.028 & 2.000 & 2000 & 36.717 \\
\hline $19: 35: 00$ & 600 & 0.583 & -0.611 & -0.028 & 2.000 & 2000 & 36.717 \\
\hline $19: 40: 00$ & 600 & 0.574 & -0.602 & -0.028 & 2.000 & 2000 & 36.717 \\
\hline $19: 45: 00$ & 599 & 0.568 & -0.596 & -0.028 & 2.000 & 2000 & 36.717 \\
\hline $19: 50: 00$ & 599 & 0.560 & -0.588 & -0.028 & 2.000 & 2000 & 36.717 \\
\hline $19: 55: 00$ & 600 & 0.551 & -0.578 & -0.027 & 2.000 & 2000 & 36.717 \\
\hline 20:00:00 & 599 & 0.543 & -0.571 & -0.028 & 2.000 & 2000 & 36.717 \\
\hline $20: 05: 00$ & 599 & 0.541 & -0.569 & -0.028 & 2.000 & 2000 & 36.717 \\
\hline 20:10:00 & 600 & 0.532 & -0.560 & -0.028 & 2.000 & 2000 & 36.717 \\
\hline $20: 15: 00$ & 599 & 0.523 & -0.551 & -0.028 & 2.000 & 2000 & 36.717 \\
\hline 20:20:00 & 599 & 0.514 & -0.543 & -0.029 & 2.000 & 2000 & 36.717 \\
\hline $20: 25: 00$ & 600 & 0.505 & -0.533 & -0.028 & 2.000 & 2000 & 36.717 \\
\hline $20: 30: 00$ & 600 & 0.497 & -0.526 & -0.029 & 2.000 & 2000 & 36.717 \\
\hline $20: 35: 00$ & 599 & 0.483 & -0.512 & -0.029 & 2.000 & 2000 & 36.717 \\
\hline $20: 40: 00$ & 600 & 0.478 & -0.508 & -0.030 & 2.000 & 2000 & 36.717 \\
\hline $20: 45: 00$ & 600 & 0.471 & -0.500 & -0.029 & 2.000 & 2000 & 36.717 \\
\hline 20:50:00 & 599 & 0.461 & -0.491 & -0.030 & 2.000 & 2000 & 36.717 \\
\hline $20: 55: 00$ & 600 & 0.458 & -0.487 & -0.029 & 2.000 & 2000 & 36.717 \\
\hline 21:00:00 & 600 & 0.447 & -0.477 & -0.030 & 2.000 & 2000 & 36.717 \\
\hline 21:05:00 & 599 & 0.444 & -0.474 & -0.030 & 2.000 & 2000 & 36.717 \\
\hline
\end{tabular}




\begin{tabular}{|c|c|c|c|c|c|c|c|}
\hline 21:10:00 & 599 & 0.436 & -0.466 & -0.030 & 2.000 & 2000 & 36.717 \\
\hline 21:15:00 & 600 & 0.429 & -0.459 & -0.030 & 2.000 & 2000 & 36.717 \\
\hline 21:20:00 & 599 & 0.427 & -0.457 & -0.030 & 2.005 & 2005 & 36.809 \\
\hline 21:25:00 & 599 & 0.423 & -0.453 & -0.030 & 2.005 & 2005 & 36.809 \\
\hline 21:30:00 & 600 & 0.418 & -0.449 & -0.031 & 2.000 & 2000 & 36.717 \\
\hline 21:35:00 & 600 & 0.410 & -0.441 & -0.031 & 2.000 & 2000 & 36.717 \\
\hline 21:40:00 & 599 & 0.402 & -0.432 & -0.030 & 2.000 & 2000 & 36.717 \\
\hline $21: 45: 00$ & 599 & 0.398 & -0.429 & -0.031 & 2.000 & 2000 & 36.717 \\
\hline 21:50:00 & 600 & 0.397 & -0.427 & -0.030 & 2.005 & 2005 & 36.809 \\
\hline 21:55:00 & 599 & 0.394 & -0.424 & -0.030 & 2.005 & 2005 & 36.809 \\
\hline 22:00:00 & 599 & 0.395 & -0.426 & -0.031 & 2.000 & 2000 & 36.717 \\
\hline 22:05:00 & 600 & 0.394 & -0.423 & -0.029 & 2.005 & 2005 & 36.809 \\
\hline 22:10:00 & 600 & 0.389 & -0.419 & -0.030 & 2.000 & 2000 & 36.717 \\
\hline $22: 15: 00$ & 599 & 0.388 & -0.417 & -0.029 & 2.000 & 2000 & 36.717 \\
\hline 22:20:00 & 599 & 0.376 & -0.407 & -0.031 & 2.000 & 2000 & 36.717 \\
\hline $22: 25: 00$ & 600 & 0.373 & -0.403 & -0.030 & 2.000 & 2000 & 36.717 \\
\hline 22:30:00 & 599 & 0.369 & -0.399 & -0.030 & 2.000 & 2000 & 36.717 \\
\hline 22:35:00 & 599 & 0.364 & -0.393 & -0.029 & 2.000 & 2000 & 36.717 \\
\hline 22:40:00 & 600 & 0.358 & -0.386 & -0.028 & 2.005 & 2005 & 36.809 \\
\hline $22: 45: 00$ & 600 & 0.357 & -0.385 & -0.028 & 2.005 & 2005 & 36.809 \\
\hline $22: 50: 00$ & 600 & 0.350 & -0.379 & -0.029 & 2.005 & 2005 & 36.809 \\
\hline 22:55:00 & 599 & 0.357 & -0.387 & -0.030 & 2.005 & 2005 & 36.809 \\
\hline 23:00:00 & 599 & 0.351 & -0.381 & -0.030 & 2.000 & 2000 & 36.717 \\
\hline 23:05:00 & 600 & 0.373 & -0.403 & -0.030 & 2.005 & 2005 & 36.809 \\
\hline 23:10:00 & 600 & 0.375 & -0.406 & -0.031 & 2.000 & 2000 & 36.717 \\
\hline 23:15:00 & 599 & 0.381 & -0.411 & -0.030 & 2.000 & 2000 & 36.717 \\
\hline 23:20:00 & 599 & 0.378 & -0.408 & -0.030 & 2.000 & 2000 & 36.717 \\
\hline $23: 25: 00$ & 600 & 0.375 & -0.406 & -0.031 & 2.000 & 2000 & 36.717 \\
\hline 23:30:00 & 599 & 0.362 & -0.392 & -0.030 & 2.005 & 2005 & 36.809 \\
\hline $23: 35: 00$ & 600 & 0.386 & -0.416 & -0.030 & 2.000 & 2000 & 36.717 \\
\hline 23:40:00 & 600 & 0.385 & -0.415 & -0.030 & 2.005 & 2005 & 36.809 \\
\hline 23:45:00 & 600 & 0.383 & -0.414 & -0.031 & 2.005 & 2005 & 36.809 \\
\hline 23:50:00 & 599 & 0.395 & -0.426 & -0.031 & 2.005 & 2005 & 36.809 \\
\hline 23:55:00 & 599 & 0.388 & -0.419 & -0.031 & 2.000 & 2000 & 36.717 \\
\hline 00:00:00 & 600 & 0.391 & -0.422 & -0.031 & 2.005 & 2005 & 36.809 \\
\hline 00:05:00 & 600 & 0.389 & -0.419 & -0.030 & 2.005 & 2005 & 36.809 \\
\hline 00:10:00 & 600 & 0.388 & -0.418 & -0.030 & 2.005 & 2005 & 36.809 \\
\hline 00:15:00 & 599 & 0.387 & -0.418 & -0.031 & 2.005 & 2005 & 36.809 \\
\hline 00:20:00 & 599 & 0.395 & -0.426 & -0.031 & 2.000 & 2000 & 36.717 \\
\hline 00:25:00 & 599 & 0.391 & -0.422 & -0.031 & 2.000 & 2000 & 36.717 \\
\hline 00:30:00 & 599 & 0.385 & -0.416 & -0.031 & 2.000 & 2000 & 36.717 \\
\hline 00:35:00 & 600 & 0.386 & -0.418 & -0.032 & 2.000 & 2000 & 36.717 \\
\hline $00: 40: 00$ & 600 & 0.387 & -0.418 & -0.031 & 2.005 & 2005 & 36.809 \\
\hline $00: 45: 00$ & 599 & 0.382 & -0.415 & -0.033 & 2.005 & 2005 & 36.809 \\
\hline 00:50:00 & 600 & 0.395 & -0.426 & -0.031 & 2.005 & 2005 & 36.809 \\
\hline $00: 55: 00$ & 600 & 0.399 & -0.431 & -0.032 & 2.005 & 2005 & 36.809 \\
\hline 01:00:00 & 599 & 0.395 & -0.427 & -0.032 & 2.005 & 2005 & 36.809 \\
\hline 01:05:00 & 600 & 0.392 & -0.425 & -0.033 & 2.005 & 2005 & 36.809 \\
\hline 01:10:00 & 600 & 0.399 & -0.431 & -0.032 & 2.005 & 2005 & 36.809 \\
\hline 01:15:00 & 599 & 0.402 & -0.434 & -0.032 & 2.005 & 2005 & 36.809 \\
\hline 01:20:00 & 599 & 0.400 & -0.433 & -0.033 & 2.005 & 2005 & 36.809 \\
\hline 01:25:00 & 600 & 0.399 & -0.432 & -0.033 & 2.005 & 2005 & 36.809 \\
\hline 01:30:00 & 599 & 0.404 & -0.436 & -0.032 & 2.005 & 2005 & 36.809 \\
\hline 01:35:00 & 600 & 0.403 & -0.436 & -0.033 & 2.005 & 2005 & 36.809 \\
\hline 01:40:00 & 600 & 0.401 & -0.433 & -0.032 & 2.005 & 2005 & 36.809 \\
\hline 01:45:00 & 599 & 0.405 & -0.437 & -0.032 & 2.005 & 2005 & 36.809 \\
\hline 01:50:00 & 600 & 0.405 & -0.437 & -0.032 & 2.005 & 2005 & 36.809 \\
\hline 01:55:00 & 600 & 0.401 & -0.435 & -0.034 & 2.005 & 2005 & 36.809 \\
\hline 02:00:00 & 599 & 0.401 & -0.434 & -0.033 & 2.005 & 2005 & 36.809 \\
\hline 02:05:00 & 599 & 0.403 & -0.436 & -0.033 & 2.005 & 2005 & 36.809 \\
\hline 02:10:00 & 600 & 0.408 & -0.440 & -0.032 & 2.005 & 2005 & 36.809 \\
\hline 02:15:00 & 600 & 0.398 & -0.431 & -0.033 & 2.005 & 2005 & 36.809 \\
\hline 02:20:00 & 599 & 0.399 & -0.433 & -0.034 & 2.005 & 2005 & 36.809 \\
\hline
\end{tabular}




\begin{tabular}{|c|c|c|c|c|c|c|c|}
\hline 02:25:00 & 600 & 0.399 & -0.432 & -0.033 & 2.005 & 2005 & 36.809 \\
\hline 02:30:00 & 600 & 0.397 & -0.430 & -0.033 & 2.005 & 2005 & 36.809 \\
\hline 02:35:00 & 600 & 0.397 & -0.431 & -0.034 & 2.005 & 2005 & 36.809 \\
\hline 02:40:00 & 599 & 0.388 & -0.421 & -0.033 & 2.005 & 2005 & 36.809 \\
\hline 02:45:00 & 600 & 0.384 & -0.417 & -0.033 & 2.005 & 2005 & 36.809 \\
\hline 02:50:00 & 600 & 0.374 & -0.406 & -0.032 & 2.005 & 2005 & 36.809 \\
\hline 02:55:00 & 599 & 0.361 & -0.394 & -0.033 & 2.005 & 2005 & 36.809 \\
\hline 03:00:00 & 599 & 0.353 & -0.386 & -0.033 & 2.005 & 2005 & 36.809 \\
\hline 03:05:00 & 600 & 0.339 & -0.372 & -0.033 & 2.005 & 2005 & 36.809 \\
\hline 03:10:00 & 600 & 0.335 & -0.368 & -0.033 & 2.005 & 2005 & 36.809 \\
\hline 03:15:00 & 599 & 0.323 & -0.356 & -0.033 & 2.005 & 2005 & 36.809 \\
\hline 03:20:00 & 600 & 0.371 & -0.404 & -0.033 & 2.005 & 2005 & 36.809 \\
\hline $03: 25: 00$ & 600 & 0.364 & -0.398 & -0.034 & 2.005 & 2005 & 36.809 \\
\hline 03:30:00 & 600 & 0.367 & -0.400 & -0.033 & 2.005 & 2005 & 36.809 \\
\hline 03:35:00 & 599 & 0.359 & -0.392 & -0.033 & 2.005 & 2005 & 36.809 \\
\hline 03:40:00 & 599 & 0.357 & -0.390 & -0.033 & 2.005 & 2005 & 36.809 \\
\hline 03:45:00 & 600 & 0.343 & -0.376 & -0.033 & 2.005 & 2005 & 36.809 \\
\hline 03:50:00 & 600 & 0.340 & -0.373 & -0.033 & 2.005 & 2005 & 36.809 \\
\hline 03:55:00 & 600 & 0.341 & -0.374 & -0.033 & 2.005 & 2005 & 36.809 \\
\hline 04:00:00 & 600 & 0.332 & -0.364 & -0.032 & 2.005 & 2005 & 36.809 \\
\hline 04:05:00 & 600 & 0.323 & -0.356 & -0.033 & 2.005 & 2005 & 36.809 \\
\hline 04:10:00 & 599 & 0.310 & -0.343 & -0.033 & 2.005 & 2005 & 36.809 \\
\hline 04:15:00 & 600 & 0.302 & -0.335 & -0.033 & 2.005 & 2005 & 36.809 \\
\hline 04:20:00 & 600 & 0.293 & -0.325 & -0.032 & 2.005 & 2005 & 36.809 \\
\hline 04:25:00 & 599 & 0.290 & -0.322 & -0.032 & 2.005 & 2005 & 36.809 \\
\hline 04:30:00 & 599 & 0.277 & -0.308 & -0.031 & 2.005 & 2005 & 36.809 \\
\hline 04:35:00 & 600 & 0.260 & -0.291 & -0.031 & 2.005 & 2005 & 36.809 \\
\hline 04:40:00 & 600 & 0.247 & -0.278 & -0.031 & 2.005 & 2005 & 36.809 \\
\hline 04:45:00 & 600 & 0.231 & -0.262 & -0.031 & 2.005 & 2005 & 36.809 \\
\hline 04:50:00 & 600 & 0.211 & -0.243 & -0.032 & 2.005 & 2005 & 36.809 \\
\hline 04:55:00 & 600 & 0.194 & -0.224 & -0.030 & 2.000 & 2000 & 36.717 \\
\hline 05:00:00 & 600 & 0.162 & -0.192 & -0.030 & 2.000 & 2000 & 36.717 \\
\hline 05:05:00 & 600 & 0.141 & -0.171 & -0.030 & 2.000 & 2000 & 36.717 \\
\hline 05:10:00 & 600 & 0.114 & -0.144 & -0.030 & 2.000 & 2000 & 36.717 \\
\hline 05:15:00 & 600 & 0.066 & -0.096 & -0.030 & 1.915 & 1915 & 35.157 \\
\hline 05:20:00 & 599 & 0.054 & -0.082 & -0.028 & 1.770 & 1770 & 32.495 \\
\hline 05:25:00 & 600 & 0.045 & -0.068 & -0.023 & 1.555 & 1555 & 28.548 \\
\hline 05:30:00 & 600 & 0.044 & -0.067 & -0.023 & 1.510 & 1510 & 27.722 \\
\hline 05:35:00 & 599 & 0.040 & -0.061 & -0.021 & 1.355 & 1355 & 24.876 \\
\hline 05:40:00 & 600 & 0.033 & -0.052 & -0.019 & 1.100 & 1100 & 20.195 \\
\hline 05:45:00 & 600 & 0.035 & -0.054 & -0.019 & 1.155 & 1155 & 21.204 \\
\hline 05:50:00 & 599 & 0.033 & -0.051 & -0.018 & 1.160 & 1160 & 21.296 \\
\hline 05:55:00 & 600 & 0.031 & -0.048 & -0.017 & 1.030 & 1030 & 18.909 \\
\hline 06:00:00 & 600 & 0.031 & -0.048 & -0.017 & 1.050 & 1050 & 19.277 \\
\hline 06:05:00 & 599 & 0.027 & -0.043 & -0.016 & 0.960 & 960 & 17.624 \\
\hline 06:10:00 & 600 & 0.028 & -0.044 & -0.016 & 0.995 & 995 & 18.267 \\
\hline 06:15:00 & 600 & 0.028 & -0.044 & -0.016 & 0.965 & 965 & 17.716 \\
\hline 06:20:00 & 600 & 0.026 & -0.041 & -0.015 & 0.875 & 875 & 16.064 \\
\hline $06: 25: 00$ & 600 & 0.029 & -0.045 & -0.016 & 0.945 & 945 & 17.349 \\
\hline 06:30:00 & 600 & 0.029 & -0.045 & -0.016 & 0.945 & 945 & 17.349 \\
\hline 06:35:00 & 600 & 0.027 & -0.043 & -0.016 & 0.855 & 855 & 15.697 \\
\hline 06:40:00 & 599 & 0.025 & -0.040 & -0.015 & 0.825 & 825 & 15.146 \\
\hline 06:45:00 & 600 & 0.029 & -0.045 & -0.016 & 0.955 & 955 & 17.533 \\
\hline 06:50:00 & 600 & 0.025 & -0.040 & -0.015 & 0.830 & 830 & 15.238 \\
\hline 06:55:00 & 599 & 0.032 & -0.049 & -0.017 & 0.965 & 965 & 17.716 \\
\hline 07:00:00 & 600 & 0.028 & -0.044 & -0.016 & 0.985 & 985 & 18.083 \\
\hline 07:05:00 & 600 & 0.027 & -0.042 & -0.015 & 0.925 & 925 & 16.982 \\
\hline 07:10:00 & 599 & 0.024 & -0.039 & -0.015 & 0.950 & 950 & 17.441 \\
\hline 07:15:00 & 600 & 0.024 & -0.039 & -0.015 & 0.865 & 865 & 15.880 \\
\hline 07:20:00 & 600 & 0.029 & -0.045 & -0.016 & 0.945 & 945 & 17.349 \\
\hline 07:25:00 & 599 & 0.027 & -0.042 & -0.015 & 0.870 & 870 & 15.972 \\
\hline 07:30:00 & 600 & 0.026 & -0.041 & -0.015 & 0.855 & 855 & 15.697 \\
\hline 07:35:00 & 600 & 0.027 & -0.042 & -0.015 & 0.910 & 910 & 16.706 \\
\hline
\end{tabular}




$\begin{array}{llllrlrl}\text { 07:40:00 } & 600 & 0.028 & -0.045 & -0.017 & 0.975 & 975 & 17.900 \\ \text { 07:45:00 } & 599 & 0.026 & -0.042 & -0.016 & 0.900 & 900 & 16.523 \\ \text { 07:50:00 } & 600 & 0.029 & -0.045 & -0.016 & 0.915 & 915 & 16.798 \\ \text { 07:55:00 } & 600 & 0.027 & -0.043 & -0.016 & 0.955 & 955 & 17.533 \\ \text { 08:00:00 } & 600 & 0.027 & -0.042 & -0.015 & 1.005 & 1005 & 18.451 \\ \text { 08:05:00 } & 600 & 0.029 & -0.044 & -0.015 & 0.955 & 955 & 17.533 \\ \text { 08:10:00 } & 600 & 0.028 & -0.044 & -0.016 & 0.945 & 945 & 17.349 \\ \text { 08:15:00 } & 600 & 0.028 & -0.043 & -0.015 & 0.940 & 940 & 17.257 \\ \text { 08:20:00 } & 600 & 0.029 & -0.044 & -0.015 & 0.930 & 930 & 17.074 \\ \text { 08:25:00 } & 600 & 0.029 & -0.044 & -0.015 & 0.890 & 890 & 16.339\end{array}$

\begin{tabular}{|c|c|c|c|c|c|c|c|c|}
\hline \multicolumn{3}{|c|}{0.50 SLPM } & \multicolumn{3}{|c|}{0.25 SLPM } & \multicolumn{3}{|c|}{0.75 SLPM } \\
\hline I/SA & VCELL & P/SA & I/SA & VCELL & P/SA & I/SA & VCELL & P/SA \\
\hline 0.459 & 0.690 & 0.000 & 0.367 & 0.727 & 0.000 & 0.275 & 0.727 & 0.000 \\
\hline 0.459 & 0.687 & 0.000 & 0.367 & 0.725 & 0.000 & 0.367 & 0.681 & 0.000 \\
\hline 0.459 & 0.696 & 0.000 & 0.826 & 0.745 & 0.001 & 0.367 & 0.687 & 0.000 \\
\hline 0.459 & 0.692 & 0.000 & 0.826 & 0.742 & 0.001 & 0.367 & 0.734 & 0.000 \\
\hline 0.459 & 0.690 & 0.000 & 1.744 & 0.732 & 0.001 & 0.367 & 0.733 & 0.000 \\
\hline 0.734 & 0.738 & 0.001 & 3.580 & 0.723 & 0.003 & 0.367 & 0.731 & 0.000 \\
\hline 0.826 & 0.744 & 0.001 & 7.252 & 0.704 & 0.005 & 1.744 & 0.688 & 0.001 \\
\hline 0.826 & 0.727 & 0.001 & 9.179 & 0.696 & 0.006 & 3.580 & 0.679 & 0.002 \\
\hline 1.744 & 0.688 & 0.001 & 9.179 & 0.692 & 0.006 & 5.508 & 0.671 & 0.004 \\
\hline 3.672 & 0.681 & 0.003 & 10.923 & 0.686 & 0.007 & 7.252 & 0.672 & 0.005 \\
\hline 5.416 & 0.676 & 0.004 & 12.851 & 0.677 & 0.009 & 9.271 & 0.673 & 0.006 \\
\hline 7.252 & 0.663 & 0.005 & 14.687 & 0.666 & 0.010 & 11.015 & 0.661 & 0.007 \\
\hline 9.088 & 0.663 & 0.006 & 16.431 & 0.658 & 0.011 & 12.943 & 0.661 & 0.009 \\
\hline 10.923 & 0.657 & 0.007 & 18.267 & 0.650 & 0.012 & 14.687 & 0.665 & 0.010 \\
\hline 12.759 & 0.650 & 0.008 & 20.195 & 0.643 & 0.013 & 16.615 & 0.659 & 0.011 \\
\hline 14.595 & 0.645 & 0.009 & 22.030 & 0.635 & 0.014 & 18.359 & 0.655 & 0.012 \\
\hline 16.523 & 0.639 & 0.011 & 23.958 & 0.626 & 0.015 & 22.122 & 0.649 & 0.014 \\
\hline 18.359 & 0.635 & 0.012 & 25.702 & 0.622 & 0.016 & 23.866 & 0.640 & 0.015 \\
\hline 18.359 & 0.660 & 0.012 & 27.538 & 0.613 & 0.017 & 25.794 & 0.639 & 0.016 \\
\hline 20.195 & 0.630 & 0.013 & 29.374 & 0.607 & 0.018 & 27.538 & 0.631 & 0.017 \\
\hline 21.939 & 0.625 & 0.014 & 31.302 & 0.600 & 0.019 & 29.558 & 0.631 & 0.019 \\
\hline 23.866 & 0.621 & 0.015 & 33.046 & 0.592 & 0.020 & 31.302 & 0.628 & 0.020 \\
\hline 25.702 & 0.615 & 0.016 & 36.717 & 0.579 & 0.021 & 33.138 & 0.621 & 0.021 \\
\hline 27.630 & 0.611 & 0.017 & 40.389 & 0.566 & 0.023 & 34.973 & 0.616 & 0.022 \\
\hline 29.374 & 0.609 & 0.018 & 44.061 & 0.552 & 0.024 & 36.809 & 0.611 & 0.022 \\
\hline 31.210 & 0.600 & 0.019 & 47.733 & 0.541 & 0.026 & 40.389 & 0.605 & 0.024 \\
\hline 33.138 & 0.597 & 0.020 & 49.660 & 0.532 & 0.026 & 44.061 & 0.595 & 0.026 \\
\hline 34.973 & 0.592 & 0.021 & 53.332 & 0.520 & 0.028 & 45.897 & 0.590 & 0.027 \\
\hline 36.809 & 0.586 & 0.022 & 55.260 & 0.514 & 0.028 & 49.569 & 0.582 & 0.029 \\
\hline 38.645 & 0.582 & 0.022 & 58.840 & 0.500 & 0.029 & 51.496 & 0.575 & 0.030 \\
\hline 40.481 & 0.579 & 0.023 & 62.787 & 0.489 & 0.031 & 53.424 & 0.572 & 0.031 \\
\hline 42.317 & 0.577 & 0.024 & 66.275 & 0.476 & 0.032 & 55.168 & 0.567 & 0.031 \\
\hline 44.153 & 0.577 & 0.025 & 69.947 & 0.463 & 0.032 & 57.096 & 0.562 & 0.032 \\
\hline 45.897 & 0.575 & 0.026 & 73.710 & 0.446 & 0.033 & 59.023 & 0.557 & 0.033 \\
\hline 47.824 & 0.572 & 0.027 & 77.290 & 0.435 & 0.034 & 60.767 & 0.552 & 0.034 \\
\hline 49.660 & 0.567 & 0.028 & 82.798 & 0.414 & 0.034 & 64.531 & 0.540 & 0.035 \\
\hline 51.496 & 0.563 & 0.029 & 86.470 & 0.398 & 0.034 & 68.019 & 0.534 & 0.036 \\
\hline 53.332 & 0.559 & 0.030 & 90.233 & 0.375 & 0.034 & 71.783 & 0.523 & 0.038 \\
\hline 55.260 & 0.553 & 0.031 & 95.741 & 0.337 & 0.032 & 75.454 & 0.514 & 0.039 \\
\hline 55.260 & 0.533 & 0.029 & 97.668 & 0.328 & 0.032 & 77.198 & 0.508 & 0.039 \\
\hline
\end{tabular}




\begin{tabular}{|c|c|c|c|c|c|c|c|c|}
\hline 58.932 & 0.546 & 0.032 & 103.084 & 0.289 & 0.030 & 80.962 & 0.498 & 0.040 \\
\hline 62.511 & 0.536 & 0.034 & & & & 84.817 & 0.486 & 0.041 \\
\hline 66.183 & 0.526 & 0.035 & & & & 88.305 & 0.474 & 0.042 \\
\hline 69.855 & 0.518 & 0.036 & & & & 92.069 & 0.455 & 0.042 \\
\hline 73.527 & 0.506 & 0.037 & & & & 95.741 & 0.444 & 0.043 \\
\hline 77.290 & 0.497 & 0.038 & & & & 99.504 & 0.405 & 0.040 \\
\hline 80.962 & 0.485 & 0.039 & & & & 103.084 & 0.379 & 0.039 \\
\hline 84.634 & 0.477 & 0.040 & & & & 106.848 & 0.326 & 0.035 \\
\hline 88.305 & 0.460 & 0.041 & & & & & & \\
\hline 92.069 & 0.444 & 0.041 & & & & & & \\
\hline 95.741 & 0.422 & 0.040 & & & & & & \\
\hline 99.413 & 0.387 & 0.038 & & & & & & \\
\hline 103.084 & 0.358 & 0.037 & & & & & & \\
\hline 106.756 & 0.287 & 0.031 & & & & & & \\
\hline
\end{tabular}

Graphite Rod, Long Term Run, Air Flow Rate $=0.50$ SLPM, $\mathrm{T}=600^{\circ} \mathrm{C}, 2 / 21 / 2006$

\begin{tabular}{|c|c|c|c|c|c|c|c|}
\hline Time & $\begin{array}{c}\text { Temp } \\
\left({ }^{\circ} \mathrm{C}\right)\end{array}$ & VCELL & VANODE & VCATHODE & I (A) & $\begin{array}{c}\text { I } \\
(\mathrm{mA})\end{array}$ & I/SA \\
\hline $14: 20: 00$ & 598 & 0.611 & -0.647 & -0.036 & 2.000 & 2000 & 36.717 \\
\hline $14: 25: 00$ & 598 & 0.612 & -0.647 & -0.035 & 2.005 & 2005 & 36.809 \\
\hline $14: 30: 00$ & 599 & 0.613 & -0.649 & -0.036 & 2.005 & 2005 & 36.809 \\
\hline $14: 35: 00$ & 598 & 0.623 & -0.659 & -0.036 & 2.005 & 2005 & 36.809 \\
\hline $14: 40: 00$ & 598 & 0.620 & -0.657 & -0.037 & 2.005 & 2005 & 36.809 \\
\hline $14: 45: 00$ & 599 & 0.616 & -0.652 & -0.036 & 2.005 & 2005 & 36.809 \\
\hline $14: 50: 00$ & 599 & 0.620 & -0.655 & -0.035 & 2.005 & 2005 & 36.809 \\
\hline $14: 55: 00$ & 598 & 0.617 & -0.653 & -0.036 & 2.005 & 2005 & 36.809 \\
\hline $15: 00: 00$ & 598 & 0.618 & -0.655 & -0.037 & 2.005 & 2005 & 36.809 \\
\hline $15: 05: 00$ & 599 & 0.617 & -0.652 & -0.035 & 2.005 & 2005 & 36.809 \\
\hline $15: 10: 00$ & 598 & 0.618 & -0.654 & -0.036 & 2.005 & 2005 & 36.809 \\
\hline $15: 15: 00$ & 598 & 0.620 & -0.656 & -0.036 & 2.005 & 2005 & 36.809 \\
\hline $15: 20: 00$ & 599 & 0.621 & -0.659 & -0.038 & 2.005 & 2005 & 36.809 \\
\hline $15: 25: 00$ & 599 & 0.619 & -0.657 & -0.038 & 2.005 & 2005 & 36.809 \\
\hline $15: 30: 00$ & 598 & 0.621 & -0.656 & -0.035 & 2.005 & 2005 & 36.809 \\
\hline $15: 35: 00$ & 599 & 0.630 & -0.669 & -0.039 & 2.005 & 2005 & 36.809 \\
\hline $15: 40: 00$ & 599 & 0.626 & -0.663 & -0.037 & 2.005 & 2005 & 36.809 \\
\hline $15: 45: 00$ & 598 & 0.624 & -0.660 & -0.036 & 2.005 & 2005 & 36.809 \\
\hline $15: 50: 00$ & 598 & 0.625 & -0.661 & -0.036 & 2.005 & 2005 & 36.809 \\
\hline $15: 55: 00$ & 599 & 0.625 & -0.662 & -0.037 & 2.005 & 2005 & 36.809 \\
\hline 16:00:00 & 598 & 0.633 & -0.669 & -0.036 & 2.005 & 2005 & 36.809 \\
\hline $16: 05: 00$ & 598 & 0.631 & -0.668 & -0.037 & 2.005 & 2005 & 36.809 \\
\hline $16: 10: 00$ & 599 & 0.635 & -0.673 & -0.038 & 2.005 & 2005 & 36.809 \\
\hline $16: 15: 00$ & 599 & 0.631 & -0.669 & -0.038 & 2.005 & 2005 & 36.809 \\
\hline $16: 20: 00$ & 598 & 0.627 & -0.664 & -0.037 & 2.005 & 2005 & 36.809 \\
\hline $16: 25: 00$ & 598 & 0.629 & -0.668 & -0.039 & 2.005 & 2005 & 36.809 \\
\hline $16: 30: 00$ & 598 & 0.634 & -0.671 & -0.037 & 2.005 & 2005 & 36.809 \\
\hline $16: 35: 00$ & 598 & 0.635 & -0.672 & -0.037 & 2.005 & 2005 & 36.809 \\
\hline $16: 40: 00$ & 598 & 0.652 & -0.691 & -0.039 & 2.005 & 2005 & 36.809 \\
\hline $16: 45: 00$ & 598 & 0.636 & -0.674 & -0.038 & 2.005 & 2005 & 36.809 \\
\hline $16: 50: 00$ & 599 & 0.635 & -0.672 & -0.037 & 2.005 & 2005 & 36.809 \\
\hline $16: 55: 00$ & 598 & 0.634 & -0.673 & -0.039 & 2.005 & 2005 & 36.809 \\
\hline $17: 00: 00$ & 598 & 0.635 & -0.672 & -0.037 & 2.005 & 2005 & 36.809 \\
\hline $17: 05: 00$ & 598 & 0.636 & -0.675 & -0.039 & 2.005 & 2005 & 36.809 \\
\hline $17: 10: 00$ & 598 & 0.636 & -0.672 & -0.036 & 2.005 & 2005 & 36.809 \\
\hline $17: 15: 00$ & 598 & 0.635 & -0.672 & -0.037 & 2.005 & 2005 & 36.809 \\
\hline $17: 20: 00$ & 598 & 0.633 & -0.671 & -0.038 & 2.005 & 2005 & 36.809 \\
\hline $17: 25: 00$ & 598 & 0.629 & -0.666 & -0.037 & 2.005 & 2005 & 36.809 \\
\hline $17: 30: 00$ & 598 & 0.632 & -0.670 & -0.038 & 2.005 & 2005 & 36.809 \\
\hline $17: 35: 00$ & 598 & 0.632 & -0.669 & -0.037 & 2.005 & 2005 & 36.809 \\
\hline $17: 40: 00$ & 598 & 0.641 & -0.678 & -0.037 & 2.005 & 2005 & 36.809 \\
\hline $17: 45: 00$ & 598 & 0.638 & -0.676 & -0.038 & 2.005 & 2005 & 36.809 \\
\hline $17: 50: 00$ & 598 & 0.635 & -0.673 & -0.038 & 2.005 & 2005 & 36.809 \\
\hline
\end{tabular}




\begin{tabular}{|c|c|c|c|c|c|c|c|}
\hline $17: 55: 00$ & 599 & 0.635 & -0.673 & -0.038 & 2.005 & 2005 & 36.809 \\
\hline 18:00:00 & 598 & 0.633 & -0.670 & -0.037 & 2.005 & 2005 & 36.809 \\
\hline 18:05:00 & 598 & 0.632 & -0.669 & -0.037 & 2.005 & 2005 & 36.809 \\
\hline 18:10:00 & 599 & 0.631 & -0.669 & -0.038 & 2.005 & 2005 & 36.809 \\
\hline 18:15:00 & 598 & 0.633 & -0.671 & -0.038 & 2.005 & 2005 & 36.809 \\
\hline 18:20:00 & 598 & 0.632 & -0.670 & -0.038 & 2.005 & 2005 & 36.809 \\
\hline $18: 25: 00$ & 598 & 0.633 & -0.672 & -0.039 & 2.005 & 2005 & 36.809 \\
\hline 18:30:00 & 598 & 0.632 & -0.669 & -0.037 & 2.005 & 2005 & 36.809 \\
\hline 18:35:00 & 598 & 0.653 & -0.689 & -0.036 & 2.005 & 2005 & 36.809 \\
\hline 18:40:00 & 598 & 0.638 & -0.678 & -0.040 & 2.005 & 2005 & 36.809 \\
\hline $18: 45: 00$ & 599 & 0.639 & -0.676 & -0.037 & 2.005 & 2005 & 36.809 \\
\hline 18:50:00 & 598 & 0.634 & -0.671 & -0.037 & 2.005 & 2005 & 36.809 \\
\hline 18:55:00 & 598 & 0.636 & -0.675 & -0.039 & 2.010 & 2010 & 36.901 \\
\hline 19:00:00 & 598 & 0.635 & -0.672 & -0.037 & 2.005 & 2005 & 36.809 \\
\hline 19:05:00 & 598 & 0.634 & -0.672 & -0.038 & 2.005 & 2005 & 36.809 \\
\hline 19:10:00 & 598 & 0.635 & -0.672 & -0.037 & 2.010 & 2010 & 36.901 \\
\hline 19:15:00 & 598 & 0.642 & -0.679 & -0.037 & 2.010 & 2010 & 36.901 \\
\hline 19:20:00 & 599 & 0.641 & -0.678 & -0.037 & 2.005 & 2005 & 36.809 \\
\hline $19: 25: 00$ & 598 & 0.636 & -0.674 & -0.038 & 2.005 & 2005 & 36.809 \\
\hline 19:30:00 & 598 & 0.636 & -0.674 & -0.038 & 2.005 & 2005 & 36.809 \\
\hline 19:35:00 & 599 & 0.635 & -0.673 & -0.038 & 2.010 & 2010 & 36.901 \\
\hline 19:40:00 & 598 & 0.634 & -0.671 & -0.037 & 2.005 & 2005 & 36.809 \\
\hline $19: 45: 00$ & 598 & 0.636 & -0.673 & -0.037 & 2.005 & 2005 & 36.809 \\
\hline 19:50:00 & 598 & 0.634 & -0.672 & -0.038 & 2.005 & 2005 & 36.809 \\
\hline $19: 55: 00$ & 599 & 0.635 & -0.672 & -0.037 & 2.005 & 2005 & 36.809 \\
\hline $20: 00: 00$ & 598 & 0.633 & -0.671 & -0.038 & 2.005 & 2005 & 36.809 \\
\hline 20:05:00 & 598 & 0.641 & -0.680 & -0.039 & 2.005 & 2005 & 36.809 \\
\hline 20:10:00 & 598 & 0.637 & -0.674 & -0.037 & 2.005 & 2005 & 36.809 \\
\hline 20:15:00 & 598 & 0.637 & -0.674 & -0.037 & 2.005 & 2005 & 36.809 \\
\hline 20:20:00 & 598 & 0.636 & -0.673 & -0.037 & 2.005 & 2005 & 36.809 \\
\hline $20: 25: 00$ & 598 & 0.636 & -0.674 & -0.038 & 2.005 & 2005 & 36.809 \\
\hline 20:30:00 & 599 & 0.636 & -0.674 & -0.038 & 2.005 & 2005 & 36.809 \\
\hline 20:35:00 & 598 & 0.647 & -0.684 & -0.037 & 2.010 & 2010 & 36.901 \\
\hline 20:40:00 & 598 & 0.642 & -0.680 & -0.038 & 2.010 & 2010 & 36.901 \\
\hline $20: 45: 00$ & 598 & 0.637 & -0.674 & -0.037 & 2.005 & 2005 & 36.809 \\
\hline 20:50:00 & 598 & 0.640 & -0.678 & -0.038 & 2.010 & 2010 & 36.901 \\
\hline 20:55:00 & 599 & 0.636 & -0.674 & -0.038 & 2.010 & 2010 & 36.901 \\
\hline 21:00:00 & 599 & 0.636 & -0.673 & -0.037 & 2.005 & 2005 & 36.809 \\
\hline 21:05:00 & 598 & 0.635 & -0.673 & -0.038 & 2.010 & 2010 & 36.901 \\
\hline 21:10:00 & 598 & 0.635 & -0.672 & -0.037 & 2.010 & 2010 & 36.901 \\
\hline 21:15:00 & 599 & 0.637 & -0.674 & -0.037 & 2.010 & 2010 & 36.901 \\
\hline 21:20:00 & 599 & 0.649 & -0.685 & -0.036 & 2.010 & 2010 & 36.901 \\
\hline $21: 25: 00$ & 598 & 0.642 & -0.680 & -0.038 & 2.010 & 2010 & 36.901 \\
\hline 21:30:00 & 599 & 0.641 & -0.680 & -0.039 & 2.010 & 2010 & 36.901 \\
\hline 21:35:00 & 598 & 0.637 & -0.675 & -0.038 & 2.010 & 2010 & 36.901 \\
\hline $21: 40: 00$ & 598 & 0.638 & -0.677 & -0.039 & 2.010 & 2010 & 36.901 \\
\hline $21: 45: 00$ & 598 & 0.642 & -0.679 & -0.037 & 2.010 & 2010 & 36.901 \\
\hline 21:50:00 & 598 & 0.638 & -0.676 & -0.038 & 2.010 & 2010 & 36.901 \\
\hline $21: 55: 00$ & 598 & 0.635 & -0.672 & -0.037 & 2.010 & 2010 & 36.901 \\
\hline 22:00:00 & 598 & 0.636 & -0.673 & -0.037 & 2.010 & 2010 & 36.901 \\
\hline 22:05:00 & 598 & 0.634 & -0.672 & -0.038 & 2.010 & 2010 & 36.901 \\
\hline 22:10:00 & 599 & 0.636 & -0.674 & -0.038 & 2.010 & 2010 & 36.901 \\
\hline 22:15:00 & 598 & 0.637 & -0.675 & -0.038 & 2.010 & 2010 & 36.901 \\
\hline 22:20:00 & 598 & 0.643 & -0.683 & -0.040 & 2.010 & 2010 & 36.901 \\
\hline $22: 25: 00$ & 599 & 0.641 & -0.680 & -0.039 & 2.010 & 2010 & 36.901 \\
\hline 22:30:00 & 598 & 0.636 & -0.673 & -0.037 & 2.010 & 2010 & 36.901 \\
\hline 22:35:00 & 598 & 0.636 & -0.673 & -0.037 & 2.010 & 2010 & 36.901 \\
\hline 22:40:00 & 599 & 0.635 & -0.673 & -0.038 & 2.010 & 2010 & 36.901 \\
\hline $22: 45: 00$ & 598 & 0.635 & -0.673 & -0.038 & 2.010 & 2010 & 36.901 \\
\hline 22:50:00 & 598 & 0.637 & -0.675 & -0.038 & 2.010 & 2010 & 36.901 \\
\hline 22:55:00 & 599 & 0.634 & -0.673 & -0.039 & 2.010 & 2010 & 36.901 \\
\hline 23:00:00 & 598 & 0.636 & -0.673 & -0.037 & 2.010 & 2010 & 36.901 \\
\hline 23:05:00 & 598 & 0.643 & -0.680 & -0.037 & 2.010 & 2010 & 36.901 \\
\hline
\end{tabular}




\begin{tabular}{|c|c|c|c|c|c|c|c|}
\hline 23:10:00 & 599 & 0.641 & -0.679 & -0.038 & 2.010 & 2010 & 36.901 \\
\hline $23: 15: 00$ & 598 & 0.641 & -0.679 & -0.038 & 2.010 & 2010 & 36.901 \\
\hline 23:20:00 & 598 & 0.635 & -0.672 & -0.037 & 2.010 & 2010 & 36.901 \\
\hline 23:25:00 & 599 & 0.635 & -0.673 & -0.038 & 2.010 & 2010 & 36.901 \\
\hline 23:30:00 & 599 & 0.636 & -0.674 & -0.038 & 2.010 & 2010 & 36.901 \\
\hline $23: 35: 00$ & 598 & 0.635 & -0.672 & -0.037 & 2.010 & 2010 & 36.901 \\
\hline 23:40:00 & 598 & 0.636 & -0.674 & -0.038 & 2.010 & 2010 & 36.901 \\
\hline $23: 45: 00$ & 598 & 0.639 & -0.677 & -0.038 & 2.010 & 2010 & 36.901 \\
\hline 23:50:00 & 598 & 0.638 & -0.678 & -0.040 & 2.010 & 2010 & 36.901 \\
\hline 23:55:00 & 599 & 0.635 & -0.673 & -0.038 & 2.010 & 2010 & 36.901 \\
\hline 00:00:00 & 598 & 0.635 & -0.673 & -0.038 & 2.010 & 2010 & 36.901 \\
\hline 00:05:00 & 598 & 0.634 & -0.672 & -0.038 & 2.010 & 2010 & 36.901 \\
\hline 00:10:00 & 599 & 0.635 & -0.673 & -0.038 & 2.010 & 2010 & 36.901 \\
\hline $00: 15: 00$ & 598 & 0.633 & -0.671 & -0.038 & 2.010 & 2010 & 36.901 \\
\hline 00:20:00 & 598 & 0.634 & -0.671 & -0.037 & 2.010 & 2010 & 36.901 \\
\hline $00: 25: 00$ & 599 & 0.639 & -0.677 & -0.038 & 2.010 & 2010 & 36.901 \\
\hline 00:30:00 & 598 & 0.637 & -0.675 & -0.038 & 2.010 & 2010 & 36.901 \\
\hline 00:35:00 & 598 & 0.635 & -0.673 & -0.038 & 2.010 & 2010 & 36.901 \\
\hline 00:40:00 & 598 & 0.635 & -0.673 & -0.038 & 2.010 & 2010 & 36.901 \\
\hline $00: 45: 00$ & 598 & 0.634 & -0.673 & -0.039 & 2.010 & 2010 & 36.901 \\
\hline 00:50:00 & 598 & 0.635 & -0.673 & -0.038 & 2.010 & 2010 & 36.901 \\
\hline 00:55:00 & 599 & 0.640 & -0.678 & -0.038 & 2.010 & 2010 & 36.901 \\
\hline 01:00:00 & 598 & 0.638 & -0.676 & -0.038 & 2.010 & 2010 & 36.901 \\
\hline 01:05:00 & 598 & 0.637 & -0.675 & -0.038 & 2.010 & 2010 & 36.901 \\
\hline 01:10:00 & 599 & 0.638 & -0.676 & -0.038 & 2.010 & 2010 & 36.901 \\
\hline 01:15:00 & 598 & 0.634 & -0.673 & -0.039 & 2.010 & 2010 & 36.901 \\
\hline 01:20:00 & 598 & 0.635 & -0.673 & -0.038 & 2.010 & 2010 & 36.901 \\
\hline 01:25:00 & 598 & 0.633 & -0.671 & -0.038 & 2.010 & 2010 & 36.901 \\
\hline 01:30:00 & 598 & 0.632 & -0.670 & -0.038 & 2.010 & 2010 & 36.901 \\
\hline 01:35:00 & 598 & 0.635 & -0.672 & -0.037 & 2.010 & 2010 & 36.901 \\
\hline 01:40:00 & 598 & 0.635 & -0.674 & -0.039 & 2.010 & 2010 & 36.901 \\
\hline 01:45:00 & 598 & 0.633 & -0.671 & -0.038 & 2.010 & 2010 & 36.901 \\
\hline 01:50:00 & 598 & 0.636 & -0.674 & -0.038 & 2.010 & 2010 & 36.901 \\
\hline 01:55:00 & 598 & 0.633 & -0.671 & -0.038 & 2.010 & 2010 & 36.901 \\
\hline 02:00:00 & 598 & 0.637 & -0.676 & -0.039 & 2.010 & 2010 & 36.901 \\
\hline 02:05:00 & 598 & 0.637 & -0.674 & -0.037 & 2.010 & 2010 & 36.901 \\
\hline 02:10:00 & 599 & 0.638 & -0.677 & -0.039 & 2.010 & 2010 & 36.901 \\
\hline 02:15:00 & 598 & 0.633 & -0.671 & -0.038 & 2.010 & 2010 & 36.901 \\
\hline 02:20:00 & 598 & 0.630 & -0.667 & -0.037 & 2.010 & 2010 & 36.901 \\
\hline 02:25:00 & 599 & 0.631 & -0.669 & -0.038 & 2.010 & 2010 & 36.901 \\
\hline 02:30:00 & 598 & 0.632 & -0.670 & -0.038 & 2.010 & 2010 & 36.901 \\
\hline 02:35:00 & 598 & 0.631 & -0.669 & -0.038 & 2.010 & 2010 & 36.901 \\
\hline 02:40:00 & 599 & 0.632 & -0.670 & -0.038 & 2.010 & 2010 & 36.901 \\
\hline 02:45:00 & 598 & 0.632 & -0.671 & -0.039 & 2.010 & 2010 & 36.901 \\
\hline 02:50:00 & 598 & 0.639 & -0.677 & -0.038 & 2.010 & 2010 & 36.901 \\
\hline 02:55:00 & 599 & 0.635 & -0.674 & -0.039 & 2.010 & 2010 & 36.901 \\
\hline 03:00:00 & 599 & 0.632 & -0.671 & -0.039 & 2.010 & 2010 & 36.901 \\
\hline 03:05:00 & 598 & 0.631 & -0.669 & -0.038 & 2.010 & 2010 & 36.901 \\
\hline 03:10:00 & 598 & 0.630 & -0.668 & -0.038 & 2.010 & 2010 & 36.901 \\
\hline 03:15:00 & 598 & 0.631 & -0.669 & -0.038 & 2.010 & 2010 & 36.901 \\
\hline 03:20:00 & 598 & 0.629 & -0.666 & -0.037 & 2.010 & 2010 & 36.901 \\
\hline 03:25:00 & 598 & 0.628 & -0.666 & -0.038 & 2.010 & 2010 & 36.901 \\
\hline 03:30:00 & 598 & 0.629 & -0.667 & -0.038 & 2.010 & 2010 & 36.901 \\
\hline 03:35:00 & 598 & 0.627 & -0.666 & -0.039 & 2.010 & 2010 & 36.901 \\
\hline 03:40:00 & 597 & 0.631 & -0.672 & -0.041 & 2.010 & 2010 & 36.901 \\
\hline 03:45:00 & 598 & 0.630 & -0.670 & -0.040 & 2.010 & 2010 & 36.901 \\
\hline 03:50:00 & 599 & 0.629 & -0.668 & -0.039 & 2.010 & 2010 & 36.901 \\
\hline 03:55:00 & 598 & 0.628 & -0.667 & -0.039 & 2.010 & 2010 & 36.901 \\
\hline 04:00:00 & 598 & 0.630 & -0.669 & -0.039 & 2.010 & 2010 & 36.901 \\
\hline 04:05:00 & 598 & 0.628 & -0.668 & -0.040 & 2.010 & 2010 & 36.901 \\
\hline 04:10:00 & 598 & 0.628 & -0.667 & -0.039 & 2.010 & 2010 & 36.901 \\
\hline 04:15:00 & 598 & 0.630 & -0.669 & -0.039 & 2.010 & 2010 & 36.901 \\
\hline 04:20:00 & 598 & 0.629 & -0.668 & -0.039 & 2.010 & 2010 & 36.901 \\
\hline
\end{tabular}




\begin{tabular}{|c|c|c|c|c|c|c|c|}
\hline 04:25:00 & 598 & 0.630 & -0.668 & -0.038 & 2.010 & 2010 & 36.901 \\
\hline 04:30:00 & 598 & 0.630 & -0.669 & -0.039 & 2.010 & 2010 & 36.901 \\
\hline 04:35:00 & 598 & 0.636 & -0.676 & -0.040 & 2.010 & 2010 & 36.901 \\
\hline 04:40:00 & 598 & 0.632 & -0.672 & -0.040 & 2.010 & 2010 & 36.901 \\
\hline 04:45:00 & 598 & 0.629 & -0.668 & -0.039 & 2.010 & 2010 & 36.901 \\
\hline 04:50:00 & 598 & 0.629 & -0.668 & -0.039 & 2.010 & 2010 & 36.901 \\
\hline 04:55:00 & 598 & 0.628 & -0.667 & -0.039 & 2.010 & 2010 & 36.901 \\
\hline 05:00:00 & 599 & 0.627 & -0.666 & -0.039 & 2.010 & 2010 & 36.901 \\
\hline 05:05:00 & 598 & 0.627 & -0.667 & -0.040 & 2.010 & 2010 & 36.901 \\
\hline 05:10:00 & 598 & 0.624 & -0.668 & -0.044 & 2.010 & 2010 & 36.901 \\
\hline 05:15:00 & 598 & 0.626 & -0.668 & -0.042 & 2.010 & 2010 & 36.901 \\
\hline 05:20:00 & 598 & 0.628 & -0.669 & -0.041 & 2.010 & 2010 & 36.901 \\
\hline 05:25:00 & 598 & 0.627 & -0.668 & -0.041 & 2.010 & 2010 & 36.901 \\
\hline 05:30:00 & 598 & 0.626 & -0.667 & -0.041 & 2.010 & 2010 & 36.901 \\
\hline 05:35:00 & 598 & 0.622 & -0.663 & -0.041 & 2.010 & 2010 & 36.901 \\
\hline 05:40:00 & 598 & 0.621 & -0.661 & -0.040 & 2.010 & 2010 & 36.901 \\
\hline 05:45:00 & 599 & 0.622 & -0.662 & -0.040 & 2.010 & 2010 & 36.901 \\
\hline 05:50:00 & 598 & 0.620 & -0.661 & -0.041 & 2.010 & 2010 & 36.901 \\
\hline 05:55:00 & 598 & 0.619 & -0.659 & -0.040 & 2.010 & 2010 & 36.901 \\
\hline 06:00:00 & 598 & 0.621 & -0.662 & -0.041 & 2.010 & 2010 & 36.901 \\
\hline 06:05:00 & 598 & 0.620 & -0.660 & -0.040 & 2.010 & 2010 & 36.901 \\
\hline 06:10:00 & 598 & 0.621 & -0.661 & -0.040 & 2.010 & 2010 & 36.901 \\
\hline 06:15:00 & 598 & 0.619 & -0.661 & -0.042 & 2.010 & 2010 & 36.901 \\
\hline 06:20:00 & 598 & 0.618 & -0.660 & -0.042 & 2.010 & 2010 & 36.901 \\
\hline 06:25:00 & 598 & 0.618 & -0.659 & -0.041 & 2.010 & 2010 & 36.901 \\
\hline 06:30:00 & 598 & 0.618 & -0.660 & -0.042 & 2.010 & 2010 & 36.901 \\
\hline 06:35:00 & 598 & 0.618 & -0.659 & -0.041 & 2.010 & 2010 & 36.901 \\
\hline 06:40:00 & 598 & 0.618 & -0.659 & -0.041 & 2.010 & 2010 & 36.901 \\
\hline 06:45:00 & 598 & 0.618 & -0.659 & -0.041 & 2.010 & 2010 & 36.901 \\
\hline 06:50:00 & 598 & 0.618 & -0.658 & -0.040 & 2.010 & 2010 & 36.901 \\
\hline 06:55:00 & 598 & 0.617 & -0.658 & -0.041 & 2.010 & 2010 & 36.901 \\
\hline 07:00:00 & 598 & 0.615 & -0.656 & -0.041 & 2.010 & 2010 & 36.901 \\
\hline 07:05:00 & 598 & 0.617 & -0.657 & -0.04 & 2.01 & 2010 & 36.901 \\
\hline 07:10:00 & 598 & 0.616 & -0.657 & -0.041 & 2.01 & 2010 & 36.901 \\
\hline 07:15:00 & 598 & 0.616 & -0.658 & -0.042 & 2.01 & 2010 & 36.901 \\
\hline 07:20:00 & 598 & 0.615 & -0.655 & -0.04 & 2.005 & 2005 & 36.809 \\
\hline 07:25:00 & 598 & 0.613 & -0.654 & -0.041 & 2.005 & 2005 & 36.809 \\
\hline 07:30:00 & 598 & 0.616 & -0.658 & -0.042 & 2.005 & 2005 & 36.809 \\
\hline 07:35:00 & 598 & 0.614 & -0.655 & -0.041 & 2.005 & 2005 & 36.809 \\
\hline 07:40:00 & 598 & 0.611 & -0.660 & -0.049 & 2.005 & 2005 & 36.809 \\
\hline 07:45:00 & 598 & 0.611 & -0.656 & -0.045 & 2.005 & 2005 & 36.809 \\
\hline 07:50:00 & 598 & 0.613 & -0.656 & -0.043 & 2.005 & 2005 & 36.809 \\
\hline 07:55:00 & 598 & 0.612 & -0.653 & -0.041 & 2.005 & 2005 & 36.809 \\
\hline 08:00:00 & 598 & 0.611 & -0.652 & -0.041 & 2.005 & 2005 & 36.809 \\
\hline 08:05:00 & 598 & 0.611 & -0.652 & -0.041 & 2.005 & 2005 & 36.809 \\
\hline 08:10:00 & 598 & 0.613 & -0.653 & -0.04 & 2.010 & 2010 & 36.901 \\
\hline 08:15:00 & 598 & 0.611 & -0.652 & -0.041 & 2.005 & 2005 & 36.809 \\
\hline 08:20:00 & 598 & 0.611 & -0.651 & -0.04 & 2.005 & 2005 & 36.809 \\
\hline 08:25:00 & 598 & 0.612 & -0.654 & -0.042 & 2.005 & 2005 & 36.809 \\
\hline 08:30:00 & 598 & 0.610 & -0.651 & -0.041 & 2.005 & 2005 & 36.809 \\
\hline 08:35:00 & 598 & 0.612 & -0.653 & -0.041 & 2.005 & 2005 & 36.809 \\
\hline 08:40:00 & 598 & 0.615 & -0.657 & -0.042 & 2.005 & 2005 & 36.809 \\
\hline 08:45:00 & 598 & 0.611 & -0.654 & -0.043 & 2.005 & 2005 & 36.809 \\
\hline 08:50:00 & 598 & 0.610 & -0.651 & -0.041 & 2.005 & 2005 & 36.809 \\
\hline 08:55:00 & 598 & 0.609 & -0.650 & -0.041 & 2.005 & 2005 & 36.809 \\
\hline 09:00:00 & 598 & 0.609 & -0.651 & -0.042 & 2.005 & 2005 & 36.809 \\
\hline 09:05:00 & 598 & 0.609 & -0.651 & -0.042 & 2.005 & 2005 & 36.809 \\
\hline 09:10:00 & 598 & 0.609 & -0.651 & -0.042 & 2.005 & 2005 & 36.809 \\
\hline 09:15:00 & 598 & 0.610 & -0.652 & -0.042 & 2.005 & 2005 & 36.809 \\
\hline 09:20:00 & 598 & 0.609 & -0.651 & -0.042 & 2.005 & 2005 & 36.809 \\
\hline 09:25:00 & 598 & 0.607 & -0.649 & -0.042 & 2.005 & 2005 & 36.809 \\
\hline 09:30:00 & 598 & 0.609 & -0.652 & -0.043 & 2.005 & 2005 & 36.809 \\
\hline 09:35:00 & 598 & 0.607 & -0.650 & -0.043 & 2.005 & 2005 & 36.809 \\
\hline
\end{tabular}




$\begin{array}{llllllll}09: 40: 00 & 598 & 0.606 & -0.649 & -0.043 & 2.005 & 2005 & 36.809 \\ \text { 09:45:00 } & 598 & 0.607 & -0.650 & -0.043 & 2.005 & 2005 & 36.809 \\ \text { 09:50:00 } & 598 & 0.606 & -0.648 & -0.042 & 2.005 & 2005 & 36.809 \\ \text { 09:55:00 } & 598 & 0.606 & -0.649 & -0.043 & 2.005 & 2005 & 36.809 \\ \text { 10:00:00 } & 598 & 0.606 & -0.650 & -0.044 & 2.005 & 2005 & 36.809 \\ \text { 10:05:00 } & 598 & 0.608 & -0.651 & -0.043 & 2.005 & 2005 & 36.809 \\ \text { 10:10:00 } & 598 & 0.606 & -0.649 & -0.043 & 2.005 & 2005 & 36.809 \\ \text { 10:15:00 } & 599 & 0.606 & -0.650 & -0.044 & 2.005 & 2005 & 36.809 \\ \text { 10:20:00 } & 598 & 0.605 & -0.647 & -0.042 & 2.005 & 2005 & 36.809 \\ \text { 10:25:00 } & 598 & 0.605 & -0.648 & -0.043 & 2.005 & 2005 & 36.809 \\ 10: 30: 00 & 598 & 0.605 & -0.648 & -0.043 & 2.01 & 2010 & 36.901\end{array}$

Graphite Rod, Air Flow Rate $=0.50$ SLPM, T $=600^{\circ} \mathrm{C}, 3 / 8 / 2006$

\begin{tabular}{cccccc}
\multicolumn{2}{c}{0.50 SLPM $(1)$} & \multicolumn{4}{c}{0.50 SLPM $(2)$} \\
I/SA & VCELL & P/SA & I/SA & VCELL & P/SA \\
0.090 & 0.736 & 0.000 & 0.090 & 0.767 & 0.000 \\
0.090 & 0.735 & 0.000 & 0.090 & 0.766 & 0.000 \\
0.090 & 0.736 & 0.000 & 0.090 & 0.766 & 0.000 \\
0.090 & 0.751 & 0.000 & 0.090 & 0.757 & 0.000 \\
0.090 & 0.752 & 0.000 & 0.090 & 0.760 & 0.000 \\
0.090 & 0.754 & 0.000 & 0.090 & 0.763 & 0.000 \\
2.255 & 0.730 & 0.002 & 0.090 & 0.764 & 0.000 \\
4.511 & 0.726 & 0.003 & 2.255 & 0.760 & 0.002 \\
6.766 & 0.722 & 0.005 & 4.511 & 0.752 & 0.003 \\
9.021 & 0.716 & 0.006 & 6.766 & 0.746 & 0.005 \\
11.322 & 0.713 & 0.008 & 9.021 & 0.738 & 0.007 \\
13.532 & 0.711 & 0.010 & 11.322 & 0.731 & 0.008 \\
15.832 & 0.713 & 0.011 & 13.577 & 0.724 & 0.010 \\
18.088 & 0.708 & 0.013 & 15.832 & 0.716 & 0.011 \\
20.343 & 0.703 & 0.014 & 18.088 & 0.710 & 0.013 \\
22.598 & 0.698 & 0.016 & 20.343 & 0.703 & 0.014 \\
24.853 & 0.693 & 0.017 & 22.598 & 0.698 & 0.016 \\
27.109 & 0.688 & 0.019 & 24.853 & 0.689 & 0.017 \\
29.364 & 0.681 & 0.020 & 27.109 & 0.684 & 0.019 \\
31.619 & 0.676 & 0.021 & 29.364 & 0.675 & 0.020 \\
33.875 & 0.669 & 0.023 & 31.619 & 0.669 & 0.021 \\
36.130 & 0.663 & 0.024 & 33.875 & 0.664 & 0.022 \\
38.385 & 0.657 & 0.025 & 36.130 & 0.657 & 0.024 \\
40.641 & 0.652 & 0.026 & 38.385 & 0.650 & 0.025 \\
42.896 & 0.647 & 0.028 & 40.641 & 0.643 & 0.026 \\
45.151 & 0.642 & 0.029 & 42.896 & 0.638 & 0.027 \\
47.406 & 0.639 & 0.030 & 45.151 & 0.631 & 0.028 \\
49.662 & 0.635 & 0.032 & 47.406 & 0.624 & 0.030 \\
51.962 & 0.631 & 0.033 & 49.662 & 0.617 & 0.031 \\
54.172 & 0.625 & 0.034 & 51.962 & 0.611 & 0.032 \\
56.428 & 0.621 & 0.035 & 54.172 & 0.604 & 0.033 \\
58.683 & 0.617 & 0.036 & 56.473 & 0.598 & 0.034 \\
60.983 & 0.612 & 0.037 & 58.683 & 0.591 & 0.035 \\
63.194 & 0.608 & 0.038 & 60.983 & 0.585 & 0.036 \\
65.494 & 0.604 & 0.040 & 63.239 & 0.579 & 0.037 \\
67.749 & 0.598 & 0.041 & 65.494 & 0.569 & 0.037 \\
70.005 & 0.593 & 0.042 & 67.749 & 0.562 & 0.038 \\
72.260 & 0.589 & 0.043 & 70.005 & 0.556 & 0.039 \\
74.515 & 0.587 & 0.044 & 72.260 & 0.547 & 0.040 \\
79.026 & 0.578 & 0.046 & 76.770 & 0.533 & 0.041
\end{tabular}




$\begin{array}{cccccc}81.281 & 0.574 & 0.047 & 79.026 & 0.519 & 0.041 \\ 83.536 & 0.570 & 0.048 & 81.281 & 0.509 & 0.041 \\ 85.792 & 0.567 & 0.049 & 83.536 & 0.497 & 0.042 \\ 88.047 & 0.561 & 0.049 & 85.792 & 0.491 & 0.042 \\ 90.302 & 0.557 & 0.050 & 88.047 & 0.477 & 0.042 \\ 92.558 & 0.553 & 0.051 & 90.302 & 0.457 & 0.041 \\ 94.813 & 0.548 & 0.052 & 92.558 & 0.431 & 0.040 \\ 97.068 & 0.545 & 0.053 & 94.813 & 0.414 & 0.039 \\ 99.323 & 0.539 & 0.054 & 97.068 & 0.395 & 0.038 \\ 101.579 & 0.537 & 0.055 & 99.323 & 0.346 & 0.034 \\ 103.834 & 0.529 & 0.055 & 101.579 & 0.283 & 0.029 \\ 106.089 & 0.527 & 0.056 & & & \\ 108.345 & 0.520 & 0.056 & & & \\ 110.645 & 0.514 & 0.057 & & & \\ 112.900 & 0.509 & 0.057 & & & \\ 115.111 & 0.507 & 0.058 & & & \\ 117.366 & 0.501 & 0.059 & & & \\ 119.666 & 0.495 & 0.059 & & & \\ 121.922 & 0.488 & 0.059 & & & \\ 124.177 & 0.478 & 0.059 & & & \\ 126.432 & 0.476 & 0.060 & & & \\ 128.687 & 0.459 & 0.059 & & & \\ 130.943 & 0.452 & 0.059 & & & \\ 133.198 & 0.435 & 0.058 & & & \\ 135.453 & 0.431 & 0.058 & & & \\ 137.709 & 0.394 & 0.054 & & & \\ 139.964 & 0.363 & 0.051 & & & \end{array}$

Graphite Rod, Long Term Run, Air Flow Rate $=0.50$ SLPM, $\mathrm{T}=600^{\circ} \mathrm{C}, 3 / 8 / 2006$

\begin{tabular}{|c|c|c|c|c|c|c|}
\hline $\begin{array}{l}\text { Cemp } \\
\left({ }^{\circ} \mathrm{C}\right)\end{array}$ & VCELL & VANODE & VCATHODE & I (A) & $\stackrel{\text { I }}{\text { I } \mathrm{mA})}$ & I/SA \\
\hline 600 & 0.690 & -0.717 & -0.027 & 1.502 & 1502 & 33.875 \\
\hline 600 & 0.688 & -0.716 & -0.028 & 1.502 & 1502 & 33.875 \\
\hline 600 & 0.689 & -0.716 & -0.027 & 1.502 & 1502 & 33.875 \\
\hline 600 & 0.687 & -0.714 & -0.027 & 1.502 & 1502 & 33.875 \\
\hline 600 & 0.685 & -0.711 & -0.026 & 1.502 & 1502 & 33.875 \\
\hline 600 & 0.682 & -0.708 & -0.026 & 1.502 & 1502 & 33.875 \\
\hline 600 & 0.680 & -0.706 & -0.026 & 1.502 & 1502 & 33.875 \\
\hline 600 & 0.676 & -0.702 & -0.026 & 1.502 & 1502 & 33.875 \\
\hline 600 & 0.671 & -0.696 & -0.025 & 1.502 & 1502 & 33.875 \\
\hline 600 & 0.663 & -0.688 & -0.025 & 1.502 & 1502 & 33.875 \\
\hline 600 & 0.657 & -0.682 & -0.025 & 1.502 & 1502 & 33.875 \\
\hline 600 & 0.650 & -0.674 & -0.024 & 1.502 & 1502 & 33.875 \\
\hline 600 & 0.638 & -0.663 & -0.025 & 1.502 & 1502 & 33.875 \\
\hline 600 & 0.629 & -0.653 & -0.024 & 1.502 & 1502 & 33.875 \\
\hline 600 & 0.623 & -0.647 & -0.024 & 1.502 & 1502 & 33.875 \\
\hline 600 & 0.616 & -0.641 & -0.025 & 1.502 & 1502 & 33.875 \\
\hline 600 & 0.609 & -0.633 & -0.024 & 1.502 & 1502 & 33.875 \\
\hline 600 & 0.603 & -0.629 & -0.026 & 1.502 & 1502 & 33.875 \\
\hline 600 & 0.596 & -0.620 & -0.024 & 1.502 & 1502 & 33.875 \\
\hline 600 & 0.592 & -0.617 & -0.025 & 1.502 & 1502 & 33.875 \\
\hline 600 & 0.586 & -0.611 & -0.025 & 1.502 & 1502 & 33.875 \\
\hline 600 & 0.584 & -0.609 & -0.025 & 1.502 & 1502 & 33.875 \\
\hline 600 & 0.582 & -0.606 & -0.024 & 1.502 & 1502 & 33.875 \\
\hline 600 & 0.572 & -0.596 & -0.024 & 1.502 & 1502 & 33.875 \\
\hline 600 & 0.571 & -0.595 & -0.024 & 1.502 & 1502 & 33.875 \\
\hline 600 & 0.564 & -0.588 & -0.024 & 1.502 & 1502 & 33.875 \\
\hline
\end{tabular}




\begin{tabular}{|c|c|c|c|c|c|c|}
\hline 600 & 0.566 & -0.590 & -0.024 & 1.502 & 1502 & 33.875 \\
\hline 600 & 0.564 & -0.588 & -0.024 & 1.502 & 1502 & 33.875 \\
\hline 600 & 0.710 & -0.734 & -0.024 & 1.502 & 1502 & 33.875 \\
\hline 600 & 0.665 & -0.692 & -0.027 & 1.502 & 1502 & 33.875 \\
\hline 600 & 0.660 & -0.688 & -0.028 & 1.502 & 1502 & 33.875 \\
\hline 600 & 0.666 & -0.691 & -0.025 & 1.502 & 1502 & 33.875 \\
\hline 600 & 0.669 & -0.694 & -0.025 & 1.502 & 1502 & 33.875 \\
\hline 600 & 0.669 & -0.695 & -0.026 & 1.502 & 1502 & 33.875 \\
\hline 600 & 0.669 & -0.694 & -0.025 & 1.502 & 1502 & 33.875 \\
\hline 600 & 0.671 & -0.697 & -0.026 & 1.502 & 1502 & 33.875 \\
\hline 600 & 0.671 & -0.697 & -0.026 & 1.502 & 1502 & 33.875 \\
\hline 600 & 0.671 & -0.696 & -0.025 & 1.502 & 1502 & 33.875 \\
\hline 600 & 0.670 & -0.696 & -0.026 & 1.502 & 1502 & 33.875 \\
\hline 600 & 0.671 & -0.696 & -0.025 & 1.502 & 1502 & 33.875 \\
\hline 600 & 0.674 & -0.700 & -0.026 & 1.502 & 1502 & 33.875 \\
\hline 600 & 0.671 & -0.698 & -0.027 & 1.502 & 1502 & 33.875 \\
\hline 600 & 0.669 & -0.695 & -0.026 & 1.502 & 1502 & 33.875 \\
\hline 600 & 0.671 & -0.698 & -0.027 & 1.502 & 1502 & 33.875 \\
\hline 600 & 0.672 & -0.699 & -0.027 & 1.502 & 1502 & 33.875 \\
\hline 600 & 0.673 & -0.699 & -0.026 & 1.502 & 1502 & 33.875 \\
\hline 600 & 0.672 & -0.698 & -0.026 & 1.502 & 1502 & 33.875 \\
\hline 600 & 0.676 & -0.702 & -0.026 & 1.502 & 1502 & 33.875 \\
\hline 600 & 0.676 & -0.703 & -0.027 & 1.502 & 1502 & 33.875 \\
\hline 600 & 0.674 & -0.700 & -0.026 & 1.502 & 1502 & 33.875 \\
\hline 600 & 0.676 & -0.703 & -0.027 & 1.502 & 1502 & 33.875 \\
\hline 600 & 0.677 & -0.703 & -0.026 & 1.502 & 1502 & 33.875 \\
\hline 600 & 0.679 & -0.705 & -0.026 & 1.502 & 1502 & 33.875 \\
\hline 600 & 0.678 & -0.704 & -0.026 & 1.502 & 1502 & 33.875 \\
\hline 600 & 0.678 & -0.704 & -0.026 & 1.502 & 1502 & 33.875 \\
\hline 600 & 0.677 & -0.704 & -0.027 & 1.502 & 1502 & 33.875 \\
\hline 600 & 0.679 & -0.705 & -0.026 & 1.502 & 1502 & 33.875 \\
\hline 600 & 0.680 & -0.707 & -0.027 & 1.502 & 1502 & 33.875 \\
\hline 600 & 0.688 & -0.714 & -0.026 & 1.502 & 1502 & 33.875 \\
\hline 600 & 0.686 & -0.713 & -0.027 & 1.502 & 1502 & 33.875 \\
\hline 600 & 0.686 & -0.712 & -0.026 & 1.502 & 1502 & 33.875 \\
\hline 600 & 0.686 & -0.712 & -0.026 & 1.502 & 1502 & 33.875 \\
\hline 600 & 0.686 & -0.712 & -0.026 & 1.502 & 1502 & 33.875 \\
\hline 600 & 0.685 & -0.711 & -0.026 & 1.502 & 1502 & 33.875 \\
\hline 600 & 0.687 & -0.713 & -0.026 & 1.502 & 1502 & 33.875 \\
\hline 600 & 0.686 & -0.713 & -0.027 & 1.502 & 1502 & 33.875 \\
\hline 600 & 0.686 & -0.713 & -0.027 & 1.502 & 1502 & 33.875 \\
\hline 600 & 0.685 & -0.712 & -0.027 & 1.502 & 1502 & 33.875 \\
\hline 600 & 0.684 & -0.711 & -0.027 & 1.502 & 1502 & 33.875 \\
\hline 600 & 0.684 & -0.711 & -0.027 & 1.502 & 1502 & 33.875 \\
\hline 600 & 0.683 & -0.710 & -0.027 & 1.502 & 1502 & 33.875 \\
\hline 600 & 0.684 & -0.710 & -0.026 & 1.502 & 1502 & 33.875 \\
\hline 600 & 0.678 & -0.706 & -0.028 & 1.502 & 1502 & 33.875 \\
\hline 600 & 0.677 & -0.704 & -0.027 & 1.502 & 1502 & 33.875 \\
\hline 600 & 0.675 & -0.702 & -0.027 & 1.502 & 1502 & 33.875 \\
\hline 600 & 0.673 & -0.700 & -0.027 & 1.502 & 1502 & 33.87 \\
\hline 600 & 0.671 & -0.699 & -0.028 & 1.502 & 1502 & 33.875 \\
\hline 600 & 0.670 & -0.699 & -0.029 & 1.502 & 1502 & 33.875 \\
\hline 600 & 0.667 & -0.694 & -0.027 & 1.502 & 1502 & 33.875 \\
\hline 600 & 0.665 & -0.693 & -0.028 & 1.502 & 1502 & 33.875 \\
\hline 600 & 0.669 & -0.698 & -0.029 & 1.502 & 1502 & 33.87 \\
\hline 600 & 0.668 & -0.697 & -0.029 & 1.502 & 1502 & 33.875 \\
\hline 600 & 0.668 & -0.696 & -0.028 & 1.502 & 1502 & 33.87 \\
\hline 600 & 0.667 & -0.695 & -0.028 & 1.502 & 1502 & 33.875 \\
\hline 600 & 0.668 & -0.696 & -0.028 & 1.502 & 1502 & 33.875 \\
\hline 600 & 0.668 & -0.696 & -0.028 & 1.502 & 1502 & 33.87 \\
\hline 600 & 0.666 & -0.694 & -0.028 & 1.502 & 1502 & 33.875 \\
\hline 600 & 0.668 & -0.697 & -0.029 & 1.502 & 1502 & 33.875 \\
\hline 600 & 0.667 & -0.695 & -0.028 & 1.502 & 1502 & 33.87 \\
\hline
\end{tabular}




\begin{tabular}{|c|c|c|c|c|c|c|}
\hline 600 & 0.665 & -0.693 & -0.028 & 1.502 & 1502 & 33.875 \\
\hline 600 & 0.667 & -0.695 & -0.028 & 1.502 & 1502 & 33.875 \\
\hline 600 & 0.667 & -0.697 & -0.030 & 1.502 & 1502 & 33.875 \\
\hline 600 & 0.667 & -0.696 & -0.029 & 1.502 & 1502 & 33.875 \\
\hline 600 & 0.667 & -0.695 & -0.028 & 1.502 & 1502 & 33.875 \\
\hline 600 & 0.668 & -0.696 & -0.028 & 1.502 & 1502 & 33.875 \\
\hline 600 & 0.666 & -0.695 & -0.029 & 1.502 & 1502 & 33.875 \\
\hline 600 & 0.668 & -0.696 & -0.028 & 1.502 & 1502 & 33.875 \\
\hline 600 & 0.667 & -0.695 & -0.028 & 1.502 & 1502 & 33.875 \\
\hline 600 & 0.667 & -0.696 & -0.029 & 1.502 & 1502 & 33.875 \\
\hline 600 & 0.667 & -0.696 & -0.029 & 1.502 & 1502 & 33.875 \\
\hline 600 & 0.668 & -0.696 & -0.028 & 1.502 & 1502 & 33.875 \\
\hline 600 & 0.667 & -0.696 & -0.029 & 1.502 & 1502 & 33.875 \\
\hline 600 & 0.667 & -0.696 & -0.029 & 1.502 & 1502 & 33.875 \\
\hline 600 & 0.669 & -0.698 & -0.029 & 1.502 & 1502 & 33.875 \\
\hline 600 & 0.667 & -0.696 & -0.029 & 1.502 & 1502 & 33.875 \\
\hline 600 & 0.667 & -0.697 & -0.030 & 1.502 & 1502 & 33.875 \\
\hline 600 & 0.669 & -0.698 & -0.029 & 1.502 & 1502 & 33.875 \\
\hline 600 & 0.666 & -0.695 & -0.029 & 1.502 & 1502 & 33.875 \\
\hline 600 & 0.668 & -0.697 & -0.029 & 1.502 & 1502 & 33.875 \\
\hline 600 & 0.667 & -0.696 & -0.029 & 1.502 & 1502 & 33.875 \\
\hline 600 & 0.666 & -0.695 & -0.029 & 1.502 & 1502 & 33.875 \\
\hline 600 & 0.666 & -0.696 & -0.030 & 1.502 & 1502 & 33.875 \\
\hline 600 & 0.667 & -0.696 & -0.029 & 1.502 & 1502 & 33.875 \\
\hline 600 & 0.666 & -0.695 & -0.029 & 1.502 & 1502 & 33.875 \\
\hline 600 & 0.668 & -0.698 & -0.030 & 1.502 & 1502 & 33.875 \\
\hline 600 & 0.670 & -0.699 & -0.029 & 1.502 & 1502 & 33.875 \\
\hline 600 & 0.670 & -0.699 & -0.029 & 1.502 & 1502 & 33.875 \\
\hline 600 & 0.670 & -0.699 & -0.029 & 1.502 & 1502 & 33.875 \\
\hline 600 & 0.669 & -0.699 & -0.030 & 1.502 & 1502 & 33.875 \\
\hline 600 & 0.670 & -0.700 & -0.030 & 1.502 & 1502 & 33.875 \\
\hline 600 & 0.669 & -0.699 & -0.030 & 1.502 & 1502 & 33.875 \\
\hline 600 & 0.668 & -0.699 & -0.031 & 1.502 & 1502 & 33.875 \\
\hline 600 & 0.671 & -0.701 & -0.030 & 1.502 & 1502 & 33.875 \\
\hline 600 & 0.671 & -0.701 & -0.030 & 1.502 & 1502 & 33.875 \\
\hline 600 & 0.673 & -0.704 & -0.031 & 1.502 & 1502 & 33.875 \\
\hline 600 & 0.674 & -0.705 & -0.031 & 1.502 & 1502 & 33.875 \\
\hline 600 & 0.676 & -0.707 & -0.031 & 1.502 & 1502 & 33.875 \\
\hline 600 & 0.674 & -0.704 & -0.030 & 1.502 & 1502 & 33.875 \\
\hline 600 & 0.675 & -0.707 & -0.032 & 1.502 & 1502 & 33.875 \\
\hline 600 & 0.675 & -0.706 & -0.031 & 1.502 & 1502 & 33.875 \\
\hline 600 & 0.675 & -0.707 & -0.032 & 1.502 & 1502 & 33.875 \\
\hline 600 & 0.675 & -0.705 & -0.030 & 1.502 & 1502 & 33.87 \\
\hline 600 & 0.673 & -0.704 & -0.031 & 1.502 & 1502 & 33.875 \\
\hline 600 & 0.678 & -0.708 & -0.030 & 1.502 & 1502 & 33.875 \\
\hline 600 & 0.677 & -0.707 & -0.030 & 1.502 & 1502 & 33.875 \\
\hline 600 & 0.677 & -0.707 & -0.030 & 1.502 & 1502 & 33.875 \\
\hline 600 & 0.677 & -0.708 & -0.031 & 1.502 & 1502 & 33.875 \\
\hline 600 & 0.678 & -0.709 & -0.031 & 1.502 & 1502 & 33.875 \\
\hline 600 & 0.676 & -0.707 & -0.031 & 1.502 & 1502 & 33.875 \\
\hline 600 & 0.677 & -0.708 & -0.031 & 1.502 & 1502 & 33.875 \\
\hline 600 & 0.676 & -0.708 & -0.032 & 1.502 & 1502 & 33.875 \\
\hline 600 & 0.676 & -0.707 & -0.031 & 1.502 & 1502 & 33.875 \\
\hline 600 & 0.677 & -0.708 & -0.031 & 1.502 & 1502 & 33.87 \\
\hline 600 & 0.675 & -0.707 & -0.032 & 1.502 & 1502 & 33.87 \\
\hline 600 & 0.676 & -0.707 & -0.031 & 1.502 & 1502 & 33.87 \\
\hline 600 & 0.675 & -0.708 & -0.033 & 1.502 & 1502 & 33.87 \\
\hline 600 & 0.675 & -0.706 & -0.031 & 1.502 & 1502 & 33.875 \\
\hline 600 & 0.674 & -0.708 & -0.034 & 1.502 & 1502 & 33.875 \\
\hline 600 & 0.675 & -0.706 & -0.031 & 1.502 & 1502 & 33.875 \\
\hline 600 & 0.677 & -0.708 & -0.031 & 1.502 & 1502 & 33.87 \\
\hline 600 & 0.673 & -0.705 & -0.032 & 1.502 & 1502 & 33.875 \\
\hline 600 & 0.673 & -0.703 & -0.030 & 1.502 & 1502 & 33.87 \\
\hline
\end{tabular}




\begin{tabular}{|c|c|c|c|c|c|c|}
\hline 600 & 0.674 & -0.705 & -0.031 & 1.502 & 1502 & 33.875 \\
\hline 600 & 0.676 & -0.708 & -0.032 & 1.502 & 1502 & 33.875 \\
\hline 600 & 0.677 & -0.708 & -0.031 & 1.502 & 1502 & 33.875 \\
\hline 600 & 0.677 & -0.708 & -0.031 & 1.502 & 1502 & 33.875 \\
\hline 600 & 0.677 & -0.709 & -0.032 & 1.502 & 1502 & 33.875 \\
\hline 600 & 0.677 & -0.708 & -0.031 & 1.502 & 1502 & 33.875 \\
\hline 600 & 0.676 & -0.708 & -0.032 & 1.502 & 1502 & 33.875 \\
\hline 600 & 0.676 & -0.707 & -0.031 & 1.502 & 1502 & 33.875 \\
\hline 600 & 0.675 & -0.706 & -0.031 & 1.502 & 1502 & 33.875 \\
\hline 600 & 0.675 & -0.706 & -0.031 & 1.502 & 1502 & 33.875 \\
\hline 600 & 0.675 & -0.707 & -0.032 & 1.502 & 1502 & 33.875 \\
\hline 600 & 0.675 & -0.707 & -0.032 & 1.502 & 1502 & 33.875 \\
\hline 600 & 0.675 & -0.706 & -0.031 & 1.502 & 1502 & 33.875 \\
\hline 600 & 0.676 & -0.708 & -0.032 & 1.502 & 1502 & 33.875 \\
\hline 600 & 0.673 & -0.705 & -0.032 & 1.502 & 1502 & 33.875 \\
\hline 600 & 0.674 & -0.705 & -0.031 & 1.502 & 1502 & 33.875 \\
\hline 600 & 0.673 & -0.706 & -0.033 & 1.502 & 1502 & 33.875 \\
\hline 600 & 0.675 & -0.707 & -0.032 & 1.502 & 1502 & 33.875 \\
\hline 600 & 0.675 & -0.707 & -0.032 & 1.502 & 1502 & 33.875 \\
\hline 600 & 0.673 & -0.704 & -0.031 & 1.502 & 1502 & 33.875 \\
\hline 600 & 0.670 & -0.703 & -0.033 & 1.502 & 1502 & 33.875 \\
\hline 600 & 0.670 & -0.703 & -0.033 & 1.502 & 1502 & 33.875 \\
\hline 600 & 0.670 & -0.701 & -0.031 & 1.502 & 1502 & 33.875 \\
\hline 600 & 0.671 & -0.704 & -0.033 & 1.502 & 1502 & 33.875 \\
\hline 600 & 0.670 & -0.702 & -0.032 & 1.502 & 1502 & 33.875 \\
\hline 600 & 0.669 & -0.702 & -0.033 & 1.502 & 1502 & 33.875 \\
\hline 600 & 0.671 & -0.703 & -0.032 & 1.502 & 1502 & 33.875 \\
\hline 600 & 0.669 & -0.701 & -0.032 & 1.502 & 1502 & 33.875 \\
\hline 600 & 0.669 & -0.702 & -0.033 & 1.502 & 1502 & 33.875 \\
\hline 600 & 0.669 & -0.702 & -0.033 & 1.502 & 1502 & 33.875 \\
\hline 600 & 0.667 & -0.700 & -0.033 & 1.502 & 1502 & 33.875 \\
\hline 600 & 0.669 & -0.701 & -0.032 & 1.502 & 1502 & 33.875 \\
\hline 600 & 0.667 & -0.699 & -0.032 & 1.502 & 1502 & 33.875 \\
\hline 600 & 0.666 & -0.698 & -0.032 & 1.502 & 1502 & 33.875 \\
\hline 600 & 0.666 & -0.698 & -0.032 & 1.502 & 1502 & 33.875 \\
\hline 600 & 0.666 & -0.698 & -0.032 & 1.502 & 1502 & 33.875 \\
\hline 600 & 0.666 & -0.698 & -0.032 & 1.502 & 1502 & 33.875 \\
\hline 600 & 0.668 & -0.700 & -0.032 & 1.502 & 1502 & 33.875 \\
\hline 600 & 0.667 & -0.699 & -0.032 & 1.502 & 1502 & 33.875 \\
\hline 600 & 0.669 & -0.702 & -0.033 & 1.502 & 1502 & 33.875 \\
\hline 600 & 0.669 & -0.701 & -0.032 & 1.502 & 1502 & 33.875 \\
\hline 600 & 0.668 & -0.699 & -0.031 & 1.502 & 1502 & 33.875 \\
\hline 600 & 0.666 & -0.699 & -0.033 & 1.502 & 1502 & 33.875 \\
\hline 600 & 0.668 & -0.699 & -0.031 & 1.502 & 1502 & 33.875 \\
\hline 600 & 0.667 & -0.699 & -0.032 & 1.502 & 1502 & 33.875 \\
\hline 600 & 0.667 & -0.698 & -0.031 & 1.502 & 1502 & 33.875 \\
\hline 600 & 0.667 & -0.698 & -0.031 & 1.502 & 1502 & 33.875 \\
\hline 600 & 0.666 & -0.698 & -0.032 & 1.502 & 1502 & 33.875 \\
\hline 600 & 0.665 & -0.697 & -0.032 & 1.502 & 1502 & 33.875 \\
\hline 600 & 0.667 & -0.698 & -0.031 & 1.502 & 1502 & 33.87 \\
\hline 600 & 0.664 & -0.696 & -0.032 & 1.502 & 1502 & 33.875 \\
\hline 600 & 0.663 & -0.695 & -0.032 & 1.502 & 1502 & 33.875 \\
\hline 600 & 0.665 & -0.697 & -0.032 & 1.502 & 1502 & 33.875 \\
\hline 600 & 0.663 & -0.696 & -0.033 & 1.502 & 1502 & 33.875 \\
\hline 600 & 0.665 & -0.697 & -0.032 & 1.502 & 1502 & 33.87 \\
\hline 600 & 0.663 & -0.696 & -0.033 & 1.502 & 1502 & 33.875 \\
\hline 600 & 0.663 & -0.695 & -0.032 & 1.502 & 1502 & 33.87 \\
\hline 600 & 0.663 & -0.696 & -0.033 & 1.502 & 1502 & 33.875 \\
\hline 600 & 0.663 & -0.696 & -0.033 & 1.502 & 1502 & 33.875 \\
\hline 600 & 0.664 & -0.696 & -0.032 & 1.502 & 1502 & 33.87 \\
\hline 600 & 0.662 & -0.694 & -0.032 & 1.502 & 1502 & 33.875 \\
\hline 600 & 0.663 & -0.695 & -0.032 & 1.502 & 1502 & 33.875 \\
\hline 600 & 0.664 & -0.696 & -0.032 & 1.502 & 1502 & 33.87 \\
\hline
\end{tabular}




$\begin{array}{rrrrrrr}600 & 0.663 & -0.695 & -0.032 & 1.502 & 1502 & 33.875 \\ 600 & 0.663 & -0.694 & -0.031 & 1.502 & 1502 & 33.875 \\ 600 & 0.662 & -0.694 & -0.032 & 1.502 & 1502 & 33.875 \\ 600 & 0.764 & -0.771 & -0.007 & 0.004 & 4 & 0.090 \\ 600 & 0.764 & -0.772 & -0.008 & 0.004 & 4 & 0.090\end{array}$

\begin{tabular}{|c|c|c|c|c|c|c|c|c|c|c|c|c|c|c|}
\hline \multicolumn{3}{|c|}{$\mathrm{T}=600$} & \multicolumn{3}{|c|}{$\mathrm{T}=625$} & \multicolumn{3}{|c|}{$T=650$} & \multicolumn{3}{|c|}{$\mathrm{T}=675$} & \multicolumn{3}{|c|}{$\mathrm{T}=700$} \\
\hline I/SA & VCELL & P/SA & I/SA & VCELL & P/SA & I/SA & VCELL & P/SA & I/SA & VCELL & P/SA & I/SA & VCELL & P/SA \\
\hline 0.039 & 0.704 & 0.000 & 0.039 & 0.732 & 0.000 & 0.039 & 0.759 & 0.000 & 0.077 & 0.765 & 0.000 & 0.077 & 0.723 & 0.000 \\
\hline 0.039 & 0.705 & 0.000 & 0.039 & 0.733 & 0.000 & 0.039 & 0.760 & 0.000 & 0.077 & 0.768 & 0.000 & 0.077 & 0.724 & 0.000 \\
\hline 0.039 & 0.702 & 0.000 & 0.039 & 0.733 & 0.000 & 0.039 & 0.758 & 0.000 & 0.077 & 0.769 & 0.000 & 0.077 & 0.729 & 0.000 \\
\hline 0.039 & 0.759 & 0.000 & 0.077 & 0.757 & 0.000 & 0.077 & 0.759 & 0.000 & 0.077 & 0.768 & 0.000 & 0.077 & 0.742 & 0.000 \\
\hline 0.039 & 0.756 & 0.000 & 0.077 & 0.757 & 0.000 & 0.077 & 0.762 & 0.000 & 0.077 & 0.761 & 0.000 & 0.077 & 0.746 & 0.000 \\
\hline 1.926 & 0.700 & 0.001 & 0.077 & 0.758 & 0.000 & 1.926 & 0.754 & 0.001 & 0.077 & 0.768 & 0.000 & 3.851 & 0.723 & 0.003 \\
\hline 3.851 & 0.695 & 0.003 & 1.926 & 0.728 & 0.001 & 3.851 & 0.751 & 0.003 & 0.077 & 0.770 & 0.000 & 7.741 & 0.712 & 0.006 \\
\hline 5.777 & 0.689 & 0.004 & 3.851 & 0.727 & 0.003 & 5.777 & 0.749 & 0.004 & 1.926 & 0.764 & 0.001 & 11.554 & 0.719 & 0.008 \\
\hline 7.703 & 0.680 & 0.005 & 5.777 & 0.720 & 0.004 & 7.703 & 0.744 & 0.006 & 3.851 & 0.762 & 0.003 & 15.444 & 0.706 & 0.011 \\
\hline 9.667 & 0.677 & 0.007 & 7.703 & 0.713 & 0.005 & 9.667 & 0.742 & 0.007 & 5.777 & 0.760 & 0.004 & 19.295 & 0.697 & 0.013 \\
\hline 11.593 & 0.674 & 0.008 & 9.667 & 0.712 & 0.007 & 11.593 & 0.739 & 0.009 & 7.741 & 0.758 & 0.006 & 23.147 & 0.692 & 0.016 \\
\hline 13.518 & 0.666 & 0.009 & 11.593 & 0.707 & 0.008 & 13.518 & 0.734 & 0.010 & 9.667 & 0.754 & 0.007 & 26.998 & 0.685 & 0.018 \\
\hline 15.444 & 0.662 & 0.010 & 13.518 & 0.705 & 0.010 & 15.444 & 0.733 & 0.011 & 11.593 & 0.749 & 0.009 & 30.849 & 0.675 & 0.021 \\
\hline 17.370 & 0.656 & 0.011 & 15.444 & 0.700 & 0.011 & 17.370 & 0.729 & 0.013 & 13.518 & 0.746 & 0.010 & 34.701 & 0.666 & 0.023 \\
\hline 19.295 & 0.653 & 0.013 & 17.370 & 0.694 & 0.012 & 19.295 & 0.725 & 0.014 & 15.444 & 0.745 & 0.012 & 38.552 & 0.656 & 0.025 \\
\hline 21.221 & 0.649 & 0.014 & 19.295 & 0.691 & 0.013 & 21.221 & 0.722 & 0.015 & 17.370 & 0.739 & 0.013 & 42.442 & 0.649 & 0.028 \\
\hline 23.147 & 0.643 & 0.015 & 21.221 & 0.687 & 0.015 & 23.147 & 0.719 & 0.017 & 19.295 & 0.740 & 0.014 & 48.219 & 0.642 & 0.031 \\
\hline 25.072 & 0.639 & 0.016 & 23.147 & 0.683 & 0.016 & 25.072 & 0.715 & 0.018 & 21.221 & 0.736 & 0.016 & 53.996 & 0.628 & 0.034 \\
\hline 26.998 & 0.632 & 0.017 & 25.072 & 0.679 & 0.017 & 26.998 & 0.711 & 0.019 & 23.147 & 0.732 & 0.017 & 59.773 & 0.621 & 0.037 \\
\hline 28.924 & 0.632 & 0.018 & 26.998 & 0.673 & 0.018 & 28.924 & 0.707 & 0.020 & 25.072 & 0.729 & 0.018 & 65.550 & 0.611 & 0.040 \\
\hline 30.849 & 0.626 & 0.019 & 28.924 & 0.669 & 0.019 & 30.849 & 0.705 & 0.022 & 26.998 & 0.727 & 0.020 & 71.327 & 0.600 & 0.043 \\
\hline 32.775 & 0.622 & 0.020 & 30.849 & 0.666 & 0.021 & 32.813 & 0.701 & 0.023 & 28.924 & 0.724 & 0.021 & 77.104 & 0.589 & 0.045 \\
\hline 34.701 & 0.618 & 0.021 & 32.813 & 0.664 & 0.022 & 34.701 & 0.698 & 0.024 & 30.849 & 0.721 & 0.022 & 82.919 & 0.578 & 0.048 \\
\hline 36.626 & 0.614 & 0.022 & 34.701 & 0.660 & 0.023 & 36.626 & 0.694 & 0.025 & 32.775 & 0.717 & 0.023 & 88.696 & 0.567 & 0.050 \\
\hline 38.552 & 0.610 & 0.024 & 36.626 & 0.653 & 0.024 & 38.552 & 0.691 & 0.027 & 34.701 & 0.715 & 0.025 & 94.473 & 0.554 & 0.052 \\
\hline 40.516 & 0.608 & 0.025 & 38.552 & 0.652 & 0.025 & 40.478 & 0.689 & 0.028 & 36.626 & 0.712 & 0.026 & 100.212 & 0.544 & 0.055 \\
\hline 42.403 & 0.603 & 0.026 & 40.516 & 0.647 & 0.026 & 42.403 & 0.685 & 0.029 & 38.590 & 0.710 & 0.027 & 106.027 & 0.527 & 0.056 \\
\hline 44.367 & 0.598 & 0.027 & 42.403 & 0.643 & 0.027 & 44.367 & 0.683 & 0.030 & 40.478 & 0.708 & 0.029 & 111.804 & 0.511 & 0.057 \\
\hline 46.255 & 0.596 & 0.028 & 44.367 & 0.640 & 0.028 & 46.255 & 0.679 & 0.031 & 42.442 & 0.704 & 0.030 & 117.581 & 0.498 & 0.059 \\
\hline 48.219 & 0.591 & 0.028 & 46.255 & 0.637 & 0.029 & 48.219 & 0.677 & 0.033 & 44.367 & 0.703 & 0.031 & 123.358 & 0.483 & 0.060 \\
\hline 50.106 & 0.587 & 0.029 & 48.219 & 0.632 & 0.030 & 50.106 & 0.673 & 0.034 & 46.255 & 0.700 & 0.032 & 129.135 & 0.469 & 0.061 \\
\hline 52.070 & 0.583 & 0.030 & 50.106 & 0.630 & 0.032 & 52.070 & 0.670 & 0.035 & 48.219 & 0.697 & 0.034 & 134.912 & 0.452 & 0.061 \\
\hline 53.996 & 0.579 & 0.031 & 52.070 & 0.626 & 0.033 & 53.996 & 0.666 & 0.036 & 50.144 & 0.694 & 0.035 & 140.689 & 0.438 & 0.062 \\
\hline 55.921 & 0.575 & 0.032 & 53.957 & 0.622 & 0.034 & 55.921 & 0.664 & 0.037 & 52.070 & 0.691 & 0.036 & 146.466 & 0.420 & 0.062 \\
\hline 57.847 & 0.570 & 0.033 & 55.921 & 0.619 & 0.035 & 57.847 & 0.659 & 0.038 & 53.996 & 0.688 & 0.037 & 152.243 & 0.407 & 0.062 \\
\hline 61.698 & 0.561 & 0.035 & 57.847 & 0.614 & 0.036 & 61.698 & 0.654 & 0.040 & 55.921 & 0.685 & 0.038 & 158.059 & 0.385 & 0.061 \\
\hline 65.550 & 0.554 & 0.036 & 61.698 & 0.606 & 0.037 & 65.550 & 0.648 & 0.042 & 57.847 & 0.682 & 0.039 & 163.836 & 0.371 & 0.061 \\
\hline 69.401 & 0.545 & 0.038 & 65.550 & 0.598 & 0.039 & 69.401 & 0.642 & 0.045 & 61.698 & 0.675 & 0.042 & 169.613 & 0.359 & 0.061 \\
\hline 73.252 & 0.536 & 0.039 & 69.401 & 0.588 & 0.041 & 73.252 & 0.636 & 0.047 & 65.550 & 0.669 & 0.044 & 175.390 & 0.338 & 0.059 \\
\hline 77.104 & 0.528 & 0.041 & 73.252 & 0.582 & 0.043 & 77.104 & 0.629 & 0.048 & 69.401 & 0.664 & 0.046 & 181.167 & 0.326 & 0.059 \\
\hline 80.955 & 0.517 & 0.042 & 77.104 & 0.578 & 0.045 & 80.955 & 0.622 & 0.050 & 73.252 & 0.659 & 0.048 & 186.944 & 0.307 & 0.057 \\
\hline 84.806 & 0.506 & 0.043 & 80.955 & 0.571 & 0.046 & 84.845 & 0.616 & 0.052 & 77.104 & 0.652 & 0.050 & 192.721 & 0.290 & 0.056 \\
\hline 88.696 & 0.494 & 0.044 & 84.806 & 0.561 & 0.048 & 88.658 & 0.610 & 0.054 & 80.955 & 0.647 & 0.052 & 196.572 & 0.272 & 0.053 \\
\hline 92.548 & 0.480 & 0.044 & 88.658 & 0.554 & 0.049 & 92.548 & 0.603 & 0.056 & 84.806 & 0.640 & 0.054 & 200.424 & 0.269 & 0.054 \\
\hline 96.399 & 0.449 & 0.043 & 92.548 & 0.543 & 0.050 & 96.399 & 0.596 & 0.057 & 88.658 & 0.632 & 0.056 & 204.275 & 0.258 & 0.053 \\
\hline 100.212 & 0.395 & 0.040 & 96.399 & 0.538 & 0.052 & 100.250 & 0.591 & 0.059 & 92.548 & 0.626 & 0.058 & 208.126 & 0.239 & 0.050 \\
\hline 102.176 & 0.396 & 0.040 & 100.250 & 0.528 & 0.053 & 104.102 & 0.583 & 0.061 & 96.399 & 0.621 & 0.060 & 211.978 & 0.225 & 0.048 \\
\hline 104.102 & 0.363 & 0.038 & 104.102 & 0.522 & 0.054 & 107.953 & 0.575 & 0.062 & 100.250 & 0.615 & 0.062 & 213.903 & 0.212 & 0.045 \\
\hline 106.027 & 0.327 & 0.035 & 107.953 & 0.509 & 0.055 & 111.804 & 0.568 & 0.064 & 104.102 & 0.609 & 0.063 & & & \\
\hline & & & 111.804 & 0.496 & 0.055 & 115.656 & 0.561 & 0.065 & 107.953 & 0.602 & 0.065 & & & \\
\hline & & & 115.656 & 0.489 & 0.057 & 119.507 & 0.551 & 0.066 & 111.804 & 0.596 & 0.067 & & & \\
\hline & & & 119.507 & 0.475 & 0.057 & 123.358 & 0.547 & 0.067 & 115.656 & 0.588 & 0.068 & & & \\
\hline & & & 123.358 & 0.454 & 0.056 & 127.210 & 0.535 & 0.068 & 119.507 & 0.581 & 0.069 & & & \\
\hline & & & 127.210 & 0.438 & 0.056 & 131.061 & 0.530 & 0.069 & 123.358 & 0.576 & 0.071 & & & \\
\hline & & & 131.061 & 0.400 & 0.052 & 134.912 & 0.521 & 0.070 & 127.210 & 0.565 & 0.072 & & & \\
\hline & & & 132.987 & 0.378 & 0.050 & 138.764 & 0.511 & 0.071 & 131.061 & 0.562 & 0.074 & & & \\
\hline
\end{tabular}




$\begin{array}{llllll}142.615 & 0.500 & 0.071 & 134.912 & 0.555 & 0.075 \\ 146.505 & 0.488 & 0.071 & 138.764 & 0.547 & 0.076 \\ 150.318 & 0.479 & 0.072 & 142.615 & 0.542 & 0.077 \\ 154.208 & 0.471 & 0.073 & 146.466 & 0.531 & 0.078 \\ 158.059 & 0.456 & 0.072 & 150.318 & 0.525 & 0.079 \\ 159.985 & 0.444 & 0.071 & 154.208 & 0.517 & 0.080 \\ 161.910 & 0.420 & 0.068 & 158.059 & 0.512 & 0.081 \\ 163.836 & 0.422 & 0.069 & 161.910 & 0.501 & 0.081 \\ 165.762 & 0.405 & 0.067 & 165.762 & 0.494 & 0.082 \\ 167.687 & 0.391 & 0.066 & 169.613 & 0.487 & 0.083 \\ 169.613 & 0.369 & 0.063 & 173.464 & 0.474 & 0.082 \\ & & & 177.316 & 0.464 & 0.082 \\ & & & 181.167 & 0.461 & 0.084 \\ & & & 185.018 & 0.448 & 0.083 \\ & & & 186.944 & 0.436 & 0.082 \\ & & & 188.870 & 0.425 & 0.080 \\ & & & 190.795 & 0.424 & 0.081 \\ & & & 192.721 & 0.419 & 0.081 \\ & & & 194.647 & 0.401 & 0.078 \\ & & & 196.572 & 0.399 & 0.078\end{array}$

Graphite Rod, Long Term Run, Air Flow Rate $=0.50 \mathrm{SLPM}, \mathrm{T}=650^{\circ} \mathrm{C}, 3 / 15 / 2006$

$\begin{array}{ccrrrcc}\text { Temp } & & & & & \\ \left({ }^{\circ} \mathrm{C}\right) & \text { VCELL } & \text { VANODE } & \text { VCATHODE } & \text { I }(\mathrm{A}) & (\mathrm{mA}) & \text { I/SA } \\ 647 & 0.636 & -0.662 & -0.026 & 1.502 & 1502 & 28.924 \\ 640 & 0.637 & -0.665 & -0.028 & 1.502 & 1502 & 28.924 \\ 652 & 0.620 & -0.647 & -0.027 & 1.502 & 1502 & 28.924 \\ 651 & 0.607 & -0.633 & -0.026 & 1.502 & 1502 & 28.924 \\ 648 & 0.597 & -0.623 & -0.026 & 1.502 & 1502 & 28.924 \\ 650 & 0.588 & -0.614 & -0.026 & 1.502 & 1502 & 28.924 \\ 650 & 0.582 & -0.608 & -0.026 & 1.502 & 1502 & 28.924 \\ 649 & 0.578 & -0.604 & -0.026 & 1.502 & 1502 & 28.924 \\ 649 & 0.577 & -0.602 & -0.025 & 1.502 & 1502 & 28.924 \\ 649 & 0.572 & -0.598 & -0.026 & 1.502 & 1502 & 28.924 \\ 649 & 0.568 & -0.594 & -0.026 & 1.502 & 1502 & 28.924 \\ 649 & 0.568 & -0.594 & -0.026 & 1.502 & 1502 & 28.924 \\ 649 & 0.566 & -0.592 & -0.026 & 1.502 & 1502 & 28.924 \\ 649 & 0.567 & -0.592 & -0.025 & 1.502 & 1502 & 28.924 \\ 649 & 0.570 & -0.596 & -0.026 & 1.502 & 1502 & 28.924 \\ 649 & 0.572 & -0.598 & -0.026 & 1.502 & 1502 & 28.924 \\ 649 & 0.571 & -0.596 & -0.025 & 1.502 & 1502 & 28.924 \\ 649 & 0.580 & -0.606 & -0.026 & 1.502 & 1502 & 28.924 \\ 649 & 0.587 & -0.613 & -0.026 & 1.502 & 1502 & 28.924 \\ 649 & 0.600 & -0.626 & -0.026 & 1.502 & 1502 & 28.924 \\ 649 & 0.611 & -0.637 & -0.026 & 1.502 & 1502 & 28.924 \\ 649 & 0.620 & -0.645 & -0.025 & 1.502 & 1502 & 28.924 \\ 649 & 0.627 & -0.653 & -0.026 & 1.502 & 1502 & 28.924 \\ 649 & 0.631 & -0.657 & -0.026 & 1.502 & 1502 & 28.924 \\ 649 & 0.635 & -0.661 & -0.026 & 1.502 & 1502 & 28.924 \\ 649 & 0.636 & -0.662 & -0.026 & 1.502 & 1502 & 28.924 \\ 649 & 0.635 & -0.660 & -0.025 & 1.502 & 1502 & 28.924 \\ 649 & 0.636 & -0.662 & -0.026 & 1.502 & 1502 & 28.924 \\ 649 & 0.630 & -0.656 & -0.026 & 1.502 & 1502 & 28.924 \\ 649 & 0.626 & -0.652 & -0.026 & 1.502 & 1502 & 28.924 \\ 649 & 0.622 & -0.647 & -0.025 & 1.502 & 1502 & 28.924 \\ 649 & 0.619 & -0.644 & -0.025 & 1.502 & 1502 & 28.924 \\ 649 & 0.614 & -0.639 & -0.025 & 1.502 & 1502 & 28.924 \\ 649 & 0.613 & -0.638 & -0.025 & 1.502 & 1502 & 28.924 \\ 650 & 0.608 & -0.634 & -0.026 & 1.502 & 1502 & 28.924 \\ 649 & 0.603 & -0.628 & -0.025 & 1.502 & 1502 & 28.924 \\ 649 & 0.601 & -0.627 & -0.026 & 1.502 & 1502 & 28.924 \\ 649 & 0.593 & -0.619 & -0.026 & 1.502 & 1502 & 28.924\end{array}$




\begin{tabular}{|c|c|c|c|c|c|c|}
\hline 649 & 0.586 & -0.611 & -0.025 & 1.502 & 1502 & 28.924 \\
\hline 649 & 0.578 & -0.603 & -0.025 & 1.502 & 1502 & 28.924 \\
\hline 649 & 0.562 & -0.588 & -0.026 & 1.502 & 1502 & 28.924 \\
\hline 649 & 0.559 & -0.585 & -0.026 & 1.502 & 1502 & 28.924 \\
\hline 650 & 0.621 & -0.647 & -0.026 & 1.502 & 1502 & 28.924 \\
\hline 649 & 0.604 & -0.630 & -0.026 & 1.502 & 1502 & 28.924 \\
\hline 650 & 0.571 & -0.597 & -0.026 & 1.502 & 1502 & 28.924 \\
\hline 649 & 0.583 & -0.610 & -0.027 & 1.502 & 1502 & 28.924 \\
\hline 649 & 0.650 & -0.676 & -0.026 & 1.502 & 1502 & 28.924 \\
\hline 650 & 0.629 & -0.656 & -0.027 & 1.502 & 1502 & 28.924 \\
\hline 649 & 0.596 & -0.622 & -0.026 & 1.502 & 1502 & 28.924 \\
\hline 649 & 0.575 & -0.602 & -0.027 & 1.502 & 1502 & 28.924 \\
\hline 650 & 0.589 & -0.615 & -0.026 & 1.502 & 1502 & 28.924 \\
\hline 649 & 0.601 & -0.628 & -0.027 & 1.502 & 1502 & 28.924 \\
\hline 649 & 0.604 & -0.631 & -0.027 & 1.502 & 1502 & 28.924 \\
\hline 649 & 0.659 & -0.686 & -0.027 & 1.502 & 1502 & 28.924 \\
\hline 650 & 0.620 & -0.646 & -0.026 & 1.502 & 1502 & 28.924 \\
\hline 649 & 0.579 & -0.605 & -0.026 & 1.502 & 1502 & 28.924 \\
\hline 649 & 0.553 & -0.579 & -0.026 & 1.502 & 1502 & 28.924 \\
\hline 650 & 0.568 & -0.595 & -0.027 & 1.502 & 1502 & 28.924 \\
\hline 649 & 0.561 & -0.587 & -0.026 & 1.502 & 1502 & 28.924 \\
\hline 649 & 0.579 & -0.605 & -0.026 & 1.502 & 1502 & 28.924 \\
\hline 649 & 0.630 & -0.656 & -0.026 & 1.502 & 1502 & 28.924 \\
\hline 650 & 0.600 & -0.626 & -0.026 & 1.502 & 1502 & 28.924 \\
\hline 649 & 0.576 & -0.601 & -0.025 & 1.502 & 1502 & 28.924 \\
\hline 649 & 0.587 & -0.612 & -0.025 & 1.502 & 1502 & 28.924 \\
\hline 649 & 0.581 & -0.607 & -0.026 & 1.502 & 1502 & 28.924 \\
\hline 650 & 0.556 & -0.581 & -0.025 & 1.502 & 1502 & 28.924 \\
\hline 649 & 0.581 & -0.606 & -0.025 & 1.502 & 1502 & 28.924 \\
\hline 649 & 0.563 & -0.588 & -0.025 & 1.502 & 1502 & 28.924 \\
\hline 649 & 0.559 & -0.584 & -0.025 & 1.502 & 1502 & 28.924 \\
\hline 649 & 0.580 & -0.605 & -0.025 & 1.502 & 1502 & 28.924 \\
\hline 650 & 0.585 & -0.610 & -0.025 & 1.502 & 1502 & 28.924 \\
\hline 649 & 0.588 & -0.613 & -0.025 & 1.502 & 1502 & 28.924 \\
\hline 650 & 0.579 & -0.603 & -0.024 & 1.502 & 1502 & 28.924 \\
\hline 650 & 0.565 & -0.590 & -0.025 & 1.502 & 1502 & 28.924 \\
\hline 650 & 0.545 & -0.570 & -0.025 & 1.502 & 1502 & 28.924 \\
\hline 649 & 0.551 & -0.576 & -0.025 & 1.502 & 1502 & 28.924 \\
\hline 649 & 0.564 & -0.590 & -0.026 & 1.502 & 1502 & 28.924 \\
\hline 649 & 0.590 & -0.616 & -0.026 & 1.502 & 1502 & 28.924 \\
\hline 649 & 0.568 & -0.594 & -0.026 & 1.502 & 1502 & 28.924 \\
\hline 649 & 0.568 & -0.594 & -0.026 & 1.502 & 1502 & 28.924 \\
\hline 649 & 0.561 & -0.587 & -0.026 & 1.502 & 1502 & 28.924 \\
\hline 649 & 0.557 & -0.583 & -0.026 & 1.502 & 1502 & 28.924 \\
\hline 650 & 0.543 & -0.569 & -0.026 & 1.502 & 1502 & 28.924 \\
\hline 649 & 0.534 & -0.560 & -0.026 & 1.502 & 1502 & 28.924 \\
\hline 649 & 0.516 & -0.541 & -0.025 & 1.502 & 1502 & 28.924 \\
\hline 649 & 0.501 & -0.526 & -0.025 & 1.502 & 1502 & 28.924 \\
\hline 649 & 0.487 & -0.512 & -0.025 & 1.502 & 1502 & 28.924 \\
\hline 650 & 0.478 & -0.504 & -0.026 & 1.502 & 1502 & 28.924 \\
\hline 649 & 0.468 & -0.493 & -0.025 & 1.502 & 1502 & 28.924 \\
\hline 649 & 0.458 & -0.483 & -0.025 & 1.502 & 1502 & 28.924 \\
\hline 649 & 0.452 & -0.477 & -0.025 & 1.502 & 1502 & 28.924 \\
\hline 649 & 0.441 & -0.466 & -0.025 & 1.502 & 1502 & 28.924 \\
\hline 649 & 0.433 & -0.458 & -0.025 & 1.502 & 1502 & 28.924 \\
\hline 649 & 0.423 & -0.448 & -0.025 & 1.502 & 1502 & 28.924 \\
\hline 649 & 0.421 & -0.446 & -0.025 & 1.502 & 1502 & 28.924 \\
\hline 649 & 0.415 & -0.440 & -0.025 & 1.502 & 1502 & 28.924 \\
\hline 650 & 0.403 & -0.428 & -0.025 & 1.502 & 1502 & 28.924 \\
\hline 649 & 0.403 & -0.428 & -0.025 & 1.502 & 1502 & 28.924 \\
\hline 650 & 0.394 & -0.418 & -0.024 & 1.502 & 1502 & 28.924 \\
\hline 650 & 0.385 & -0.410 & -0.025 & 1.502 & 1502 & 28.924 \\
\hline 649 & 0.372 & -0.397 & -0.025 & 1.502 & 1502 & 28.924 \\
\hline
\end{tabular}




\begin{tabular}{|c|c|c|c|c|c|c|}
\hline 649 & 0.368 & -0.393 & -0.025 & 1.502 & 1502 & 28.924 \\
\hline 650 & 0.370 & -0.394 & -0.024 & 1.502 & 1502 & 28.924 \\
\hline 650 & 0.357 & -0.381 & -0.024 & 1.502 & 1502 & 28.924 \\
\hline 649 & 0.356 & -0.380 & -0.024 & 1.502 & 1502 & 28.924 \\
\hline 649 & 0.349 & -0.374 & -0.025 & 1.502 & 1502 & 28.924 \\
\hline 650 & 0.350 & -0.375 & -0.025 & 1.502 & 1502 & 28.924 \\
\hline 650 & 0.336 & -0.360 & -0.024 & 1.502 & 1502 & 28.924 \\
\hline 649 & 0.339 & -0.363 & -0.024 & 1.502 & 1502 & 28.924 \\
\hline 650 & 0.349 & -0.373 & -0.024 & 1.502 & 1502 & 28.924 \\
\hline 650 & 0.341 & -0.366 & -0.025 & 1.502 & 1502 & 28.924 \\
\hline 649 & 0.334 & -0.358 & -0.024 & 1.502 & 1502 & 28.924 \\
\hline 649 & 0.321 & -0.345 & -0.024 & 1.502 & 1502 & 28.924 \\
\hline 650 & 0.303 & -0.328 & -0.025 & 1.502 & 1502 & 28.924 \\
\hline 649 & 0.306 & -0.332 & -0.026 & 1.502 & 1502 & 28.924 \\
\hline 649 & 0.297 & -0.322 & -0.025 & 1.502 & 1502 & 28.924 \\
\hline 650 & 0.276 & -0.301 & -0.025 & 1.502 & 1502 & 28.924 \\
\hline 649 & 0.269 & -0.294 & -0.025 & 1.502 & 1502 & 28.924 \\
\hline 650 & 0.253 & -0.278 & -0.025 & 1.502 & 1502 & 28.924 \\
\hline 650 & 0.243 & -0.268 & -0.025 & 1.502 & 1502 & 28.924 \\
\hline 649 & 0.248 & -0.273 & -0.025 & 1.502 & 1502 & 28.924 \\
\hline 649 & 0.236 & -0.262 & -0.026 & 1.502 & 1502 & 28.924 \\
\hline 650 & 0.207 & -0.232 & -0.025 & 1.502 & 1502 & 28.924 \\
\hline 650 & 0.204 & -0.229 & -0.025 & 1.502 & 1502 & 28.924 \\
\hline 649 & 0.199 & -0.224 & -0.025 & 1.502 & 1502 & 28.924 \\
\hline 649 & 0.173 & -0.198 & -0.025 & 1.502 & 1502 & 28.924 \\
\hline 649 & 0.168 & -0.193 & -0.025 & 1.502 & 1502 & 28.924 \\
\hline 649 & 0.143 & -0.168 & -0.025 & 1.502 & 1502 & 28.924 \\
\hline 650 & 0.129 & -0.154 & -0.025 & 1.502 & 1502 & 28.924 \\
\hline 649 & 0.091 & -0.115 & -0.024 & 1.502 & 1502 & 28.924 \\
\hline 649 & 0.062 & -0.086 & -0.024 & 1.502 & 1502 & 28.924 \\
\hline 650 & 0.053 & -0.078 & -0.025 & 1.502 & 1502 & 28.924 \\
\hline 649 & 0.019 & -0.044 & -0.025 & 1.502 & 1502 & 28.924 \\
\hline 649 & 0.018 & -0.043 & -0.025 & 1.466 & 1466 & 28.230 \\
\hline 650 & 0.018 & -0.042 & -0.024 & 1.420 & 1420 & 27.345 \\
\hline 650 & 0.017 & -0.041 & -0.024 & 1.432 & 1432 & 27.576 \\
\hline 650 & 0.017 & -0.039 & -0.022 & 1.308 & 1308 & 25.188 \\
\hline 650 & 0.017 & -0.039 & -0.022 & 1.318 & 1318 & 25.380 \\
\hline 650 & 0.016 & -0.038 & -0.022 & 1.322 & 1322 & 25.457 \\
\hline 649 & 0.014 & -0.035 & -0.021 & 1.142 & 1142 & 21.991 \\
\hline 650 & 0.015 & -0.036 & -0.021 & 1.158 & 1158 & 22.299 \\
\hline 650 & 0.015 & -0.035 & -0.020 & 1.050 & 1050 & 20.220 \\
\hline 649 & 0.015 & -0.036 & -0.021 & 1.150 & 1150 & 22.145 \\
\hline 650 & 0.015 & -0.036 & -0.021 & 1.084 & 1084 & 20.874 \\
\hline 650 & 0.014 & -0.035 & -0.021 & 1.140 & 1140 & 21.953 \\
\hline 650 & 0.015 & -0.034 & -0.019 & 1.070 & 1070 & 20.605 \\
\hline 650 & 0.014 & -0.033 & -0.019 & 1.104 & 1104 & 21.259 \\
\hline 650 & 0.014 & -0.034 & -0.020 & 1.092 & 1092 & 21.028 \\
\hline 650 & 0.014 & -0.033 & -0.019 & 1.038 & 1038 & 19.988 \\
\hline 650 & 0.013 & -0.032 & -0.019 & 0.986 & 986 & 18.987 \\
\hline 650 & 0.013 & -0.031 & -0.018 & 0.970 & 970 & 18.679 \\
\hline 649 & 0.012 & -0.030 & -0.018 & 1.000 & 1000 & 19.257 \\
\hline 650 & 0.012 & -0.029 & -0.017 & 0.900 & 900 & 17.331 \\
\hline 650 & 0.011 & -0.027 & -0.016 & 0.854 & 854 & 16.445 \\
\hline 650 & 0.010 & -0.026 & -0.016 & 0.800 & 800 & 15.405 \\
\hline 650 & 0.013 & -0.028 & -0.015 & 0.768 & 768 & 14.789 \\
\hline 649 & 0.013 & -0.031 & -0.018 & 0.992 & 992 & 19.103 \\
\hline 650 & 0.013 & -0.031 & -0.018 & 0.926 & 926 & 17.832 \\
\hline 650 & 0.012 & -0.029 & -0.017 & 0.952 & 952 & 18.332 \\
\hline 649 & 0.011 & -0.028 & -0.017 & 0.898 & 898 & 17.293 \\
\hline 650 & 0.010 & -0.025 & -0.015 & 0.806 & 806 & 15.521 \\
\hline 650 & 0.010 & -0.025 & -0.015 & 0.726 & 726 & 13.980 \\
\hline 649 & 0.011 & -0.026 & -0.015 & 0.728 & 728 & 14.019 \\
\hline 650 & 0.015 & -0.032 & -0.017 & 0.800 & 800 & 15.405 \\
\hline
\end{tabular}




$\begin{array}{lllllll}650 & 0.015 & -0.039 & -0.024 & 1.134 & 1134 & 21.837 \\ 650 & 0.016 & -0.040 & -0.024 & 1.146 & 1146 & 22.068 \\ 650 & 0.017 & -0.041 & -0.024 & 1.218 & 1218 & 23.455 \\ 650 & 0.017 & -0.042 & -0.025 & 1.216 & 1216 & 23.416 \\ 649 & 0.020 & -0.045 & -0.025 & 1.314 & 1314 & 25.303 \\ 650 & 0.139 & -0.166 & -0.027 & 1.446 & 1446 & 27.845 \\ 650 & 0.217 & -0.244 & -0.027 & 1.502 & 1502 & 28.924 \\ 649 & 0.256 & -0.283 & -0.027 & 1.502 & 1502 & 28.924 \\ 650 & 0.290 & -0.317 & -0.027 & 1.502 & 1502 & 28.924 \\ 650 & 0.300 & -0.327 & -0.027 & 1.502 & 1502 & 28.924 \\ 650 & 0.297 & -0.325 & -0.028 & 1.502 & 1502 & 28.924 \\ 650 & 0.321 & -0.349 & -0.028 & 1.502 & 1502 & 28.924 \\ 650 & 0.307 & -0.335 & -0.028 & 1.502 & 1502 & 28.924 \\ 650 & 0.308 & -0.336 & -0.028 & 1.502 & 1502 & 28.924 \\ 649 & 0.296 & -0.323 & -0.027 & 1.502 & 1502 & 28.924 \\ 650 & 0.287 & -0.315 & -0.028 & 1.502 & 1502 & 28.924 \\ 650 & 0.285 & -0.313 & -0.028 & 1.502 & 1502 & 28.924 \\ 649 & 0.300 & -0.328 & -0.028 & 1.502 & 1502 & 28.924 \\ 650 & 0.316 & -0.344 & -0.028 & 1.502 & 1502 & 28.924 \\ 650 & 0.303 & -0.331 & -0.028 & 1.502 & 1502 & 28.924 \\ 649 & 0.313 & -0.341 & -0.028 & 1.502 & 1502 & 28.924 \\ 650 & 0.329 & -0.357 & -0.028 & 1.502 & 1502 & 28.924 \\ 650 & 0.344 & -0.372 & -0.028 & 1.502 & 1502 & 28.924 \\ 650 & 0.325 & -0.352 & -0.027 & 1.502 & 1502 & 28.924 \\ 650 & 0.335 & -0.363 & -0.028 & 1.502 & 1502 & 28.924 \\ 650 & 0.384 & -0.412 & -0.028 & 1.502 & 1502 & 28.924 \\ 650 & 0.394 & -0.421 & -0.027 & 1.502 & 1502 & 28.924 \\ 649 & 0.407 & -0.433 & -0.026 & 1.502 & 1502 & 28.924 \\ 650 & 0.415 & -0.442 & -0.027 & 1.502 & 1502 & 28.924 \\ 650 & 0.417 & -0.443 & -0.026 & 1.502 & 1502 & 28.924 \\ 649 & 0.434 & -0.460 & -0.026 & 1.502 & 1502 & 28.924 \\ 650 & 0.439 & -0.465 & -0.026 & 1.502 & 1502 & 28.924 \\ 650 & 0.454 & -0.480 & -0.026 & 1.502 & 1502 & 28.924 \\ 650 & 0.462 & -0.487 & -0.025 & 1.502 & 1502 & 28.924\end{array}$

Graphite Rod, Air Flow Rate $=0.50$ SLPM, T is Varied, 3/20/2006

\begin{tabular}{cccccccccccc} 
& $\mathrm{T}=600$ & \multicolumn{3}{c}{$\mathrm{c}=625$} & \multicolumn{3}{c}{$\mathrm{T}=650$} & & \multicolumn{3}{c}{$\mathrm{T}=675$} \\
I/SA & $\mathrm{VCELL}$ & $\mathrm{P} / \mathrm{SA}$ & $\mathrm{I} / \mathrm{SA}$ & $\mathrm{VCELL}$ & $\mathrm{P} / \mathrm{SA}$ & $\mathrm{I} / \mathrm{SA}$ & $\mathrm{VCELL}$ & $\mathrm{P} / \mathrm{SA}$ & $\mathrm{I} / \mathrm{SA}$ & $\mathrm{VCELL}$ & $\mathrm{P} / \mathrm{SA}$ \\
0.000 & 0.707 & 0.000 & 0.073 & 0.735 & 0.000 & 0.073 & 0.756 & 0.000 & 0.073 & 0.742 & 0.000 \\
0.000 & 0.711 & 0.000 & 0.073 & 0.735 & 0.000 & 0.073 & 0.759 & 0.000 & 0.073 & 0.744 & 0.000 \\
0.000 & 0.709 & 0.000 & 0.073 & 0.736 & 0.000 & 0.073 & 0.748 & 0.000 & 0.073 & 0.738 & 0.000 \\
0.073 & 0.748 & 0.000 & 0.073 & 0.750 & 0.000 & 3.672 & 0.750 & 0.003 & 0.073 & 0.749 & 0.000 \\
0.073 & 0.748 & 0.000 & 0.073 & 0.751 & 0.000 & 7.345 & 0.740 & 0.005 & 3.672 & 0.734 & 0.003 \\
3.672 & 0.700 & 0.003 & 3.672 & 0.723 & 0.003 & 11.054 & 0.731 & 0.008 & 7.382 & 0.727 & 0.005 \\
7.382 & 0.689 & 0.005 & 7.345 & 0.713 & 0.005 & 14.726 & 0.722 & 0.011 & 11.054 & 0.718 & 0.008 \\
11.054 & 0.672 & 0.007 & 11.054 & 0.704 & 0.008 & 18.399 & 0.715 & 0.013 & 14.690 & 0.712 & 0.010 \\
14.726 & 0.662 & 0.010 & 14.726 & 0.693 & 0.010 & 22.071 & 0.707 & 0.016 & 18.399 & 0.702 & 0.013 \\
18.399 & 0.654 & 0.012 & 18.399 & 0.687 & 0.013 & 25.744 & 0.700 & 0.018 & 22.071 & 0.696 & 0.015 \\
22.071 & 0.646 & 0.014 & 22.071 & 0.676 & 0.015 & 29.416 & 0.693 & 0.020 & 25.744 & 0.687 & 0.018 \\
25.744 & 0.633 & 0.016 & 25.744 & 0.668 & 0.017 & 33.089 & 0.686 & 0.023 & 29.416 & 0.679 & 0.020 \\
29.416 & 0.626 & 0.018 & 29.416 & 0.661 & 0.019 & 36.761 & 0.680 & 0.025 & 33.089 & 0.670 & 0.022 \\
33.089 & 0.616 & 0.020 & 33.089 & 0.652 & 0.022 & 40.433 & 0.674 & 0.027 & 36.761 & 0.660 & 0.024 \\
36.761 & 0.608 & 0.022 & 36.761 & 0.644 & 0.024 & 44.106 & 0.667 & 0.029 & 40.433 & 0.650 & 0.026 \\
40.433 & 0.599 & 0.024 & 40.433 & 0.636 & 0.026 & 47.778 & 0.661 & 0.032 & 44.106 & 0.638 & 0.028 \\
44.106 & 0.591 & 0.026 & 44.106 & 0.629 & 0.028 & 51.487 & 0.654 & 0.034 & 47.815 & 0.625 & 0.030 \\
47.815 & 0.582 & 0.028 & 47.815 & 0.622 & 0.030 & 55.160 & 0.648 & 0.036 & 51.487 & 0.612 & 0.032
\end{tabular}




\begin{tabular}{|c|c|c|c|c|c|c|c|c|c|c|c|}
\hline 51.487 & 0.575 & 0.030 & 51.487 & 0.614 & 0.032 & 60.668 & 0.640 & 0.039 & 55.160 & 0.598 & 0.033 \\
\hline 55.160 & 0.567 & 0.031 & 55.160 & 0.608 & 0.034 & 66.177 & 0.629 & 0.042 & 58.832 & 0.584 & 0.034 \\
\hline 58.832 & 0.559 & 0.033 & 55.160 & 0.607 & 0.033 & 71.686 & 0.619 & 0.044 & 62.505 & 0.566 & 0.035 \\
\hline 62.505 & 0.550 & 0.034 & 60.668 & 0.597 & 0.036 & 77.194 & 0.611 & 0.047 & 66.177 & 0.549 & 0.036 \\
\hline 66.177 & 0.541 & 0.036 & 66.177 & 0.586 & 0.039 & 82.740 & 0.602 & 0.050 & 69.849 & 0.532 & 0.037 \\
\hline 69.849 & 0.532 & 0.037 & 71.686 & 0.575 & 0.041 & 88.248 & 0.593 & 0.052 & 73.522 & 0.517 & 0.038 \\
\hline 73.522 & 0.523 & 0.038 & 77.194 & 0.565 & 0.044 & 93.757 & 0.584 & 0.055 & 77.194 & 0.495 & 0.038 \\
\hline 77.194 & 0.514 & 0.040 & 82.740 & 0.554 & 0.046 & 99.266 & 0.573 & 0.057 & 80.867 & 0.479 & 0.039 \\
\hline 80.867 & 0.504 & 0.041 & 88.212 & 0.542 & 0.048 & 104.774 & 0.562 & 0.059 & 84.539 & 0.463 & 0.039 \\
\hline 84.576 & 0.494 & 0.042 & 93.757 & 0.531 & 0.050 & 110.283 & 0.549 & 0.061 & 88.212 & 0.446 & 0.039 \\
\hline 88.212 & 0.485 & 0.043 & 99.266 & 0.518 & 0.051 & 115.791 & 0.535 & 0.062 & 91.921 & 0.432 & 0.040 \\
\hline 91.921 & 0.472 & 0.043 & 104.774 & 0.509 & 0.053 & 121.300 & 0.521 & 0.063 & 95.593 & 0.437 & 0.042 \\
\hline 95.593 & 0.459 & 0.044 & 110.283 & 0.495 & 0.055 & 126.809 & 0.509 & 0.065 & 99.266 & 0.429 & 0.043 \\
\hline 99.266 & 0.446 & 0.044 & 115.791 & 0.481 & 0.056 & 132.317 & 0.494 & 0.065 & 102.938 & 0.427 & 0.044 \\
\hline 102.938 & 0.425 & 0.044 & 121.300 & 0.463 & 0.056 & 137.863 & 0.484 & 0.067 & 106.610 & 0.414 & 0.044 \\
\hline 106.610 & 0.405 & 0.043 & 126.809 & 0.448 & 0.057 & 143.335 & 0.472 & 0.068 & 110.283 & 0.404 & 0.045 \\
\hline 110.283 & 0.370 & 0.041 & 132.317 & 0.420 & 0.056 & 143.371 & 0.472 & 0.068 & 113.955 & 0.398 & 0.045 \\
\hline \multirow[t]{28}{*}{113.955} & 0.310 & 0.035 & 135.990 & 0.411 & 0.056 & 147.044 & 0.457 & 0.067 & 117.628 & 0.385 & 0.045 \\
\hline & & & 139.699 & 0.395 & 0.055 & 150.716 & 0.450 & 0.068 & 121.300 & 0.371 & 0.045 \\
\hline & & & 141.498 & 0.375 & 0.053 & 154.389 & 0.446 & 0.069 & 124.972 & 0.363 & 0.045 \\
\hline & & & 143.335 & 0.352 & 0.050 & 156.225 & 0.441 & 0.069 & 128.645 & 0.348 & 0.045 \\
\hline & & & & & & 158.061 & 0.433 & 0.068 & 128.645 & 0.345 & 0.044 \\
\hline & & & & & & 159.897 & 0.422 & 0.067 & 132.317 & 0.340 & 0.045 \\
\hline & & & & & & 161.733 & 0.423 & 0.068 & 136.026 & 0.328 & 0.045 \\
\hline & & & & & & 163.570 & 0.405 & 0.066 & 139.699 & 0.320 & 0.045 \\
\hline & & & & & & & & & 143.335 & 0.310 & 0.044 \\
\hline & & & & & & & & & 147.044 & 0.296 & 0.044 \\
\hline & & & & & & & & & 150.716 & 0.290 & 0.044 \\
\hline & & & & & & & & & 154.389 & 0.277 & 0.043 \\
\hline & & & & & & & & & 158.061 & 0.267 & 0.042 \\
\hline & & & & & & & & & 161.733 & 0.257 & 0.041 \\
\hline & & & & & & & & & 165.406 & 0.246 & 0.041 \\
\hline & & & & & & & & & 169.078 & 0.236 & 0.040 \\
\hline & & & & & & & & & 172.751 & 0.225 & 0.039 \\
\hline & & & & & & & & & 176.423 & 0.215 & 0.038 \\
\hline & & & & & & & & & 178.259 & 0.204 & 0.036 \\
\hline & & & & & & & & & 180.095 & 0.193 & 0.035 \\
\hline & & & & & & & & & 181.932 & 0.183 & 0.033 \\
\hline & & & & & & & & & 183.768 & 0.172 & 0.032 \\
\hline & & & & & & & & & 185.604 & 0.162 & 0.030 \\
\hline & & & & & & & & & 187.440 & 0.151 & 0.028 \\
\hline & & & & & & & & & 189.277 & 0.141 & 0.027 \\
\hline & & & & & & & & & 191.113 & 0.130 & 0.025 \\
\hline & & & & & & & & & 192.949 & 0.120 & 0.023 \\
\hline & & & & & & & & & 194.785 & 0.109 & 0.021 \\
\hline
\end{tabular}

GrafTech Graphite Rod, Air Flow Rate $=0.50 \mathrm{SLPM}, \mathrm{T}=600^{\circ} \mathrm{C}, 3 / 28 / 2006$

\begin{tabular}{cccccc} 
& Run 1 & & \multicolumn{3}{c}{ Run 2 } \\
I/SA & VCELL & P/SA & I/SA & VCELL & P/SA \\
0.048 & 0.672 & 0.000 & 0.048 & 0.678 & 0.000 \\
0.048 & 0.675 & 0.000 & 0.097 & 0.681 & 0.000 \\
0.097 & 0.702 & 0.000 & 0.097 & 0.681 & 0.000
\end{tabular}




\begin{tabular}{cccccc}
0.097 & 0.705 & 0.000 & 0.097 & 0.695 & 0.000 \\
2.420 & 0.668 & 0.002 & 0.097 & 0.698 & 0.000 \\
4.840 & 0.662 & 0.003 & 2.420 & 0.675 & 0.002 \\
7.260 & 0.657 & 0.005 & 4.840 & 0.664 & 0.003 \\
9.681 & 0.648 & 0.006 & 7.260 & 0.660 & 0.005 \\
12.149 & 0.644 & 0.008 & 9.681 & 0.655 & 0.006 \\
14.521 & 0.635 & 0.009 & 12.149 & 0.651 & 0.008 \\
16.989 & 0.631 & 0.011 & 14.569 & 0.643 & 0.009 \\
19.409 & 0.625 & 0.012 & 19.361 & 0.636 & 0.012 \\
21.830 & 0.622 & 0.014 & 24.250 & 0.627 & 0.015 \\
24.250 & 0.617 & 0.015 & 29.090 & 0.613 & 0.018 \\
26.670 & 0.611 & 0.016 & 33.930 & 0.604 & 0.020 \\
29.090 & 0.606 & 0.018 & 38.771 & 0.593 & 0.023 \\
31.510 & 0.602 & 0.019 & 43.611 & 0.581 & 0.025 \\
33.930 & 0.598 & 0.020 & 48.451 & 0.573 & 0.028 \\
36.350 & 0.593 & 0.022 & 53.291 & 0.560 & 0.030 \\
38.771 & 0.588 & 0.023 & 58.132 & 0.553 & 0.032 \\
41.191 & 0.583 & 0.024 & 62.972 & 0.541 & 0.034 \\
43.611 & 0.574 & 0.025 & 67.861 & 0.526 & 0.036 \\
46.031 & 0.572 & 0.026 & 72.701 & 0.514 & 0.037 \\
48.451 & 0.564 & 0.027 & 72.701 & 0.512 & 0.037 \\
50.871 & 0.560 & 0.028 & 77.541 & 0.495 & 0.038 \\
53.291 & 0.558 & 0.030 & 82.381 & 0.485 & 0.040 \\
55.712 & 0.551 & 0.031 & 87.222 & 0.464 & 0.040 \\
58.132 & 0.545 & 0.032 & 92.062 & 0.446 & 0.041 \\
60.552 & 0.538 & 0.033 & 94.482 & 0.432 & 0.041 \\
62.972 & 0.536 & 0.034 & 96.902 & 0.411 & 0.040 \\
65.440 & 0.530 & 0.035 & 99.322 & 0.393 & 0.039 \\
67.861 & 0.523 & 0.035 & 101.742 & 0.350 & 0.036 \\
70.281 & 0.515 & 0.036 & 104.163 & 0.317 & 0.033 \\
72.701 & 0.511 & 0.037 & & & \\
75.121 & 0.505 & 0.038 & & & \\
77.541 & 0.495 & 0.038 & & & \\
79.961 & 0.488 & 0.039 & & & \\
82.381 & 0.478 & 0.039 & & & \\
84.802 & 0.471 & 0.040 & & & \\
87.222 & 0.459 & 0.040 & & & \\
89.642 & 0.450 & 0.040 & & & \\
92.062 & 0.440 & 0.041 & & & \\
94.482 & 0.429 & 0.041 & & & \\
96.902 & 0.413 & 0.040 & & & \\
99.322 & 0.392 & 0.039 & & & \\
101.742 & 0.367 & 0.037 & & & \\
104.163 & 0.333 & 0.035 & & & \\
106.583 & 0.298 & 0.032 & & & \\
& & & & & \\
\hline 10 &
\end{tabular}

GrafTech Graphite Rod, Long Term Run, Air Flow Rate $=0.50 \mathrm{SLPM}, \mathrm{T}=600^{\circ} \mathrm{C}$, $3 / 28 / 2006$

$\begin{array}{cccccccc}\begin{array}{c}\text { Temp } \\ \left({ }^{\circ} \mathrm{C}\right)\end{array} & \text { VCELL } & \text { VANODE } & \text { VCATHODE } & \text { I }(\mathrm{A}) & \begin{array}{c}\text { I } \\ (\mathrm{mA})\end{array} & \text { I/SA } & \begin{array}{c}\text { Time } \\ (\mathrm{min})\end{array} \\ 600 & 0.627 & -0.655 & -0.028 & 1.002 & 1002 & 24.250 & 0 \\ 600 & 0.625 & -0.656 & -0.031 & 1.002 & 1002 & 24.250 & 2\end{array}$




\begin{tabular}{|c|c|c|c|c|c|c|c|}
\hline 600 & 0.622 & -0.651 & -0.029 & 1.002 & 1002 & 24.250 & 4 \\
\hline 600 & 0.622 & -0.652 & -0.030 & 1.002 & 1002 & 24.250 & 6 \\
\hline 600 & 0.625 & -0.654 & -0.029 & 1.002 & 1002 & 24.250 & 8 \\
\hline 600 & 0.623 & -0.652 & -0.029 & 1.002 & 1002 & 24.250 & 10 \\
\hline 600 & 0.621 & -0.649 & -0.028 & 1.002 & 1002 & 24.250 & 12 \\
\hline 600 & 0.625 & -0.654 & -0.029 & 1.002 & 1002 & 24.250 & 14 \\
\hline 600 & 0.624 & -0.653 & -0.029 & 1.002 & 1002 & 24.250 & 16 \\
\hline 600 & 0.623 & -0.652 & -0.029 & 1.002 & 1002 & 24.250 & 18 \\
\hline 600 & 0.623 & -0.652 & -0.029 & 1.002 & 1002 & 24.250 & 20 \\
\hline 600 & 0.625 & -0.655 & -0.030 & 1.002 & 1002 & 24.250 & 22 \\
\hline 600 & 0.620 & -0.650 & -0.030 & 1.002 & 1002 & 24.250 & 24 \\
\hline 600 & 0.625 & -0.655 & -0.030 & 1.002 & 1002 & 24.250 & 26 \\
\hline 600 & 0.624 & -0.653 & -0.029 & 1.002 & 1002 & 24.250 & 28 \\
\hline 600 & 0.627 & -0.657 & -0.030 & 1.002 & 1002 & 24.250 & 30 \\
\hline 600 & 0.625 & -0.654 & -0.029 & 1.002 & 1002 & 24.250 & 32 \\
\hline 600 & 0.628 & -0.658 & -0.030 & 1.002 & 1002 & 24.250 & 34 \\
\hline 600 & 0.624 & -0.653 & -0.029 & 1.002 & 1002 & 24.250 & 36 \\
\hline 600 & 0.625 & -0.655 & -0.030 & 1.002 & 1002 & 24.250 & 38 \\
\hline 600 & 0.628 & -0.658 & -0.030 & 1.002 & 1002 & 24.250 & 40 \\
\hline 600 & 0.626 & -0.655 & -0.029 & 1.002 & 1002 & 24.250 & 42 \\
\hline 599 & 0.628 & -0.659 & -0.031 & 1.002 & 1002 & 24.250 & 44 \\
\hline 600 & 0.628 & -0.659 & -0.031 & 1.002 & 1002 & 24.250 & 46 \\
\hline 600 & 0.627 & -0.657 & -0.030 & 1.002 & 1002 & 24.250 & 48 \\
\hline 600 & 0.623 & -0.653 & -0.030 & 1.002 & 1002 & 24.250 & 50 \\
\hline 600 & 0.628 & -0.658 & -0.030 & 1.002 & 1002 & 24.250 & 52 \\
\hline 600 & 0.627 & -0.657 & -0.030 & 1.002 & 1002 & 24.250 & 54 \\
\hline 600 & 0.631 & -0.663 & -0.032 & 1.002 & 1002 & 24.250 & 56 \\
\hline 600 & 0.628 & -0.659 & -0.031 & 1.002 & 1002 & 24.250 & 58 \\
\hline 600 & 0.626 & -0.656 & -0.030 & 1.002 & 1002 & 24.250 & 60 \\
\hline 600 & 0.630 & -0.661 & -0.031 & 1.002 & 1002 & 24.250 & 62 \\
\hline 600 & 0.631 & -0.662 & -0.031 & 1.002 & 1002 & 24.250 & 64 \\
\hline 600 & 0.630 & -0.661 & -0.031 & 1.002 & 1002 & 24.250 & 66 \\
\hline 600 & 0.628 & -0.659 & -0.031 & 1.002 & 1002 & 24.250 & 68 \\
\hline 600 & 0.630 & -0.660 & -0.030 & 1.002 & 1002 & 24.250 & 70 \\
\hline 599 & 0.626 & -0.656 & -0.030 & 1.002 & 1002 & 24.250 & 72 \\
\hline 599 & 0.629 & -0.660 & -0.031 & 1.002 & 1002 & 24.250 & 74 \\
\hline 600 & 0.626 & -0.657 & -0.031 & 1.002 & 1002 & 24.250 & 76 \\
\hline 600 & 0.628 & -0.659 & -0.031 & 1.002 & 1002 & 24.250 & 78 \\
\hline 600 & 0.631 & -0.663 & -0.032 & 1.002 & 1002 & 24.250 & 80 \\
\hline 600 & 0.629 & -0.661 & -0.032 & 1.002 & 1002 & 24.250 & 82 \\
\hline 600 & 0.630 & -0.661 & -0.031 & 1.002 & 1002 & 24.250 & 84 \\
\hline 600 & 0.628 & -0.659 & -0.031 & 1.002 & 1002 & 24.250 & 86 \\
\hline 600 & 0.631 & -0.662 & -0.031 & 1.002 & 1002 & 24.250 & 88 \\
\hline 599 & 0.629 & -0.660 & -0.031 & 1.002 & 1002 & 24.250 & 90 \\
\hline 599 & 0.630 & -0.661 & -0.031 & 1.002 & 1002 & 24.250 & 92 \\
\hline 600 & 0.628 & -0.659 & -0.031 & 1.002 & 1002 & 24.250 & 94 \\
\hline 600 & 0.627 & -0.657 & -0.030 & 1.002 & 1002 & 24.250 & 96 \\
\hline 600 & 0.629 & -0.660 & -0.031 & 1.002 & 1002 & 24.250 & 98 \\
\hline 600 & 0.630 & -0.661 & -0.031 & 1.002 & 1002 & 24.250 & 100 \\
\hline 600 & 0.631 & -0.662 & -0.031 & 1.002 & 1002 & 24.250 & 102 \\
\hline 600 & 0.631 & -0.662 & -0.031 & 1.002 & 1002 & 24.250 & 104 \\
\hline 599 & 0.631 & -0.662 & -0.031 & 1.002 & 1002 & 24.250 & 106 \\
\hline 599 & 0.629 & -0.660 & -0.031 & 1.002 & 1002 & 24.250 & 108 \\
\hline 600 & 0.629 & -0.661 & -0.032 & 1.002 & 1002 & 24.250 & 110 \\
\hline 600 & 0.631 & -0.662 & -0.031 & 1.002 & 1002 & 24.250 & 112 \\
\hline 600 & 0.632 & -0.663 & -0.031 & 1.002 & 1002 & 24.250 & 114 \\
\hline 600 & 0.632 & -0.663 & -0.031 & 1.002 & 1002 & 24.250 & 116 \\
\hline 600 & 0.631 & -0.662 & -0.031 & 1.002 & 1002 & 24.250 & 118 \\
\hline 600 & 0.631 & -0.662 & -0.031 & 1.002 & 1002 & 24.250 & 120 \\
\hline 600 & 0.632 & -0.663 & -0.031 & 1.002 & 1002 & 24.250 & 122 \\
\hline 600 & 0.631 & -0.662 & -0.031 & 1.002 & 1002 & 24.250 & 124 \\
\hline 599 & 0.633 & -0.664 & -0.031 & 1.002 & 1002 & 24.250 & 126 \\
\hline 599 & 0.631 & -0.662 & -0.031 & 1.002 & 1002 & 24.250 & 128 \\
\hline
\end{tabular}




\begin{tabular}{|c|c|c|c|c|c|c|c|}
\hline 600 & 0.631 & -0.662 & -0.031 & 1.002 & 1002 & 24.250 & 130 \\
\hline 600 & 0.631 & -0.663 & -0.032 & 1.002 & 1002 & 24.250 & 132 \\
\hline 600 & 0.632 & -0.664 & -0.032 & 1.002 & 1002 & 24.250 & 134 \\
\hline 600 & 0.633 & -0.664 & -0.031 & 1.002 & 1002 & 24.250 & 136 \\
\hline 600 & 0.635 & -0.666 & -0.031 & 1.002 & 1002 & 24.250 & 138 \\
\hline 600 & 0.631 & -0.662 & -0.031 & 1.002 & 1002 & 24.250 & 140 \\
\hline 600 & 0.633 & -0.664 & -0.031 & 1.002 & 1002 & 24.250 & 142 \\
\hline 599 & 0.632 & -0.663 & -0.031 & 1.002 & 1002 & 24.250 & 144 \\
\hline 600 & 0.633 & -0.665 & -0.032 & 1.002 & 1002 & 24.250 & 146 \\
\hline 600 & 0.633 & -0.665 & -0.032 & 1.002 & 1002 & 24.250 & 148 \\
\hline 600 & 0.633 & -0.664 & -0.031 & 1.002 & 1002 & 24.250 & 150 \\
\hline 600 & 0.631 & -0.662 & -0.031 & 1.002 & 1002 & 24.250 & 152 \\
\hline 600 & 0.634 & -0.665 & -0.031 & 1.002 & 1002 & 24.250 & 154 \\
\hline 600 & 0.632 & -0.663 & -0.031 & 1.002 & 1002 & 24.250 & 156 \\
\hline 600 & 0.632 & -0.663 & -0.031 & 1.002 & 1002 & 24.250 & 158 \\
\hline 600 & 0.631 & -0.662 & -0.031 & 1.002 & 1002 & 24.250 & 160 \\
\hline 600 & 0.633 & -0.664 & -0.031 & 1.002 & 1002 & 24.250 & 162 \\
\hline 600 & 0.637 & -0.668 & -0.031 & 1.002 & 1002 & 24.250 & 164 \\
\hline 600 & 0.634 & -0.666 & -0.032 & 1.002 & 1002 & 24.250 & 166 \\
\hline 600 & 0.635 & -0.666 & -0.031 & 1.002 & 1002 & 24.250 & 168 \\
\hline 600 & 0.635 & -0.666 & -0.031 & 1.002 & 1002 & 24.250 & 170 \\
\hline 600 & 0.635 & -0.667 & -0.032 & 1.002 & 1002 & 24.250 & 172 \\
\hline 600 & 0.634 & -0.666 & -0.032 & 1.002 & 1002 & 24.250 & 174 \\
\hline 600 & 0.634 & -0.666 & -0.032 & 1.002 & 1002 & 24.250 & 176 \\
\hline 600 & 0.635 & -0.668 & -0.033 & 1.002 & 1002 & 24.250 & 178 \\
\hline 600 & 0.633 & -0.665 & -0.032 & 1.002 & 1002 & 24.250 & 180 \\
\hline 600 & 0.635 & -0.667 & -0.032 & 1.002 & 1002 & 24.250 & 182 \\
\hline 600 & 0.636 & -0.667 & -0.031 & 1.002 & 1002 & 24.250 & 184 \\
\hline 600 & 0.636 & -0.667 & -0.031 & 1.002 & 1002 & 24.250 & 186 \\
\hline 600 & 0.637 & -0.669 & -0.032 & 1.002 & 1002 & 24.250 & 188 \\
\hline 600 & 0.635 & -0.667 & -0.032 & 1.002 & 1002 & 24.250 & 190 \\
\hline 600 & 0.637 & -0.668 & -0.031 & 1.002 & 1002 & 24.250 & 192 \\
\hline 600 & 0.635 & -0.666 & -0.031 & 1.002 & 1002 & 24.250 & 194 \\
\hline 600 & 0.635 & -0.666 & -0.031 & 1.002 & 1002 & 24.250 & 196 \\
\hline 600 & 0.637 & -0.668 & -0.031 & 1.002 & 1002 & 24.250 & 198 \\
\hline 600 & 0.635 & -0.665 & -0.030 & 1.002 & 1002 & 24.250 & 200 \\
\hline 600 & 0.635 & -0.666 & -0.031 & 1.002 & 1002 & 24.250 & 202 \\
\hline 600 & 0.636 & -0.667 & -0.031 & 1.002 & 1002 & 24.250 & 204 \\
\hline 600 & 0.636 & -0.667 & -0.031 & 1.002 & 1002 & 24.250 & 206 \\
\hline 600 & 0.641 & -0.672 & -0.031 & 1.002 & 1002 & 24.250 & 208 \\
\hline 600 & 0.633 & -0.665 & -0.032 & 1.002 & 1002 & 24.250 & 210 \\
\hline 600 & 0.636 & -0.667 & -0.031 & 1.002 & 1002 & 24.250 & 212 \\
\hline 600 & 0.637 & -0.668 & -0.031 & 1.002 & 1002 & 24.250 & 214 \\
\hline 600 & 0.636 & -0.668 & -0.032 & 1.002 & 1002 & 24.250 & 216 \\
\hline 600 & 0.638 & -0.669 & -0.031 & 1.002 & 1002 & 24.250 & 218 \\
\hline 600 & 0.638 & -0.669 & -0.031 & 1.002 & 1002 & 24.250 & 220 \\
\hline 599 & 0.635 & -0.666 & -0.031 & 1.002 & 1002 & 24.250 & 222 \\
\hline 600 & 0.637 & -0.669 & -0.032 & 1.002 & 1002 & 24.250 & 224 \\
\hline 600 & 0.636 & -0.667 & -0.031 & 1.002 & 1002 & 24.250 & 226 \\
\hline 600 & 0.637 & -0.669 & -0.032 & 1.002 & 1002 & 24.250 & 228 \\
\hline 600 & 0.637 & -0.668 & -0.031 & 1.002 & 1002 & 24.250 & 230 \\
\hline 600 & 0.635 & -0.667 & -0.032 & 1.002 & 1002 & 24.250 & 232 \\
\hline 600 & 0.635 & -0.667 & -0.032 & 1.002 & 1002 & 24.250 & 234 \\
\hline 600 & 0.636 & -0.667 & -0.031 & 1.002 & 1002 & 24.250 & 236 \\
\hline 600 & 0.636 & -0.667 & -0.031 & 1.002 & 1002 & 24.250 & 238 \\
\hline 599 & 0.635 & -0.666 & -0.031 & 1.002 & 1002 & 24.250 & 240 \\
\hline 599 & 0.637 & -0.669 & -0.032 & 1.002 & 1002 & 24.250 & 242 \\
\hline 600 & 0.636 & -0.667 & -0.031 & 1.002 & 1002 & 24.250 & 244 \\
\hline 600 & 0.638 & -0.670 & -0.032 & 1.002 & 1002 & 24.250 & 246 \\
\hline 600 & 0.637 & -0.668 & -0.031 & 1.002 & 1002 & 24.250 & 248 \\
\hline 600 & 0.637 & -0.668 & -0.031 & 1.002 & 1002 & 24.250 & 250 \\
\hline 600 & 0.638 & -0.669 & -0.031 & 1.002 & 1002 & 24.250 & 252 \\
\hline 600 & 0.637 & -0.670 & -0.033 & 1.002 & 1002 & 24.250 & 254 \\
\hline
\end{tabular}




\begin{tabular}{|c|c|c|c|c|c|c|c|}
\hline 600 & 0.637 & -0.669 & -0.032 & 1.002 & 1002 & 24.250 & 256 \\
\hline 600 & 0.637 & -0.668 & -0.031 & 1.002 & 1002 & 24.250 & 258 \\
\hline 600 & 0.637 & -0.669 & -0.032 & 1.002 & 1002 & 24.250 & 260 \\
\hline 600 & 0.638 & -0.669 & -0.031 & 1.002 & 1002 & 24.250 & 262 \\
\hline 600 & 0.638 & -0.669 & -0.031 & 1.002 & 1002 & 24.250 & 264 \\
\hline 600 & 0.637 & -0.667 & -0.030 & 1.002 & 1002 & 24.250 & 26 \\
\hline 600 & 0.640 & -0.671 & -0.031 & 1.002 & 1002 & 24.250 & 268 \\
\hline 600 & 0.636 & -0.667 & -0.031 & 1.002 & 1002 & 24.250 & 270 \\
\hline 599 & 0.640 & -0.671 & -0.031 & 1.002 & 1002 & 24.250 & 272 \\
\hline 599 & 0.635 & -0.666 & -0.031 & 1.002 & 1002 & 24.250 & 274 \\
\hline 600 & 0.636 & -0.667 & -0.031 & 1.002 & 1002 & 24.250 & 276 \\
\hline 600 & 0.636 & -0.667 & -0.031 & 1.002 & 1002 & 24.250 & 278 \\
\hline 600 & 0.638 & -0.669 & -0.031 & 1.002 & 1002 & 24.250 & 28 \\
\hline 600 & 0.639 & -0.670 & -0.031 & 1.002 & 1002 & 24.250 & 282 \\
\hline 600 & 0.638 & -0.669 & -0.031 & 1.002 & 1002 & 24.250 & 284 \\
\hline 600 & 0.635 & -0.667 & -0.032 & 1.002 & 1002 & 24.250 & 286 \\
\hline 600 & 0.634 & -0.665 & -0.031 & 1.002 & 1002 & 24.250 & 288 \\
\hline 600 & 0.636 & -0.668 & -0.032 & 1.002 & 1002 & 24.250 & 29 \\
\hline 600 & 0.638 & -0.670 & -0.032 & 1.002 & 1002 & 24.250 & 29 \\
\hline 600 & 0.638 & -0.670 & -0.032 & 1.002 & 1002 & 24.250 & 29 \\
\hline 600 & 0.636 & -0.667 & -0.031 & 1.002 & 1002 & 24.250 & 296 \\
\hline 600 & 0.642 & -0.673 & -0.031 & 1.002 & 1002 & 24.250 & 298 \\
\hline 600 & 0.636 & -0.667 & -0.031 & 1.002 & 1002 & 24.250 & 300 \\
\hline 600 & 0.638 & -0.670 & -0.032 & 1.002 & 1002 & 24.250 & 30 \\
\hline 600 & 0.637 & -0.668 & -0.031 & 1.002 & 1002 & 24.250 & 30 \\
\hline 600 & 0.637 & -0.669 & -0.032 & 1.002 & 1002 & 24.250 & 30 \\
\hline 600 & 0.639 & -0.671 & -0.032 & 1.002 & 1002 & 24.250 & 308 \\
\hline 600 & 0.639 & -0.670 & -0.031 & 1.002 & 1002 & 24.250 & 310 \\
\hline 600 & 0.638 & -0.670 & -0.032 & 1.002 & 1002 & 24.250 & 312 \\
\hline 600 & 0.639 & -0.670 & -0.031 & 1.002 & 1002 & 24.250 & 314 \\
\hline 600 & 0.637 & -0.668 & -0.031 & 1.002 & 1002 & 24.250 & 31 \\
\hline 600 & 0.637 & -0.669 & -0.032 & 1.002 & 1002 & 24.250 & 31 \\
\hline 600 & 0.637 & -0.668 & -0.031 & 1.002 & 1002 & 24.250 & 32 \\
\hline 600 & 0.638 & -0.669 & -0.031 & 1.002 & 1002 & 24.250 & 322 \\
\hline 600 & 0.639 & -0.670 & -0.031 & 1.002 & 1002 & 24.250 & 324 \\
\hline 600 & 0.640 & -0.671 & -0.031 & 1.002 & 1002 & 24.250 & 326 \\
\hline 600 & 0.638 & -0.669 & -0.031 & 1.002 & 1002 & 24.250 & 328 \\
\hline 600 & 0.639 & -0.670 & -0.031 & 1.002 & 1002 & 24.250 & 33 \\
\hline 600 & 0.640 & -0.672 & -0.032 & 1.002 & 1002 & 24.250 & 33 \\
\hline 600 & 0.638 & -0.669 & -0.031 & 1.002 & 1002 & 24.250 & 334 \\
\hline 600 & 0.638 & -0.669 & -0.031 & 1.002 & 1002 & 24.250 & 336 \\
\hline 600 & 0.639 & -0.671 & -0.032 & 1.002 & 1002 & 24.250 & 338 \\
\hline 600 & 0.639 & -0.670 & -0.031 & 1.002 & 1002 & 24.250 & 340 \\
\hline 600 & 0.637 & -0.668 & -0.031 & 1.002 & 1002 & 24.250 & 34 \\
\hline 600 & 0.636 & -0.667 & -0.031 & 1.002 & 1002 & 24.250 & 34 \\
\hline 600 & 0.636 & -0.667 & -0.031 & 1.002 & 1002 & 24.250 & 346 \\
\hline 600 & 0.639 & -0.670 & -0.031 & 1.002 & 1002 & 24.250 & 348 \\
\hline 600 & 0.638 & -0.670 & -0.032 & 1.002 & 1002 & 24.250 & 350 \\
\hline 600 & 0.638 & -0.669 & -0.031 & 1.002 & 1002 & 24.250 & 35 \\
\hline 600 & 0.636 & -0.668 & -0.032 & 1.002 & 1002 & 24.250 & 35 \\
\hline 600 & 0.639 & -0.670 & -0.031 & 1.002 & 1002 & 24.250 & 35 \\
\hline 600 & 0.638 & -0.669 & -0.031 & 1.002 & 1002 & 24.250 & 35 \\
\hline 600 & 0.637 & -0.668 & -0.031 & 1.002 & 1002 & 24.250 & 360 \\
\hline 600 & 0.638 & -0.669 & -0.031 & 1.002 & 1002 & 24.250 & 362 \\
\hline 600 & 0.639 & -0.671 & -0.032 & 1.002 & 1002 & 24.250 & 36 \\
\hline 600 & 0.639 & -0.671 & -0.032 & 1.002 & 1002 & 24.250 & 36 \\
\hline 600 & 0.638 & -0.669 & -0.031 & 1.002 & 1002 & 24.250 & 36 \\
\hline 600 & 0.635 & -0.666 & -0.031 & 1.002 & 1002 & 24.250 & 37 \\
\hline 600 & 0.639 & -0.670 & -0.031 & 1.002 & 1002 & 24.250 & 372 \\
\hline 600 & 0.639 & -0.670 & -0.031 & 1.002 & 1002 & 24.250 & 37 \\
\hline 600 & 0.637 & -0.668 & -0.031 & 1.002 & 1002 & 24.250 & 37 \\
\hline 600 & 0.638 & -0.668 & -0.030 & 1.002 & 1002 & 24.250 & 378 \\
\hline 600 & 0.636 & -0.666 & -0.030 & 1.002 & 1002 & 24.250 & 380 \\
\hline
\end{tabular}




\begin{tabular}{|c|c|c|c|c|c|c|c|}
\hline 600 & 0.636 & -0.667 & -0.031 & 1.002 & 1002 & 24.250 & 382 \\
\hline 600 & 0.637 & -0.668 & -0.031 & 1.002 & 1002 & 24.250 & 384 \\
\hline 600 & 0.637 & -0.668 & -0.031 & 1.002 & 1002 & 24.250 & 386 \\
\hline 600 & 0.639 & -0.670 & -0.031 & 1.002 & 1002 & 24.250 & 388 \\
\hline 600 & 0.639 & -0.670 & -0.031 & 1.002 & 1002 & 24.250 & 390 \\
\hline 600 & 0.638 & -0.669 & -0.031 & 1.002 & 1002 & 24.250 & 392 \\
\hline 600 & 0.638 & -0.669 & -0.031 & 1.002 & 1002 & 24.250 & 394 \\
\hline 600 & 0.637 & -0.667 & -0.030 & 1.002 & 1002 & 24.250 & 396 \\
\hline 600 & 0.636 & -0.667 & -0.031 & 1.002 & 1002 & 24.250 & 398 \\
\hline 600 & 0.637 & -0.668 & -0.031 & 1.002 & 1002 & 24.250 & 400 \\
\hline 600 & 0.638 & -0.670 & -0.032 & 1.002 & 1002 & 24.250 & 402 \\
\hline 601 & 0.640 & -0.672 & -0.032 & 1.002 & 1002 & 24.250 & 404 \\
\hline 600 & 0.639 & -0.671 & -0.032 & 1.002 & 1002 & 24.250 & 406 \\
\hline 600 & 0.637 & -0.669 & -0.032 & 1.002 & 1002 & 24.250 & 408 \\
\hline 600 & 0.635 & -0.667 & -0.032 & 1.002 & 1002 & 24.250 & 410 \\
\hline 600 & 0.637 & -0.669 & -0.032 & 1.002 & 1002 & 24.250 & 412 \\
\hline 600 & 0.638 & -0.669 & -0.031 & 1.002 & 1002 & 24.250 & 414 \\
\hline 600 & 0.635 & -0.667 & -0.032 & 1.002 & 1002 & 24.250 & 416 \\
\hline 600 & 0.638 & -0.669 & -0.031 & 1.002 & 1002 & 24.250 & 418 \\
\hline 600 & 0.638 & -0.670 & -0.032 & 1.002 & 1002 & 24.250 & 420 \\
\hline 600 & 0.638 & -0.670 & -0.032 & 1.002 & 1002 & 24.250 & 422 \\
\hline 600 & 0.632 & -0.663 & -0.031 & 1.002 & 1002 & 24.250 & 424 \\
\hline 600 & 0.637 & -0.668 & -0.031 & 1.002 & 1002 & 24.250 & 426 \\
\hline 600 & 0.638 & -0.669 & -0.031 & 1.002 & 1002 & 24.250 & 428 \\
\hline 600 & 0.637 & -0.669 & -0.032 & 1.002 & 1002 & 24.250 & 430 \\
\hline 600 & 0.636 & -0.667 & -0.031 & 1.002 & 1002 & 24.250 & 432 \\
\hline 600 & 0.638 & -0.669 & -0.031 & 1.002 & 1002 & 24.250 & 434 \\
\hline 600 & 0.637 & -0.668 & -0.031 & 1.002 & 1002 & 24.250 & 436 \\
\hline 600 & 0.638 & -0.669 & -0.031 & 1.002 & 1002 & 24.250 & 438 \\
\hline 600 & 0.636 & -0.667 & -0.031 & 1.002 & 1002 & 24.250 & 440 \\
\hline 600 & 0.637 & -0.668 & -0.031 & 1.002 & 1002 & 24.250 & 442 \\
\hline 600 & 0.637 & -0.668 & -0.031 & 1.002 & 1002 & 24.250 & 444 \\
\hline 600 & 0.636 & -0.667 & -0.031 & 1.002 & 1002 & 24.250 & 446 \\
\hline 600 & 0.637 & -0.668 & -0.031 & 1.002 & 1002 & 24.250 & 448 \\
\hline 600 & 0.636 & -0.667 & -0.031 & 1.002 & 1002 & 24.250 & 450 \\
\hline 600 & 0.637 & -0.668 & -0.031 & 1.002 & 1002 & 24.250 & 452 \\
\hline 600 & 0.635 & -0.666 & -0.031 & 1.002 & 1002 & 24.250 & 454 \\
\hline 600 & 0.638 & -0.669 & -0.031 & 1.002 & 1002 & 24.250 & 456 \\
\hline 600 & 0.637 & -0.668 & -0.031 & 1.002 & 1002 & 24.250 & 458 \\
\hline 600 & 0.636 & -0.667 & -0.031 & 1.002 & 1002 & 24.250 & 460 \\
\hline 600 & 0.638 & -0.669 & -0.031 & 1.002 & 1002 & 24.250 & 462 \\
\hline 600 & 0.637 & -0.668 & -0.031 & 1.002 & 1002 & 24.250 & 464 \\
\hline 600 & 0.637 & -0.668 & -0.031 & 1.002 & 1002 & 24.250 & 466 \\
\hline 600 & 0.637 & -0.669 & -0.032 & 1.002 & 1002 & 24.250 & 468 \\
\hline 600 & 0.637 & -0.668 & -0.031 & 1.002 & 1002 & 24.250 & 470 \\
\hline 600 & 0.637 & -0.668 & -0.031 & 1.002 & 1002 & 24.250 & 472 \\
\hline 600 & 0.635 & -0.667 & -0.032 & 1.002 & 1002 & 24.250 & 474 \\
\hline 600 & 0.637 & -0.669 & -0.032 & 1.002 & 1002 & 24.250 & 476 \\
\hline 600 & 0.636 & -0.667 & -0.031 & 1.002 & 1002 & 24.250 & 478 \\
\hline 600 & 0.637 & -0.668 & -0.031 & 1.002 & 1002 & 24.250 & 480 \\
\hline 600 & 0.635 & -0.666 & -0.031 & 1.002 & 1002 & 24.250 & 482 \\
\hline 600 & 0.638 & -0.669 & -0.031 & 1.002 & 1002 & 24.250 & 484 \\
\hline 601 & 0.637 & -0.668 & -0.031 & 1.002 & 1002 & 24.250 & 486 \\
\hline 600 & 0.637 & -0.668 & -0.031 & 1.002 & 1002 & 24.250 & 488 \\
\hline 600 & 0.635 & -0.667 & -0.032 & 1.002 & 1002 & 24.250 & 490 \\
\hline 600 & 0.635 & -0.667 & -0.032 & 1.002 & 1002 & 24.250 & 492 \\
\hline 600 & 0.638 & -0.670 & -0.032 & 1.002 & 1002 & 24.250 & 494 \\
\hline 600 & 0.635 & -0.667 & -0.032 & 1.002 & 1002 & 24.250 & 496 \\
\hline 601 & 0.636 & -0.668 & -0.032 & 1.002 & 1002 & 24.250 & 498 \\
\hline 601 & 0.637 & -0.669 & -0.032 & 1.002 & 1002 & 24.250 & 500 \\
\hline 600 & 0.638 & -0.669 & -0.031 & 1.002 & 1002 & 24.250 & 502 \\
\hline 600 & 0.638 & -0.670 & -0.032 & 1.002 & 1002 & 24.250 & 504 \\
\hline 600 & 0.635 & -0.666 & -0.031 & 1.002 & 1002 & 24.250 & 506 \\
\hline
\end{tabular}




\begin{tabular}{|c|c|c|c|c|c|c|c|}
\hline 600 & 0.636 & -0.667 & -0.031 & 1.002 & 1002 & 24.250 & 508 \\
\hline 600 & 0.637 & -0.668 & -0.031 & 1.002 & 1002 & 24.250 & 510 \\
\hline 600 & 0.638 & -0.669 & -0.031 & 1.002 & 1002 & 24.250 & 512 \\
\hline 600 & 0.638 & -0.669 & -0.031 & 1.002 & 1002 & 24.250 & 514 \\
\hline 600 & 0.636 & -0.667 & -0.031 & 1.002 & 1002 & 24.250 & 516 \\
\hline 600 & 0.636 & -0.668 & -0.032 & 1.002 & 1002 & 24.250 & 518 \\
\hline 600 & 0.638 & -0.670 & -0.032 & 1.002 & 1002 & 24.250 & 520 \\
\hline 600 & 0.637 & -0.668 & -0.031 & 1.002 & 1002 & 24.250 & 522 \\
\hline 600 & 0.636 & -0.667 & -0.031 & 1.002 & 1002 & 24.250 & 524 \\
\hline 600 & 0.636 & -0.668 & -0.032 & 1.002 & 1002 & 24.250 & 526 \\
\hline 600 & 0.636 & -0.668 & -0.032 & 1.002 & 1002 & 24.250 & 528 \\
\hline 600 & 0.634 & -0.665 & -0.031 & 1.002 & 1002 & 24.250 & 530 \\
\hline 600 & 0.636 & -0.668 & -0.032 & 1.002 & 1002 & 24.250 & 532 \\
\hline 600 & 0.638 & -0.670 & -0.032 & 1.002 & 1002 & 24.250 & 534 \\
\hline 600 & 0.637 & -0.669 & -0.032 & 1.002 & 1002 & 24.250 & 536 \\
\hline 600 & 0.635 & -0.667 & -0.032 & 1.002 & 1002 & 24.250 & 538 \\
\hline 600 & 0.633 & -0.665 & -0.032 & 1.002 & 1002 & 24.250 & 540 \\
\hline 600 & 0.638 & -0.669 & -0.031 & 1.002 & 1002 & 24.250 & 542 \\
\hline 600 & 0.635 & -0.666 & -0.031 & 1.002 & 1002 & 24.250 & 544 \\
\hline 600 & 0.638 & -0.670 & -0.032 & 1.002 & 1002 & 24.250 & 546 \\
\hline 600 & 0.636 & -0.668 & -0.032 & 1.002 & 1002 & 24.250 & 548 \\
\hline 600 & 0.633 & -0.664 & -0.031 & 1.002 & 1002 & 24.250 & 550 \\
\hline 600 & 0.637 & -0.668 & -0.031 & 1.002 & 1002 & 24.250 & 552 \\
\hline 600 & 0.637 & -0.668 & -0.031 & 1.002 & 1002 & 24.250 & 554 \\
\hline 600 & 0.635 & -0.668 & -0.033 & 1.002 & 1002 & 24.250 & 556 \\
\hline 600 & 0.634 & -0.666 & -0.032 & 1.002 & 1002 & 24.250 & 558 \\
\hline 600 & 0.636 & -0.667 & -0.031 & 1.002 & 1002 & 24.250 & 560 \\
\hline 600 & 0.636 & -0.667 & -0.031 & 1.002 & 1002 & 24.250 & 562 \\
\hline 600 & 0.637 & -0.669 & -0.032 & 1.002 & 1002 & 24.250 & 564 \\
\hline 600 & 0.636 & -0.668 & -0.032 & 1.002 & 1002 & 24.250 & 566 \\
\hline 600 & 0.636 & -0.667 & -0.031 & 1.002 & 1002 & 24.250 & 568 \\
\hline 600 & 0.637 & -0.669 & -0.032 & 1.002 & 1002 & 24.250 & 570 \\
\hline 600 & 0.634 & -0.665 & -0.031 & 1.002 & 1002 & 24.250 & 572 \\
\hline 600 & 0.637 & -0.668 & -0.031 & 1.002 & 1002 & 24.250 & 574 \\
\hline 600 & 0.636 & -0.668 & -0.032 & 1.002 & 1002 & 24.250 & 576 \\
\hline 600 & 0.635 & -0.666 & -0.031 & 1.002 & 1002 & 24.250 & 578 \\
\hline 600 & 0.637 & -0.669 & -0.032 & 1.002 & 1002 & 24.250 & 580 \\
\hline 600 & 0.638 & -0.671 & -0.033 & 1.002 & 1002 & 24.250 & 582 \\
\hline 600 & 0.635 & -0.667 & -0.032 & 1.002 & 1002 & 24.250 & 584 \\
\hline 600 & 0.637 & -0.669 & -0.032 & 1.002 & 1002 & 24.250 & 586 \\
\hline 600 & 0.636 & -0.667 & -0.031 & 1.002 & 1002 & 24.250 & 588 \\
\hline 600 & 0.633 & -0.664 & -0.031 & 1.002 & 1002 & 24.250 & 590 \\
\hline 600 & 0.636 & -0.668 & -0.032 & 1.002 & 1002 & 24.250 & 592 \\
\hline 600 & 0.637 & -0.668 & -0.031 & 1.002 & 1002 & 24.250 & 594 \\
\hline 600 & 0.635 & -0.666 & -0.031 & 1.002 & 1002 & 24.250 & 596 \\
\hline 600 & 0.637 & -0.669 & -0.032 & 1.002 & 1002 & 24.250 & 598 \\
\hline 600 & 0.638 & -0.670 & -0.032 & 1.002 & 1002 & 24.250 & 600 \\
\hline 600 & 0.638 & -0.669 & -0.031 & 1.002 & 1002 & 24.250 & 602 \\
\hline 600 & 0.636 & -0.668 & -0.032 & 1.002 & 1002 & 24.250 & 604 \\
\hline 600 & 0.637 & -0.669 & -0.032 & 1.002 & 1002 & 24.250 & 606 \\
\hline 600 & 0.637 & -0.668 & -0.031 & 1.002 & 1002 & 24.250 & 608 \\
\hline 600 & 0.635 & -0.666 & -0.031 & 1.002 & 1002 & 24.250 & 610 \\
\hline 600 & 0.637 & -0.669 & -0.032 & 1.002 & 1002 & 24.250 & 612 \\
\hline 600 & 0.638 & -0.669 & -0.031 & 1.002 & 1002 & 24.250 & 614 \\
\hline 600 & 0.634 & -0.665 & -0.031 & 1.002 & 1002 & 24.250 & 616 \\
\hline 600 & 0.636 & -0.668 & -0.032 & 1.002 & 1002 & 24.250 & 618 \\
\hline 600 & 0.636 & -0.668 & -0.032 & 1.002 & 1002 & 24.250 & 620 \\
\hline 600 & 0.638 & -0.669 & -0.031 & 1.002 & 1002 & 24.250 & 622 \\
\hline 600 & 0.633 & -0.664 & -0.031 & 1.002 & 1002 & 24.250 & 624 \\
\hline 599 & 0.635 & -0.667 & -0.032 & 1.002 & 1002 & 24.250 & 626 \\
\hline 599 & 0.635 & -0.667 & -0.032 & 1.002 & 1002 & 24.250 & 628 \\
\hline 600 & 0.635 & -0.667 & -0.032 & 1.002 & 1002 & 24.250 & 630 \\
\hline 600 & 0.635 & -0.666 & -0.031 & 1.002 & 1002 & 24.250 & 632 \\
\hline
\end{tabular}




\begin{tabular}{|c|c|c|c|c|c|c|c|}
\hline 600 & 0.634 & -0.665 & -0.031 & 1.002 & 1002 & 24.250 & 634 \\
\hline 600 & 0.637 & -0.670 & -0.033 & 1.002 & 1002 & 24.250 & 636 \\
\hline 600 & 0.635 & -0.667 & -0.032 & 1.002 & 1002 & 24.250 & 638 \\
\hline 600 & 0.638 & -0.670 & -0.032 & 1.002 & 1002 & 24.250 & 640 \\
\hline 600 & 0.635 & -0.667 & -0.032 & 1.002 & 1002 & 24.250 & 642 \\
\hline 600 & 0.634 & -0.666 & -0.032 & 1.002 & 1002 & 24.250 & 644 \\
\hline 600 & 0.634 & -0.666 & -0.032 & 1.002 & 1002 & 24.250 & 646 \\
\hline 600 & 0.636 & -0.667 & -0.031 & 1.002 & 1002 & 24.250 & 648 \\
\hline 600 & 0.635 & -0.667 & -0.032 & 1.002 & 1002 & 24.250 & 650 \\
\hline 600 & 0.636 & -0.667 & -0.031 & 1.002 & 1002 & 24.250 & 652 \\
\hline 600 & 0.635 & -0.667 & -0.032 & 1.002 & 1002 & 24.250 & 654 \\
\hline 600 & 0.635 & -0.667 & -0.032 & 1.002 & 1002 & 24.250 & 656 \\
\hline 600 & 0.633 & -0.664 & -0.031 & 1.002 & 1002 & 24.250 & 658 \\
\hline 600 & 0.635 & -0.667 & -0.032 & 1.002 & 1002 & 24.250 & 660 \\
\hline 600 & 0.634 & -0.666 & -0.032 & 1.002 & 1002 & 24.250 & 662 \\
\hline 600 & 0.634 & -0.666 & -0.032 & 1.002 & 1002 & 24.250 & 664 \\
\hline 600 & 0.634 & -0.666 & -0.032 & 1.002 & 1002 & 24.250 & 666 \\
\hline 600 & 0.632 & -0.663 & -0.031 & 1.002 & 1002 & 24.250 & 668 \\
\hline 600 & 0.634 & -0.666 & -0.032 & 1.002 & 1002 & 24.250 & 670 \\
\hline 600 & 0.636 & -0.668 & -0.032 & 1.002 & 1002 & 24.250 & 672 \\
\hline 601 & 0.637 & -0.668 & -0.031 & 1.002 & 1002 & 24.250 & 674 \\
\hline 600 & 0.634 & -0.665 & -0.031 & 1.002 & 1002 & 24.250 & 676 \\
\hline 600 & 0.636 & -0.667 & -0.031 & 1.002 & 1002 & 24.250 & 678 \\
\hline 599 & 0.635 & -0.666 & -0.031 & 1.002 & 1002 & 24.250 & 680 \\
\hline 599 & 0.634 & -0.665 & -0.031 & 1.002 & 1002 & 24.250 & 682 \\
\hline 600 & 0.635 & -0.667 & -0.032 & 1.002 & 1002 & 24.250 & 684 \\
\hline 600 & 0.634 & -0.666 & -0.032 & 1.002 & 1002 & 24.250 & 686 \\
\hline 600 & 0.634 & -0.666 & -0.032 & 1.002 & 1002 & 24.250 & 688 \\
\hline 600 & 0.634 & -0.665 & -0.031 & 1.002 & 1002 & 24.250 & 690 \\
\hline 601 & 0.631 & -0.663 & -0.032 & 1.002 & 1002 & 24.250 & 692 \\
\hline 600 & 0.636 & -0.667 & -0.031 & 1.002 & 1002 & 24.250 & 694 \\
\hline 600 & 0.633 & -0.664 & -0.031 & 1.002 & 1002 & 24.250 & 696 \\
\hline 600 & 0.634 & -0.665 & -0.031 & 1.002 & 1002 & 24.250 & 698 \\
\hline 600 & 0.632 & -0.663 & -0.031 & 1.002 & 1002 & 24.250 & 700 \\
\hline 600 & 0.632 & -0.665 & -0.033 & 1.002 & 1002 & 24.250 & 702 \\
\hline 600 & 0.632 & -0.663 & -0.031 & 1.002 & 1002 & 24.250 & 704 \\
\hline 600 & 0.633 & -0.665 & -0.032 & 1.002 & 1002 & 24.250 & 706 \\
\hline 600 & 0.633 & -0.665 & -0.032 & 1.002 & 1002 & 24.250 & 708 \\
\hline 600 & 0.631 & -0.663 & -0.032 & 1.002 & 1002 & 24.250 & 710 \\
\hline 600 & 0.632 & -0.664 & -0.032 & 1.002 & 1002 & 24.250 & 712 \\
\hline 600 & 0.630 & -0.662 & -0.032 & 1.002 & 1002 & 24.250 & 714 \\
\hline 600 & 0.630 & -0.662 & -0.032 & 1.002 & 1002 & 24.250 & 716 \\
\hline 600 & 0.630 & -0.661 & -0.031 & 1.002 & 1002 & 24.250 & 718 \\
\hline 600 & 0.630 & -0.662 & -0.032 & 1.002 & 1002 & 24.250 & 720 \\
\hline 600 & 0.629 & -0.661 & -0.032 & 1.002 & 1002 & 24.250 & 722 \\
\hline 600 & 0.630 & -0.662 & -0.032 & 1.002 & 1002 & 24.250 & 724 \\
\hline 600 & 0.629 & -0.660 & -0.031 & 1.002 & 1002 & 24.250 & 726 \\
\hline 600 & 0.630 & -0.661 & -0.031 & 1.002 & 1002 & 24.250 & 728 \\
\hline 600 & 0.629 & -0.661 & -0.032 & 1.002 & 1002 & 24.250 & 730 \\
\hline 600 & 0.628 & -0.659 & -0.031 & 1.002 & 1002 & 24.250 & 732 \\
\hline 600 & 0.629 & -0.660 & -0.031 & 1.002 & 1002 & 24.250 & 734 \\
\hline 600 & 0.628 & -0.659 & -0.031 & 1.002 & 1002 & 24.250 & 736 \\
\hline 600 & 0.629 & -0.660 & -0.031 & 1.002 & 1002 & 24.250 & 738 \\
\hline 600 & 0.629 & -0.661 & -0.032 & 1.002 & 1002 & 24.250 & 740 \\
\hline 600 & 0.627 & -0.658 & -0.031 & 1.002 & 1002 & 24.250 & 742 \\
\hline 600 & 0.626 & -0.658 & -0.032 & 1.002 & 1002 & 24.250 & 744 \\
\hline 600 & 0.626 & -0.658 & -0.032 & 1.002 & 1002 & 24.250 & 746 \\
\hline 600 & 0.625 & -0.657 & -0.032 & 1.002 & 1002 & 24.250 & 748 \\
\hline 600 & 0.625 & -0.657 & -0.032 & 1.002 & 1002 & 24.250 & 750 \\
\hline 600 & 0.628 & -0.660 & -0.032 & 1.002 & 1002 & 24.250 & 752 \\
\hline 600 & 0.626 & -0.658 & -0.032 & 1.002 & 1002 & 24.250 & 754 \\
\hline 600 & 0.626 & -0.658 & -0.032 & 1.002 & 1002 & 24.250 & 756 \\
\hline 600 & 0.622 & -0.654 & -0.032 & 1.002 & 1002 & 24.250 & 758 \\
\hline
\end{tabular}




\begin{tabular}{|c|c|c|c|c|c|c|c|}
\hline 600 & 0.627 & -0.659 & -0.032 & 1.002 & 1002 & 24.250 & 760 \\
\hline 600 & 0.625 & -0.657 & -0.032 & 1.002 & 1002 & 24.250 & 762 \\
\hline 600 & 0.625 & -0.657 & -0.032 & 1.002 & 1002 & 24.250 & 764 \\
\hline 600 & 0.622 & -0.655 & -0.033 & 1.002 & 1002 & 24.250 & 766 \\
\hline 600 & 0.625 & -0.657 & -0.032 & 1.002 & 1002 & 24.250 & 768 \\
\hline 600 & 0.623 & -0.655 & -0.032 & 1.002 & 1002 & 24.250 & 770 \\
\hline 600 & 0.623 & -0.655 & -0.032 & 1.002 & 1002 & 24.250 & 772 \\
\hline 600 & 0.623 & -0.655 & -0.032 & 1.002 & 1002 & 24.250 & 774 \\
\hline 600 & 0.621 & -0.653 & -0.032 & 1.002 & 1002 & 24.250 & 776 \\
\hline 600 & 0.624 & -0.656 & -0.032 & 1.002 & 1002 & 24.250 & 778 \\
\hline 600 & 0.621 & -0.653 & -0.032 & 1.002 & 1002 & 24.250 & 780 \\
\hline 600 & 0.620 & -0.652 & -0.032 & 1.002 & 1002 & 24.250 & 782 \\
\hline 600 & 0.623 & -0.655 & -0.032 & 1.002 & 1002 & 24.250 & 784 \\
\hline 600 & 0.620 & -0.652 & -0.032 & 1.002 & 1002 & 24.250 & 786 \\
\hline 600 & 0.621 & -0.653 & -0.032 & 1.002 & 1002 & 24.250 & 788 \\
\hline 600 & 0.619 & -0.652 & -0.033 & 1.002 & 1002 & 24.250 & 790 \\
\hline 600 & 0.620 & -0.652 & -0.032 & 1.002 & 1002 & 24.250 & 792 \\
\hline 600 & 0.619 & -0.651 & -0.032 & 1.002 & 1002 & 24.250 & 794 \\
\hline 600 & 0.618 & -0.650 & -0.032 & 1.002 & 1002 & 24.250 & 796 \\
\hline 600 & 0.620 & -0.653 & -0.033 & 1.002 & 1002 & 24.250 & 798 \\
\hline 600 & 0.620 & -0.652 & -0.032 & 1.002 & 1002 & 24.250 & 800 \\
\hline 600 & 0.619 & -0.651 & -0.032 & 1.002 & 1002 & 24.250 & 802 \\
\hline 600 & 0.619 & -0.652 & -0.033 & 1.002 & 1002 & 24.250 & 804 \\
\hline 600 & 0.618 & -0.650 & -0.032 & 1.002 & 1002 & 24.250 & 806 \\
\hline 600 & 0.617 & -0.649 & -0.032 & 1.002 & 1002 & 24.250 & 808 \\
\hline 600 & 0.618 & -0.651 & -0.033 & 1.002 & 1002 & 24.250 & 810 \\
\hline 600 & 0.617 & -0.649 & -0.032 & 1.002 & 1002 & 24.250 & 812 \\
\hline 600 & 0.619 & -0.651 & -0.032 & 1.002 & 1002 & 24.250 & 814 \\
\hline 600 & 0.618 & -0.650 & -0.032 & 1.002 & 1002 & 24.250 & 816 \\
\hline 600 & 0.617 & -0.650 & -0.033 & 1.002 & 1002 & 24.250 & 818 \\
\hline 600 & 0.617 & -0.649 & -0.032 & 1.002 & 1002 & 24.250 & 820 \\
\hline 600 & 0.618 & -0.650 & -0.032 & 1.002 & 1002 & 24.250 & 822 \\
\hline 600 & 0.616 & -0.648 & -0.032 & 1.002 & 1002 & 24.250 & 824 \\
\hline 600 & 0.613 & -0.645 & -0.032 & 1.002 & 1002 & 24.250 & 826 \\
\hline 599 & 0.619 & -0.651 & -0.032 & 1.002 & 1002 & 24.250 & 828 \\
\hline 600 & 0.616 & -0.649 & -0.033 & 1.002 & 1002 & 24.250 & 830 \\
\hline 600 & 0.613 & -0.645 & -0.032 & 1.002 & 1002 & 24.250 & 832 \\
\hline 600 & 0.613 & -0.645 & -0.032 & 1.002 & 1002 & 24.250 & 834 \\
\hline 600 & 0.614 & -0.646 & -0.032 & 1.002 & 1002 & 24.250 & 836 \\
\hline 600 & 0.615 & -0.647 & -0.032 & 1.002 & 1002 & 24.250 & 838 \\
\hline 600 & 0.613 & -0.645 & -0.032 & 1.002 & 1002 & 24.250 & 840 \\
\hline 600 & 0.615 & -0.647 & -0.032 & 1.002 & 1002 & 24.250 & 842 \\
\hline 600 & 0.616 & -0.648 & -0.032 & 1.002 & 1002 & 24.250 & 844 \\
\hline 600 & 0.613 & -0.646 & -0.033 & 1.002 & 1002 & 24.250 & 846 \\
\hline 600 & 0.612 & -0.644 & -0.032 & 1.002 & 1002 & 24.250 & 848 \\
\hline 600 & 0.614 & -0.646 & -0.032 & 1.002 & 1002 & 24.250 & 850 \\
\hline 600 & 0.614 & -0.646 & -0.032 & 1.002 & 1002 & 24.250 & 852 \\
\hline 600 & 0.613 & -0.645 & -0.032 & 1.002 & 1002 & 24.250 & 854 \\
\hline 600 & 0.614 & -0.647 & -0.033 & 1.002 & 1002 & 24.250 & 856 \\
\hline 600 & 0.613 & -0.646 & -0.033 & 1.002 & 1002 & 24.250 & 858 \\
\hline 600 & 0.615 & -0.646 & -0.031 & 1.002 & 1002 & 24.250 & 860 \\
\hline 600 & 0.614 & -0.647 & -0.033 & 1.002 & 1002 & 24.250 & 862 \\
\hline 600 & 0.614 & -0.646 & -0.032 & 1.002 & 1002 & 24.250 & 864 \\
\hline 600 & 0.614 & -0.646 & -0.032 & 1.002 & 1002 & 24.250 & 866 \\
\hline 600 & 0.614 & -0.646 & -0.032 & 1.002 & 1002 & 24.250 & 868 \\
\hline 600 & 0.613 & -0.646 & -0.033 & 1.002 & 1002 & 24.250 & 870 \\
\hline 600 & 0.614 & -0.647 & -0.033 & 1.002 & 1002 & 24.250 & 872 \\
\hline 600 & 0.615 & -0.647 & -0.032 & 1.002 & 1002 & 24.250 & 874 \\
\hline 600 & 0.613 & -0.646 & -0.033 & 1.002 & 1002 & 24.250 & 876 \\
\hline 600 & 0.610 & -0.643 & -0.033 & 1.002 & 1002 & 24.250 & 878 \\
\hline 600 & 0.612 & -0.644 & -0.032 & 1.002 & 1002 & 24.250 & 880 \\
\hline 600 & 0.612 & -0.644 & -0.032 & 1.002 & 1002 & 24.250 & 882 \\
\hline 600 & 0.615 & -0.648 & -0.033 & 1.002 & 1002 & 24.250 & 884 \\
\hline
\end{tabular}




\begin{tabular}{|c|c|c|c|c|c|c|c|}
\hline 600 & 0.612 & -0.645 & -0.033 & 1.002 & 1002 & 24.250 & 886 \\
\hline 600 & 0.611 & -0.644 & -0.033 & 1.002 & 1002 & 24.250 & 888 \\
\hline 600 & 0.611 & -0.644 & -0.033 & 1.002 & 1002 & 24.250 & 890 \\
\hline 600 & 0.615 & -0.648 & -0.033 & 1.002 & 1002 & 24.250 & 892 \\
\hline 600 & 0.613 & -0.645 & -0.032 & 1.002 & 1002 & 24.250 & 894 \\
\hline 600 & 0.612 & -0.645 & -0.033 & 1.002 & 1002 & 24.250 & 896 \\
\hline 600 & 0.614 & -0.647 & -0.033 & 1.002 & 1002 & 24.250 & 898 \\
\hline 600 & 0.612 & -0.645 & -0.033 & 1.002 & 1002 & 24.250 & 900 \\
\hline 600 & 0.613 & -0.645 & -0.032 & 1.002 & 1002 & 24.250 & 902 \\
\hline 600 & 0.611 & -0.644 & -0.033 & 1.002 & 1002 & 24.250 & 904 \\
\hline 600 & 0.611 & -0.643 & -0.032 & 1.002 & 1002 & 24.250 & 906 \\
\hline 600 & 0.611 & -0.644 & -0.033 & 1.002 & 1002 & 24.250 & 908 \\
\hline 600 & 0.611 & -0.644 & -0.033 & 1.002 & 1002 & 24.250 & 910 \\
\hline 600 & 0.612 & -0.644 & -0.032 & 1.002 & 1002 & 24.250 & 912 \\
\hline 600 & 0.612 & -0.644 & -0.032 & 1.002 & 1002 & 24.250 & 914 \\
\hline 600 & 0.611 & -0.643 & -0.032 & 1.002 & 1002 & 24.250 & 916 \\
\hline 600 & 0.610 & -0.642 & -0.032 & 1.002 & 1002 & 24.250 & 918 \\
\hline 600 & 0.610 & -0.643 & -0.033 & 1.002 & 1002 & 24.250 & 920 \\
\hline 600 & 0.609 & -0.642 & -0.033 & 1.002 & 1002 & 24.250 & 922 \\
\hline 599 & 0.612 & -0.644 & -0.032 & 1.002 & 1002 & 24.250 & 924 \\
\hline 600 & 0.610 & -0.642 & -0.032 & 1.002 & 1002 & 24.250 & 926 \\
\hline 600 & 0.611 & -0.644 & -0.033 & 1.002 & 1002 & 24.250 & 928 \\
\hline 600 & 0.611 & -0.644 & -0.033 & 1.002 & 1002 & 24.250 & 930 \\
\hline 600 & 0.611 & -0.643 & -0.032 & 1.002 & 1002 & 24.250 & 932 \\
\hline 600 & 0.612 & -0.645 & -0.033 & 1.002 & 1002 & 24.250 & 934 \\
\hline 600 & 0.608 & -0.641 & -0.033 & 1.002 & 1002 & 24.250 & 936 \\
\hline 600 & 0.606 & -0.638 & -0.032 & 1.002 & 1002 & 24.250 & 938 \\
\hline 600 & 0.607 & -0.640 & -0.033 & 1.002 & 1002 & 24.250 & 940 \\
\hline 600 & 0.607 & -0.639 & -0.032 & 1.002 & 1002 & 24.250 & 942 \\
\hline 600 & 0.609 & -0.641 & -0.032 & 1.002 & 1002 & 24.250 & 944 \\
\hline 600 & 0.606 & -0.639 & -0.033 & 1.002 & 1002 & 24.250 & 946 \\
\hline 600 & 0.609 & -0.642 & -0.033 & 1.002 & 1002 & 24.250 & 948 \\
\hline 600 & 0.610 & -0.643 & -0.033 & 1.002 & 1002 & 24.250 & 950 \\
\hline 600 & 0.607 & -0.639 & -0.032 & 1.002 & 1002 & 24.250 & 952 \\
\hline 600 & 0.605 & -0.637 & -0.032 & 1.002 & 1002 & 24.250 & 954 \\
\hline 600 & 0.607 & -0.640 & -0.033 & 1.002 & 1002 & 24.250 & 956 \\
\hline 599 & 0.607 & -0.640 & -0.033 & 1.002 & 1002 & 24.250 & 958 \\
\hline 600 & 0.606 & -0.638 & -0.032 & 1.002 & 1002 & 24.250 & 960 \\
\hline 600 & 0.605 & -0.638 & -0.033 & 1.002 & 1002 & 24.250 & 962 \\
\hline 600 & 0.605 & -0.638 & -0.033 & 1.002 & 1002 & 24.250 & 964 \\
\hline 600 & 0.605 & -0.637 & -0.032 & 1.002 & 1002 & 24.250 & 966 \\
\hline 600 & 0.606 & -0.639 & -0.033 & 1.002 & 1002 & 24.250 & 968 \\
\hline 600 & 0.607 & -0.639 & -0.032 & 1.002 & 1002 & 24.250 & 970 \\
\hline 600 & 0.605 & -0.638 & -0.033 & 1.002 & 1002 & 24.250 & 972 \\
\hline 600 & 0.607 & -0.640 & -0.033 & 1.002 & 1002 & 24.250 & 97 \\
\hline 600 & 0.606 & -0.639 & -0.033 & 1.002 & 1002 & 24.250 & 976 \\
\hline 600 & 0.607 & -0.640 & -0.033 & 1.002 & 1002 & 24.250 & 978 \\
\hline 600 & 0.606 & -0.638 & -0.032 & 1.002 & 1002 & 24.250 & 980 \\
\hline 600 & 0.606 & -0.639 & -0.033 & 1.002 & 1002 & 24.250 & 982 \\
\hline 600 & 0.602 & -0.634 & -0.032 & 1.002 & 1002 & 24.250 & 98 \\
\hline 600 & 0.603 & -0.636 & -0.033 & 1.002 & 1002 & 24.250 & 98 \\
\hline 600 & 0.605 & -0.638 & -0.033 & 1.002 & 1002 & 24.250 & 988 \\
\hline 600 & 0.604 & -0.637 & -0.033 & 1.002 & 1002 & 24.250 & 990 \\
\hline 600 & 0.605 & -0.638 & -0.033 & 1.002 & 1002 & 24.250 & 992 \\
\hline 600 & 0.605 & -0.638 & -0.033 & 1.002 & 1002 & 24.250 & 994 \\
\hline 600 & 0.603 & -0.636 & -0.033 & 1.002 & 1002 & 24.250 & 99 \\
\hline 600 & 0.604 & -0.637 & -0.033 & 1.002 & 1002 & 24.250 & 998 \\
\hline 600 & 0.603 & -0.636 & -0.033 & 1.002 & 1002 & 24.250 & 100 \\
\hline 600 & 0.602 & -0.635 & -0.033 & 1.002 & 1002 & 24.250 & 100 \\
\hline 600 & 0.600 & -0.633 & -0.033 & 1.002 & 1002 & 24.250 & 100 \\
\hline 600 & 0.599 & -0.632 & -0.033 & 1.002 & 1002 & 24.250 & 1006 \\
\hline 600 & 0.598 & -0.631 & -0.033 & 1.002 & 1002 & 24.250 & 100 \\
\hline 600 & 0.599 & -0.632 & -0.033 & 1.002 & 1002 & 24.250 & 1010 \\
\hline
\end{tabular}




\begin{tabular}{|c|c|c|c|c|c|c|c|}
\hline 600 & 0.598 & -0.630 & -0.032 & 1.002 & 1002 & 24.250 & 1012 \\
\hline 600 & 0.597 & -0.630 & -0.033 & 1.002 & 1002 & 24.250 & 1014 \\
\hline 600 & 0.598 & -0.631 & -0.033 & 1.002 & 1002 & 24.250 & 1016 \\
\hline 600 & 0.595 & -0.628 & -0.033 & 1.002 & 1002 & 24.250 & 1018 \\
\hline 600 & 0.598 & -0.631 & -0.033 & 1.002 & 1002 & 24.250 & $102 C$ \\
\hline 600 & 0.591 & -0.624 & -0.033 & 1.002 & 1002 & 24.250 & 102 \\
\hline 600 & 0.595 & -0.629 & -0.034 & 1.002 & 1002 & 24.250 & 10 \\
\hline 600 & 0.594 & -0.628 & -0.034 & 1.002 & 1002 & 24.250 & 102 \\
\hline 600 & 0.591 & -0.624 & -0.033 & 1.002 & 1002 & 24.250 & $102 \varepsilon$ \\
\hline 600 & 0.592 & -0.626 & -0.034 & 1.002 & 1002 & 24.250 & 1030 \\
\hline 600 & 0.590 & -0.623 & -0.033 & 1.002 & 1002 & 24.250 & 103 \\
\hline 600 & 0.591 & -0.624 & -0.033 & 1.002 & 1002 & 24.250 & 103 \\
\hline 600 & 0.591 & -0.625 & -0.034 & 1.002 & 1002 & 24.250 & 103 \\
\hline 600 & 0.589 & -0.622 & -0.033 & 1.002 & 1002 & 24.250 & 103 \\
\hline 599 & 0.591 & -0.624 & -0.033 & 1.002 & 1002 & 24.250 & 104 \\
\hline 599 & 0.589 & -0.623 & -0.034 & 1.002 & 1002 & 24.250 & 1042 \\
\hline 600 & 0.588 & -0.622 & -0.034 & 1.002 & 1002 & 24.250 & 10 \\
\hline 600 & 0.588 & -0.622 & -0.034 & 1.002 & 1002 & 24.250 & 10 \\
\hline 600 & 0.587 & -0.621 & -0.034 & 1.002 & 1002 & 24.250 & 10 \\
\hline 600 & 0.587 & -0.621 & -0.034 & 1.002 & 1002 & 24.250 & 105 \\
\hline 600 & 0.588 & -0.622 & -0.034 & 1.002 & 1002 & 24.250 & 105 \\
\hline 600 & 0.586 & -0.619 & -0.033 & 1.002 & 1002 & 24.250 & 105 \\
\hline 600 & 0.583 & -0.617 & -0.034 & 1.002 & 1002 & 24.250 & 105 \\
\hline 600 & 0.586 & -0.620 & -0.034 & 1.002 & 1002 & 24.250 & 105 \\
\hline 600 & 0.585 & -0.619 & -0.034 & 1.002 & 1002 & 24.250 & 106 \\
\hline 600 & 0.585 & -0.619 & -0.034 & 1.002 & 1002 & 24.250 & 106 \\
\hline 600 & 0.583 & -0.617 & -0.034 & 1.002 & 1002 & 24.250 & 106 \\
\hline 600 & 0.581 & -0.614 & -0.033 & 1.002 & 1002 & 24.250 & 106 \\
\hline 600 & 0.583 & -0.616 & -0.033 & 1.002 & 1002 & 24.250 & 106 \\
\hline 600 & 0.580 & -0.613 & -0.033 & 1.002 & 1002 & 24.250 & 107 \\
\hline 600 & 0.580 & -0.613 & -0.033 & 1.002 & 1002 & 24.250 & 107 \\
\hline 600 & 0.581 & -0.615 & -0.034 & 1.002 & 1002 & 24.250 & 107 \\
\hline 600 & 0.580 & -0.613 & -0.033 & 1.002 & 1002 & 24.250 & 107 \\
\hline 600 & 0.581 & -0.615 & -0.034 & 1.002 & 1002 & 24.250 & 107 \\
\hline 600 & 0.582 & -0.618 & -0.036 & 1.002 & 1002 & 24.250 & 108 \\
\hline 600 & 0.580 & -0.614 & -0.034 & 1.002 & 1002 & 24.250 & 108 \\
\hline 600 & 0.579 & -0.614 & -0.035 & 1.002 & 1002 & 24.250 & 108 \\
\hline 600 & 0.579 & -0.614 & -0.035 & 1.002 & 1002 & 24.250 & 108 \\
\hline 600 & 0.580 & -0.616 & -0.036 & 1.002 & 1002 & 24.250 & 108 \\
\hline 600 & 0.580 & -0.616 & -0.036 & 1.002 & 1002 & 24.250 & $10 s$ \\
\hline 600 & 0.578 & -0.615 & -0.037 & 1.002 & 1002 & 24.250 & 109 \\
\hline 600 & 0.578 & -0.614 & -0.036 & 1.002 & 1002 & 24.250 & 109 \\
\hline 600 & 0.576 & -0.611 & -0.035 & 1.002 & 1002 & 24.250 & $10 s$ \\
\hline 600 & 0.576 & -0.611 & -0.035 & 1.002 & 1002 & 24.250 & $10 s$ \\
\hline 600 & 0.576 & -0.612 & -0.036 & 1.002 & 1002 & 24.250 & 110 \\
\hline 601 & 0.576 & -0.612 & -0.036 & 1.002 & 1002 & 24.250 & 110 \\
\hline 601 & 0.576 & -0.613 & -0.037 & 1.002 & 1002 & 24.250 & 110 \\
\hline 601 & 0.576 & -0.613 & -0.037 & 1.002 & 1002 & 24.250 & 110 \\
\hline 600 & 0.574 & -0.611 & -0.037 & 1.002 & 1002 & 24.250 & 110 \\
\hline 600 & 0.575 & -0.611 & -0.036 & 1.002 & 1002 & 24.250 & 111 \\
\hline 600 & 0.573 & -0.609 & -0.036 & 1.002 & 1002 & 24.250 & 111 \\
\hline 600 & 0.573 & -0.610 & -0.037 & 1.002 & 1002 & 24.250 & 111 \\
\hline 600 & 0.572 & -0.610 & -0.038 & 1.002 & 1002 & 24.250 & 111 \\
\hline 600 & 0.572 & -0.609 & -0.037 & 1.002 & 1002 & 24.250 & 111 \\
\hline 600 & 0.571 & -0.608 & -0.037 & 1.002 & 1002 & 24.250 & 112 \\
\hline 600 & 0.570 & -0.608 & -0.038 & 1.002 & 1002 & 24.250 & 112 \\
\hline 600 & 0.569 & -0.607 & -0.038 & 1.002 & 1002 & 24.250 & 112 \\
\hline 600 & 0.569 & -0.606 & -0.037 & 1.002 & 1002 & 24.250 & 112 \\
\hline 600 & 0.568 & -0.606 & -0.038 & 1.002 & 1002 & 24.250 & 112 \\
\hline 600 & 0.567 & -0.604 & -0.037 & 1.002 & 1002 & 24.250 & 113 \\
\hline 600 & 0.568 & -0.606 & -0.038 & 1.002 & 1002 & 24.250 & 113 \\
\hline 600 & 0.569 & -0.607 & -0.038 & 1.002 & 1002 & 24.250 & 113 \\
\hline 600 & 0.566 & -0.605 & -0.039 & 1.002 & 1002 & 24.250 & 113 \\
\hline
\end{tabular}




\begin{tabular}{|c|c|c|c|c|c|c|c|}
\hline 600 & 0.567 & -0.605 & -0.038 & 1.002 & 1002 & 24.250 & 1138 \\
\hline 600 & 0.566 & -0.604 & -0.038 & 1.002 & 1002 & 24.250 & 1140 \\
\hline 600 & 0.566 & -0.604 & -0.038 & 1.002 & 1002 & 24.250 & 1142 \\
\hline 600 & 0.565 & -0.603 & -0.038 & 1.002 & 1002 & 24.250 & 1144 \\
\hline 600 & 0.565 & -0.604 & -0.039 & 1.002 & 1002 & 24.250 & 114 \\
\hline 600 & 0.564 & -0.604 & -0.040 & 1.002 & 1002 & 24.250 & 114 \\
\hline 600 & 0.565 & -0.605 & -0.040 & 1.002 & 1002 & 24.250 & 115 \\
\hline 600 & 0.564 & -0.604 & -0.040 & 1.002 & 1002 & 24.250 & 115 \\
\hline 600 & 0.564 & -0.603 & -0.039 & 1.002 & 1002 & 24.250 & 115 \\
\hline 600 & 0.562 & -0.602 & -0.040 & 1.002 & 1002 & 24.250 & 115 \\
\hline 600 & 0.562 & -0.603 & -0.041 & 1.002 & 1002 & 24.250 & 115 \\
\hline 600 & 0.559 & -0.601 & -0.042 & 1.002 & 1002 & 24.250 & 116 \\
\hline 600 & 0.562 & -0.602 & -0.040 & 1.002 & 1002 & 24.250 & 116 \\
\hline 600 & 0.561 & -0.603 & -0.042 & 1.002 & 1002 & 24.250 & 116 \\
\hline 600 & 0.560 & -0.601 & -0.041 & 1.002 & 1002 & 24.250 & 116 \\
\hline 600 & 0.560 & -0.601 & -0.041 & 1.002 & 1002 & 24.250 & 116 \\
\hline 600 & 0.560 & -0.601 & -0.041 & 1.002 & 1002 & 24.250 & 117 \\
\hline 600 & 0.559 & -0.601 & -0.042 & 1.002 & 1002 & 24.250 & 117 \\
\hline 600 & 0.558 & -0.601 & -0.043 & 1.002 & 1002 & 24.250 & 117 \\
\hline 600 & 0.558 & -0.599 & -0.041 & 1.002 & 1002 & 24.250 & 117 \\
\hline 600 & 0.555 & -0.597 & -0.042 & 1.002 & 1002 & 24.250 & 117 \\
\hline 599 & 0.555 & -0.597 & -0.042 & 1.002 & 1002 & 24.250 & 118 \\
\hline 600 & 0.554 & -0.596 & -0.042 & 1.002 & 1002 & 24.250 & 118 \\
\hline 600 & 0.555 & -0.597 & -0.042 & 1.002 & 1002 & 24.250 & $11 \varepsilon$ \\
\hline 600 & 0.553 & -0.596 & -0.043 & 1.002 & 1002 & 24.250 & $11 \varepsilon$ \\
\hline 600 & 0.553 & -0.595 & -0.042 & 1.002 & 1002 & 24.250 & $11 \varepsilon$ \\
\hline 600 & 0.553 & -0.595 & -0.042 & 1.002 & 1002 & 24.250 & 115 \\
\hline 599 & 0.553 & -0.596 & -0.043 & 1.002 & 1002 & 24.250 & 119 \\
\hline 599 & 0.553 & -0.596 & -0.043 & 1.002 & 1002 & 24.250 & 119 \\
\hline 600 & 0.552 & -0.597 & -0.045 & 1.002 & 1002 & 24.250 & 119 \\
\hline 600 & 0.551 & -0.598 & -0.047 & 1.002 & 1002 & 24.250 & $11 S$ \\
\hline 600 & 0.551 & -0.598 & -0.047 & 1.002 & 1002 & 24.250 & $12 C$ \\
\hline 601 & 0.551 & -0.598 & -0.047 & 1.002 & 1002 & 24.250 & 120 \\
\hline 600 & 0.549 & -0.596 & -0.047 & 1.002 & 1002 & 24.250 & 120 \\
\hline 601 & 0.548 & -0.596 & -0.048 & 1.002 & 1002 & 24.250 & 120 \\
\hline 601 & 0.549 & -0.598 & -0.049 & 1.002 & 1002 & 24.250 & 120 \\
\hline 600 & 0.550 & -0.598 & -0.048 & 1.002 & 1002 & 24.250 & 121 \\
\hline 601 & 0.549 & -0.597 & -0.048 & 1.002 & 1002 & 24.250 & 121 \\
\hline 601 & 0.548 & -0.596 & -0.048 & 1.002 & 1002 & 24.250 & 121 \\
\hline 600 & 0.548 & -0.598 & -0.050 & 1.002 & 1002 & 24.250 & 121 \\
\hline 600 & 0.547 & -0.597 & -0.050 & 1.002 & 1002 & 24.250 & 121 \\
\hline 601 & 0.546 & -0.595 & -0.049 & 1.002 & 1002 & 24.250 & 122 \\
\hline 601 & 0.547 & -0.596 & -0.049 & 1.002 & 1002 & 24.250 & 122 \\
\hline 600 & 0.544 & -0.595 & -0.051 & 1.002 & 1002 & 24.250 & 122 \\
\hline 600 & 0.544 & -0.595 & -0.051 & 1.002 & 1002 & 24.250 & 12 \\
\hline 600 & 0.546 & -0.595 & -0.049 & 1.002 & 1002 & 24.250 & 122 \\
\hline 600 & 0.543 & -0.595 & -0.052 & 1.002 & 1002 & 24.250 & 123 \\
\hline 600 & 0.550 & -0.593 & -0.043 & 1.002 & 1002 & 24.250 & 123 \\
\hline 601 & 0.549 & -0.598 & -0.049 & 1.002 & 1002 & 24.250 & 123 \\
\hline 600 & 0.547 & -0.596 & -0.049 & 1.002 & 1002 & 24.250 & 123 \\
\hline 600 & 0.548 & -0.595 & -0.047 & 1.002 & 1002 & 24.250 & 123 \\
\hline 600 & 0.543 & -0.595 & -0.052 & 1.002 & 1002 & 24.250 & 124 \\
\hline 600 & 0.543 & -0.593 & -0.050 & 1.002 & 1002 & 24.250 & 124 \\
\hline 600 & 0.545 & -0.594 & -0.049 & 1.002 & 1002 & 24.250 & 12 \\
\hline 600 & 0.540 & -0.594 & -0.054 & 1.002 & 1002 & 24.250 & 124 \\
\hline 601 & 0.538 & -0.593 & -0.055 & 1.002 & 1002 & 24.250 & 124 \\
\hline 600 & 0.535 & -0.593 & -0.058 & 1.002 & 1002 & 24.250 & 125 \\
\hline 601 & 0.534 & -0.592 & -0.058 & 1.002 & 1002 & 24.250 & 125 \\
\hline 600 & 0.530 & -0.590 & -0.060 & 1.002 & 1002 & 24.250 & 125 \\
\hline 600 & 0.533 & -0.590 & -0.057 & 1.002 & 1002 & 24.250 & 125 \\
\hline 600 & 0.530 & -0.589 & -0.059 & 1.002 & 1002 & 24.250 & 125 \\
\hline 601 & 0.527 & -0.586 & -0.059 & 1.002 & 1002 & 24.250 & 126 \\
\hline 600 & 0.524 & -0.590 & -0.066 & 1.002 & 1002 & 24.250 & 126 \\
\hline
\end{tabular}




$\begin{array}{llllllll}601 & 0.523 & -0.587 & -0.064 & 1.002 & 1002 & 24.250 & 1264 \\ 600 & 0.526 & -0.584 & -0.058 & 1.002 & 1002 & 24.250 & 1266 \\ 600 & 0.527 & -0.586 & -0.059 & 1.002 & 1002 & 24.250 & 1268 \\ 600 & 0.518 & -0.585 & -0.067 & 1.002 & 1002 & 24.250 & 1270 \\ 600 & 0.516 & -0.585 & -0.069 & 1.002 & 1002 & 24.250 & 1272 \\ 601 & 0.509 & -0.584 & -0.075 & 1.002 & 1002 & 24.250 & 1274 \\ 600 & 0.534 & -0.590 & -0.056 & 1.002 & 1002 & 24.250 & 1276 \\ 600 & 0.516 & -0.588 & -0.072 & 1.002 & 1002 & 24.250 & 1278 \\ 601 & 0.508 & -0.585 & -0.077 & 1.002 & 1002 & 24.250 & 1280 \\ 601 & 0.512 & -0.584 & -0.072 & 1.002 & 1002 & 24.250 & 1282 \\ 600 & 0.524 & -0.584 & -0.060 & 1.002 & 1002 & 24.250 & 1284 \\ 600 & 0.509 & -0.582 & -0.073 & 1.002 & 1002 & 24.250 & 1286 \\ 600 & 0.514 & -0.584 & -0.070 & 1.002 & 1002 & 24.250 & 1288 \\ 600 & 0.512 & -0.582 & -0.070 & 1.002 & 1002 & 24.250 & 1290\end{array}$




\section{Appendix B - Coal-Derived Rods Raw Data}

Coal-Derived Rod \#11 (100\% PetCoke), Air Flow Rate is Varied, $\mathrm{T}=600^{\circ} \mathrm{C}, 2 / 28 / 2006$

\begin{tabular}{|c|c|c|c|c|c|c|c|c|}
\hline \multicolumn{3}{|c|}{0.50 SLPM } & \multicolumn{3}{|c|}{0.75 SLPM } & \multicolumn{3}{|c|}{0.90 SLPM } \\
\hline I/SA & VCELL & P/SA & I/SA & VCELL & P/SA & I/SA & VCELL & $\mathrm{P} / \mathrm{SA}$ \\
\hline 0.033 & 0.936 & 0.000 & 0.000 & 0.974 & 0.000 & 0.000 & 0.975 & 0.000 \\
\hline 0.066 & 0.936 & 0.000 & 0.000 & 0.977 & 0.000 & 0.000 & 0.975 & 0.000 \\
\hline 0.066 & 0.936 & 0.000 & 0.000 & 0.978 & 0.000 & 0.000 & 0.985 & 0.000 \\
\hline 0.066 & 0.936 & 0.000 & 0.000 & 0.978 & 0.000 & 0.066 & 0.983 & 0.000 \\
\hline 0.066 & 0.937 & 0.000 & 0.066 & 0.958 & 0.000 & 0.066 & 0.986 & 0.000 \\
\hline 0.066 & 0.956 & 0.000 & 0.066 & 0.959 & 0.000 & 0.066 & 0.986 & 0.000 \\
\hline 0.066 & 0.961 & 0.000 & 0.066 & 0.959 & 0.000 & 0.066 & 0.987 & 0.000 \\
\hline 0.066 & 0.963 & 0.000 & 0.066 & 0.960 & 0.000 & 0.066 & 0.986 & 0.000 \\
\hline 0.066 & 0.964 & 0.000 & 1.649 & 0.955 & 0.002 & 1.649 & 0.979 & 0.002 \\
\hline 1.649 & 0.932 & 0.002 & 3.298 & 0.949 & 0.003 & 1.649 & 0.977 & 0.002 \\
\hline 3.298 & 0.925 & 0.003 & 4.947 & 0.944 & 0.005 & 3.298 & 0.971 & 0.003 \\
\hline 4.947 & 0.921 & 0.005 & 6.596 & 0.937 & 0.006 & 4.947 & 0.963 & 0.005 \\
\hline 6.596 & 0.913 & 0.006 & 8.278 & 0.932 & 0.008 & 6.596 & 0.963 & 0.006 \\
\hline 8.278 & 0.907 & 0.008 & 8.278 & 0.939 & 0.008 & 8.278 & 0.965 & 0.008 \\
\hline 8.278 & 0.915 & 0.008 & 9.894 & 0.927 & 0.009 & 8.278 & 0.947 & 0.008 \\
\hline 9.927 & 0.902 & 0.009 & 11.577 & 0.921 & 0.011 & 8.278 & 0.951 & 0.008 \\
\hline 11.577 & 0.896 & 0.010 & 13.193 & 0.916 & 0.012 & 9.927 & 0.953 & 0.009 \\
\hline 13.193 & 0.890 & 0.012 & 14.875 & 0.910 & 0.014 & 11.577 & 0.944 & 0.011 \\
\hline 14.875 & 0.883 & 0.013 & 16.524 & 0.905 & 0.015 & 13.193 & 0.935 & 0.012 \\
\hline 16.524 & 0.877 & 0.014 & 16.524 & 0.903 & 0.015 & 14.875 & .932 & 0.014 \\
\hline 16.524 & 0.875 & 0.014 & 18.173 & 0.898 & 0.016 & 16.524 & 0.912 & 0.015 \\
\hline 18.173 & 0.869 & 0.016 & 18.173 & 0.898 & 0.016 & 18.173 & 0.920 & 0.017 \\
\hline 19.822 & 0.863 & 0.017 & 19.822 & 0.892 & 0.018 & 18.173 & 0.918 & 0.017 \\
\hline 21.471 & 0.857 & 0.018 & 21.471 & 0.886 & 0.019 & 19.822 & 0.913 & 0.018 \\
\hline 23.120 & 0.851 & 0.020 & 23.120 & 0.880 & 0.020 & 21.471 & 0.906 & 0.019 \\
\hline 24.769 & 0.847 & 0.021 & 24.769 & 0.874 & 0.022 & 23.120 & 0.897 & 0.021 \\
\hline 24.769 & 0.826 & 0.020 & 24.769 & 0.863 & 0.021 & 24.769 & 0.889 & 0.022 \\
\hline 26.418 & 0.839 & 0.022 & 26.418 & 0.868 & 0.023 & 24.769 & .873 & 0.022 \\
\hline 28.067 & 0.831 & 0.023 & 28.067 & 0.863 & 0.024 & 26.418 & 0.881 & 0.023 \\
\hline 29.716 & 0.824 & 0.024 & 29.716 & 0.856 & 0.025 & 28.067 & .875 & 0.025 \\
\hline 31.365 & 0.819 & 0.026 & 31.365 & 0.850 & 0.027 & 29.716 & 0.868 & 0.026 \\
\hline 33.015 & 0.811 & 0.027 & 31.365 & 0.849 & 0.027 & 31.365 & .860 & 0.027 \\
\hline 33.015 & 0.774 & 0.026 & 33.015 & 0.842 & 0.028 & 33.015 & 0.854 & 0.028 \\
\hline 34.664 & 0.804 & 0.028 & 33.015 & 0.818 & 0.027 & 33.015 & 0.827 & 0.027 \\
\hline 36.313 & 0.795 & 0.029 & 34.664 & 0.836 & 0.029 & 34.664 & 0.846 & 0.029 \\
\hline 37.995 & 0.784 & 0.030 & 36.313 & 0.830 & 0.030 & 36.313 & 0.838 & 0.030 \\
\hline 39.611 & 0.775 & 0.031 & 37.962 & 0.822 & 0.031 & 37.962 & 0.833 & 0.032 \\
\hline 41.260 & 0.762 & 0.031 & 39.611 & 0.814 & 0.032 & 39.611 & 0.826 & 0.033 \\
\hline 41.293 & 0.704 & 0.029 & 41.260 & 0.808 & 0.033 & 41.260 & 0.818 & 0.034 \\
\hline 42.909 & 0.744 & 0.032 & 41.293 & 0.767 & 0.032 & 41.293 & 0.769 & 0.032 \\
\hline 44.558 & 0.700 & 0.031 & 42.909 & 0.798 & 0.034 & 42.909 & 0.803 & 0.034 \\
\hline 46.240 & 0.693 & 0.032 & 44.591 & 0.790 & 0.035 & 44.558 & 0.785 & 0.035 \\
\hline 47.889 & 0.681 & 0.033 & 46.207 & 0.778 & 0.036 & 46.207 & 0.766 & 0.035 \\
\hline 49.538 & 0.666 & 0.033 & 47.889 & 0.767 & 0.037 & 47.889 & 0.753 & 0.036 \\
\hline 51.187 & 0.633 & 0.032 & 49.538 & 0.754 & 0.037 & 49.538 & 0.744 & 0.037 \\
\hline 52.836 & 0.587 & 0.031 & 49.538 & 0.687 & 0.034 & 49.538 & 0.694 & 0.034 \\
\hline & & & 51.187 & 0.742 & 0.038 & 51.187 & 0.731 & 0.037 \\
\hline & & & 52.836 & 0.726 & 0.038 & 52.836 & 0.706 & 0.037 \\
\hline & & & 54.485 & 0.699 & 0.038 & 54.485 & 0.676 & 0.037 \\
\hline & & & 56.135 & 0.681 & 0.038 & 56.135 & 0.640 & 0.036 \\
\hline
\end{tabular}




$\begin{array}{llllll}57.784 & 0.654 & 0.038 & 57.784 & 0.591 & 0.034 \\ 59.433 & 0.612 & 0.036 & & & \\ 61.082 & 0.561 & 0.034 & & & \end{array}$

Coal-Derived Rod \#10 (100\% PetCoke), Air Flow Rate is Varied, T $=600^{\circ} \mathrm{C}, 3 / 2 / 2006$

\begin{tabular}{|c|c|c|c|c|c|c|c|c|c|c|c|}
\hline \multicolumn{3}{|c|}{0.50 SLPM } & \multicolumn{3}{|c|}{0.75 SLPM } & \multicolumn{3}{|c|}{0.90 SLPM } & \multicolumn{3}{|c|}{0.50 SLPM (2) } \\
\hline I/SA & VCELL & P/SA & I/SA & VCELL & P/SA & I/SA & VCELL & P/SA & I/SA & VCELL & $\mathrm{P} / \mathrm{SA}$ \\
\hline 0.092 & 0.979 & 0.000 & 0.092 & 0.993 & 0.000 & 0.092 & 1.003 & 0.000 & 0.092 & 0.978 & 0.000 \\
\hline 0.092 & 0.980 & 0.000 & 0.092 & 0.995 & 0.000 & 0.092 & 1.004 & 0.000 & 0.092 & 0.981 & 0.000 \\
\hline 0.092 & 0.981 & 0.000 & 0.092 & 0.996 & 0.000 & 0.092 & 1.004 & 0.000 & 2.289 & 0.965 & 0.002 \\
\hline 0.092 & 0.946 & 0.000 & 0.092 & 0.997 & 0.000 & 0.092 & 0.967 & 0.000 & 4.578 & 0.949 & 0.004 \\
\hline 0.092 & 0.964 & 0.000 & 0.092 & 0.997 & 0.000 & 0.092 & 0.983 & 0.000 & 6.867 & 0.932 & 0.006 \\
\hline 2.289 & 0.975 & 0.002 & 0.092 & 0.998 & 0.000 & 0.092 & 0.990 & 0.000 & 9.155 & 0.911 & 0.008 \\
\hline 4.578 & 0.968 & 0.004 & 0.092 & 0.998 & 0.000 & 0.092 & 0.998 & 0.000 & 11.490 & 0.887 & 0.010 \\
\hline 6.867 & 0.961 & 0.007 & 0.092 & 0.998 & 0.000 & 0.092 & 0.997 & 0.000 & 13.779 & 0.861 & 0.012 \\
\hline 9.155 & 0.953 & 0.009 & 0.092 & 0.998 & 0.000 & 2.289 & 0.998 & 0.002 & 16.068 & 0.822 & 0.013 \\
\hline 11.490 & 0.945 & 0.011 & 0.092 & 0.998 & 0.000 & 4.578 & 0.991 & 0.005 & 18.357 & 0.769 & 0.014 \\
\hline 13.779 & 0.935 & 0.013 & 0.092 & 0.950 & 0.000 & 6.867 & 0.983 & 0.007 & 20.645 & 0.716 & 0.015 \\
\hline 16.068 & 0.926 & 0.015 & 0.092 & 0.975 & 0.000 & 9.155 & 0.975 & 0.009 & 22.934 & 0.651 & 0.015 \\
\hline 18.357 & 0.918 & 0.017 & 0.092 & 0.984 & 0.000 & 11.490 & 0.967 & 0.011 & & & \\
\hline 20.645 & 0.910 & 0.019 & 2.289 & 0.992 & 0.002 & 13.779 & 0.959 & 0.013 & & & \\
\hline 22.934 & 0.901 & 0.021 & 4.578 & 0.985 & 0.005 & 16.068 & 0.950 & 0.015 & & & \\
\hline 25.223 & 0.890 & 0.022 & 6.867 & 0.977 & 0.007 & 18.357 & 0.942 & 0.017 & & & \\
\hline 27.512 & 0.880 & 0.024 & 9.155 & 0.970 & 0.009 & 20.645 & 0.932 & 0.019 & & & \\
\hline 29.801 & 0.868 & 0.026 & 11.490 & 0.963 & 0.011 & 22.934 & 0.923 & 0.021 & & & \\
\hline 32.090 & 0.857 & 0.028 & 13.779 & 0.954 & 0.013 & 25.223 & 0.909 & 0.023 & & & \\
\hline 34.379 & 0.840 & 0.029 & 16.068 & 0.946 & 0.015 & 27.512 & 0.886 & 0.024 & & & \\
\hline 36.667 & 0.826 & 0.030 & 18.357 & 0.938 & 0.017 & 29.801 & 0.864 & 0.026 & & & \\
\hline 39.002 & 0.804 & 0.031 & 20.645 & 0.929 & 0.019 & 32.090 & 0.837 & 0.027 & & & \\
\hline 41.245 & 0.774 & 0.032 & 22.934 & 0.920 & 0.021 & 34.379 & 0.804 & 0.028 & & & \\
\hline 43.534 & 0.735 & 0.032 & 25.223 & 0.910 & 0.023 & 36.667 & 0.770 & 0.028 & & & \\
\hline 45.823 & 0.673 & 0.031 & 27.512 & 0.898 & 0.025 & 38.956 & 0.699 & 0.027 & & & \\
\hline 48.112 & 0.601 & 0.029 & 29.801 & 0.889 & 0.026 & 41.245 & 0.598 & 0.025 & & & \\
\hline & & & 32.090 & 0.875 & 0.028 & & & & & & \\
\hline & & & 34.379 & 0.859 & 0.030 & & & & & & \\
\hline & & & 36.667 & 0.844 & 0.031 & & & & & & \\
\hline & & & 38.956 & 0.825 & 0.032 & & & & & & \\
\hline & & & 41.245 & 0.796 & 0.033 & & & & & & \\
\hline & & & 43.534 & 0.761 & 0.033 & & & & & & \\
\hline & & & 45.823 & 0.671 & 0.031 & & & & & & \\
\hline & & & 48.157 & 0.536 & 0.026 & & & & & & \\
\hline
\end{tabular}

Coal-Derived Rod \#10 (100\% PetCoke), Long Term Run, Air Flow Rate = 0.5 SLPM, T $=600^{\circ} \mathrm{C}, 3 / 2 / 2006$

$\begin{array}{lccccccc} & \text { Temp } & & & & & \text { I } & \\ \text { Time } & \left({ }^{\circ} \mathrm{C}\right) & \text { VCELL } & \text { VANODE } & \text { VCATHODE } & \text { I }(\mathrm{A}) & (\mathrm{mA}) & \text { I/SA } \\ \text { 12:21:30 } & 600 & 0.786 & -0.798 & -0.012 & 0.004 & 4 & 0.066\end{array}$




\begin{tabular}{|c|c|c|c|c|c|c|c|}
\hline $12: 22: 00$ & 600 & 0.900 & -0.889 & 0.011 & 0.004 & 4 & 0.066 \\
\hline $12: 22: 30$ & 600 & 0.896 & -0.877 & 0.019 & 0.004 & 4 & 0.066 \\
\hline $12: 23: 00$ & 600 & 0.903 & -0.885 & 0.018 & 0.004 & 4 & 0.066 \\
\hline $12: 23: 30$ & 600 & 0.898 & -0.869 & 0.029 & 0.004 & 4 & 0.066 \\
\hline $12: 24: 00$ & 600 & 0.899 & -0.877 & 0.022 & 0.004 & 4 & 0.066 \\
\hline $12: 24: 30$ & 600 & 0.896 & -0.849 & 0.047 & 0.004 & 4 & 0.066 \\
\hline $12: 25: 00$ & 600 & 0.896 & -0.845 & 0.051 & 0.004 & 4 & 0.066 \\
\hline $12: 25: 30$ & 600 & 0.893 & -0.847 & 0.046 & 0.004 & 4 & 0.066 \\
\hline $12: 26: 00$ & 600 & 0.893 & -0.841 & 0.052 & 0.004 & 4 & 0.066 \\
\hline $12: 26: 30$ & 600 & 0.891 & -0.837 & 0.054 & 0.004 & 4 & 0.066 \\
\hline $12: 27: 00$ & 600 & 0.896 & -0.844 & 0.052 & 0.004 & 4 & 0.066 \\
\hline $12: 27: 30$ & 600 & 0.878 & -0.820 & 0.058 & 0.004 & 4 & 0.066 \\
\hline $12: 28: 00$ & 600 & 0.893 & -0.827 & 0.066 & 0.004 & 4 & 0.066 \\
\hline $12: 28: 30$ & 600 & 0.893 & -0.817 & 0.076 & 0.004 & 4 & 0.066 \\
\hline 12:29:00 & 600 & 0.893 & -0.826 & 0.067 & 0.004 & 4 & 0.066 \\
\hline 12:29:30 & 600 & 0.895 & -0.819 & 0.076 & 0.004 & 4 & 0.066 \\
\hline $12: 30: 00$ & 600 & 0.896 & -0.826 & 0.070 & 0.004 & 4 & 0.066 \\
\hline $12: 30: 30$ & 600 & 0.897 & -0.820 & 0.077 & 0.004 & 4 & 0.066 \\
\hline $12: 31: 00$ & 600 & 0.892 & -0.803 & 0.089 & 0.004 & 4 & 0.066 \\
\hline $12: 31: 30$ & 600 & 0.796 & -0.696 & 0.100 & 0.004 & 4 & 0.066 \\
\hline $12: 32: 00$ & 600 & 0.891 & -0.796 & 0.095 & 0.004 & 4 & 0.066 \\
\hline $12: 32: 30$ & 600 & 0.891 & -0.789 & 0.102 & 0.004 & 4 & 0.066 \\
\hline $12: 33: 00$ & 600 & 0.892 & -0.790 & 0.102 & 0.004 & 4 & 0.066 \\
\hline $12: 33: 30$ & 600 & 0.654 & -0.534 & 0.120 & 0.004 & 4 & 0.066 \\
\hline $12: 34: 00$ & 600 & 0.892 & -0.781 & 0.111 & 0.004 & 4 & 0.066 \\
\hline $12: 34: 30$ & 600 & 0.889 & -0.763 & 0.126 & 0.004 & 4 & 0.066 \\
\hline $12: 35: 00$ & 600 & 0.890 & -0.746 & 0.144 & 0.004 & 4 & 0.066 \\
\hline $12: 35: 30$ & 600 & 0.885 & -0.755 & 0.130 & 0.004 & 4 & 0.066 \\
\hline $12: 36: 00$ & 600 & 0.884 & -0.741 & 0.143 & 0.004 & 4 & 0.066 \\
\hline $12: 36: 30$ & 600 & 0.884 & -0.713 & 0.171 & 0.004 & 4 & 0.066 \\
\hline $12: 37: 00$ & 600 & 0.766 & -0.592 & 0.174 & 0.004 & 4 & 0.066 \\
\hline $12: 37: 30$ & 600 & 0.879 & -0.697 & 0.182 & 0.004 & 4 & 0.066 \\
\hline $12: 38: 00$ & 600 & 0.885 & -0.715 & 0.170 & 0.004 & 4 & 0.066 \\
\hline $12: 38: 30$ & 600 & 0.881 & -0.716 & 0.165 & 0.004 & 4 & 0.066 \\
\hline 12:39:00 & 600 & 0.880 & -0.690 & 0.190 & 0.004 & 4 & 0.066 \\
\hline $12: 39: 30$ & 600 & 0.877 & -0.690 & 0.187 & 0.004 & 4 & 0.066 \\
\hline $12: 40: 00$ & 600 & 0.875 & -0.680 & 0.195 & 0.004 & 4 & 0.066 \\
\hline $12: 40: 30$ & 600 & 0.874 & -0.671 & 0.203 & 0.004 & 4 & 0.066 \\
\hline $12: 41: 00$ & 600 & 0.874 & -0.663 & 0.211 & 0.004 & 4 & 0.066 \\
\hline $12: 41: 30$ & 600 & 0.860 & -0.652 & 0.208 & 0.004 & 4 & 0.066 \\
\hline $12: 42: 00$ & 600 & 0.871 & -0.655 & 0.216 & 0.004 & 4 & 0.066 \\
\hline $12: 42: 30$ & 600 & 0.867 & -0.661 & 0.206 & 0.004 & 4 & 0.066 \\
\hline $12: 43: 00$ & 600 & 0.869 & -0.657 & 0.212 & 0.004 & 4 & 0.066 \\
\hline $12: 43: 30$ & 600 & 0.872 & -0.656 & 0.216 & 0.004 & 4 & 0.066 \\
\hline $12: 44: 00$ & 600 & 0.872 & -0.653 & 0.219 & 0.004 & 4 & 0.066 \\
\hline $12: 44: 30$ & 600 & 0.876 & -0.644 & 0.232 & 0.004 & 4 & 0.066 \\
\hline $12: 45: 00$ & 600 & 0.868 & -0.654 & 0.214 & 0.004 & 4 & 0.066 \\
\hline $12: 45: 30$ & 600 & 0.873 & -0.642 & 0.231 & 0.004 & 4 & 0.066 \\
\hline $12: 46: 00$ & 600 & 0.873 & -0.637 & 0.236 & 0.004 & 4 & 0.066 \\
\hline $12: 46: 30$ & 600 & 0.871 & -0.638 & 0.233 & 0.004 & 4 & 0.066 \\
\hline $12: 47: 00$ & 600 & 0.870 & -0.629 & 0.241 & 0.004 & 4 & 0.066 \\
\hline $12: 47: 30$ & 600 & 0.862 & -0.620 & 0.242 & 0.004 & 4 & 0.066 \\
\hline $12: 48: 00$ & 600 & 0.861 & -0.619 & 0.242 & 0.004 & 4 & 0.066 \\
\hline $12: 48: 30$ & 600 & 0.864 & -0.610 & 0.254 & 0.004 & 4 & 0.066 \\
\hline $12: 49: 00$ & 600 & 0.864 & -0.606 & 0.258 & 0.004 & 4 & 0.066 \\
\hline $12: 49: 30$ & 600 & 0.858 & -0.608 & 0.250 & 0.004 & 4 & 0.066 \\
\hline $12: 50: 00$ & 600 & 0.861 & -0.586 & 0.275 & 0.004 & 4 & 0.066 \\
\hline $12: 50: 30$ & 600 & 0.856 & -0.592 & 0.264 & 0.004 & 4 & 0.066 \\
\hline $12: 51: 00$ & 600 & 0.860 & -0.593 & 0.267 & 0.004 & 4 & 0.066 \\
\hline 12:51:30 & 600 & 0.858 & -0.585 & 0.273 & 0.004 & 4 & 0.066 \\
\hline $12: 52: 00$ & 600 & 0.858 & -0.581 & 0.277 & 0.004 & 4 & 0.066 \\
\hline $12: 52: 30$ & 600 & 0.853 & -0.570 & 0.283 & 0.004 & 4 & 0.066 \\
\hline $12: 53: 00$ & 600 & 0.851 & -0.555 & 0.296 & 0.004 & 4 & 0.066 \\
\hline
\end{tabular}




\begin{tabular}{|c|c|c|c|c|c|c|c|}
\hline $12: 53: 30$ & 600 & 0.850 & -0.548 & 0.302 & 0.004 & 4 & 0.066 \\
\hline $12: 54: 00$ & 600 & 0.851 & -0.529 & 0.322 & 0.004 & 4 & 0.066 \\
\hline $12: 54: 30$ & 600 & 0.852 & -0.520 & 0.332 & 0.004 & 4 & 0.066 \\
\hline $12: 55: 00$ & 600 & 0.853 & -0.496 & 0.357 & 0.004 & 4 & 0.066 \\
\hline $12: 55: 30$ & 600 & 0.854 & -0.502 & 0.352 & 0.004 & 4 & 0.066 \\
\hline $12: 56: 00$ & 600 & 0.853 & -0.502 & 0.351 & 0.004 & 4 & 0.066 \\
\hline $12: 56: 30$ & 600 & 0.843 & -0.480 & 0.363 & 0.004 & 4 & 0.066 \\
\hline $12: 57: 00$ & 600 & 0.845 & -0.476 & 0.369 & 0.004 & 4 & 0.066 \\
\hline $12: 57: 30$ & 600 & 0.840 & -0.462 & 0.378 & 0.004 & 4 & 0.066 \\
\hline 12:58:00 & 600 & 0.841 & -0.448 & 0.393 & 0.004 & 4 & 0.066 \\
\hline $12: 58: 30$ & 600 & 0.832 & -0.451 & 0.381 & 0.004 & 4 & 0.066 \\
\hline $12: 59: 00$ & 600 & 0.697 & -0.311 & 0.386 & 0.004 & 4 & 0.066 \\
\hline $12: 59: 30$ & 600 & 0.818 & -0.440 & 0.378 & 0.004 & 4 & 0.066 \\
\hline $13: 00: 00$ & 600 & 0.813 & -0.431 & 0.382 & 0.004 & 4 & 0.066 \\
\hline 13:00:30 & 600 & 0.811 & -0.412 & 0.399 & 0.004 & 4 & 0.066 \\
\hline 13:01:00 & 600 & 0.806 & -0.415 & 0.391 & 0.004 & 4 & 0.066 \\
\hline $13: 01: 30$ & 600 & 0.779 & -0.398 & 0.381 & 0.004 & 4 & 0.066 \\
\hline $13: 02: 00$ & 600 & 0.780 & -0.396 & 0.384 & 0.004 & 4 & 0.066 \\
\hline $13: 02: 30$ & 600 & 0.745 & -0.382 & 0.363 & 0.004 & 4 & 0.066 \\
\hline 13:03:00 & 600 & 0.723 & -0.382 & 0.341 & 0.004 & 4 & 0.066 \\
\hline $13: 03: 30$ & 600 & 0.655 & -0.388 & 0.267 & 0.004 & 4 & 0.066 \\
\hline 13:04:00 & 600 & 0.653 & -0.384 & 0.269 & 0.004 & 4 & 0.066 \\
\hline $13: 04: 30$ & 600 & 0.606 & -0.377 & 0.229 & 0.004 & 4 & 0.066 \\
\hline $13: 05: 00$ & 600 & 0.495 & -0.319 & 0.176 & 0.004 & 4 & 0.066 \\
\hline $13: 05: 30$ & 600 & 0.540 & -0.346 & 0.194 & 0.004 & 4 & 0.066 \\
\hline 13:06:00 & 600 & 0.540 & -0.284 & 0.256 & 0.004 & 4 & 0.066 \\
\hline $13: 06: 30$ & 600 & 0.533 & -0.249 & 0.284 & 0.004 & 4 & 0.066 \\
\hline 13:07:00 & 600 & 0.689 & -0.343 & 0.346 & 0.004 & 4 & 0.066 \\
\hline 13:07:30 & 600 & 0.721 & -0.344 & 0.377 & 0.004 & 4 & 0.066 \\
\hline 13:08:00 & 600 & 0.742 & -0.325 & 0.417 & 0.004 & 4 & 0.066 \\
\hline $13: 08: 30$ & 600 & 0.760 & -0.296 & 0.464 & 0.004 & 4 & 0.066 \\
\hline 13:09:00 & 600 & 0.767 & -0.266 & 0.501 & 0.004 & 4 & 0.066 \\
\hline 13:09:30 & 600 & 0.768 & -0.251 & 0.517 & 0.004 & 4 & 0.066 \\
\hline $13: 10: 00$ & 600 & 0.739 & -0.222 & 0.517 & 0.004 & 4 & 0.066 \\
\hline 13:10:30 & 600 & 0.768 & -0.250 & 0.518 & 0.004 & 4 & 0.066 \\
\hline 13:11:00 & 600 & 0.780 & -0.250 & 0.530 & 0.004 & 4 & 0.066 \\
\hline $13: 11: 30$ & 600 & 0.647 & -0.120 & 0.527 & 0.004 & 4 & 0.066 \\
\hline $13: 12: 00$ & 600 & 0.776 & -0.250 & 0.526 & 0.004 & 4 & 0.066 \\
\hline $13: 12: 30$ & 600 & 0.784 & -0.249 & 0.535 & 0.004 & 4 & 0.066 \\
\hline $13: 13: 00$ & 600 & 0.774 & -0.244 & 0.530 & 0.004 & 4 & 0.066 \\
\hline 13:13:30 & 600 & 0.778 & -0.244 & 0.534 & 0.004 & 4 & 0.066 \\
\hline 13:14:00 & 600 & 0.768 & -0.245 & 0.523 & 0.004 & 4 & 0.066 \\
\hline $13: 14: 30$ & 600 & 0.768 & -0.243 & 0.525 & 0.004 & 4 & 0.066 \\
\hline $13: 15: 00$ & 600 & 0.769 & -0.241 & 0.528 & 0.004 & 4 & 0.066 \\
\hline $13: 15: 30$ & 600 & 0.763 & -0.239 & 0.524 & 0.004 & 4 & 0.066 \\
\hline $13: 16: 00$ & 600 & 0.100 & 0.420 & 0.520 & 0.004 & 4 & 0.066 \\
\hline $13: 16: 30$ & 600 & 0.759 & -0.241 & 0.518 & 0.004 & 4 & 0.066 \\
\hline 13:17:00 & 600 & 0.757 & -0.238 & 0.519 & 0.004 & 4 & 0.066 \\
\hline $13: 17: 30$ & 600 & 0.749 & -0.236 & 0.513 & 0.004 & 4 & 0.066 \\
\hline 13:18:00 & 600 & 0.750 & -0.234 & 0.516 & 0.004 & 4 & 0.066 \\
\hline $13: 18: 30$ & 600 & 0.742 & -0.211 & 0.531 & 0.004 & 4 & 0.066 \\
\hline 13:19:00 & 600 & 0.737 & -0.230 & 0.507 & 0.004 & 4 & 0.066 \\
\hline $13: 19: 30$ & 600 & 0.734 & -0.234 & 0.500 & 0.004 & 4 & 0.066 \\
\hline 13:20:00 & 600 & 0.722 & -0.226 & 0.496 & 0.004 & 4 & 0.066 \\
\hline $13: 20: 30$ & 600 & 0.724 & -0.229 & 0.495 & 0.004 & 4 & 0.066 \\
\hline $13: 21: 00$ & 600 & 0.728 & -0.229 & 0.499 & 0.004 & 4 & 0.066 \\
\hline $13: 21: 30$ & 600 & 0.716 & -0.218 & 0.498 & 0.004 & 4 & 0.066 \\
\hline $13: 22: 00$ & 600 & 0.718 & -0.208 & 0.510 & 0.004 & 4 & 0.066 \\
\hline $13: 22: 30$ & 600 & 0.716 & -0.218 & 0.498 & 0.004 & 4 & 0.066 \\
\hline 13:23:00 & 600 & 0.719 & -0.219 & 0.500 & 0.004 & 4 & 0.066 \\
\hline $13: 23: 30$ & 600 & 0.710 & -0.222 & 0.488 & 0.004 & 4 & 0.066 \\
\hline $13: 24: 00$ & 600 & 0.694 & -0.218 & 0.476 & 0.004 & 4 & 0.066 \\
\hline $13: 24: 30$ & 600 & 0.702 & -0.217 & 0.485 & 0.004 & 4 & 0.066 \\
\hline
\end{tabular}




\begin{tabular}{|c|c|c|c|c|c|c|c|}
\hline $13: 25: 00$ & 600 & 0.699 & -0.222 & 0.477 & 0.004 & 4 & 0.066 \\
\hline $13: 25: 30$ & 600 & 0.686 & -0.219 & 0.467 & 0.004 & 4 & 0.066 \\
\hline $13: 26: 00$ & 600 & 0.690 & -0.198 & 0.492 & 0.004 & 4 & 0.066 \\
\hline $13: 26: 30$ & 600 & 0.683 & -0.220 & 0.463 & 0.004 & 4 & 0.066 \\
\hline $13: 27: 00$ & 600 & 0.683 & -0.213 & 0.470 & 0.004 & 4 & 0.066 \\
\hline $13: 27: 30$ & 600 & 0.672 & -0.212 & 0.460 & 0.004 & 4 & 0.066 \\
\hline $13: 28: 00$ & 600 & 0.665 & -0.208 & 0.457 & 0.004 & 4 & 0.066 \\
\hline $13: 28: 30$ & 600 & 0.636 & -0.180 & 0.456 & 0.004 & 4 & 0.066 \\
\hline $13: 29: 00$ & 600 & 0.639 & -0.199 & 0.440 & 0.004 & 4 & 0.066 \\
\hline 13:29:30 & 600 & 0.638 & -0.197 & 0.441 & 0.004 & 4 & 0.066 \\
\hline $13: 30: 00$ & 600 & 0.635 & -0.200 & 0.435 & 0.004 & 4 & 0.066 \\
\hline $13: 30: 30$ & 600 & 0.639 & -0.192 & 0.447 & 0.004 & 4 & 0.066 \\
\hline $13: 31: 00$ & 600 & 0.637 & -0.193 & 0.444 & 0.004 & 4 & 0.066 \\
\hline $13: 31: 30$ & 600 & 0.635 & -0.198 & 0.437 & 0.004 & 4 & 0.066 \\
\hline 13:32:00 & 600 & 0.071 & 0.368 & 0.439 & 0.004 & 4 & 0.066 \\
\hline 13:32:30 & 600 & 0.619 & -0.190 & 0.429 & 0.004 & 4 & 0.066 \\
\hline $13: 33: 00$ & 600 & 0.585 & -0.167 & 0.418 & 0.004 & 4 & 0.066 \\
\hline $13: 33: 30$ & 600 & 0.588 & -0.174 & 0.414 & 0.004 & 4 & 0.066 \\
\hline $13: 34: 00$ & 600 & 0.586 & -0.162 & 0.424 & 0.006 & 6 & 0.099 \\
\hline $13: 34: 30$ & 600 & 0.586 & -0.153 & 0.433 & 0.004 & 4 & 0.066 \\
\hline 13:35:00 & 600 & 0.578 & -0.160 & 0.418 & 0.004 & 4 & 0.066 \\
\hline 13:35:30 & 600 & 0.292 & 0.137 & 0.429 & 0.004 & 4 & 0.066 \\
\hline $13: 36: 00$ & 600 & 0.489 & -0.070 & 0.419 & 0.004 & 4 & 0.066 \\
\hline $13: 36: 30$ & 600 & 0.567 & -0.133 & 0.434 & 0.004 & 4 & 0.066 \\
\hline $13: 37: 00$ & 600 & 0.550 & -0.152 & 0.398 & 0.004 & 4 & 0.066 \\
\hline 13:37:30 & 600 & 0.544 & -0.156 & 0.388 & 0.004 & 4 & 0.066 \\
\hline $13: 38: 00$ & 600 & 0.533 & -0.143 & 0.390 & 0.004 & 4 & 0.066 \\
\hline 13:38:30 & 600 & 0.515 & -0.141 & 0.374 & 0.004 & 4 & 0.066 \\
\hline 13:39:00 & 600 & 0.500 & -0.139 & 0.361 & 0.004 & 4 & 0.066 \\
\hline $13: 39: 30$ & 600 & 0.481 & -0.136 & 0.345 & 0.004 & 4 & 0.066 \\
\hline $13: 40: 00$ & 600 & 0.466 & -0.140 & 0.326 & 0.004 & 4 & 0.066 \\
\hline $13: 40: 30$ & 600 & 0.363 & -0.038 & 0.325 & 0.006 & 6 & 0.099 \\
\hline $13: 41: 00$ & 600 & 0.429 & -0.109 & 0.320 & 0.004 & 4 & 0.066 \\
\hline $13: 41: 30$ & 600 & 0.104 & 0.216 & 0.320 & 0.004 & 4 & 0.066 \\
\hline $13: 42: 00$ & 600 & 0.444 & -0.131 & 0.313 & 0.004 & 4 & 0.066 \\
\hline $13: 42: 30$ & 600 & 0.090 & 0.211 & 0.301 & 0.004 & 4 & 0.066 \\
\hline $13: 43: 00$ & 600 & 0.419 & -0.132 & 0.287 & 0.004 & 4 & 0.066 \\
\hline $13: 43: 30$ & 600 & 0.367 & -0.084 & 0.283 & 0.004 & 4 & 0.066 \\
\hline $13: 44: 00$ & 600 & 0.402 & -0.130 & 0.272 & 0.004 & 4 & 0.066 \\
\hline $13: 44: 30$ & 600 & 0.245 & 0.033 & 0.278 & 0.004 & 4 & 0.066 \\
\hline 13:45:00 & 600 & 0.385 & -0.119 & 0.266 & 0.004 & 4 & 0.066 \\
\hline $13: 45: 30$ & 600 & 0.391 & -0.123 & 0.268 & 0.004 & 4 & 0.066 \\
\hline $13: 46: 00$ & 600 & 0.242 & 0.004 & 0.246 & 0.004 & 4 & 0.066 \\
\hline $13: 46: 30$ & 600 & 0.354 & -0.117 & 0.237 & 0.004 & 4 & 0.066 \\
\hline 13:47:00 & 600 & 0.362 & -0.122 & 0.240 & 0.004 & 4 & 0.066 \\
\hline $13: 47: 30$ & 600 & 0.356 & -0.107 & 0.249 & 0.004 & 4 & 0.066 \\
\hline 13:48:00 & 600 & 0.357 & -0.117 & 0.240 & 0.004 & 4 & 0.066 \\
\hline $13: 48: 30$ & 600 & 0.321 & -0.085 & 0.236 & 0.036 & 36 & 0.594 \\
\hline $13: 49: 00$ & 600 & 0.342 & -0.117 & 0.225 & 0.036 & 36 & 0.594 \\
\hline $13: 49: 30$ & 600 & 0.346 & -0.119 & 0.227 & 0.036 & 36 & 0.594 \\
\hline $13: 50: 00$ & 600 & 0.334 & -0.115 & 0.219 & 0.036 & 36 & 0.594 \\
\hline $13: 50: 30$ & 600 & 0.330 & -0.106 & 0.224 & 0.036 & 36 & 0.594 \\
\hline $13: 51: 00$ & 600 & 0.332 & -0.119 & 0.213 & 0.036 & 36 & 0.594 \\
\hline $13: 51: 30$ & 600 & 0.326 & -0.111 & 0.215 & 0.036 & 36 & 0.594 \\
\hline $13: 52: 00$ & 600 & 0.297 & -0.084 & 0.213 & 0.038 & 38 & 0.627 \\
\hline $13: 52: 30$ & 600 & 0.329 & -0.116 & 0.213 & 0.036 & 36 & 0.594 \\
\hline $13: 53: 00$ & 600 & 0.296 & -0.087 & 0.209 & 0.004 & 4 & 0.066 \\
\hline $13: 53: 30$ & 600 & 0.323 & -0.113 & 0.210 & 0.004 & 4 & 0.066 \\
\hline $13: 54: 00$ & 600 & 0.319 & -0.112 & 0.207 & 0.004 & 4 & 0.066 \\
\hline 13:54:30 & 600 & 0.319 & -0.113 & 0.206 & 0.004 & 4 & 0.066 \\
\hline $13: 55: 00$ & 600 & 0.315 & -0.107 & 0.208 & 0.004 & 4 & 0.066 \\
\hline $13: 55: 30$ & 600 & 0.315 & -0.104 & 0.211 & 0.004 & 4 & 0.066 \\
\hline 13:56:00 & 600 & 0.319 & -0.113 & 0.206 & 0.004 & 4 & 0.066 \\
\hline
\end{tabular}




\begin{tabular}{|c|c|c|c|c|c|c|c|}
\hline $13: 56: 30$ & 600 & 0.314 & -0.113 & 0.201 & 0.004 & 4 & 0.066 \\
\hline $13: 57: 00$ & 600 & 0.311 & -0.109 & 0.202 & 0.004 & 4 & 0.066 \\
\hline $13: 57: 30$ & 600 & 0.088 & 0.115 & 0.203 & 0.004 & 4 & 0.066 \\
\hline 13:58:00 & 600 & 0.309 & -0.104 & 0.205 & 0.004 & 4 & 0.066 \\
\hline $13: 58: 30$ & 600 & 0.309 & -0.107 & 0.202 & 0.004 & 4 & 0.066 \\
\hline $13: 59: 00$ & 600 & 0.303 & -0.104 & 0.199 & 0.004 & 4 & 0.066 \\
\hline 13:59:30 & 600 & 0.309 & -0.113 & 0.196 & 0.004 & 4 & 0.066 \\
\hline $14: 00: 00$ & 600 & 0.301 & -0.103 & 0.198 & 0.004 & 4 & 0.066 \\
\hline $14: 00: 30$ & 600 & 0.036 & 0.164 & 0.200 & 0.004 & 4 & 0.066 \\
\hline 14:01:00 & 600 & 0.299 & -0.103 & 0.196 & 0.004 & 4 & 0.066 \\
\hline $14: 01: 30$ & 600 & 0.294 & -0.102 & 0.192 & 0.004 & 4 & 0.066 \\
\hline $14: 02: 00$ & 600 & 0.176 & 0.026 & 0.202 & 0.004 & 4 & 0.066 \\
\hline $14: 02: 30$ & 600 & 0.216 & -0.015 & 0.201 & 0.004 & 4 & 0.066 \\
\hline $14: 03: 00$ & 600 & 0.298 & -0.102 & 0.196 & 0.004 & 4 & 0.066 \\
\hline 14:03:30 & 600 & 0.294 & -0.096 & 0.198 & 0.004 & 4 & 0.066 \\
\hline 14:04:00 & 600 & 0.294 & -0.100 & 0.194 & 0.004 & 4 & 0.066 \\
\hline $14: 04: 30$ & 600 & 0.290 & -0.098 & 0.192 & 0.004 & 4 & 0.066 \\
\hline $14: 05: 00$ & 600 & 0.289 & -0.097 & 0.192 & 0.004 & 4 & 0.066 \\
\hline $14: 05: 30$ & 600 & 0.183 & 0.014 & 0.197 & 0.004 & 4 & 0.066 \\
\hline 14:06:00 & 600 & 0.287 & -0.096 & 0.191 & 0.004 & 4 & 0.066 \\
\hline $14: 06: 30$ & 600 & 0.295 & -0.098 & 0.197 & 0.004 & 4 & 0.066 \\
\hline 14:07:00 & 600 & 0.288 & -0.094 & 0.194 & 0.004 & 4 & 0.066 \\
\hline $14: 07: 30$ & 600 & 0.155 & 0.034 & 0.189 & 0.004 & 4 & 0.066 \\
\hline $14: 08: 00$ & 600 & 0.282 & -0.093 & 0.189 & 0.004 & 4 & 0.066 \\
\hline 14:08:30 & 600 & 0.284 & -0.088 & 0.196 & 0.004 & 4 & 0.066 \\
\hline 14:09:00 & 600 & 0.280 & -0.089 & 0.191 & 0.004 & 4 & 0.066 \\
\hline 14:09:30 & 600 & 0.208 & -0.021 & 0.187 & 0.004 & 4 & 0.066 \\
\hline 14:10:00 & 600 & 0.281 & -0.095 & 0.186 & 0.004 & 4 & 0.066 \\
\hline 14:10:30 & 600 & 0.257 & -0.074 & 0.183 & 0.004 & 4 & 0.066 \\
\hline $14: 11: 00$ & 600 & 0.276 & -0.094 & 0.182 & 0.004 & 4 & 0.066 \\
\hline 14:11:30 & 600 & 0.273 & -0.091 & 0.182 & 0.004 & 4 & 0.066 \\
\hline $14: 12: 00$ & 600 & 0.275 & -0.095 & 0.18 & 0.004 & 4 & 0.066 \\
\hline $14: 12: 30$ & 600 & 0.278 & -0.099 & 0.179 & 0.004 & 4 & 0.066 \\
\hline 14:13:00 & 600 & 0.266 & -0.091 & 0.175 & 0.004 & 4 & 0.066 \\
\hline 14:13:30 & 600 & 0.002 & 0.177 & 0.179 & 0.004 & 4 & 0.066 \\
\hline $14: 14: 00$ & 600 & 0.271 & -0.095 & 0.176 & 0.004 & 4 & 0.066 \\
\hline $14: 14: 30$ & 600 & 0.272 & -0.091 & 0.181 & 0.004 & 4 & 0.066 \\
\hline $14: 15: 00$ & 600 & 0.265 & -0.082 & 0.183 & 0.004 & 4 & 0.066 \\
\hline $14: 15: 30$ & 600 & 0.110 & 0.063 & 0.173 & 0.004 & 4 & 0.066 \\
\hline $14: 16: 00$ & 600 & 0.136 & 0.034 & 0.17 & 0.004 & 4 & 0.066 \\
\hline 14:16:30 & 600 & 0.252 & -0.085 & 0.167 & 0.004 & 4 & 0.066 \\
\hline $14: 17: 00$ & 600 & 0.255 & -0.090 & 0.165 & 0.004 & 4 & 0.066 \\
\hline $14: 17: 30$ & 600 & 0.161 & 0.017 & 0.178 & 0.004 & 4 & 0.066 \\
\hline $14: 18: 00$ & 600 & 0.253 & -0.091 & 0.162 & 0.004 & 4 & 0.066 \\
\hline $14: 18: 30$ & 600 & 0.238 & -0.090 & 0.148 & 0.004 & 4 & 0.066 \\
\hline 14:19:00 & 600 & 0.236 & -0.091 & 0.145 & 0.004 & 4 & 0.066 \\
\hline 14:19:30 & 600 & 0.235 & -0.094 & 0.141 & 0.004 & 4 & 0.066 \\
\hline 14:20:00 & 600 & 0.156 & -0.024 & 0.132 & 0.004 & 4 & 0.066 \\
\hline $14: 20: 30$ & 600 & 0.223 & -0.096 & 0.127 & 0.004 & 4 & 0.066 \\
\hline $14: 21: 00$ & 600 & 0.214 & -0.093 & 0.121 & 0.004 & 4 & 0.066 \\
\hline $14: 21: 30$ & 600 & 0.209 & -0.097 & 0.112 & 0.004 & 4 & 0.066 \\
\hline $14: 22: 00$ & 600 & 0.200 & -0.093 & 0.107 & 0.004 & 4 & 0.066 \\
\hline $14: 22: 30$ & 600 & 0.192 & -0.092 & 0.1 & 0.004 & 4 & 0.066 \\
\hline 14:23:00 & 600 & 0.168 & -0.079 & 0.089 & 0.004 & 4 & 0.066 \\
\hline $14: 23: 30$ & 600 & 0.184 & -0.091 & 0.093 & 0.004 & 4 & 0.066 \\
\hline $14: 24: 00$ & 600 & 0.179 & -0.090 & 0.089 & 0.004 & 4 & 0.066 \\
\hline $14: 24: 30$ & 600 & 0.170 & -0.097 & 0.073 & 0.004 & 4 & 0.066 \\
\hline $14: 25: 00$ & 600 & 0.170 & -0.100 & 0.07 & 0.004 & 4 & 0.066 \\
\hline $14: 25: 30$ & 600 & 0.028 & 0.039 & 0.067 & 0.004 & 4 & 0.066 \\
\hline $14: 26: 00$ & 600 & 0.158 & -0.099 & 0.059 & 0.004 & 4 & 0.066 \\
\hline $14: 26: 30$ & 600 & 0.155 & -0.100 & 0.055 & 0.004 & 4 & 0.066 \\
\hline $14: 27: 00$ & 600 & 0.089 & -0.033 & 0.056 & 0.004 & 4 & 0.066 \\
\hline $14: 27: 30$ & 600 & 0.141 & -0.097 & 0.044 & 0.004 & 4 & 0.066 \\
\hline
\end{tabular}




\begin{tabular}{|c|c|c|c|c|c|c|c|}
\hline $14: 28: 00$ & 600 & 0.037 & -0.004 & 0.033 & 0.004 & 4 & 0.066 \\
\hline $14: 28: 30$ & 600 & 0.122 & -0.096 & 0.026 & 0.004 & 4 & 0.066 \\
\hline 14:29:00 & 600 & 0.119 & -0.091 & 0.028 & 0.004 & 4 & 0.066 \\
\hline 14:29:30 & 600 & 0.010 & 0.012 & 0.022 & 0.004 & 4 & 0.066 \\
\hline $14: 30: 00$ & 600 & 0.115 & -0.096 & 0.019 & 0.004 & 4 & 0.066 \\
\hline $14: 30: 30$ & 600 & 0.121 & -0.108 & 0.013 & 0.004 & 4 & 0.066 \\
\hline $14: 31: 00$ & 600 & 0.102 & -0.094 & 0.008 & 0.004 & 4 & 0.066 \\
\hline $14: 31: 30$ & 600 & 0.101 & -0.096 & 0.005 & 0.004 & 4 & 0.066 \\
\hline $14: 32: 00$ & 600 & 0.098 & -0.097 & 0.001 & 0.004 & 4 & 0.066 \\
\hline $14: 32: 30$ & 600 & 0.099 & -0.094 & 0.005 & 0.004 & 4 & 0.066 \\
\hline $14: 33: 00$ & 600 & 0.093 & -0.094 & -0.001 & 0.004 & 4 & 0.066 \\
\hline $14: 33: 30$ & 600 & 0.013 & -0.016 & -0.003 & 0.004 & 4 & 0.066 \\
\hline $14: 34: 00$ & 600 & 0.093 & -0.094 & -0.001 & 0.004 & 4 & 0.066 \\
\hline $14: 34: 30$ & 600 & 0.087 & -0.095 & -0.008 & 0.004 & 4 & 0.066 \\
\hline $14: 35: 00$ & 600 & 0.09 & -0.099 & -0.009 & 0 & 0 & 0.000 \\
\hline 14:35:30 & 600 & 0.079 & -0.089 & -0.01 & 0.004 & 4 & 0.066 \\
\hline $14: 36: 00$ & 600 & 0.058 & -0.068 & -0.01 & 0.004 & 4 & 0.066 \\
\hline $14: 36: 30$ & 600 & 0.085 & -0.096 & -0.011 & 0.004 & 4 & 0.066 \\
\hline $14: 37: 00$ & 600 & 0.091 & -0.100 & -0.009 & 0.004 & 4 & 0.066 \\
\hline $14: 37: 30$ & 600 & 0.085 & -0.097 & -0.012 & 0.004 & 4 & 0.066 \\
\hline $14: 38: 00$ & 600 & 0.084 & -0.097 & -0.013 & 0.004 & 4 & 0.066 \\
\hline $14: 38: 30$ & 600 & 0.082 & -0.091 & -0.009 & 0.004 & 4 & 0.066 \\
\hline 14:39:00 & 600 & 0.025 & -0.040 & -0.015 & 0.004 & 4 & 0.066 \\
\hline $14: 39: 30$ & 600 & 0.088 & -0.101 & -0.013 & 0.004 & 4 & 0.066 \\
\hline $14: 40: 00$ & 600 & 0.068 & -0.084 & -0.016 & 0.004 & 4 & 0.066 \\
\hline $14: 40: 30$ & 600 & 0.012 & -0.026 & -0.014 & 0.004 & 4 & 0.066 \\
\hline $14: 41: 00$ & 600 & 0.033 & -0.049 & -0.016 & 0.004 & 4 & 0.066 \\
\hline $14: 41: 30$ & 600 & 0.064 & -0.082 & -0.018 & 0.004 & 4 & 0.066 \\
\hline $14: 42: 00$ & 600 & 0.041 & -0.051 & -0.01 & 0.004 & 4 & 0.066 \\
\hline $14: 42: 30$ & 600 & 0.073 & -0.094 & -0.021 & 0.004 & 4 & 0.066 \\
\hline $14: 43: 00$ & 600 & 0.079 & -0.095 & -0.016 & 0.004 & 4 & 0.066 \\
\hline $14: 43: 30$ & 600 & 0.075 & -0.090 & -0.015 & 0.004 & 4 & 0.066 \\
\hline $14: 44: 00$ & 600 & 0.008 & -0.027 & -0.019 & 0.004 & 4 & 0.066 \\
\hline $14: 44: 30$ & 600 & 0.073 & -0.092 & -0.019 & 0.004 & 4 & 0.066 \\
\hline $14: 45: 00$ & 600 & 0.078 & -0.096 & -0.018 & 0.002 & 2 & 0.033 \\
\hline $14: 45: 30$ & 600 & 0.009 & -0.033 & -0.024 & 0.002 & 2 & 0.033 \\
\hline $14: 46: 00$ & 600 & 0.067 & -0.091 & -0.024 & 0.002 & 2 & 0.033 \\
\hline $14: 46: 30$ & 600 & 0.018 & -0.046 & -0.028 & 0.002 & 2 & 0.033 \\
\hline $14: 47: 00$ & 600 & 0.046 & -0.074 & -0.028 & 0.002 & 2 & 0.033 \\
\hline $14: 47: 30$ & 600 & 0.066 & -0.094 & -0.028 & 0.002 & 2 & 0.033 \\
\hline $14: 48: 00$ & 600 & 0.015 & -0.046 & -0.031 & 0.002 & 2 & 0.033 \\
\hline 14:48:30 & 600 & 0.05 & -0.083 & -0.033 & 0.002 & 2 & 0.033 \\
\hline $14: 49: 00$ & 600 & 0.06 & -0.095 & -0.035 & 0.004 & 4 & 0.066 \\
\hline $14: 49: 30$ & 600 & 0.036 & -0.071 & -0.035 & 0.004 & 4 & 0.066 \\
\hline 14:50:00 & 600 & 0.056 & -0.093 & -0.037 & 0.004 & 4 & 0.066 \\
\hline $14: 50: 30$ & 600 & 0.052 & -0.091 & -0.039 & 0.004 & 4 & 0.066 \\
\hline $14: 51: 00$ & 600 & 0.03 & -0.070 & -0.04 & 0.004 & 4 & 0.066 \\
\hline $14: 51: 30$ & 600 & 0.048 & -0.091 & -0.043 & 0.004 & 4 & 0.066 \\
\hline $14: 52: 00$ & 600 & 0.05 & -0.088 & -0.038 & 0.004 & 4 & 0.066 \\
\hline $14: 52: 30$ & 600 & 0.026 & -0.073 & -0.047 & 0.002 & 2 & 0.033 \\
\hline $14: 53: 00$ & 600 & 0.036 & -0.081 & -0.045 & 0.004 & 4 & 0.066 \\
\hline $14: 53: 30$ & 600 & 0.032 & -0.079 & -0.047 & 0.004 & 4 & 0.066 \\
\hline $14: 54: 00$ & 600 & 0.045 & -0.093 & -0.048 & 0.004 & 4 & 0.066 \\
\hline $14: 54: 30$ & 600 & 0.033 & -0.083 & -0.05 & 0.004 & 4 & 0.066 \\
\hline $14: 55: 00$ & 600 & 0.015 & -0.070 & -0.055 & 0.004 & 4 & 0.066 \\
\hline $14: 55: 30$ & 600 & 0.039 & -0.094 & -0.055 & 0.004 & 4 & 0.066 \\
\hline $14: 56: 00$ & 600 & 0.04 & -0.096 & -0.056 & 0.004 & 4 & 0.066 \\
\hline 14:56:30 & 600 & 0.038 & -0.093 & -0.055 & 0.004 & 4 & 0.066 \\
\hline $14: 57: 00$ & 600 & 0.036 & -0.093 & -0.057 & 0.004 & 4 & 0.066 \\
\hline $14: 57: 30$ & 600 & 0.034 & -0.094 & -0.06 & 0.004 & 4 & 0.066 \\
\hline 14:58:00 & 600 & 0.034 & -0.094 & -0.06 & 0.004 & 4 & 0.066 \\
\hline $14: 58: 30$ & 600 & 0.003 & -0.063 & -0.06 & 0.004 & 4 & 0.066 \\
\hline 14:59:00 & 600 & 0.001 & -0.062 & -0.061 & 0.004 & 4 & 0.066 \\
\hline
\end{tabular}




$\begin{array}{cccccccc}14: 59: 30 & 600 & 0.03 & -0.090 & -0.06 & 0.004 & 4 & 0.066 \\ 15: 00: 00 & 600 & 0 & -0.060 & -0.06 & 0.004 & 4 & 0.066 \\ 15: 00: 30 & 600 & 0.036 & -0.098 & -0.062 & 0.004 & 4 & 0.066\end{array}$

Coal-Derived Rod (100\% SECO), Air Flow Rate $=0.50$ SLPM, $\mathrm{T}=600^{\circ} \mathrm{C}, 3 / 22 / 2006$

$\begin{array}{cccccc} & \text { Run } 1 & & & \text { Run } 2 & \\ \text { I/SA } & \text { VCELL } & \text { P/SA } & \text { I/SA } & \text { VCELL } & \text { P/SA } \\ 0.000 & 1.034 & 0.000 & 0.030 & 1.043 & 0.000 \\ 0.030 & 1.032 & 0.000 & 0.030 & 1.044 & 0.000 \\ 0.030 & 0.986 & 0.000 & 0.030 & 0.991 & 0.000 \\ 0.030 & 1.012 & 0.000 & 0.030 & 1.017 & 0.000 \\ 1.505 & 1.028 & 0.002 & 1.505 & 1.037 & 0.002 \\ 3.010 & 1.021 & 0.003 & 3.010 & 1.029 & 0.003 \\ 4.515 & 1.012 & 0.005 & 6.050 & 1.012 & 0.006 \\ 6.020 & 1.003 & 0.006 & 9.029 & 0.993 & 0.009 \\ 7.555 & 0.994 & 0.008 & 12.069 & 0.974 & 0.012 \\ 9.029 & 0.985 & 0.009 & 15.079 & 0.953 & 0.014 \\ 10.564 & 0.975 & 0.010 & 18.089 & 0.930 & 0.017 \\ 12.039 & 0.965 & 0.012 & 21.099 & 0.905 & 0.019 \\ 13.574 & 0.955 & 0.013 & 24.108 & 0.878 & 0.021 \\ 15.079 & 0.944 & 0.014 & 27.118 & 0.840 & 0.023 \\ 16.584 & 0.933 & 0.015 & 30.128 & 0.794 & 0.024 \\ 18.089 & 0.920 & 0.017 & 33.138 & 0.733 & 0.024 \\ 19.594 & 0.907 & 0.018 & 34.673 & 0.655 & 0.023 \\ 21.099 & 0.894 & 0.019 & & & \\ 22.603 & 0.879 & 0.020 & & & \\ 24.108 & 0.860 & 0.021 & & & \\ 25.613 & 0.840 & 0.022 & & & \\ 27.118 & 0.815 & 0.022 & & & \\ 28.623 & 0.782 & 0.022 & & & \\ 30.128 & 0.744 & 0.022 & & & \\ 31.633 & 0.682 & 0.022 & & & \\ 31.663 & 0.608 & 0.019 & & & \end{array}$

Coal-Derived Rod (100\% SECO), Long Term Run, Air Flow Rate $=0.50$ SLPM, T = $600^{\circ} \mathrm{C}, 3 / 22 / 2006$

\begin{tabular}{|c|c|c|c|c|c|c|c|}
\hline $\begin{array}{c}\text { Temp } \\
\left({ }^{\circ} \mathrm{C}\right)\end{array}$ & VCELL & VANODE & VCATHODE & $I(A)$ & $\begin{array}{c}\text { I } \\
(\mathrm{mA})\end{array}$ & I/SA & $\begin{array}{l}\text { Time } \\
\text { (min) }\end{array}$ \\
\hline 601 & 1.002 & -1.028 & -0.026 & 0.502 & 502 & 7.555 & 0 \\
\hline 601 & 0.998 & -1.022 & -0.024 & 0.502 & 502 & 7.555 & 2 \\
\hline 601 & 0.998 & -1.024 & -0.026 & 0.502 & 502 & 7.555 & 4 \\
\hline 601 & 0.999 & -1.024 & -0.025 & 0.502 & 502 & 7.555 & 6 \\
\hline 601 & 0.998 & -1.022 & -0.024 & 0.502 & 502 & 7.555 & 8 \\
\hline 601 & 0.998 & -1.023 & -0.025 & 0.502 & 502 & 7.555 & 10 \\
\hline 601 & 0.997 & -1.024 & -0.027 & 0.502 & 502 & 7.555 & 12 \\
\hline 601 & 0.996 & -1.024 & -0.028 & 0.502 & 502 & 7.555 & 14 \\
\hline 601 & 0.997 & -1.023 & -0.026 & 0.502 & 502 & 7.555 & 16 \\
\hline 601 & 0.997 & -1.022 & -0.025 & 0.502 & 502 & 7.555 & 18 \\
\hline 601 & 0.998 & -1.025 & -0.027 & 0.502 & 502 & 7.555 & 20 \\
\hline 601 & 0.997 & -1.022 & -0.025 & 0.502 & 502 & 7.555 & 22 \\
\hline 601 & 0.996 & -1.021 & -0.025 & 0.502 & 502 & 7.555 & 24 \\
\hline 601 & 0.994 & -1.021 & -0.027 & 0.502 & 502 & 7.555 & 26 \\
\hline 601 & 0.994 & -1.020 & -0.026 & 0.502 & 502 & 7.555 & 28 \\
\hline
\end{tabular}




$\begin{array}{lrrrrrrr}601 & 0.991 & -1.020 & -0.029 & 0.502 & 502 & 7.555 & 30 \\ 601 & 0.994 & -1.021 & -0.027 & 0.502 & 502 & 7.555 & 32 \\ 600 & 0.994 & -1.018 & -0.024 & 0.502 & 502 & 7.555 & 34 \\ 600 & 0.993 & -1.022 & -0.029 & 0.502 & 502 & 7.555 & 36 \\ 600 & 0.993 & -1.019 & -0.026 & 0.502 & 502 & 7.555 & 38 \\ 601 & 0.991 & -1.019 & -0.028 & 0.502 & 502 & 7.555 & 40 \\ 601 & 0.991 & -1.013 & -0.022 & 0.502 & 502 & 7.555 & 42 \\ 601 & 0.989 & -1.015 & -0.026 & 0.502 & 502 & 7.555 & 44 \\ 601 & 0.989 & -1.015 & -0.026 & 0.502 & 502 & 7.555 & 46 \\ 601 & 0.988 & -1.013 & -0.025 & 0.502 & 502 & 7.555 & 48 \\ 601 & 0.986 & -1.015 & -0.029 & 0.502 & 502 & 7.555 & 50 \\ 601 & 0.985 & -1.012 & -0.027 & 0.502 & 502 & 7.555 & 52 \\ 600 & 0.983 & -1.011 & -0.028 & 0.502 & 502 & 7.555 & 54 \\ 600 & 0.98 & -1.012 & -0.032 & 0.502 & 502 & 7.555 & 56 \\ 600 & 0.98 & -1.008 & -0.028 & 0.502 & 502 & 7.555 & 58 \\ 601 & 0.98 & -1.005 & -0.025 & 0.502 & 502 & 7.555 & 60 \\ 601 & 0.974 & -0.996 & -0.022 & 0.502 & 502 & 7.555 & 62 \\ 601 & 0.912 & -0.943 & -0.031 & 0.502 & 502 & 7.555 & 64 \\ 601 & 0.817 & -0.869 & -0.052 & 0.502 & 502 & 7.555 & 66 \\ 601 & 0.777 & -0.849 & -0.072 & 0.502 & 502 & 7.555 & 68 \\ 600 & 0.767 & -0.843 & -0.076 & 0.502 & 502 & 7.555 & 70 \\ 600 & 0.635 & -0.709 & -0.074 & 0.502 & 502 & 7.555 & 72 \\ 600 & 0.469 & -0.569 & -0.1 & 0.502 & 502 & 7.555 & 74 \\ 600 & 0.35 & 0.044 & 0.394 & 0.502 & 502 & 7.555 & 76 \\ 601 & 0.257 & 0.081 & 0.338 & 0.502 & 502 & 7.555 & 78 \\ 601 & 0.232 & 0.086 & 0.318 & 0.502 & 502 & 7.555 & 80 \\ 601 & 0.217 & 0.084 & 0.301 & 0.502 & 502 & 7.555 & 82 \\ 601 & 0.219 & 0.078 & 0.297 & 0.500 & 500 & 7.524 & 84\end{array}$

Coal-Derived Rod $\left(50 / 50 \%\right.$ SECO/PetCoke), Air Flow Rate $=0.50 \mathrm{SLPM}, \mathrm{T}=600^{\circ} \mathrm{C}$, $3 / 23 / 2006$

$\begin{array}{ccc} & \text { Run 1 } & \\ \text { I/SA } & \text { VCELL } & \text { P/SA } \\ 0.028 & 0.963 & 0.000 \\ 0.028 & 0.932 & 0.000 \\ 0.028 & 0.950 & 0.000 \\ 1.396 & 0.955 & 0.001 \\ 2.791 & 0.948 & 0.003 \\ 4.187 & 0.940 & 0.004 \\ 5.583 & 0.932 & 0.005 \\ 7.006 & 0.922 & 0.006 \\ 8.374 & 0.914 & 0.008 \\ 9.798 & 0.905 & 0.009 \\ 11.193 & 0.895 & 0.010 \\ 12.589 & 0.885 & 0.011 \\ 13.985 & 0.877 & 0.012 \\ 15.380 & 0.865 & 0.013 \\ 16.776 & 0.854 & 0.014 \\ 18.172 & 0.843 & 0.015 \\ 19.567 & 0.830 & 0.016 \\ 20.963 & 0.816 & 0.017 \\ 22.359 & 0.803 & 0.018 \\ 23.754 & 0.790 & 0.019 \\ 25.150 & 0.767 & 0.019\end{array}$




$\begin{array}{lll}26.546 & 0.743 & 0.020 \\ 27.941 & 0.714 & 0.020 \\ 29.337 & 0.677 & 0.020 \\ 30.733 & 0.629 & 0.019 \\ 30.733 & 0.594 & 0.018\end{array}$

Coal-Derived Rod (50/50\% SECO/PetCoke), Long Term Run, Air Flow Rate $=0.50$ SLPM, T $=600^{\circ} \mathrm{C}, 3 / 23 / 2006$

\begin{tabular}{|c|c|c|c|c|c|c|c|}
\hline $\begin{array}{c}\text { Temp } \\
\left({ }^{\circ} \mathrm{C}\right)\end{array}$ & VCELL & VANODE & VCATHODE & $\mathrm{I}(\mathrm{A})$ & $\stackrel{\text { I }}{(\mathrm{mA})}$ & I/SA & $\begin{array}{l}\text { Time } \\
\text { (min) }\end{array}$ \\
\hline 599 & 0.970 & -0.986 & -0.016 & 0.002 & 2 & 0.028 & 2 \\
\hline 598 & 0.925 & -0.955 & -0.030 & 0.502 & 502 & 7.006 & 4 \\
\hline 598 & 0.921 & -0.950 & -0.029 & 0.502 & 502 & 7.006 & 6 \\
\hline 598 & 0.922 & -0.955 & -0.033 & 0.502 & 502 & 7.006 & 8 \\
\hline 598 & 0.922 & -0.954 & -0.032 & 0.502 & 502 & 7.006 & 10 \\
\hline 598 & 0.924 & -0.958 & -0.034 & 0.502 & 502 & 7.006 & 12 \\
\hline 598 & 0.927 & -0.956 & -0.029 & 0.502 & 502 & 7.006 & 14 \\
\hline 598 & 0.928 & -0.959 & -0.031 & 0.502 & 502 & 7.006 & 16 \\
\hline 598 & 0.932 & -0.965 & -0.033 & 0.502 & 502 & 7.006 & 18 \\
\hline 598 & 0.933 & -0.964 & -0.031 & 0.502 & 502 & 7.006 & 20 \\
\hline 598 & 0.934 & -0.969 & -0.035 & 0.502 & 502 & 7.006 & 22 \\
\hline 598 & 0.935 & -0.970 & -0.035 & 0.502 & 502 & 7.006 & 24 \\
\hline 598 & 0.937 & -0.970 & -0.033 & 0.502 & 502 & 7.006 & 26 \\
\hline 598 & 0.937 & -0.969 & -0.032 & 0.502 & 502 & 7.006 & 28 \\
\hline 598 & 0.937 & -0.972 & -0.035 & 0.502 & 502 & 7.006 & 30 \\
\hline 598 & 0.938 & -0.972 & -0.034 & 0.500 & 500 & 6.978 & 32 \\
\hline 598 & 0.937 & -0.975 & -0.038 & 0.502 & 502 & 7.006 & 34 \\
\hline 598 & 0.936 & -0.972 & -0.036 & 0.502 & 502 & 7.006 & 36 \\
\hline 598 & 0.934 & -0.974 & -0.040 & 0.502 & 502 & 7.006 & 38 \\
\hline 598 & 0.935 & -0.972 & -0.037 & 0.502 & 502 & 7.006 & 40 \\
\hline 598 & 0.932 & -0.969 & -0.037 & 0.502 & 502 & 7.006 & 42 \\
\hline 598 & 0.931 & -0.972 & -0.041 & 0.500 & 500 & 6.978 & 44 \\
\hline 598 & 0.927 & -0.962 & -0.035 & 0.502 & 502 & 7.006 & 46 \\
\hline 598 & 0.924 & -0.966 & -0.042 & 0.500 & 500 & 6.978 & 48 \\
\hline 599 & 0.919 & -0.966 & -0.047 & 0.502 & 502 & 7.006 & 50 \\
\hline 598 & 0.908 & -0.951 & -0.043 & 0.502 & 502 & 7.006 & 52 \\
\hline 598 & 0.899 & -0.936 & -0.037 & 0.502 & 502 & 7.006 & 54 \\
\hline 598 & 0.891 & -0.941 & -0.050 & 0.502 & 502 & 7.006 & 56 \\
\hline 598 & 0.877 & -0.937 & -0.060 & 0.502 & 502 & 7.006 & 58 \\
\hline 598 & 0.862 & -0.925 & -0.063 & 0.502 & 502 & 7.006 & 60 \\
\hline 598 & 0.845 & -0.889 & -0.044 & 0.500 & 500 & 6.978 & 62 \\
\hline 598 & 0.816 & -0.871 & -0.055 & 0.502 & 502 & 7.006 & 64 \\
\hline 598 & 0.785 & -0.829 & -0.044 & 0.500 & 500 & 6.978 & 66 \\
\hline 598 & 0.762 & -0.815 & -0.053 & 0.502 & 502 & 7.006 & 68 \\
\hline 598 & 0.738 & -0.740 & -0.002 & 0.502 & 502 & 7.006 & 70 \\
\hline 598 & 0.698 & -0.722 & -0.024 & 0.502 & 502 & 7.006 & 72 \\
\hline 598 & 0.676 & -0.698 & -0.022 & 0.502 & 502 & 7.006 & 74 \\
\hline 598 & 0.653 & -0.672 & -0.019 & 0.502 & 502 & 7.006 & 76 \\
\hline 598 & 0.615 & -0.647 & -0.032 & 0.502 & 502 & 7.006 & 78 \\
\hline 598 & 0.577 & -0.607 & -0.030 & 0.502 & 502 & 7.006 & 80 \\
\hline 598 & 0.532 & -0.496 & 0.036 & 0.500 & 500 & 6.978 & 82 \\
\hline 598 & 0.500 & -0.434 & 0.066 & 0.500 & 500 & 6.978 & 84 \\
\hline 598 & 0.455 & -0.374 & 0.081 & 0.500 & 500 & 6.978 & 86 \\
\hline 598 & 0.425 & -0.283 & 0.142 & 0.502 & 502 & 7.006 & 88 \\
\hline 598 & 0.392 & -0.279 & 0.113 & 0.502 & 502 & 7.006 & 90 \\
\hline 598 & 0.371 & -0.273 & 0.098 & 0.502 & 502 & 7.006 & 92 \\
\hline 598 & 0.358 & -0.266 & 0.092 & 0.502 & 502 & 7.006 & 94 \\
\hline
\end{tabular}




$\begin{array}{llllllll}598 & 0.338 & -0.260 & 0.078 & 0.500 & 500 & 6.978 & 96 \\ 598 & 0.332 & -0.255 & 0.077 & 0.502 & 502 & 7.006 & 98 \\ 598 & 0.322 & -0.240 & 0.082 & 0.502 & 502 & 7.006 & 100 \\ 598 & 0.315 & -0.233 & 0.082 & 0.502 & 502 & 7.006 & 102 \\ 598 & 0.312 & -0.223 & 0.089 & 0.502 & 502 & 7.006 & 104 \\ 598 & 0.304 & -0.216 & 0.088 & 0.502 & 502 & 7.006 & 106 \\ 598 & 0.297 & -0.211 & 0.086 & 0.502 & 502 & 7.006 & 108 \\ 598 & 0.292 & -0.203 & 0.089 & 0.502 & 502 & 7.006 & 110 \\ 598 & 0.274 & -0.196 & 0.078 & 0.502 & 502 & 7.006 & 112\end{array}$

GrafTech Non-Graphitized Baked Rod, Air Flow Rate $=0.50 \mathrm{SLPM}, \mathrm{T}=600^{\circ} \mathrm{C}$, 4/11/2006

$\begin{array}{cccccc} & \text { Run 1 } & & & \text { Run 2 } & \\ \text { I/SA } & \text { VCELL } & \text { P/SA } & \text { I/SA } & \text { VCELL } & \text { P/SA } \\ 0.061 & 0.972 & 0.000 & 0.061 & 0.943 & 0.000 \\ 0.061 & 0.972 & 0.000 & 0.061 & 0.960 & 0.000 \\ 0.061 & 0.972 & 0.000 & 1.534 & 0.973 & 0.001 \\ 0.061 & 0.947 & 0.000 & 3.067 & 0.967 & 0.003 \\ 0.061 & 0.964 & 0.000 & 4.601 & 0.959 & 0.004 \\ 0.061 & 0.974 & 0.000 & 6.135 & 0.953 & 0.006 \\ 1.534 & 0.966 & 0.001 & 7.699 & 0.945 & 0.007 \\ 3.067 & 0.960 & 0.003 & 9.202 & 0.938 & 0.009 \\ 4.601 & 0.954 & 0.004 & 10.767 & 0.931 & 0.010 \\ 6.135 & 0.947 & 0.006 & 12.301 & 0.923 & 0.011 \\ 7.699 & 0.943 & 0.007 & 13.834 & 0.915 & 0.013 \\ 9.233 & 0.940 & 0.009 & 15.368 & 0.907 & 0.014 \\ 12.270 & 0.929 & 0.011 & 16.902 & 0.899 & 0.015 \\ 15.368 & 0.936 & 0.014 & 18.436 & 0.891 & 0.016 \\ 15.368 & 0.931 & 0.014 & 19.969 & 0.880 & 0.018 \\ 18.436 & 0.914 & 0.017 & 21.503 & 0.871 & 0.019 \\ 18.436 & 0.908 & 0.017 & 23.037 & 0.859 & 0.020 \\ 21.503 & 0.892 & 0.019 & 24.571 & 0.848 & 0.021 \\ 23.037 & 0.878 & 0.020 & 26.104 & 0.834 & 0.022 \\ 24.571 & 0.863 & 0.021 & 26.104 & 0.825 & 0.022 \\ 27.638 & 0.840 & 0.023 & 27.638 & 0.809 & 0.022 \\ 30.706 & 0.810 & 0.025 & 29.172 & 0.785 & 0.023 \\ 33.773 & 0.755 & 0.025 & 29.172 & 0.766 & 0.022 \\ 36.840 & 0.699 & 0.026 & 30.706 & 0.724 & 0.022 \\ 38.405 & 0.625 & 0.024 & 32.239 & 0.674 & 0.022\end{array}$

GrafTech Non-Graphitized Baked Rod, Long Term Run, Air Flow Rate $=0.50$ SLPM, T $=600^{\circ} \mathrm{C}, 4 / 11 / 2006$

\begin{tabular}{|c|c|c|c|c|c|c|c|}
\hline $\begin{array}{l}\text { Temp } \\
\left({ }^{\circ} \mathrm{C}\right)\end{array}$ & VCELL & VANODE & VCATHODE & I (A) & $\stackrel{\text { I }}{(\mathrm{mA})}$ & $\mathrm{I} / \mathrm{SA}$ & $\begin{array}{c}\text { Time } \\
\text { (h) }\end{array}$ \\
\hline 600 & 0.984 & -0.990 & -0.006 & 0.000 & 0 & 0.000 & 0.000 \\
\hline 601 & 0.986 & -0.999 & -0.013 & 0.000 & 0 & 0.000 & 0.083 \\
\hline 601 & 0.987 & -0.997 & -0.010 & 0.000 & 0 & 0.000 & 0.167 \\
\hline 601 & 0.986 & -0.995 & -0.009 & 0.000 & 0 & 0.000 & 0.250 \\
\hline 601 & 0.985 & -0.983 & 0.002 & 0.000 & 0 & 0.000 & 0.333 \\
\hline 601 & 0.982 & -0.985 & -0.003 & 0.000 & 0 & 0.000 & 0.417 \\
\hline 601 & 0.979 & -0.973 & 0.006 & 0.000 & 0 & 0.000 & 0.500 \\
\hline 601 & 0.976 & -0.968 & 0.008 & 0.000 & 0 & 0.000 & 0.583 \\
\hline
\end{tabular}




\begin{tabular}{|c|c|c|c|c|c|c|c|}
\hline 601 & 0.973 & -0.945 & 0.028 & 0.000 & 0 & 0.000 & 0.667 \\
\hline 601 & 0.970 & -0.930 & 0.040 & 0.000 & 0 & 0.000 & 0.750 \\
\hline 600 & 0.967 & -0.906 & 0.061 & 0.000 & 0 & 0.000 & 0.833 \\
\hline 601 & 0.963 & -0.876 & 0.087 & 0.000 & 0 & 0.000 & 0.917 \\
\hline 601 & 0.959 & -0.806 & 0.153 & 0.000 & 0 & 0.000 & 1.000 \\
\hline 601 & 0.956 & -0.760 & 0.196 & 0.000 & 0 & 0.000 & 1.083 \\
\hline 601 & 0.951 & -0.732 & 0.219 & 0.000 & 0 & 0.000 & 1.167 \\
\hline 601 & 0.950 & -0.695 & 0.255 & 0.000 & 0 & 0.000 & 1.250 \\
\hline 601 & 0.947 & -0.679 & 0.268 & 0.000 & 0 & 0.000 & 1.333 \\
\hline 601 & 0.944 & -0.652 & 0.292 & 0.000 & 0 & 0.000 & 1.417 \\
\hline 601 & 0.938 & -0.629 & 0.309 & 0.000 & 0 & 0.000 & 1.500 \\
\hline 601 & 0.936 & -0.599 & 0.337 & 0.000 & 0 & 0.000 & 1.583 \\
\hline 601 & 0.935 & -0.583 & 0.352 & 0.000 & 0 & 0.000 & 1.667 \\
\hline 600 & 0.930 & -0.579 & 0.351 & 0.000 & 0 & 0.000 & 1.750 \\
\hline 601 & 0.926 & -0.608 & 0.318 & 0.000 & 0 & 0.000 & 1.833 \\
\hline 601 & 0.918 & -0.586 & 0.332 & 0.000 & 0 & 0.000 & 1.917 \\
\hline 601 & 0.918 & -0.568 & 0.350 & 0.000 & 0 & 0.000 & 2.000 \\
\hline 601 & 0.911 & -0.548 & 0.363 & 0.000 & 0 & 0.000 & 2.083 \\
\hline 601 & 0.912 & -0.563 & 0.349 & 0.000 & 0 & 0.000 & 2.167 \\
\hline 601 & 0.908 & -0.546 & 0.362 & 0.000 & 0 & 0.000 & 2.250 \\
\hline 601 & 0.908 & -0.555 & 0.353 & 0.000 & 0 & 0.000 & 2.333 \\
\hline 601 & 0.904 & -0.556 & 0.348 & 0.000 & 0 & 0.000 & 2.417 \\
\hline 601 & 0.901 & -0.554 & 0.347 & 0.000 & 0 & 0.000 & 2.500 \\
\hline 601 & 0.892 & -0.549 & 0.343 & 0.000 & 0 & 0.000 & 2.583 \\
\hline 600 & 0.859 & -0.503 & 0.356 & 0.000 & 0 & 0.000 & 2.667 \\
\hline 601 & 0.867 & -0.512 & 0.355 & 0.000 & 0 & 0.000 & 2.750 \\
\hline 601 & 0.878 & -0.518 & 0.360 & 0.000 & 0 & 0.000 & 2.833 \\
\hline 601 & 0.882 & -0.540 & 0.342 & 0.000 & 0 & 0.000 & 2.917 \\
\hline 601 & 0.874 & -0.520 & 0.354 & 0.000 & 0 & 0.000 & 3.000 \\
\hline 601 & 0.880 & -0.553 & 0.327 & 0.000 & 0 & 0.000 & 3.083 \\
\hline 601 & 0.878 & -0.547 & 0.331 & 0.000 & 0 & 0.000 & 3.167 \\
\hline 601 & 0.878 & -0.560 & 0.318 & 0.000 & 0 & 0.000 & 3.250 \\
\hline 601 & 0.873 & -0.555 & 0.318 & 0.000 & 0 & 0.000 & 3.333 \\
\hline 601 & 0.878 & -0.557 & 0.321 & 0.000 & 0 & 0.000 & 3.417 \\
\hline 601 & 0.872 & -0.569 & 0.303 & 0.000 & 0 & 0.000 & 3.500 \\
\hline 601 & 0.876 & -0.578 & 0.298 & 0.000 & 0 & 0.000 & 3.583 \\
\hline 601 & 0.868 & -0.557 & 0.311 & 0.000 & 0 & 0.000 & 3.667 \\
\hline 601 & 0.868 & -0.566 & 0.302 & 0.000 & 0 & 0.000 & 3.750 \\
\hline 601 & 0.859 & -0.552 & 0.307 & 0.000 & 0 & 0.000 & 3.833 \\
\hline 600 & 0.856 & -0.565 & 0.291 & 0.000 & 0 & 0.000 & 3.917 \\
\hline 601 & 0.857 & -0.582 & 0.275 & 0.000 & 0 & 0.000 & 4.000 \\
\hline 601 & 0.858 & -0.588 & 0.270 & 0.000 & 0 & 0.000 & 4.083 \\
\hline 600 & 0.861 & -0.569 & 0.292 & 0.000 & 0 & 0.000 & 4.167 \\
\hline 601 & 0.839 & -0.572 & 0.267 & 0.000 & 0 & 0.000 & 4.250 \\
\hline 601 & 0.840 & -0.560 & 0.280 & 0.000 & 0 & 0.000 & 4.333 \\
\hline 600 & 0.854 & -0.556 & 0.298 & 0.000 & 0 & 0.000 & 4.417 \\
\hline 600 & 0.856 & -0.574 & 0.282 & 0.000 & 0 & 0.000 & 4.500 \\
\hline 601 & 0.849 & -0.556 & 0.293 & 0.000 & 0 & 0.000 & 4.583 \\
\hline 600 & 0.840 & -0.560 & 0.280 & 0.000 & 0 & 0.000 & 4.667 \\
\hline 601 & 0.845 & -0.577 & 0.268 & 0.000 & 0 & 0.000 & 4.750 \\
\hline 600 & 0.844 & -0.584 & 0.260 & 0.000 & 0 & 0.000 & 4.833 \\
\hline 600 & 0.847 & -0.568 & 0.279 & 0.000 & 0 & 0.000 & 4.917 \\
\hline 600 & 0.847 & -0.575 & 0.272 & 0.000 & 0 & 0.000 & 5.000 \\
\hline 600 & 0.817 & -0.571 & 0.246 & 0.000 & 0 & 0.000 & 5.083 \\
\hline 601 & 0.820 & -0.567 & 0.253 & 0.000 & 0 & 0.000 & 5.167 \\
\hline 600 & 0.830 & -0.578 & 0.252 & 0.000 & 0 & 0.000 & 5.250 \\
\hline 600 & 0.838 & -0.596 & 0.242 & 0.000 & 0 & 0.000 & 5.333 \\
\hline 600 & 0.813 & -0.576 & 0.237 & 0.000 & 0 & 0.000 & 5.417 \\
\hline 601 & 0.816 & -0.590 & 0.226 & 0.000 & 0 & 0.000 & 5.500 \\
\hline 600 & 0.818 & -0.569 & 0.249 & 0.000 & 0 & 0.000 & 5.583 \\
\hline 601 & 0.834 & -0.597 & 0.237 & 0.000 & 0 & 0.000 & 5.667 \\
\hline 601 & 0.813 & -0.606 & 0.207 & 0.000 & 0 & 0.000 & 5.750 \\
\hline 601 & 0.810 & -0.575 & 0.235 & 0.000 & 0 & 0.000 & 5.833 \\
\hline
\end{tabular}




\begin{tabular}{|c|c|c|c|c|c|c|c|}
\hline 601 & 0.824 & -0.618 & 0.206 & 0.000 & 0 & 0.000 & 5.917 \\
\hline 600 & 0.819 & -0.596 & 0.223 & 0.000 & 0 & 0.000 & 6.000 \\
\hline 600 & 0.786 & -0.579 & 0.207 & 0.000 & 0 & 0.000 & 6.083 \\
\hline 601 & 0.786 & -0.560 & 0.226 & 0.000 & 0 & 0.000 & 6.167 \\
\hline 601 & 0.797 & -0.600 & 0.197 & 0.000 & 0 & 0.000 & 6.250 \\
\hline 600 & 0.783 & -0.578 & 0.205 & 0.000 & 0 & 0.000 & 6.333 \\
\hline 601 & 0.740 & -0.583 & 0.157 & 0.000 & 0 & 0.000 & 6.417 \\
\hline 601 & 0.757 & -0.506 & 0.251 & 0.000 & 0 & 0.000 & 6.500 \\
\hline 600 & 0.757 & -0.618 & 0.139 & 0.000 & 0 & 0.000 & 6.583 \\
\hline 601 & 0.768 & -0.577 & 0.191 & 0.000 & 0 & 0.000 & 6.667 \\
\hline 601 & 0.732 & -0.572 & 0.160 & 0.000 & 0 & 0.000 & 6.750 \\
\hline 601 & 0.734 & -0.572 & 0.162 & 0.000 & 0 & 0.000 & 6.833 \\
\hline 600 & 0.733 & -0.563 & 0.170 & 0.000 & 0 & 0.000 & 6.917 \\
\hline 601 & 0.698 & -0.545 & 0.153 & 0.000 & 0 & 0.000 & 7.000 \\
\hline 601 & 0.707 & -0.572 & 0.135 & 0.000 & 0 & 0.000 & 7.083 \\
\hline 600 & 0.718 & -0.552 & 0.166 & 0.000 & 0 & 0.000 & 7.167 \\
\hline 601 & 0.699 & -0.544 & 0.155 & 0.000 & 0 & 0.000 & 7.250 \\
\hline 601 & 0.678 & -0.521 & 0.157 & 0.000 & 0 & 0.000 & 7.333 \\
\hline 601 & 0.686 & -0.542 & 0.144 & 0.000 & 0 & 0.000 & 7.417 \\
\hline 600 & 0.691 & -0.501 & 0.190 & 0.000 & 0 & 0.000 & 7.500 \\
\hline 601 & 0.649 & -0.382 & 0.267 & 0.000 & 0 & 0.000 & 7.583 \\
\hline 601 & 0.657 & -0.385 & 0.272 & 0.000 & 0 & 0.000 & 7.667 \\
\hline 600 & 0.669 & -0.384 & 0.285 & 0.000 & 0 & 0.000 & 7.750 \\
\hline 601 & 0.657 & -0.372 & 0.285 & 0.000 & 0 & 0.000 & 7.833 \\
\hline 601 & 0.614 & -0.337 & 0.277 & 0.000 & 0 & 0.000 & 7.917 \\
\hline 600 & 0.630 & -0.335 & 0.295 & 0.000 & 0 & 0.000 & 8.000 \\
\hline 600 & 0.623 & -0.335 & 0.288 & 0.000 & 0 & 0.000 & 8.083 \\
\hline 601 & 0.575 & -0.326 & 0.249 & 0.000 & 0 & 0.000 & 8.167 \\
\hline 601 & 0.593 & -0.329 & 0.264 & 0.000 & 0 & 0.000 & 8.250 \\
\hline 600 & 0.609 & -0.332 & 0.277 & 0.000 & 0 & 0.000 & 8.333 \\
\hline 601 & 0.577 & -0.329 & 0.248 & 0.000 & 0 & 0.000 & 8.417 \\
\hline 601 & 0.575 & -0.321 & 0.254 & 0.000 & 0 & 0.000 & 8.500 \\
\hline 600 & 0.599 & -0.316 & 0.283 & 0.000 & 0 & 0.000 & 8.583 \\
\hline 601 & 0.625 & -0.319 & 0.306 & 0.000 & 0 & 0.000 & 8.667 \\
\hline 601 & 0.567 & -0.317 & 0.250 & 0.000 & 0 & 0.000 & 8.750 \\
\hline 601 & 0.600 & -0.315 & 0.285 & 0.000 & 0 & 0.000 & 8.833 \\
\hline 600 & 0.615 & -0.306 & 0.309 & 0.000 & 0 & 0.000 & 8.917 \\
\hline 600 & 0.564 & -0.307 & 0.257 & 0.000 & 0 & 0.000 & 9.000 \\
\hline 601 & 0.598 & -0.309 & 0.289 & 0.000 & 0 & 0.000 & 9.083 \\
\hline 601 & 0.592 & -0.306 & 0.286 & 0.000 & 0 & 0.000 & 9.167 \\
\hline 601 & 0.620 & -0.306 & 0.314 & 0.000 & 0 & 0.000 & 9.250 \\
\hline 600 & 0.609 & -0.308 & 0.301 & 0.000 & 0 & 0.000 & 9.333 \\
\hline 601 & 0.604 & -0.305 & 0.299 & 0.000 & 0 & 0.000 & 9.417 \\
\hline 600 & 0.597 & -0.301 & 0.296 & 0.000 & 0 & 0.000 & 9.500 \\
\hline 600 & 0.598 & -0.297 & 0.301 & 0.000 & 0 & 0.000 & 9.583 \\
\hline 600 & 0.571 & -0.281 & 0.290 & 0.000 & 0 & 0.000 & 9.667 \\
\hline 601 & 0.550 & -0.279 & 0.271 & 0.000 & 0 & 0.000 & 9.750 \\
\hline 600 & 0.581 & -0.273 & 0.308 & 0.000 & 0 & 0.000 & 9.833 \\
\hline 600 & 0.596 & -0.270 & 0.326 & 0.000 & 0 & 0.000 & 9.917 \\
\hline 600 & 0.597 & -0.268 & 0.329 & 0.000 & 0 & 0.000 & 10.000 \\
\hline 601 & 0.527 & -0.261 & 0.266 & 0.000 & 0 & 0.000 & 10.083 \\
\hline 601 & 0.538 & -0.255 & 0.283 & 0.000 & 0 & 0.000 & 10.167 \\
\hline 600 & 0.551 & -0.255 & 0.296 & 0.000 & 0 & 0.000 & 10.250 \\
\hline 601 & 0.562 & -0.252 & 0.310 & 0.000 & 0 & 0.000 & 10.333 \\
\hline 600 & 0.335 & -0.222 & 0.113 & 0.000 & 0 & 0.000 & 10.417 \\
\hline 600 & 0.555 & -0.246 & 0.309 & 0.000 & 0 & 0.000 & 10.500 \\
\hline 600 & 0.569 & -0.249 & 0.320 & 0.000 & 0 & 0.000 & 10.583 \\
\hline 600 & 0.528 & -0.239 & 0.289 & 0.000 & 0 & 0.000 & 10.667 \\
\hline 601 & 0.525 & -0.241 & 0.284 & 0.000 & 0 & 0.000 & 10.750 \\
\hline 600 & 0.560 & -0.246 & 0.314 & 0.000 & 0 & 0.000 & 10.833 \\
\hline 600 & 0.563 & -0.248 & 0.315 & 0.000 & 0 & 0.000 & 10.917 \\
\hline 600 & 0.585 & -0.241 & 0.344 & 0.000 & 0 & 0.000 & 11.000 \\
\hline 600 & 0.521 & -0.231 & 0.290 & 0.000 & 0 & 0.000 & 11.083 \\
\hline
\end{tabular}




\begin{tabular}{|c|c|c|c|c|c|c|c|}
\hline 601 & 0.528 & -0.236 & 0.292 & 0.000 & 0 & 0.000 & 11.167 \\
\hline 600 & 0.556 & -0.239 & 0.317 & 0.000 & 0 & 0.000 & 11.250 \\
\hline 600 & 0.563 & -0.239 & 0.324 & 0.000 & 0 & 0.000 & 11.333 \\
\hline 600 & 0.553 & -0.238 & 0.315 & 0.000 & 0 & 0.000 & 11.417 \\
\hline 600 & 0.549 & -0.237 & 0.312 & 0.000 & 0 & 0.000 & 11.500 \\
\hline 600 & 0.500 & -0.228 & 0.272 & 0.000 & 0 & 0.000 & 11.583 \\
\hline 601 & 0.537 & -0.234 & 0.303 & 0.000 & 0 & 0.000 & 11.667 \\
\hline 600 & 0.537 & -0.238 & 0.299 & 0.000 & 0 & 0.000 & 11.750 \\
\hline 600 & 0.549 & -0.240 & 0.309 & 0.000 & 0 & 0.000 & 11.833 \\
\hline 601 & 0.559 & -0.243 & 0.316 & 0.000 & 0 & 0.000 & 11.917 \\
\hline 600 & 0.566 & -0.249 & 0.317 & 0.000 & 0 & 0.000 & 12.000 \\
\hline 601 & 0.493 & -0.237 & 0.256 & 0.000 & 0 & 0.000 & 12.083 \\
\hline 600 & 0.520 & -0.243 & 0.277 & 0.000 & 0 & 0.000 & 12.167 \\
\hline 600 & 0.524 & -0.242 & 0.282 & 0.000 & 0 & 0.000 & 12.250 \\
\hline 601 & 0.537 & -0.245 & 0.292 & 0.000 & 0 & 0.000 & 12.333 \\
\hline 600 & 0.542 & -0.242 & 0.300 & 0.000 & 0 & 0.000 & 12.417 \\
\hline 600 & 0.490 & -0.233 & 0.257 & 0.000 & 0 & 0.000 & 12.500 \\
\hline 601 & 0.514 & -0.240 & 0.274 & 0.000 & 0 & 0.000 & 12.583 \\
\hline 600 & 0.524 & -0.241 & 0.283 & 0.000 & 0 & 0.000 & 12.667 \\
\hline 601 & 0.535 & -0.245 & 0.290 & 0.000 & 0 & 0.000 & 12.750 \\
\hline 600 & 0.540 & -0.244 & 0.296 & 0.000 & 0 & 0.000 & 12.833 \\
\hline 600 & 0.511 & -0.235 & 0.276 & 0.000 & 0 & 0.000 & 12.917 \\
\hline 601 & 0.487 & -0.236 & 0.251 & 0.000 & 0 & 0.000 & 13.000 \\
\hline 600 & 0.516 & -0.244 & 0.272 & 0.000 & 0 & 0.000 & 13.083 \\
\hline 600 & 0.527 & -0.247 & 0.280 & 0.000 & 0 & 0.000 & 13.167 \\
\hline 601 & 0.529 & -0.249 & 0.280 & 0.000 & 0 & 0.000 & 13.250 \\
\hline 600 & 0.551 & -0.250 & 0.301 & 0.000 & 0 & 0.000 & 13.333 \\
\hline 600 & 0.565 & -0.255 & 0.310 & 0.000 & 0 & 0.000 & 13.417 \\
\hline 600 & 0.505 & -0.237 & 0.268 & 0.000 & 0 & 0.000 & 13.500 \\
\hline 601 & 0.524 & -0.246 & 0.278 & 0.000 & 0 & 0.000 & 13.583 \\
\hline 601 & 0.529 & -0.252 & 0.277 & 0.000 & 0 & 0.000 & 13.667 \\
\hline 600 & 0.545 & -0.255 & 0.290 & 0.000 & 0 & 0.000 & 13.750 \\
\hline 601 & 0.560 & -0.262 & 0.298 & 0.000 & 0 & 0.000 & 13.833 \\
\hline 601 & 0.565 & -0.261 & 0.304 & 0.000 & 0 & 0.000 & 13.917 \\
\hline 600 & 0.579 & -0.268 & 0.311 & 0.000 & 0 & 0.000 & 14.000 \\
\hline 600 & 0.544 & -0.255 & 0.289 & 0.000 & 0 & 0.000 & 14.083 \\
\hline 601 & 0.530 & -0.254 & 0.276 & 0.000 & 0 & 0.000 & 14.167 \\
\hline 600 & 0.518 & -0.248 & 0.270 & 0.000 & 0 & 0.000 & 14.250 \\
\hline 600 & 0.531 & -0.253 & 0.278 & 0.000 & 0 & 0.000 & 14.333 \\
\hline 601 & 0.532 & -0.252 & 0.280 & 0.000 & 0 & 0.000 & 14.417 \\
\hline 601 & 0.560 & -0.256 & 0.304 & 0.000 & 0 & 0.000 & 14.500 \\
\hline 600 & 0.506 & -0.241 & 0.265 & 0.000 & 0 & 0.000 & 14.583 \\
\hline 601 & 0.531 & -0.249 & 0.282 & 0.000 & 0 & 0.000 & 14.667 \\
\hline 600 & 0.543 & -0.252 & 0.291 & 0.000 & 0 & 0.000 & 14.750 \\
\hline 600 & 0.553 & -0.258 & 0.295 & 0.000 & 0 & 0.000 & 14.833 \\
\hline 601 & 0.558 & -0.260 & 0.298 & 0.000 & 0 & 0.000 & 14.917 \\
\hline 601 & 0.543 & -0.258 & 0.285 & 0.000 & 0 & 0.000 & 15.000 \\
\hline 600 & 0.553 & -0.261 & 0.292 & 0.000 & 0 & 0.000 & 15.083 \\
\hline 600 & 0.533 & -0.257 & 0.276 & 0.000 & 0 & 0.000 & 15.167 \\
\hline 601 & 0.524 & -0.256 & 0.268 & 0.000 & 0 & 0.000 & 15.250 \\
\hline 601 & 0.541 & -0.256 & 0.285 & 0.000 & 0 & 0.000 & 15.333 \\
\hline 600 & 0.555 & -0.263 & 0.292 & 0.000 & 0 & 0.000 & 15.417 \\
\hline 601 & 0.570 & -0.268 & 0.302 & 0.000 & 0 & 0.000 & 15.500 \\
\hline 601 & 0.573 & -0.268 & 0.305 & 0.000 & 0 & 0.000 & 15.583 \\
\hline 601 & 0.578 & -0.270 & 0.308 & 0.000 & 0 & 0.000 & 15.667 \\
\hline 600 & 0.556 & -0.261 & 0.295 & 0.000 & 0 & 0.000 & 15.750 \\
\hline 601 & 0.533 & -0.259 & 0.274 & 0.000 & 0 & 0.000 & 15.833 \\
\hline 601 & 0.548 & -0.266 & 0.282 & 0.000 & 0 & 0.000 & 15.917 \\
\hline 600 & 0.561 & -0.268 & 0.293 & 0.000 & 0 & 0.000 & 16.000 \\
\hline 601 & 0.559 & -0.271 & 0.288 & 0.000 & 0 & 0.000 & 16.083 \\
\hline 601 & 0.579 & -0.275 & 0.304 & 0.000 & 0 & 0.000 & 16.167 \\
\hline 600 & 0.558 & -0.270 & 0.288 & 0.000 & 0 & 0.000 & 16.250 \\
\hline 601 & 0.564 & -0.271 & 0.293 & 0.000 & 0 & 0.000 & 16.333 \\
\hline
\end{tabular}




\begin{tabular}{|c|c|c|c|c|c|c|c|}
\hline 600 & 0.569 & -0.276 & 0.293 & 0.000 & 0 & 0.000 & 16.417 \\
\hline 601 & 0.517 & -0.258 & 0.259 & 0.000 & 0 & 0.000 & 16.500 \\
\hline 601 & 0.509 & -0.259 & 0.250 & 0.000 & 0 & 0.000 & 16.583 \\
\hline 601 & 0.521 & -0.263 & 0.258 & 0.000 & 0 & 0.000 & 16.667 \\
\hline 601 & 0.545 & -0.267 & 0.278 & 0.000 & 0 & 0.000 & 16.750 \\
\hline 600 & 0.555 & -0.272 & 0.283 & 0.000 & 0 & 0.000 & 16.833 \\
\hline 600 & 0.569 & -0.274 & 0.295 & 0.000 & 0 & 0.000 & 16.917 \\
\hline 600 & 0.566 & -0.277 & 0.289 & 0.000 & 0 & 0.000 & 17.000 \\
\hline 601 & 0.577 & -0.278 & 0.299 & 0.000 & 0 & 0.000 & 17.083 \\
\hline 600 & 0.582 & -0.281 & 0.301 & 0.000 & 0 & 0.000 & 17.167 \\
\hline 600 & 0.587 & -0.284 & 0.303 & 0.000 & 0 & 0.000 & 17.250 \\
\hline 601 & 0.582 & -0.283 & 0.299 & 0.000 & 0 & 0.000 & 17.333 \\
\hline 601 & 0.489 & -0.254 & 0.235 & 0.000 & 0 & 0.000 & 17.417 \\
\hline 601 & 0.516 & -0.264 & 0.252 & 0.000 & 0 & 0.000 & 17.500 \\
\hline 600 & 0.520 & -0.264 & 0.256 & 0.000 & 0 & 0.000 & 17.583 \\
\hline 601 & 0.537 & -0.273 & 0.264 & 0.000 & 0 & 0.000 & 17.667 \\
\hline 601 & 0.538 & -0.271 & 0.267 & 0.000 & 0 & 0.000 & 17.750 \\
\hline 600 & 0.524 & -0.268 & 0.256 & 0.000 & 0 & 0.000 & 17.833 \\
\hline 601 & 0.511 & -0.263 & 0.248 & 0.000 & 0 & 0.000 & 17.917 \\
\hline 601 & 0.529 & -0.273 & 0.256 & 0.000 & 0 & 0.000 & 18.000 \\
\hline 600 & 0.548 & -0.277 & 0.271 & 0.000 & 0 & 0.000 & 18.083 \\
\hline 601 & 0.536 & -0.281 & 0.255 & 0.000 & 0 & 0.000 & 18.167 \\
\hline 601 & 0.549 & -0.281 & 0.268 & 0.000 & 0 & 0.000 & 18.250 \\
\hline 600 & 0.553 & -0.287 & 0.266 & 0.000 & 0 & 0.000 & 18.333 \\
\hline 600 & 0.561 & -0.290 & 0.271 & 0.000 & 0 & 0.000 & 18.417 \\
\hline 601 & 0.524 & -0.265 & 0.259 & 0.000 & 0 & 0.000 & 18.500 \\
\hline 600 & 0.478 & -0.261 & 0.217 & 0.000 & 0 & 0.000 & 18.583 \\
\hline 600 & 0.474 & -0.255 & 0.219 & 0.000 & 0 & 0.000 & 18.667 \\
\hline 600 & 0.439 & -0.249 & 0.190 & 0.000 & 0 & 0.000 & 18.750 \\
\hline 601 & 0.468 & -0.253 & 0.215 & 0.000 & 0 & 0.000 & 18.833 \\
\hline 600 & 0.392 & -0.237 & 0.155 & 0.000 & 0 & 0.000 & 18.917 \\
\hline 600 & 0.418 & -0.238 & 0.180 & 0.000 & 0 & 0.000 & 19.000 \\
\hline 600 & 0.361 & -0.232 & 0.129 & 0.000 & 0 & 0.000 & 19.083 \\
\hline 601 & 0.363 & -0.232 & 0.131 & 0.000 & 0 & 0.000 & 19.167 \\
\hline 601 & 0.438 & -0.246 & 0.192 & 0.000 & 0 & 0.000 & 19.250 \\
\hline 600 & 0.447 & -0.260 & 0.187 & 0.000 & 0 & 0.000 & 19.333 \\
\hline 601 & 0.452 & -0.256 & 0.196 & 0.000 & 0 & 0.000 & 19.417 \\
\hline 600 & 0.458 & -0.258 & 0.200 & 0.000 & 0 & 0.000 & 19.500 \\
\hline 600 & 0.464 & -0.265 & 0.199 & 0.000 & 0 & 0.000 & 19.583 \\
\hline 601 & 0.470 & -0.259 & 0.211 & 0.000 & 0 & 0.000 & 19.667 \\
\hline 601 & 0.450 & -0.258 & 0.192 & 0.000 & 0 & 0.000 & 19.750 \\
\hline 600 & 0.468 & -0.266 & 0.202 & 0.000 & 0 & 0.000 & 19.833 \\
\hline 600 & 0.463 & -0.264 & 0.199 & 0.000 & 0 & 0.000 & 19.917 \\
\hline 601 & 0.473 & -0.269 & 0.204 & 0.000 & 0 & 0.000 & 20.000 \\
\hline 601 & 0.485 & -0.271 & 0.214 & 0.000 & 0 & 0.000 & 20.083 \\
\hline 600 & 0.459 & -0.263 & 0.196 & 0.000 & 0 & 0.000 & 20.167 \\
\hline 601 & 0.463 & -0.266 & 0.197 & 0.000 & 0 & 0.000 & 20.250 \\
\hline 600 & 0.472 & -0.271 & 0.201 & 0.000 & 0 & 0.000 & 20.333 \\
\hline 600 & 0.488 & -0.285 & 0.203 & 0.000 & 0 & 0.000 & 20.417 \\
\hline 601 & 0.501 & -0.286 & 0.215 & 0.000 & 0 & 0.000 & 20.500 \\
\hline 600 & 0.496 & -0.289 & 0.207 & 0.000 & 0 & 0.000 & 20.583 \\
\hline 601 & 0.485 & -0.282 & 0.203 & 0.000 & 0 & 0.000 & 20.667 \\
\hline 600 & 0.467 & -0.276 & 0.191 & 0.000 & 0 & 0.000 & 20.750 \\
\hline 600 & 0.352 & -0.158 & 0.194 & 0.000 & 0 & 0.000 & 20.833 \\
\hline 601 & 0.364 & -0.159 & 0.205 & 0.000 & 0 & 0.000 & 20.917 \\
\hline 600 & 0.354 & -0.147 & 0.207 & 0.000 & 0 & 0.000 & 21.000 \\
\hline 600 & 0.367 & -0.164 & 0.203 & 0.000 & 0 & 0.000 & 21.083 \\
\hline 601 & 0.383 & -0.167 & 0.216 & 0.000 & 0 & 0.000 & 21.167 \\
\hline 600 & 0.349 & -0.137 & 0.212 & 0.000 & 0 & 0.000 & 21.250 \\
\hline 600 & 0.343 & -0.143 & 0.200 & 0.000 & 0 & 0.000 & 21.333 \\
\hline 601 & 0.360 & -0.157 & 0.203 & 0.000 & 0 & 0.000 & 21.417 \\
\hline 600 & 0.346 & -0.147 & 0.199 & 0.000 & 0 & 0.000 & 21.500 \\
\hline 600 & 0.318 & -0.119 & 0.199 & 0.000 & 0 & 0.000 & 21.583 \\
\hline
\end{tabular}




$\begin{array}{llllllll}601 & 0.356 & -0.149 & 0.207 & 0.000 & 0 & 0.000 & 21.667 \\ 600 & 0.319 & -0.116 & 0.203 & 0.000 & 0 & 0.000 & 21.750 \\ 601 & 0.341 & -0.144 & 0.197 & 0.000 & 0 & 0.000 & 21.833 \\ 599 & 0.319 & -0.161 & 0.158 & 0.000 & 0 & 0.000 & 21.917 \\ 601 & 0.314 & -0.151 & 0.163 & 0.000 & 0 & 0.000 & 22.000 \\ 600 & 0.321 & -0.135 & 0.186 & 0.000 & 0 & 0.000 & 22.083 \\ 600 & 0.311 & -0.122 & 0.189 & 0.000 & 0 & 0.000 & 22.167\end{array}$


ACC\# 95584

\author{
Appendix C - MSDS \\ Material Safety Data Sheet \\ SODIUM HYDROXIDE, pellets, p.a.
}

Section 1 - Chemical Product and Company Identification

MSDS Name: Sodium hydroxide, pellets, p.a.

Catalog Numbers: AC206060000, AC206060010, AC206060025, NC9561832

Synonyms: Caustic soda; Soda lye; Sodium hydrate; Lye.

Company I dentification:

Fisher Scientific

1 Reagent Lane

Fair Lawn, NJ 07410

For information, call: 201-796-7100

Emergency Number: 201-796-7100

For CHEMTREC assistance, call: $800-424-9300$

For International CHEMTREC assistance, call: 703-527-3887

\title{
Section 2 - Composition, Information on Ingredients
}

\begin{tabular}{|c|c|c|c|}
\hline CAS\# & Chemical Name & Percent & EI NECS/ ELI NCS \\
\hline $1310-73-2$ & Sodium hydroxide & $>98$ & $215-185-5$ \\
\hline
\end{tabular}

\section{Section 3 - Hazards I dentification}

\section{EMERGENCY OVERVI EW}

Appearance: white solid.

Danger! Causes eye and skin burns. May cause severe respiratory tract irritation with possible burns. May cause severe digestive tract irritation with possible burns. Hygroscopic (absorbs moisture from the air).

Target Organs: Eyes, skin, mucous membranes.

Potential Health Effects

Eye: Causes eye burns. May cause chemical conjunctivitis and corneal damage.

Skin: Causes skin burns. May cause deep, penetrating ulcers of the skin. May cause 
skin rash (in milder cases), and cold and clammy skin with cyanosis or pale color. Ingestion: May cause severe and permanent damage to the digestive tract. Causes gastrointestinal tract burns. May cause perforation of the digestive tract. Causes severe pain, nausea, vomiting, diarrhea, and shock. May cause corrosion and permanent tissue destruction of the esophagus and digestive tract. May cause systemic effects.

I nhalation: Irritation may lead to chemical pneumonitis and pulmonary edema. Causes severe irritation of upper respiratory tract with coughing, burns, breathing difficulty, and possible coma. Causes chemical burns to the respiratory tract.

Chronic: Prolonged or repeated skin contact may cause dermatitis. Effects may be delayed.

\section{Section 4 - First Aid Measures}

Eyes: In case of contact, immediately flush eyes with plenty of water for a t least 15 minutes. Get medical aid immediately.

Skin: In case of contact, immediately flush skin with plenty of water for at least 15 minutes while removing contaminated clothing and shoes. Get medical aid immediately. Wash clothing before reuse.

Ingestion: If swallowed, do NOT induce vomiting. Get medical aid immediately. If victim is fully conscious, give a cupful of water. Never give anything by mouth to an unconscious person.

Inhalation: If inhaled, remove to fresh air. If not breathing, give artificial respiration. If breathing is difficult, give oxygen. Get medical aid.

Notes to Physician: Treat symptomatically and supportively.

\section{Section 5 - Fire Fighting Measures}

General I nformation: As in any fire, wear a self-contained breathing apparatus in pressure-demand, MSHA/NIOSH (approved or equivalent), and full protective gear. Use water spray to keep fire-exposed containers cool. Use water with caution and in flooding amounts. Contact with moisture or water may generate sufficient heat to ignite nearby combustible materials. Contact with metals may evolve flammable hydrogen gas.

Extinguishing Media: Substance is noncombustible; use agent most appropriate to extinguish surrounding fire. Do NOT get water inside containers.

Flash Point: Not applicable.

Autoignition Temperature: Not applicable.

Explosion Limits, Lower: Not available.

Upper: Not available.

NFPA Rating: (estimated) Health: 3; Flammability: 0; Instability: 1

\section{Section 6 - Accidental Release Measures}


General I nformation: Use proper personal protective equipment as indicated in Section 8.

Spills/ Leaks: Vacuum or sweep up material and place into a suitable disposal container. Avoid runoff into storm sewers and ditches which lead to waterways. Clean up spills immediately, observing precautions in the Protective Equipment section. Avoid generating dusty conditions. Provide ventilation. Do not get water on spilled substances or inside containers.

\section{Section 7 - Handling and Storage}

Handling: Wash thoroughly after handling. Do not allow water to get into the container because of violent reaction. Minimize dust generation and accumulation. Do not get in eyes, on skin, or on clothing. Keep container tightly closed. Avoid ingestion and inhalation. Discard contaminated shoes. Use only with adequate ventilation.

Storage: Store in a tightly closed container. Store in a cool, dry, well-ventilated area away from incompatible substances. Keep away from metals. Corrosives area. Keep away from acids. Store protected from moisture. Containers must be tightly closed to prevent the conversion of $\mathrm{NaOH}$ to sodium carbonate by the $\mathrm{CO} 2$ in air.

\section{Section 8 - Exposure Controls, Personal Protection}

Engineering Controls: Facilities storing or utilizing this material should be equipped with an eyewash facility and a safety shower. Use adequate general or local exhaust ventilation to keep airborne concentrations below the permissible exposure limits. Exposure Limits

\begin{tabular}{|c|c|c|c|}
\hline Chemical Name & ACGI H & NI OSH & OSHA - Final PELs \\
\hline Sodium hydroxide & $2 \mathrm{mg} / \mathrm{m} 3$ Ceiling & $10 \mathrm{mg} / \mathrm{m} 3$ IDLH & $2 \mathrm{mg} / \mathrm{m} 3 \mathrm{TWA}$ \\
\hline
\end{tabular}

OSHA Vacated PELs: Sodium hydroxide: No OSHA Vacated PELs are listed for this chemical.

Personal Protective Equipment

Eyes: Wear chemical splash goggles.

Skin: Wear appropriate protective gloves to prevent skin exposure.

Clothing: Wear appropriate protective clothing to prevent skin exposure.

Respirators: A respiratory protection program that meets OSHA'S 29 CFR 1910.134 and ANSI Z88.2 requirements or European Standard EN 149 must be followed whenever workplace conditions warrant respirator use. 


\section{Section 9 - Physical and Chemical Properties}

Physical State: Solid

Appearance: white

Odor: Odorless

pH: 14 ( $5 \%$ aq soln)

Vapor Pressure: 1 mm Hg @739 deg C

Vapor Density: Not available.

Evaporation Rate: Not available.

Viscosity: Not available.

Boiling Point: 1390 deg C @ 760 mm Hg

Freezing/ Melting Point:318 deg $\mathrm{C}$

Decomposition Temperature: Not available.

Solubility: Soluble.

Specific Gravity/ Density: $2.13 \mathrm{~g} / \mathrm{cm} 3$

Molecular Formula: $\mathrm{NaOH}$

Molecular Weight: 40.00

\section{Section 10 - Stability and Reactivity}

Chemical Stability: Stable at room temperature in closed containers under normal storage and handling conditions.

Conditions to Avoid: Moisture, contact with water, exposure to moist air or water, prolonged exposure to air.

I ncompatibilities with Other Materials: Water, metals, acids, aluminum, zinc, tin, nitromethane, leather, flammable liquids, organic halogens, wool.

Hazardous Decomposition Products: Toxic fumes of sodium oxide.

Hazardous Polymerization: Will not occur.

\section{Section 11 - Toxicological Information}

\section{RTECS\# :}

CAS\# 1310-73-2: WB4900000

LD50/ LC50:

CAS\# 1310-73-2:

Draize test, rabbit, eye: 400 ug Mild;

Draize test, rabbit, eye: $1 \%$ Severe;

Draize test, rabbit, eye: $50 \mathrm{ug} / 24 \mathrm{H}$ Severe;

Draize test, rabbit, eye: $1 \mathrm{mg} / 24 \mathrm{H}$ Severe;

Draize test, rabbit, skin: 500 mg/24H Severe; 


\section{Carcinogenicity:}

CAS\# 1310-73-2: Not listed by ACGIH, IARC, NTP, or CA Prop 65.

Epidemiology: No information found

Teratogenicity: No information found

Reproductive Effects: No information found

Mutagenicity: See actual entry in RTECS for complete information.

Neurotoxicity: No information found

Other Studies:

\section{Section 12 - Ecological Information}

No information available.

\section{Section 13 - Disposal Considerations}

Chemical waste generators must determine whether a discarded chemical is classified as a hazardous waste. US EPA guidelines for the classification determination are listed in 40 CFR Parts 261.3. Additionally, waste generators must consult state and local hazardous waste regulations to ensure complete and accurate classification.

RCRA P-Series: None listed.

RCRA U-Series: None listed.

\section{Section 14 - Transport Information}

\begin{tabular}{|c|c|c|}
\hline & US DOT & Canada TDG \\
\hline Shipping Name: & SODIUM HYDROXIDE, SOLID & SODIUM HYDROXIDE SOLID \\
\hline Hazard Class: & 8 & 8 \\
\hline UN Number: & UN1823 & UN1823 \\
\hline Packing Group: & $\mathrm{II}$ & $\mathrm{II}$ \\
\hline
\end{tabular}

\section{Section 15 - Regulatory Information}

\section{US FEDERAL}


TSCA

CAS\# 1310-73-2 is listed on the TSCA inventory.

Health \& Safety Reporting List

None of the chemicals are on the Health \& Safety Reporting List.

Chemical Test Rules

None of the chemicals in this product are under a Chemical Test Rule.

Section $\mathbf{1 2 b}$

None of the chemicals are listed under TSCA Section 12b.

TSCA Significant New Use Rule

None of the chemicals in this material have a SNUR under TSCA.

CERCLA Hazardous Substances and corresponding RQs

CAS\# 1310-73-2: $1000 \mathrm{lb}$ final RQ; $454 \mathrm{~kg}$ final RQ

SARA Section 302 Extremely Hazardous Substances

None of the chemicals in this product have a TPQ.

SARA Codes

CAS \# 1310-73-2: immediate, reactive.

Section 313 No chemicals are reportable under Section 313.

Clean Air Act:

This material does not contain any hazardous air pollutants.

This material does not contain any Class 1 Ozone depletors.

This material does not contain any Class 2 Ozone depletors.

Clean Water Act:

CAS\# 1310-73-2 is listed as a Hazardous Substance under the CWA.

None of the chemicals in this product are listed as Priority Pollutants under the

CWA.

None of the chemicals in this product are listed as Toxic Pollutants under the

CWA.

OSHA:

None of the chemicals in this product are considered highly hazardous by OSHA.

STATE

CAS\# 1310-73-2 can be found on the following state right to know lists:

California, New Jersey, Pennsylvania, Minnesota, Massachusetts.

\section{California Prop 65}

California No Significant Risk Level: None of the chemicals in this product are listed.

\section{European/ I nternational Regulations}

European Labeling in Accordance with EC Directives

Hazard Symbols:

C

Risk Phrases:

R 35 Causes severe burns.

\section{Safety Phrases:}

S 26 In case of contact with eyes, rinse immediately with plenty of water and seek medical advice.

S 37/39 Wear suitable gloves and eye/face protection.

S 45 In case of accident or if you feel unwell, seek medical advice immediately (show the label where possible). 
WGK (Water Danger/ Protection)

CAS\# 1310-73-2: 1

Canada - DSL/ NDSL

CAS\# 1310-73-2 is listed on Canada's DSL List.

\section{Canada - WHMIS}

This product has a WHMIS classification of $E$.

This product has been classified in accordance with the hazard criteria of the Controlled Products Regulations and the MSDS contains all of the information required by those regulations.

Canadian Ingredient Disclosure List

CAS\# 1310-73-2 is listed on the Canadian Ingredient Disclosure List.

\section{Section 16 - Additional Information}

ACC\# 21080

MSDS Creation Date: 12/12/1997

Revision \# 8 Date: 3/04/2004

\section{Material Safety Data Sheet SODIUM CARBONATE}

Section 1 - Chemical Product and Company Identification

MSDS Name: Sodium carbonate

Catalog Numbers: AC123670000, AC123670010, AC123670025, AC206800000,

AC206800010, AC206800025, AC207760000, AC207765000, AC207810000,

AC207810010, AC424280000, AC424285000, S71987, S71987-1, S73074, S73075, S78416, S78419, S93359, S93360, BP357-1, NC9296359, NC9644731, S261-10, S263-1, S263-10, S263-3, S263-50, S263-500, S263-50LC, S495-500, XXS263PD140KG

Synonyms: Crystal carbonate; Disodium carbonate; Sal soda; Soda ash; Washing soda; Soda, calcined.

Company I dentification:

Fisher Scientific

1 Reagent Lane

Fair Lawn, NJ 07410

For information, call: 201-796-7100

Emergency Number: 201-796-7100

For CHEMTREC assistance, call: $800-424-9300$

For International CHEMTREC assistance, call: 703-527-3887

\section{Section 2 - Composition, Information on Ingredients}

\begin{tabular}{|c|c|c|c|}
\hline CAS\# & Chemical Name & Percent & EI NECS/ ELI NCS \\
\hline $497-19-8$ & Sodium carbonate anhydrous & 100 & $207-838-8$ \\
\hline
\end{tabular}




\section{Section 3 - Hazards Identification}

\section{EMERGENCY OVERVIEW}

Appearance: white powder.

Warning! Harmful if inhaled. May cause eye and skin irritation with possible burns. May cause respiratory tract irritation. Hygroscopic (absorbs moisture from the air).

Target Organs: Eyes, skin.

\section{Potential Health Effects}

Eye: May result in corneal injury. Contact with eyes may cause severe irritation, and possible eye burns.

Skin: Contact with skin causes irritation and possible burns, especially if the skin is wet or moist.

Ingestion: May cause irritation of the digestive tract.

I nhalation: Harmful if inhaled. May cause irritation of the respiratory tract with burning pain in the nose and throat, coughing, wheezing, shortness of breath and pulmonary edema.

Chronic: Prolonged or repeated inhalation may cause nosebleeds, nasal congestion, erosion of the teeth, perforation of the nasal septum, chest pain and bronchitis.

\section{Section 4 - First Aid Measures}

Eyes: Immediately flush eyes with plenty of water for at least 15 minutes, occasionally lifting the upper and lower eyelids. Get medical aid imme diately. Skin: Get medical aid. Flush skin with plenty of water for at least 15 minutes while removing contaminated clothing and shoes. Wash clothing before reuse.

Ingestion: Do not induce vomiting. If victim is conscious and alert, give 2-4 cupfuls of milk or water. Never give anything by mouth to an unconscious person. Get medical aid immediately.

Inhalation: Remove from exposure and move to fresh air immediately. If not breathing, give artificial respiration. If breathing is difficult, give oxygen. Get medical aid if cough or other symptoms appear.

Notes to Physician: Treat symptomatically and supportively.

\section{Section 5 - Fire Fighting Measures}


General I nformation: As in any fire, wear a self-contained breathing apparatus in pressure-demand, MSHA/NIOSH (approved or equivalent), and full protective gear. Runoff from fire control or dilution water may cause pollution.

Extinguishing Media: Substance is noncombustible; use agent most appropriate to extinguish surrounding fire.

Flash Point: Not applicable.

Autoignition Temperature: Not available.

Explosion Limits, Lower: Not available.

Upper: Not available.

NFPA Rating: (estimated) Health: 2; Flammability: 0; Instability: 0

\section{Section 6 - Accidental Release Measures}

General I nformation: Use proper personal protective equipment as indicated in Section 8.

Spills/ Leaks: Vacuum or sweep up material and place into a suitable disposal container. Clean up spills immediately, observing precautions in the Protective Equipment section. Avoid generating dusty conditions. Provide ventilation.

\section{Section 7 - Handling and Storage}

Handling: Wash thoroughly after handling. Remove contaminated clothing and wash before reuse. Use with adequate ventilation. Minimize dust generation and accumulation. Do not get in eyes, on skin, or on clothing. Keep container tightly closed. Avoid ingestion and inhalation.

Storage: Store in a tightly closed container. Store in a cool, dry, well-ventilated area away from incompatible substances.

\section{Section 8 - Exposure Controls, Personal Protection}

Engineering Controls: Good general ventilation should be sufficient to control airborne levels. Facilities storing or utilizing this material should be equipped with an eyewash facility and a safety shower.

\section{Exposure Limits}

\begin{tabular}{|c|c|c|c|}
\hline Chemical Name & ACGI H & NI OSH & OSHA - Final PELs \\
\hline $\begin{array}{c}\text { Sodium carbonate } \\
\text { anhydrous }\end{array}$ & none listed & none listed & none listed \\
\hline
\end{tabular}


OSHA Vacated PELs: Sodium carbonate anhydrous: No OSHA Vacated PELS are listed for this chemical.

\title{
Personal Protective Equipment
}

Eyes: Wear appropriate protective eyeglasses or chemical safety goggles as described by OSHA's eye and face protection regulations in 29 CFR 1910.133 or European Standard EN166.

Skin: Wear appropriate protective gloves and clothing to prevent skin exposure. Clothing: Wear appropriate protective clothing to minimize contact with skin.

Respirators: Follow the OSHA respirator regulations found in 29 CFR 1910.134 or European Standard EN 149. Use a NIOSH/MSHA or European Standard EN 149 approved respirator if exposure limits are exceeded or if irritation or other symptoms are experienced.

\section{Section 9 - Physical and Chemical Properties}

\author{
Physical State: Powder \\ Appearance: white \\ Odor: odorless \\ pH: 11.6 (solution) \\ Vapor Pressure: Not available. \\ Vapor Density: Not available. \\ Evaporation Rate: Not available. \\ Viscosity: Not available. \\ Boiling Point: 1600 deg $C$ \\ Freezing/ Melting Point:851 deg C \\ Decomposition Temperature: $400 \mathrm{deg} C$ \\ Solubility: Soluble. \\ Specific Gravity/ Density:2.53 \\ Molecular Formula: $\mathrm{Na} 2 \mathrm{CO} 3$ \\ Molecular Weight: 105.99
}

\section{Section 10 - Stability and Reactivity}

Chemical Stability: Stable at room temperature in closed containers under normal storage and handling conditions. Decomposed by acids with effervescence, evolution of carbon dioxide.

Conditions to Avoid: Dust generation, excess heat, moist air.

Incompatibilities with Other Materials: Reacts explosively with red-hot alumium metal. Incompatible with ammonia + silver nitrate, 2,4-dinitrotoluene, 2,4,6trinitrotoluene, sulfuric acid, sodium sulfide + water, lithium, phosphorus pentoxide, fluorine, and hydrogen peroxide. Hot concentrated solutions of sodium carbonate are mildly corrosive to steel.

Hazardous Decomposition Products: Carbon dioxide, toxic fumes of sodium 
oxide.

Hazardous Polymerization: Has not been reported.

\section{Section 11 - Toxicological Information}

\section{RTECS\# :}

CAS\# 497-19-8: VZ4050000

LD50/ LC50:

CAS \# 497-19-8:

Draize test, rabbit, eye: $100 \mathrm{mg} / 24 \mathrm{H}$ Moderate;

Draize test, rabbit, eye: $50 \mathrm{mg}$ Severe;

Draize test, rabbit, skin: $500 \mathrm{mg} / 24 \mathrm{H}$ Mild;

Inhalation, mouse: $\mathrm{LC} 50=1200 \mathrm{mg} / \mathrm{m3} / 2 \mathrm{H}$;

Inhalation, rat: $L C 50=2300 \mathrm{mg} / \mathrm{m3} / 2 \mathrm{H}$;

Oral, mouse: $\mathrm{LD} 50=6600 \mathrm{mg} / \mathrm{kg}$;

Oral, mouse: $L D 50=6600 \mathrm{mg} / \mathrm{kg}$;

Oral, rat: $L D 50=4090 \mathrm{mg} / \mathrm{kg}$;

\section{Carcinogenicity:}

CAS\# 497-19-8: Not listed by ACGIH, IARC, NTP, or CA Prop 65.

Epidemiology: No information found Teratogenicity: No information found

Reproductive Effects: No information found

Mutagenicity: No information found

Neurotoxicity: No information found

Other Studies:

\section{Section 12 - Ecological Information}

Ecotoxicity: Fish: Bluegill/Sunfish: LC50 = 320 mg/L; 96 Hr.; Static Conditions

\section{Section 13 - Disposal Considerations}

Chemical waste generators must determine whether a discarded chemical is classified as a hazardous waste. US EPA guidelines for the classification determination are listed in 40 CFR Parts 261.3. Additionally, waste generators must consult state and local hazardous waste regulations to ensure complete and accurate classification.

RCRA P-Series: None listed.

RCRA U-Series: None listed. 


\section{Section 14 - Transport Information}

\begin{tabular}{|c|c|c|}
\hline & US DOT & Canada TDG \\
\hline Shipping Name: & Not regulated & Not Regulated \\
\hline Hazard Class: & & \\
\hline UN Number: & & \\
\hline Packing Group: & & \\
\hline
\end{tabular}

\section{Section 15 - Regulatory Information}

\section{US FEDERAL}

\section{TSCA}

CAS\# 497-19-8 is listed on the TSCA inventory.

\section{Health \& Safety Reporting List}

None of the chemicals are on the Health \& Safety Reporting List.

\section{Chemical Test Rules}

None of the chemicals in this product are under a Chemical Test Rule.

\section{Section $12 b$}

None of the chemicals are listed under TSCA Section 12b.

\section{TSCA Significant New Use Rule}

None of the chemicals in this material have a SNUR under TSCA.

\section{CERCLA Hazardous Substances and corresponding RQs}

None of the chemicals in this material have an RQ.

SARA Section 302 Extremely Hazardous Substances

None of the chemicals in this product have a TPQ.

\section{SARA Codes}

\section{CAS \# 497-19-8: immediate.}

Section 313 No chemicals are reportable under Section 313.

Clean Air Act:

This material does not contain any hazardous air pollutants.

This material does not contain any Class 1 Ozone depletors.

This material does not contain any Class 2 Ozone depletors.

\section{Clean Water Act:}

None of the chemicals in this product are listed as Hazardous Substances under the CWA. CWA.

None of the chemicals in this product are listed as Priority Pollutants under the CWA.

None of the chemicals in this product are listed as Toxic Pollutants under the

OSHA:

None of the chemicals in this product are considered highly hazardous by OSHA. STATE 
CAS\# 497-19-8 is not present on state lists from CA, PA, MN, MA, FL, or NJ .

\section{California Prop 65}

California No Significant Risk Level: None of the chemicals in this product are listed.

\section{European/ I nternational Regulations}

\section{European Labeling in Accordance with EC Directives}

Hazard Symbols:

XI

Risk Phrases:

R 36 I rritating to eyes.

\section{Safety Phrases:}

S 22 Do not breathe dust.

S 26 In case of contact with eyes, rinse immediately with plenty of water and seek medical advice.

WGK (Water Danger/ Protection)

CAS\# 497-19-8: 1

Canada - DSL/ NDSL

CAS\# 497-19-8 is listed on Canada's DSL List.

\section{Canada - WHMIS}

This product has a WHMIS classification of D2B.

This product has been classified in accordance with the hazard criteria of the Controlled Products Regulations and the MSDS contains all of the information required by those regulations.

Canadian I ngredient Disclosure List

CAS\# 497-19-8 is listed on the Canadian Ingredient Disclosure List.

\section{Section 16 - Additional Information}

MSDS Creation Date: 7/12/1999

Revision \# 3 Date: 3/07/2005

\section{Material Safety Data Sheet LITHIUM CARBONATE}

ACC\# 12880

Section 1 - Chemical Product and Company Identification

MSDS Name: Lithium Carbonate

Catalog Numbers: S80056, S93278, L119 500, L119-500, L119500

Synonyms: Carbonic Acid Dilithium Salt; Carbonic Acid Lithium Salt

Company I dentification:

Fisher Scientific

1 Reagent Lane 
Fair Lawn, NJ 07410

For information, call: 201-796-7100

Emergency Number: 201-796-7100

For CHEMTREC assistance, call: $800-424-9300$

For International CHEMTREC assistance, call: 703-527-3887

\section{Section 2 - Composition, Information on Ingredients}

\begin{tabular}{|c|l|c|c|}
\hline CAS\# & Chemical Name & Percent & EI NECS/ ELI NCS \\
\hline $554-13-2$ & Lithium carbonate & 98.0 & $209-062-5$ \\
\hline
\end{tabular}

\section{Section 3 - Hazards I dentification}

\section{EMERGENCY OVERVIEW}

Appearance: white solid.

Warning! May be harmful if swallowed. May cause eye and skin irritation. May cause respiratory and digestive tract irritation. May cause central nervous system effects. May cause kidney damage. May cause reproductive and fetal effects.

Target Organs: Kidneys, central nervous system.

\section{Potential Health Effects}

Eye: Causes eye irritation.

Skin: May cause skin irritation.

Ingestion: May cause gastrointestinal irritation with nausea, vomiting and diarrhea.

May be harmful if swallowed.

I nhalation: May cause respiratory tract irritation.

Chronic: Chronic exposure to lithium salts may cause drowsiness, visual abnormalities, weakness, ringing in the ears, and muscle tremors.

\section{Section 4 - First Aid Measures}

Eyes: Immediately flush eyes with plenty of water for at least 15 minutes, occasionally lifting the upper and lower eyelids. Get medical aid.

Skin: I mmediately flush skin with plenty of water for at least 15 minutes while removing contaminated clothing and shoes. Get medical aid if irritation develops or persists. Wash clothing before reuse. 
Ingestion: If victim is conscious and alert, give 2-4 cupfuls of milk or water. Never give anything by mouth to an unconscious person. Get medical aid immediately. Inhalation: Remove from exposure and move to fresh air immediately. If not breathing, give artificial respiration. If breathing is difficult, give oxygen. Get medical aid.

Notes to Physician: Treat symptomatically and supportively.

\section{Section 5 - Fire Fighting Measures}

General I nformation: As in any fire, wear a self-contained breathing apparatus in pressure-demand, MSHA/NIOSH (approved or equivalent), and full protective gear. Dusts at sufficient concentrations can form explosive mixtures with air. During a fire, irritating and highly toxic gases may be generated by thermal decomposition or combustion.

Extinguishing Media: For small fires, use water spray, dry chemical, carbon dioxide or chemical foam. For large fires, use dry chemical, carbon dioxide, alcohol-resistant foam, or water spray.

Flash Point: Not applicable.

Autoignition Temperature: Not available.

Explosion Limits, Lower:N/A

Upper: N/A

NFPA Rating: (estimated) Health: 1; Flammability: 0; Instability: 0

\section{Section 6 - Accidental Release Measures}

General I nformation: Use proper personal protective equipment as indicated in Section 8.

Spills/ Leaks: Clean up spills immediately, observing precautions in the Protective Equipment section. Sweep up or absorb material, then place into a suitable clean, dry, closed container for disposal. Avoid generating dusty conditions. Provide ventilation.

\section{Section 7 - Handling and Storage}

Handling: Wash thoroughly after handling. Remove contaminated clothing and wash before reuse. Use with adequate ventilation. Minimize dust generation and accumulation. Avoid contact with eyes, skin, and clothing. Keep container tightly closed. Avoid ingestion and inhalation.

Storage: Store in a tightly closed container. Store in a cool, dry, well-ventilated area away from incompatible substances. 


\section{Section 8 - Exposure Controls, Personal Protection}

Engineering Controls: Use adequate ventilation to keep airborne concentrations low.

Exposure Limits

\begin{tabular}{|l|l|c|c|}
\hline Chemical Name & ACGI H & NI OSH & OSHA - Final PELs \\
\hline Lithium carbonate & none listed & none listed & none listed \\
\hline \hline
\end{tabular}

OSHA Vacated PELs: Lithium carbonate: No OSHA Vacated PELS are listed for this chemical.

\section{Personal Protective Equipment}

Eyes: Wear appropriate protective eyeglasses or chemical safety goggles as described by OSHA's eye and face protection regulations in 29 CFR 1910.133 or European Standard EN166.

Skin: Wear appropriate protective gloves to prevent skin exposure. Clothing: Wear appropriate protective clothing to prevent skin exposure. Respirators: Follow the OSHA respirator regulations found in 29 CFR 1910.134 or European Standard EN 149. Use a NIOSH/MSHA or European Standard EN 149 approved respirator if exposure limits are exceeded or if irritation or other symptoms are experienced.

\section{Section 9 - Physical and Chemical Properties}

Physical State: Solid

Appearance: white

Odor: none reported

pH: Not available.

Vapor Pressure: Negligible.

Vapor Density: Not available.

Evaporation Rate: Negligible.

Viscosity: Not available.

Boiling Point: 1310 deg $C$

Freezing/ Melting Point:618 deg $\mathrm{C}$

Decomposition Temperature: 1310 deg C

Solubility: $1.5 \%$ in water.

Specific Gravity/ Density:2.1 (water=1)

Molecular Formula:Li2CO3

Molecular Weight: 73.8802

\section{Section 10 - Stability and Reactivity}


Chemical Stability: Stable under normal temperatures and pressures.

Conditions to Avoid: Incompatible materials.

I ncompatibilities with Other Materials: Strong oxidizing agents, strong acids,

fluorine.

Hazardous Decomposition Products: Carbon monoxide, carbon dioxide, oxides of lithium.

Hazardous Polymerization: Has not been reported.

\section{Section 11 - Toxicological Information}

\section{RTECS\# :}

CAS\# 554-13-2: OJ 5800000

LD50/ LC50:

CAS\# 554-13-2:

Oral, mouse: $\operatorname{LD} 50=531 \mathrm{mg} / \mathrm{kg}$;

Oral, mouse: LD50 = $531 \mathrm{mg} / \mathrm{kg}$;

Oral, rabbit: $L D 50=404 \mathrm{mg} / \mathrm{kg}$;

Oral, rat: $\mathrm{LD} 50=525 \mathrm{mg} / \mathrm{kg}$;

Oral, rat: $\operatorname{LD} 50=553 \mathrm{mg} / \mathrm{kg}$;

\section{Carcinogenicity:}

CAS\# 554-13-2: Not listed by ACGI H, IARC, NTP, or CA Prop 65.

Epidemiology: No information available.

Teratogenicity: No information available.

Reproductive Effects: No information available.

Mutagenicity: No information available.

Neurotoxicity: No information available.

Other Studies:

\section{Section 12 - Ecological Information}

Ecotoxicity: No data available. No information available.

Environmental: No information reported.

Physical: No information available.

Other: None.

\section{Section 13 - Disposal Considerations}


Chemical waste generators must determine whether a discarded chemical is classified as a hazardous waste. US EPA guidelines for the classification determination are listed in 40 CFR Parts 261.3. Additionally, waste generators must consult state and local hazardous waste regulations to ensure complete and accurate classification.

RCRA P-Series: None listed.

RCRA U-Series: None listed.

\section{Section 14 - Transport Information}

\begin{tabular}{|c|c|c|}
\hline & US DOT & Canada TDG \\
\hline Shipping Name: & $\begin{array}{c}\text { Not regulated as a hazardous } \\
\text { material }\end{array}$ & No information available. \\
\hline Hazard Class: & & \\
\hline UN Number: & & \\
\hline Packing Group: & & \\
\hline
\end{tabular}

\section{Section 15 - Regulatory Information}

\section{US FEDERAL}

\section{TSCA}

CAS\# 554-13-2 is listed on the TSCA inventory.

\section{Health \& Safety Reporting List}

None of the chemicals are on the Health \& Safety Reporting List.

\section{Chemical Test Rules}

None of the chemicals in this product are under a Chemical Test Rule.

\section{Section $12 b$}

None of the chemicals are listed under TSCA Section 12b.

\section{TSCA Significant New Use Rule}

None of the chemicals in this material have a SNUR under TSCA.

\section{CERCLA Hazardous Substances and corresponding RQs}

None of the chemicals in this material have an RQ.

SARA Section 302 Extremely Hazardous Substances

None of the chemicals in this product have a TPQ.

\section{SARA Codes}

CAS \# 554-13-2: delayed.

\section{Section 313}

This material contains Lithium carbonate (CAS\# 554-13-2, 98.0\%), which is subject to the reporting requirements of Section 313 of SARA Title III and 40 CFR Part 373. 


\section{Clean Air Act:}

This material does not contain any hazardous air pollutants. This material does not contain any Class 1 Ozone depletors. This material does not contain any Class 2 Ozone depletors.

\section{Clean Water Act:}

None of the chemicals in this product are listed as Hazardous Substances under the CWA.

None of the chemicals in this product are listed as Priority Pollutants under the CWA.

None of the chemicals in this product are listed as Toxic Pollutants under the CWA.

OSHA:

None of the chemicals in this product are considered highly hazardous by OSHA. STATE

CAS\# 554-13-2 can be found on the following state right to know lists: New Jersey, Massachusetts.

\section{California Prop 65}

WARNING: This product contains Lithium carbonate, a chemical known to the state of California to cause developmental reproductive toxicity.

California No Significant Risk Level: None of the chemicals in this product are listed.

\section{European/ I nternational Regulations}

European Labeling in Accordance with EC Directives

Hazard Symbols:

XN

Risk Phrases:

R 22 Harmful if swallowed.

R 36 I rritating to eyes.

\section{Safety Phrases:}

\section{WGK (Water Danger/ Protection)}

CAS\# 554-13-2: 1

Canada - DSL/ NDSL

CAS\# 554-13-2 is listed on Canada's DSL List.

\section{Canada - WHMIS}

This product has a WHMIS classification of D2B.

This product has been classified in accordance with the hazard criteria of the Controlled Products Regulations and the MSDS contains all of the information required by those regulations.

\section{Canadian Ingredient Disclosure List}

\section{Section 16 - Additional Information}

MSDS Creation Date: 4/24/1998

Revision \#5 Date: 10/03/2005 


\section{Material Safety Data Sheet LITHIUM HYDROXIDE ANHYDROUS}

ACC\# 12925

\section{Section 1 - Chemical Product and Company Identification}

MSDS Name: Lithium Hydroxide Anhydrous

Catalog Numbers: AC611545000, L128-500, ZZL1281519, ZZL1282019

Synonyms: Lithium Hydrate

Company I dentification:

Fisher Scientific

1 Reagent Lane

Fair Lawn, NJ 07410

For information, call: 201-796-7100

Emergency Number: 201-796-7100

For CHEMTREC assistance, call: $800-424-9300$

For I nternational CHEMTREC assistance, call: 703-527-3887

\section{Section 2 - Composition, Information on Ingredients}

\begin{tabular}{|c|l|c|c|}
\hline CAS\# & \multicolumn{1}{|c|}{ Chemical Name } & Percent & EI NECS/ ELI NCS \\
\hline $1310-65-2$ & LITHIUM HYDROXIDE & $>96$ & $215-183-4$ \\
\hline $554-13-2$ & Lithium carbonate & 3 & $209-062-5$ \\
\hline
\end{tabular}

\section{Section 3 - Hazards I dentification}

\section{EMERGENCY OVERVI EW}

Appearance: colorless to white solid.

Danger! Corrosive. Causes burns by all exposure routes. Harmful if inhaled or swallowed. May cause central nervous system effects. May cause kidney damage. Air sensitive. Hygroscopic (absorbs moisture from the air).

Target Organs: Kidneys, central nervous system, respiratory system, eyes, skin.

\section{Potential Health Effects}

Eye: Causes severe eye burns. May cause chemical conjunctivitis and corneal damage.

Skin: Causes severe burns with delayed tissue destruction. 
Ingestion: Harmful if swallowed. Causes gastrointestinal tract burns. May cause kidney damage. May cause corrosion and permanent tissue destruction of the esophagus and digestive tract. May cause tremors and convulsions. May cause nausea and vomiting. May cause burning sensations, coughing, wheezing, laryngitis, shortness of breath and headache.

Inhalation: Harmful if inhaled. Causes chemical burns to the respiratory tract. Inhalation may be fatal as a result of spasm, inflammation, edema of the larynx and bronchi, chemical pneumonitis and pulmonary edema. May cause burning sensation, coughing, wheezing, laryngitis, shortness of breath, headache, nausea, and vomiting.

Chronic: Repeated exposure may cause central nervous system damage. Effects may be delayed. Chronic ingestion may cause dizziness, ringing in the ears, visual disturbances, tremors, and mental confusion. Prolonged absorption may affect electrolyte balance and impair kidney function. Dehydration, weight loss, skin effects, and thyroid disturbances have been reported. May cause kidney damage.

\section{Section 4 - First Aid Measures}

Eyes: Get medical aid immediately. Do NOT allow victim to rub eyes or keep eyes closed. Extensive irrigation with water is required (at least 30 minutes).

Skin: Get medical aid immediately. Immediately flush skin with plenty of water for at least 15 minutes while removing contaminated clothing and shoes. Wash clothing before reuse. Destroy contaminated shoes.

Ingestion: Do not induce vomiting. If victim is conscious and alert, give 2-4 cupfuls of milk or water. Get medical aid immediately.

Inhalation: Get medical aid immediately. Remove from exposure and move to fresh air immediately. If breathing is difficult, give oxygen. Do NOT use mouth-to-mouth resuscitation. If breathing has ceased apply artificial respiration using oxygen and a suitable mechanical device such as a bag and a mask.

Notes to Physician: Treat symptomatically and supportively.

\section{Section 5 - Fire Fighting Measures}

General I nformation: As in any fire, wear a self-contained breathing apparatus in pressure-demand, MSHA/NIOSH (approved or equivalent), and full protective gear. During a fire, irritating and highly toxic gases may be generated by thermal decomposition or combustion. Wear appropriate protective clothing to prevent contact with skin and eyes. Wear a self-contained breathing apparatus (SCBA) to prevent contact with thermal decomposition products.

Extinguishing Media: In case of fire, use water, dry chemical, chemical foam, or alcohol-resistant foam.

Flash Point: Not available.

Autoignition Temperature: Not available.

Explosion Limits, Lower: Not available. 
Upper: Not available.

NFPA Rating: (estimated) Health: 3; Flammability: 0; Instability: 1

\section{Section 6 - Accidental Release Measures}

General I nformation: Use proper personal protective equipment as indicated in Section 8.

Spills/ Leaks: Vacuum or sweep up material and place into a suitable disposal container. Clean up spills immediately, observing precautions in the Protective Equipment section. Avoid generating dusty conditions. Provide ventilation.

\section{Section 7 - Handling and Storage}

Handling: Wash thoroughly after handling. Wash hands before eating. Minimize dust generation and accumulation. Do not get in eyes, on skin, or on clothing. Keep container tightly closed. Do not ingest or inhale. Use with adequate ventilation. Discard contaminated shoes.

Storage: Keep container closed when not in use. Keep under a nitrogen blanket. Corrosives area. Store protected from moisture.

\section{Section 8 - Exposure Controls, Personal Protection}

Engineering Controls: Facilities storing or utilizing this material should be equipped with an eyewash facility and a safety shower. Use adequate ventilation to keep airborne concentrations low.

Exposure Limits

\begin{tabular}{|c|l|c|c|}
\hline Chemical Name & \multicolumn{1}{|c|}{ ACGI H } & NI OSH & OSHA - Final PELS \\
\hline LITHIUM HYDROXIDE & none listed & none listed & none listed \\
\hline Lithium carbonate & none listed & none listed & none listed \\
\hline
\end{tabular}

OSHA Vacated PELs: LITHIUM HYDROXIDE: No OSHA Vacated PELS are listed for this chemical. Lithium carbonate: No OSHA Vacated PELS are listed for this chemical.

\section{Personal Protective Equipment}

Eyes: Wear appropriate protective eyeglasses or chemical safety goggles as described by OSHA's eye and face protection regulations in 29 CFR 1910.133 or European Standard EN166.

Skin: Wear appropriate protective gloves to prevent skin exposure.

Clothing: Wear appropriate protective clothing to minimize contact with skin. 
Respirators: A respiratory protection program that meets OSHA's 29 CFR 1910.134 and ANSI Z88.2 requirements or European Standard EN 149 must be followed whenever workplace conditions warrant respirator use.

\section{Section 9 - Physical and Chemical Properties}

Physical State: Solid

Appearance: colorless to white

Odor: none reported

pH: 14 ( $1 \mathrm{~N}$ sol.)

Vapor Pressure: Negligible.

Vapor Density: Not available.

Evaporation Rate: Negligible.

Viscosity: Not available.

Boiling Point: 1695 deg F

Freezing/ Melting Point: 842 deg F

Decomposition Temperature:1695 deg F

Solubility: Soluble in water.

Specific Gravity/ Density:2.5 (water=1)

Molecular Formula:LiOH

Molecular Weight:23.9474

\section{Section 10 - Stability and Reactivity}

Chemical Stability: Absorbs carbon dioxide from the air. Air sensitive. Hygroscopic: absorbs moisture or water from the air.

Conditions to Avoid: Dust generation, exposure to moist air or water, heat.

I ncompatibilities with Other Materials: Strong oxidizing agents, strong acids, aluminum, carbon dioxide, zinc, moisture.

Hazardous Decomposition Products: Oxides of lithium.

Hazardous Polymerization: Has not been reported

\section{Section 11 - Toxicological Information}

\section{RTECS\# :}

CAS\# 1310-65-2: OJ 6307070

CAS\# 554-13-2: 0J 5800000

LD50/ LC50:

CAS\# 1310-65-2:

Inhalation, rat: $L C 50=960 \mathrm{mg} / \mathrm{m3} / 4 \mathrm{H}$;

Oral, mouse: $L D 50=363 \mathrm{mg} / \mathrm{kg}$; 
Oral, rat: $L D 50=210 \mathrm{mg} / \mathrm{kg}$;

CAS\# 554-13-2:

Oral, mouse: $\operatorname{LD} 50=531 \mathrm{mg} / \mathrm{kg}$;

Oral, mouse: $\mathrm{LD} 50=531 \mathrm{mg} / \mathrm{kg}$;

Oral, rabbit: LD50 $=404 \mathrm{mg} / \mathrm{kg}$;

Oral, rat: $L D 50=525 \mathrm{mg} / \mathrm{kg}$;

Oral, rat: $\operatorname{LD} 50=553 \mathrm{mg} / \mathrm{kg}$;

Carcinogenicity:

CAS\# 1310-65-2: Not listed by ACGIH, IARC, NTP, or CA Prop 65.

CAS\# 554-13-2: Not listed by ACGIH, IARC, NTP, or CA Prop 65.

Epidemiology: No information found

Teratogenicity: No information found

Reproductive Effects: No information found

Mutagenicity: No information found

Neurotoxicity: No information found

Other Studies:

\section{Section 12 - Ecological Information}

No information available.

\section{Section 13 - Disposal Considerations}

Chemical waste generators must determine whether a discarded chemical is classified as a hazardous waste. US EPA guidelines for the classification determination are listed in 40 CFR Parts 261.3. Additionally, waste generators must consult state and local hazardous waste regulations to ensure complete and accurate classification.

RCRA P-Series: None listed.

RCRA U-Series: None listed.

\section{Section 14 - Transport Information}

\begin{tabular}{|c|c|c|}
\hline & US DOT & Canada TDG \\
\hline Shipping Name: & LITHIUM HYDROXIDE & LITHIUM HYDROXIDE \\
\hline Hazard Class: & 8 & 8 \\
\hline UN Number: & UN2680 & UN2680 \\
\hline
\end{tabular}


\begin{tabular}{|l|l|l|}
\hline Packing Group: & II & II
\end{tabular}

\section{Section 15 - Regulatory Information}

\section{US FEDERAL}

TSCA

CAS\# 1310-65-2 is listed on the TSCA inventory.

CAS\# 554-13-2 is listed on the TSCA inventory.

Health \& Safety Reporting List

None of the chemicals are on the Health \& Safety Reporting List.

Chemical Test Rules

None of the chemicals in this product are under a Chemical Test Rule.

\section{Section 12 b}

None of the chemicals are listed under TSCA Section 12b.

TSCA Significant New Use Rule None of the chemicals in this material have a SNUR under TSCA.

\section{CERCLA Hazardous Substances and corresponding RQs}

None of the chemicals in this material have an RQ.

SARA Section 302 Extremely Hazardous Substances None of the chemicals in this product have a TPQ.

\section{SARA Codes}

CAS \# 1310-65-2: immediate, delayed.

CAS \# 554-13-2: delayed.

\section{Section 313}

This material contains Lithium carbonate (CAS\# 554-13-2, 3\%), which is subject to the reporting requirements of Section 313 of SARA Title III and 40 CFR Part 373.

\section{Clean Air Act:}

This material does not contain any hazardous air pollutants.

This material does not contain any Class 1 Ozone depletors.

This material does not contain any Class 2 Ozone depletors.

\section{Clean Water Act:}

None of the chemicals in this product are listed as Hazardous Substances under the CWA.

None of the chemicals in this product are listed as Priority Pollutants under the CWA.

None of the chemicals in this product are listed as Toxic Pollutants under the

\section{CWA.}

OSHA:

None of the chemicals in this product are considered highly hazardous by OSHA.

\section{STATE}

CAS\# 1310-65-2 can be found on the following state right to know lists: Minnesota.

CAS\# 554-13-2 can be found on the following state right to know lists: New Jersey, Massachusetts.

\section{California Prop 65}


WARNING: This product contains Lithium carbonate, a chemical known to the state of California to cause developmental reproductive toxicity.

California No Significant Risk Level: None of the chemicals in this product are listed.

\section{European/ I nternational Regulations}

\section{European Labeling in Accordance with EC Directives}

Hazard Symbols:

C

\section{Risk Phrases:}

R 20/22 Harmful by inhalation and if swallowed.

R 35 Causes severe burns.

\section{Safety Phrases:}

S 22 Do not breathe dust.

S 26 In case of contact with eyes, rinse immediately with plenty of water and seek medical advice.

S 36/37/39 Wear suitable protective clothing, gloves and eye/face pr otection.

S 45 In case of accident or if you feel unwell, seek medical advice immediately (show the label where possible).

\section{WGK (Water Danger/ Protection)}

CAS\# 1310-65-2: No information available.

CAS\# 554-13-2: 1

\section{Canada - DSL/ NDSL}

CAS\# 1310-65-2 is listed on Canada's DSL List.

CAS\# 554-13-2 is listed on Canada's DSL List.

\section{Canada - WHMI S}

This product has a WHMIS classification of D1B, E.

This product has been classified in accordance with the hazard criteria of the Controlled Products Regulations and the MSDS contains all of the information required by those regulations.

\section{Canadian I ngredient Disclosure List}

CAS\# 1310-65-2 is listed on the Canadian Ingredient Disclosure List.

\section{Section 16 - Additional Information}

MSDS Creation Date: 9/02/1997

Revision \#6 Date: 9/22/2004 